Universidad de Lima

Facultad de Ingeniería y Arquitectura

Carrera de Ingeniería Industrial

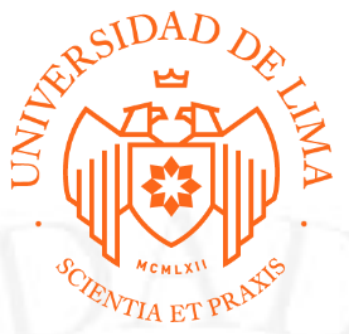

\title{
ESTUDIO DE PREFACTIBILIDAD PARA LA INSTALACIÓN DE UNA PLANTA PARA LA CONFECCIÓN DE ROPA PARA BEBÉS DE ALGODÓN 100\% ORGÁNICO PARA EXPORTACIÓN AL REINO UNIDO
}

Trabajo de investigación para optar el Título Profesional de Ingeniero Industrial

Milagros del Carmen De la Vega Rosales

Código 20120409

Natali Kimberly Maldonado Baca

Código 20121916

Asesor

Rosa Patricia Larios Francia

Lima - Perú

Marzo de 2019 


\section{ESTUDIO DE PREFACTIBILIDAD PARA}

LA INSTALACIÓN DE UNA PLANTA PARA LA CONFECCIÓN DE ROPA PARA BEBÉS DE ALGODÓN 100\% ORGÁNICO PARA EXPORTACIÓN AL REINO UNIDO 


\section{TABLA DE CONTENIDO}

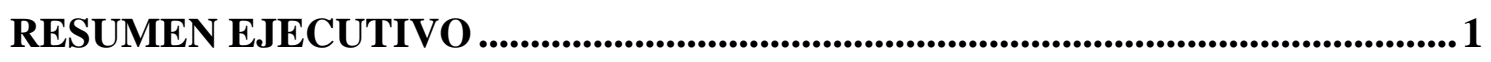

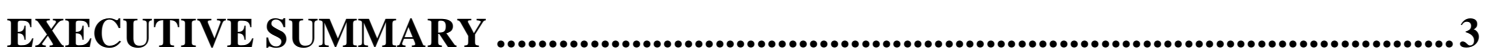

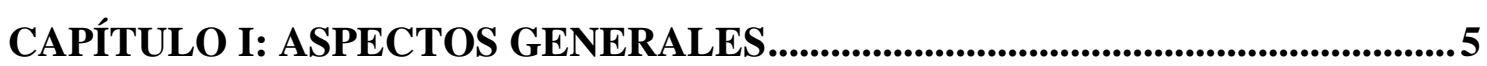

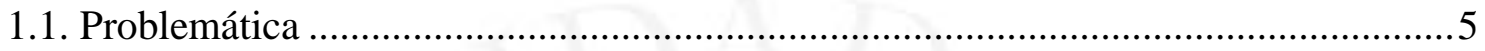

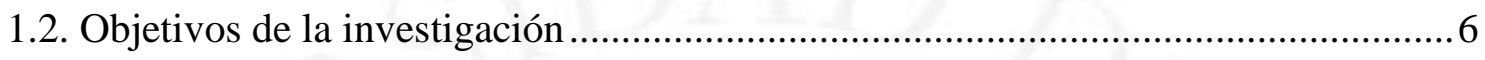

1.3. Alcance y limitaciones de la investigación .......................................................6

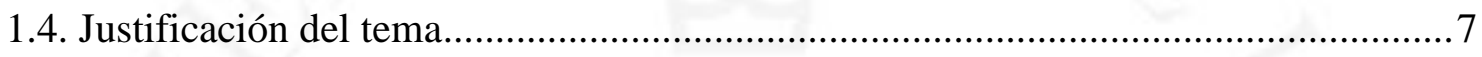

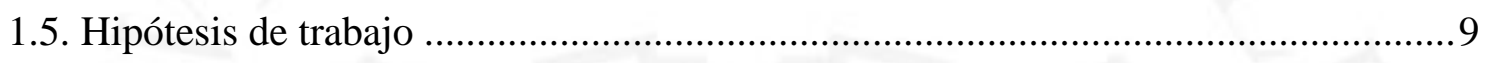

1.6. Marco referencial de la investigación ................................................................

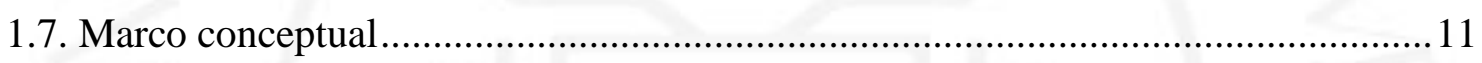

CAPÍTULO II: ESTUDIO DE MERCADO .......................................................13

2.1. Aspectos generales del estudio de mercado.................................................... 13

2.1.1. Definición comercial del producto ............................................................... 13

2.1.2. Principales características del producto: ........................................................... 14

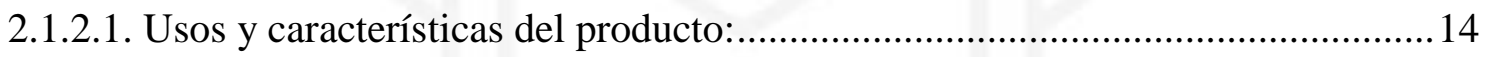

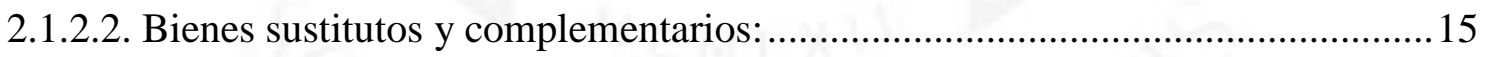

2.1.3. Determinación del área geográfica que abarcará el estudio ................................ 15

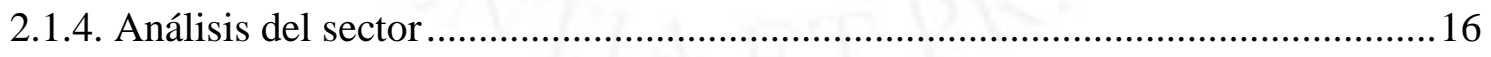

2.1.5. Determinación de la metodología que se empleará en la investigación de mercado

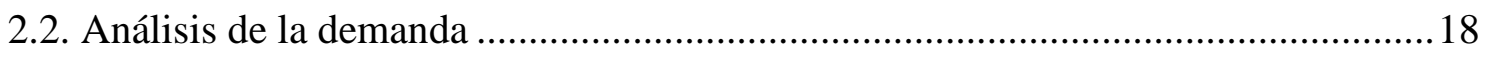

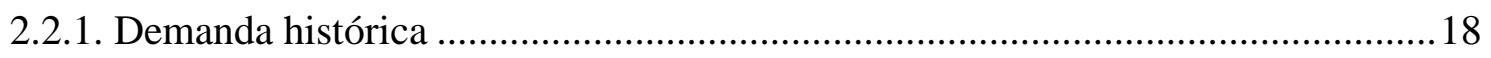

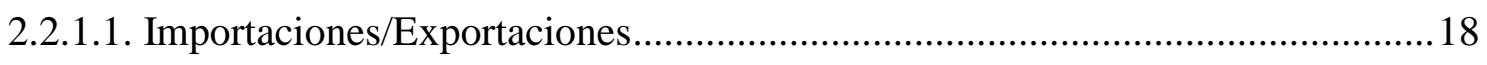

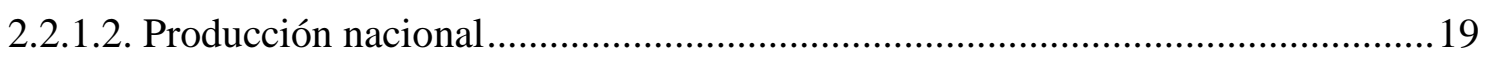


2.2.2.1. Patrones de consumo: incremento poblacional, consumo per cápita, estacionalidad..... 20

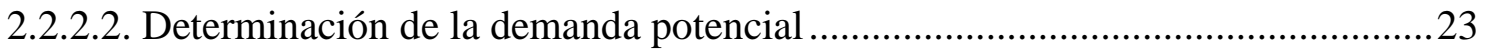

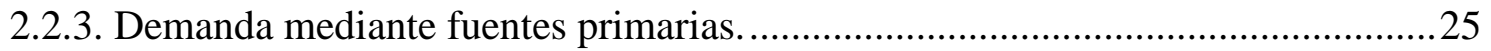

2.2.3.1. Diseño y aplicación de encuestas u otras técnicas .............................................25

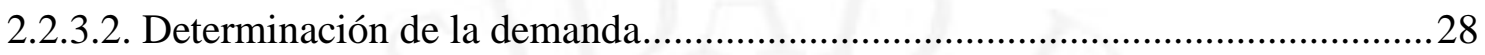

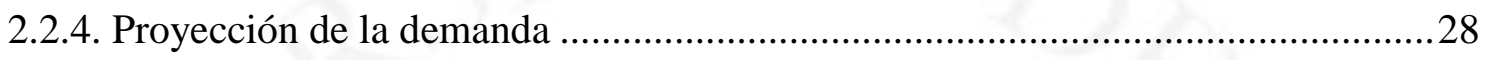

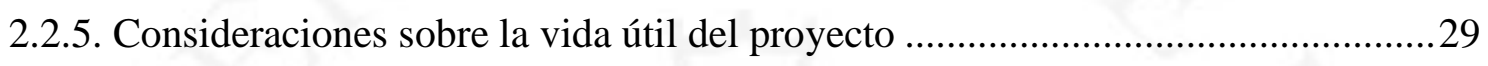

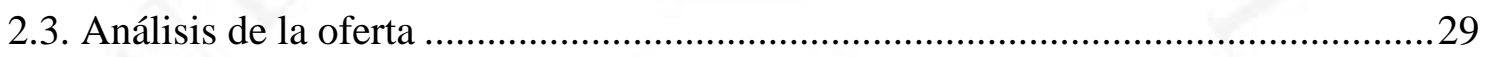

2.3.1. Empresas productoras, importadoras y comercializadoras ................................29

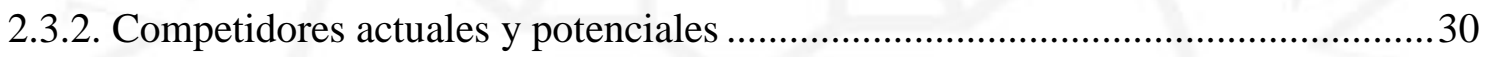

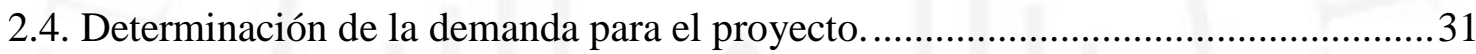

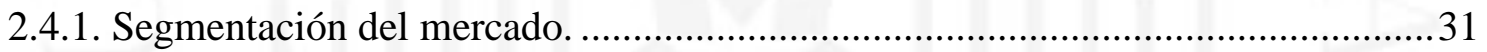

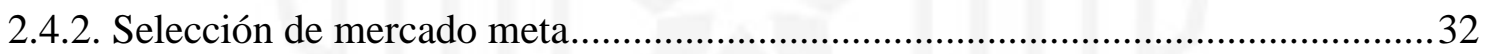

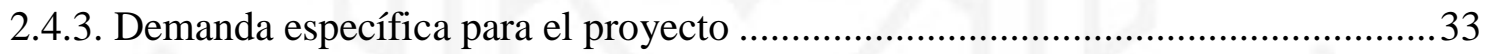

2.5. Definición de la Estrategia de Comercialización......................................................33

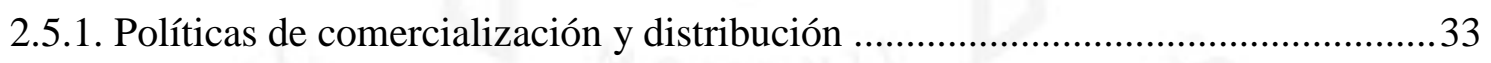

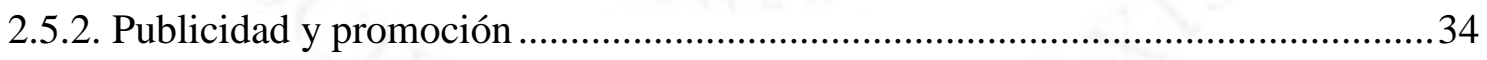

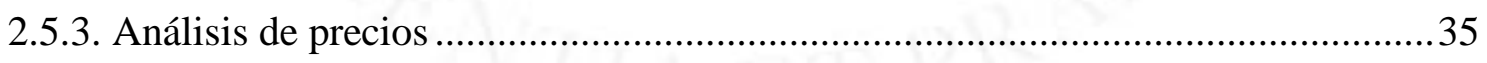

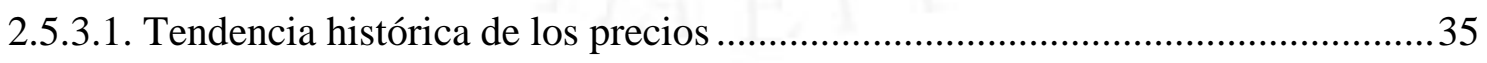

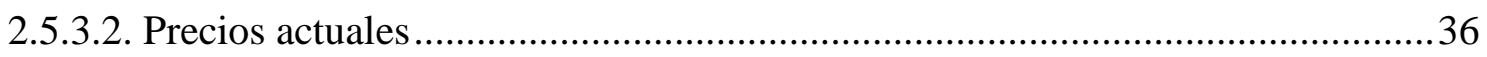

2.6. Análisis de Disponibilidad de los insumos principales ........................................ 37

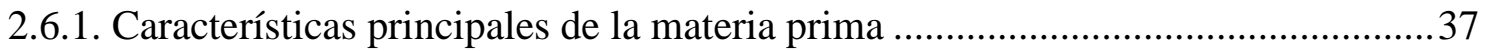

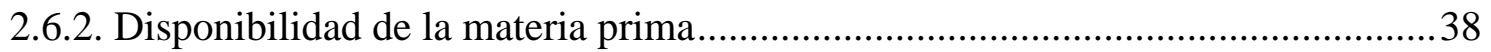

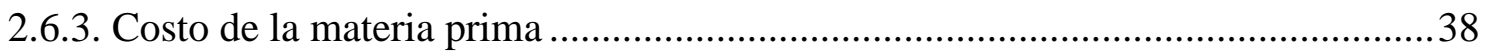


3.1. Identificación y análisis detallado de los factores de localización ..........................39

3.2. Identificación y descripción de las alternativas de localización ..............................40

3.3. Evaluación y selección de localización .............................................................. 42

3.3.1. Evaluación y selección de la macro localización................................................ 42

3.3.2. Evaluación y selección de la micro localización ................................................. 48

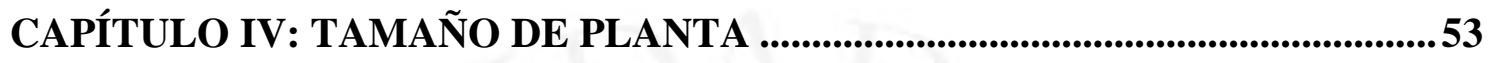

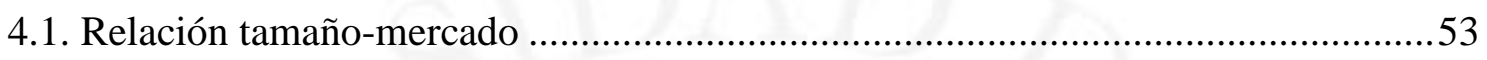

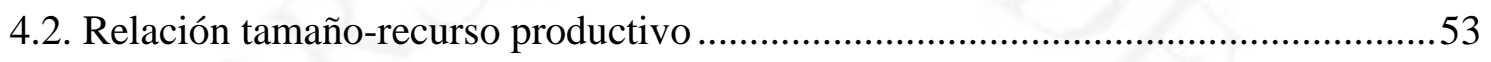

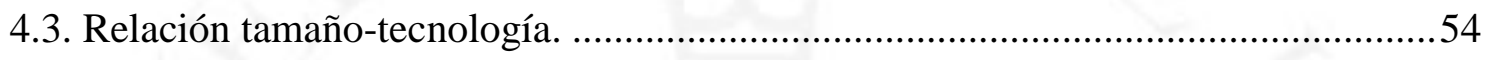

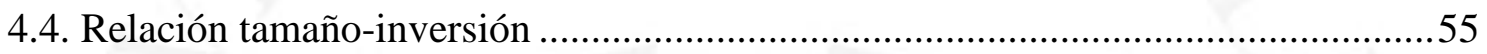

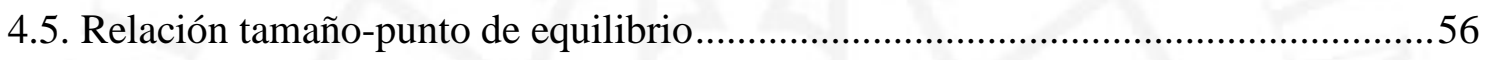

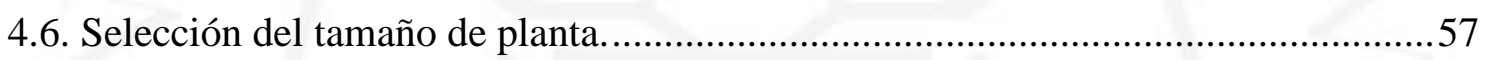

CAPÍTULO V: INGENIERÍA DEL PROYECTO...................................................58

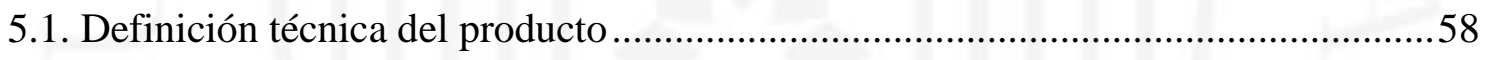

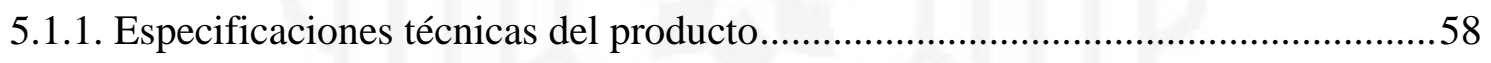

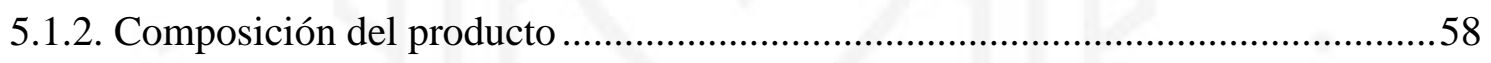

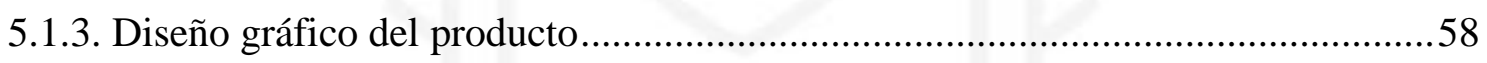

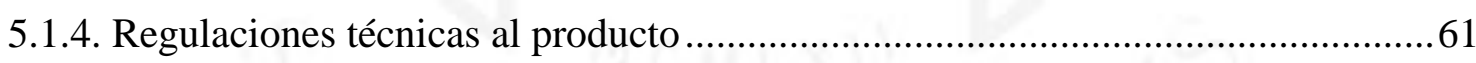

5.2. Tecnologías existentes y procesos de producción. ................................................62

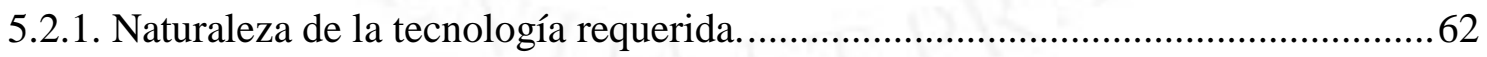

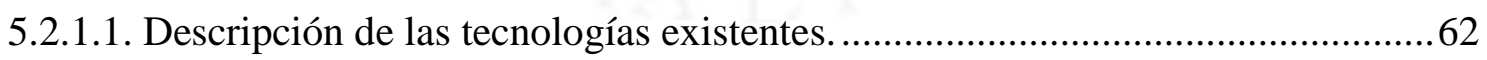

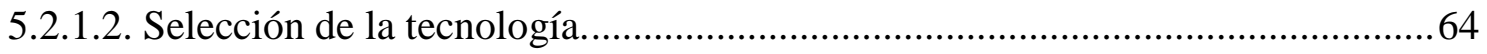

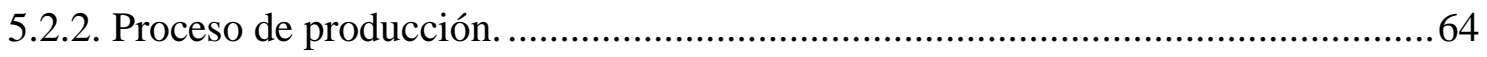

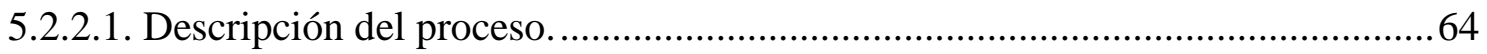

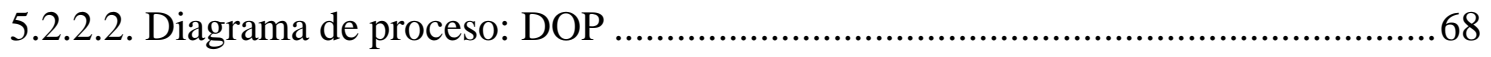

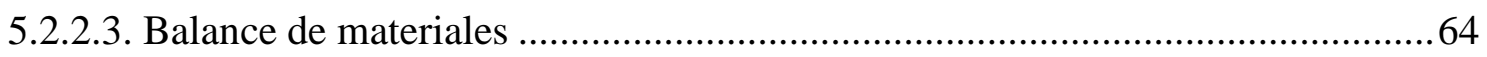


5.3. Características de las instalaciones y equipos .75

5.3.1. Selección de la maquinaria y equipos................................................................. 75

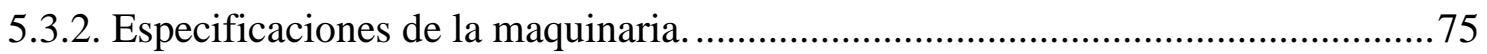

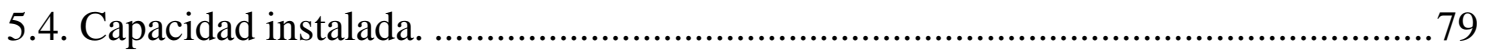

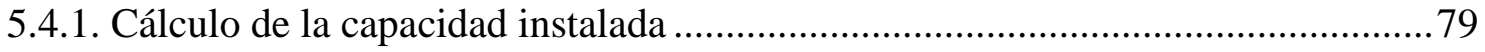

5.4.2. Cálculo detallado del número de máquinas requeridas ...................................... 80

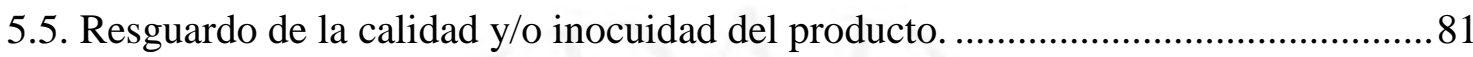

5.5.1. Calidad de la materia prima, de los insumos, del proceso y del producto.............81

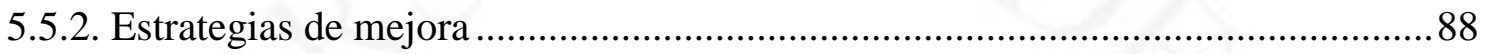

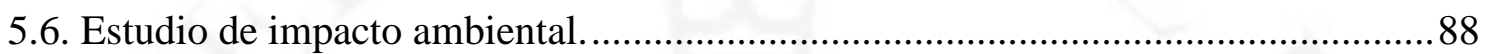

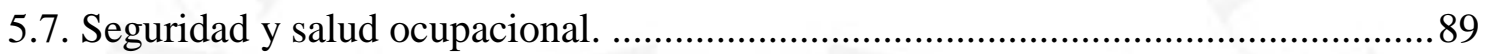

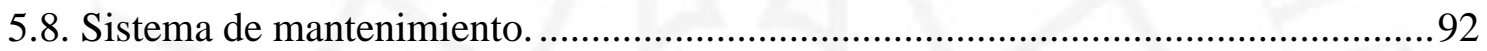

5.9. Programa de Producción ................................................................................... 95

5.9.1. Factores para la programación de la producción .................................................95

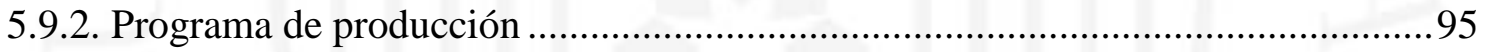

5.10. Requerimiento de insumos, servicios y personal ................................................. 96

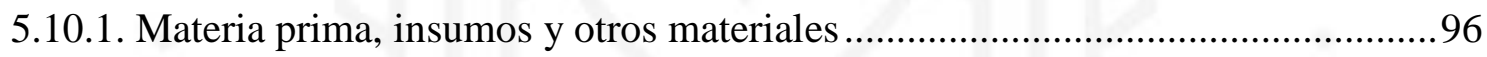

5.10.2. Servicios: Energía eléctrica, agua, vapor, combustible, etc............................. 97

5.10.3. Determinación del número de operarios y trabajadores indirectos.....................98

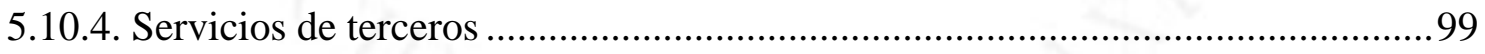

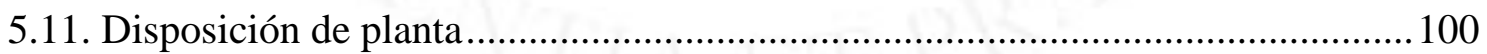

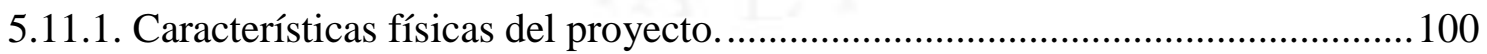

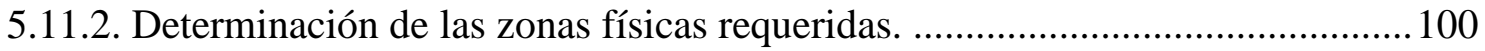

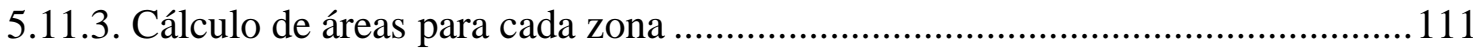

5.11.4. Dispositivos de seguridad industrial y señalización ........................................ 115

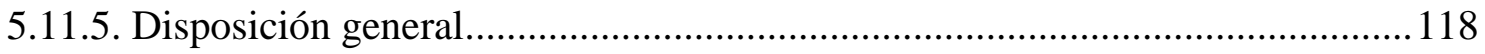

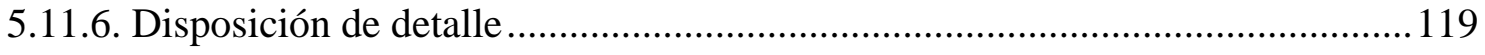


6.1. Formación de la organización empresarial ............................................................. 123

6.2. Requerimientos de personal directivo, administrativo y de servicios ................... 123

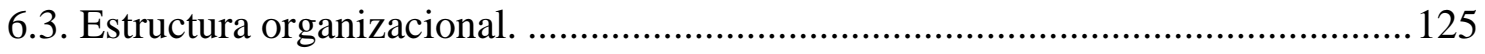

CAPÍTULO VII: ASPECTOS ECONÓMICOS Y FINANCIEROS.....................126

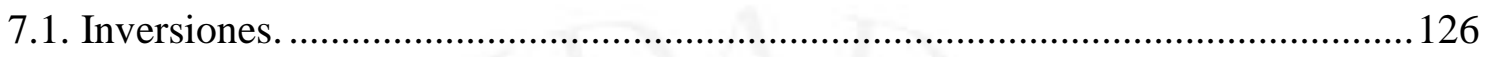

7.1.1. Estimación de las inversiones de largo plazo (tangibles e intangibles).............. 126

7.1.2. Estimación de las inversiones de corto plazo (capital de trabajo). ...................... 128

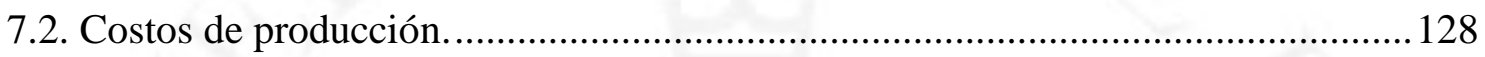

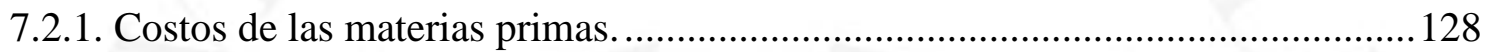

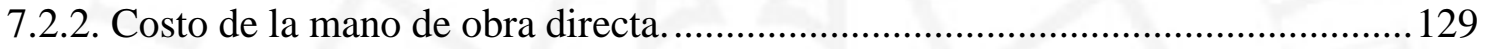

7.2.3. Costo indirecto de fabricación (materiales indirectos, mano de obra indirecta y

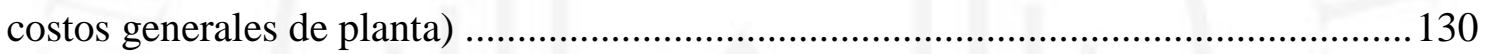

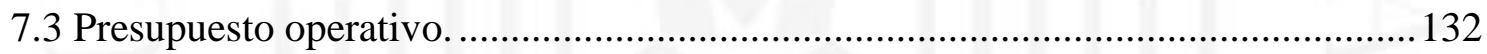

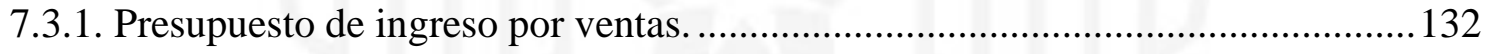

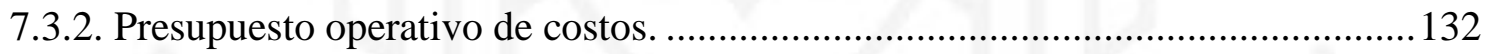

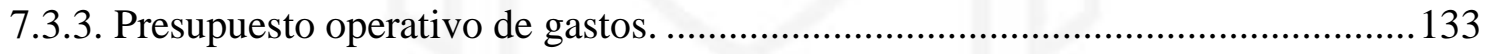

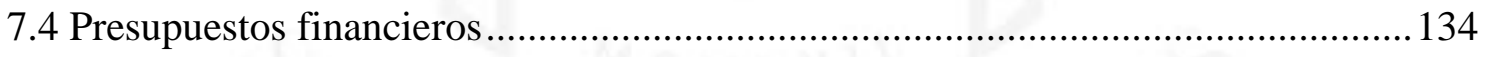

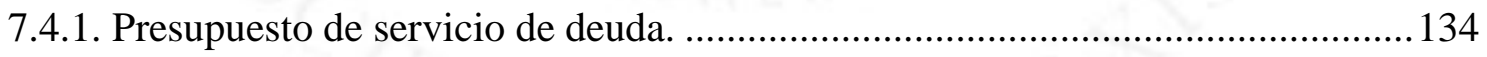

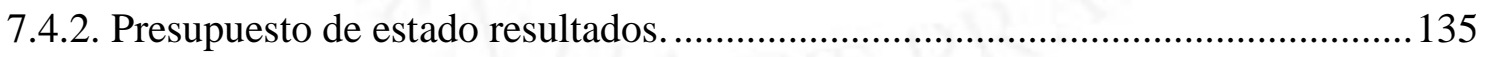

7.4.3. Presupuesto de estado de situación financiera................................................ 135

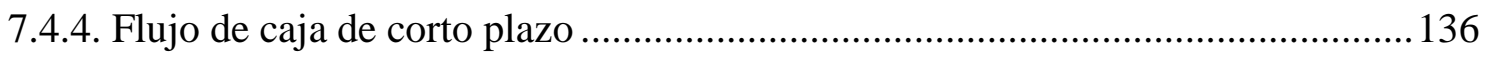

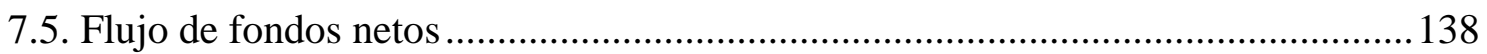

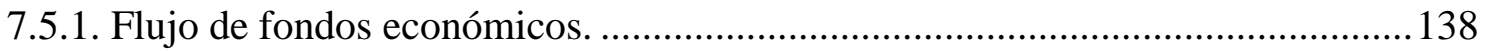

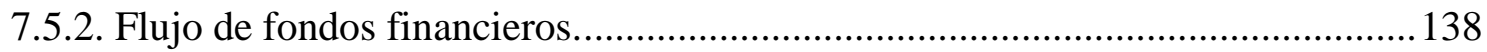

CAPÍTULO VIII: EVALUACIÓN ECONÓMICA Y FINANCIERA DEL PROYECTO ................................................................................................................................139 
8.1. Evaluación económica: VAN, TIR, B/C, PR ....................................................... 140

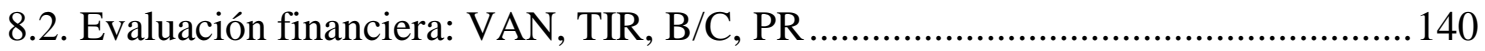

8.3 Análisis de ratios (liquidez, solvencia, rentabilidad) e indicadores económicos y

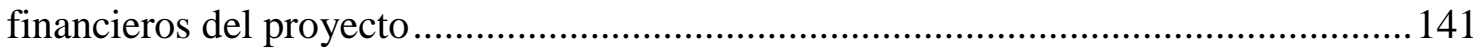

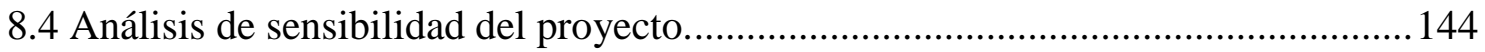

CAPÍTULO IX: EVALUACIÓN SOCIAL DEL PROYECTO ............................... 145

9.1. Identificación de las zonas y comunidades de influencia del proyecto .................. 145

9.2. Análisis de indicadores sociales (valor agregado, densidad de capital, intensidad de

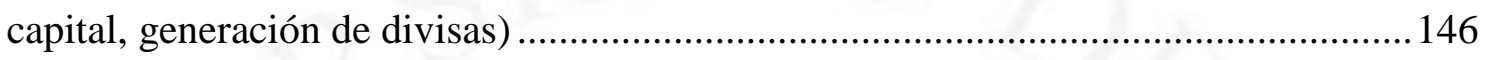

CONCLUSIONES ............................................................................................................................ 148

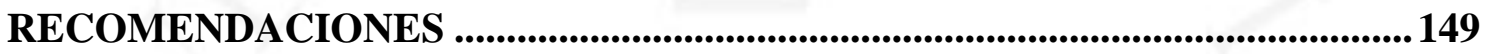

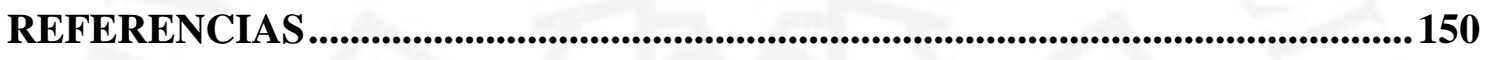

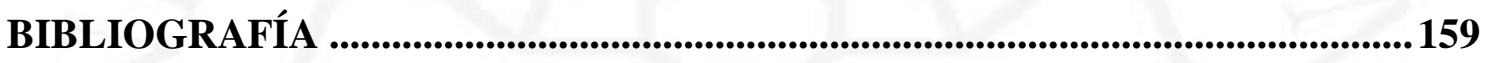

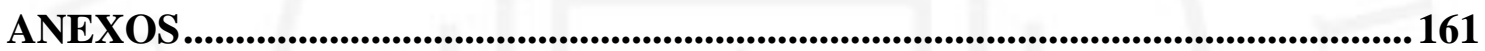




\section{ÍNDICE DE TABLAS}

Tabla 2. 1. Importaciones de prendas de bebé de Reino Unido (2012 - 2016) ............... 18

Tabla 2. 2. Exportaciones de ropa de bebé de Reino Unido (2012-2016) ....................... 19

Tabla 2. 3. Producción nacional de prendas de bebé de Reino Unido............................. 19

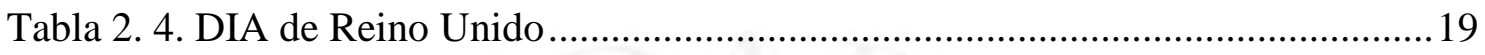

Tabla 2. 5. Población proyectada de Reino Unido .......................................................20

Tabla 2. 6. Millones de personas afectados por variables de nacimientos, muertes y

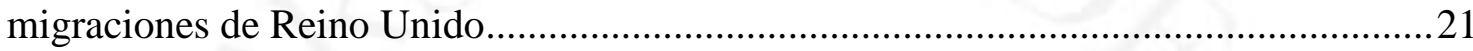

Tabla 2. 7. Demanda potencial de ropa de bebé ...........................................................24

Tabla 2. 8. Grupo de personas encuestadas por edad ..................................................25

Tabla 2. 9. Grupo de personas encuestadas por región ....................................................25

Tabla 2. 10. Grupo de personas encuestadas por nivel socio económico......................26

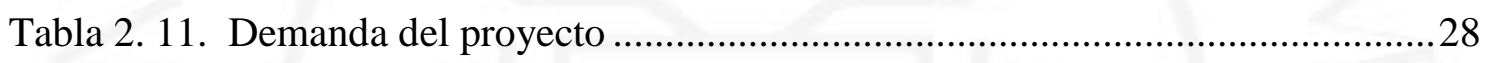

Tabla 2. 12. Demanda proyectada 2017-2022 en millones de unidades........................29

Tabla 2. 13. Participación de mercado (Porcentaje) …...................................................... 30

Tabla 2. 14. Segmentación por grupos socio-económicos.............................................. 32

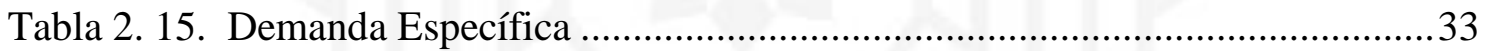

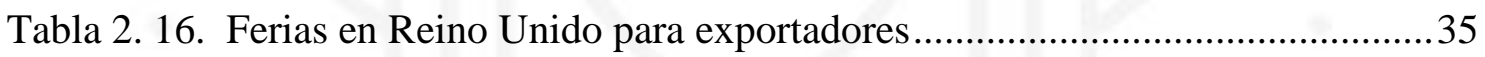

Tabla 2. 17. Exportaciones peruanas de conjuntos de ropa para bebés de algodón

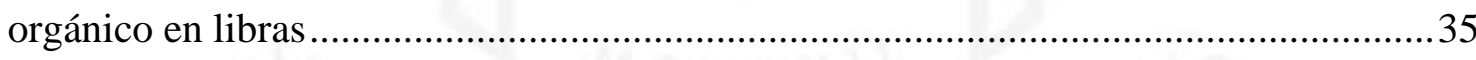

Tabla 2. 18. Precios y modelos de los productos disponibles en el mercado .................. 36

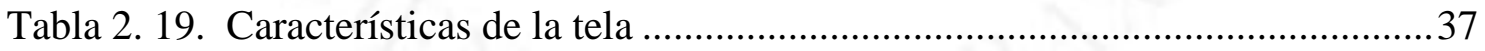

Tabla 3. 1. Proximidad con proveedores de materia prima .......................................... 43

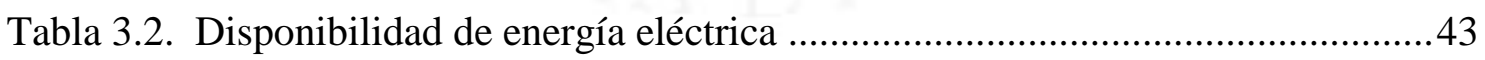

Tabla 3. 3. Número de parques industriales por departamento ................................... 43

Tabla 3. 4. Número de proyectos de parques industriales en comercialización .............44

Tabla 3. 5. Proyectos de Parques Industriales en Comercialización ...............................45

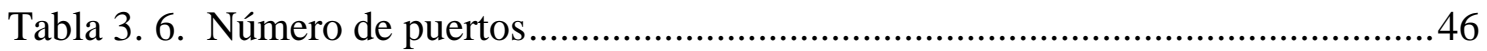

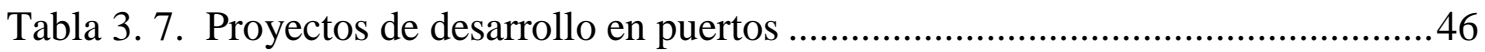

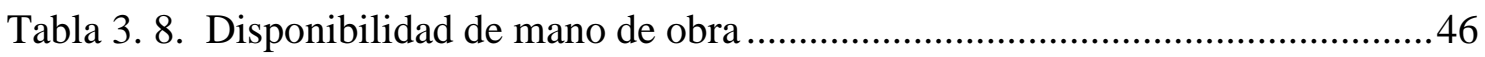


Tabla 3. 9. Nivel de desarrollo humano

Tabla 3. 10. Importancia de factores macrolocalización

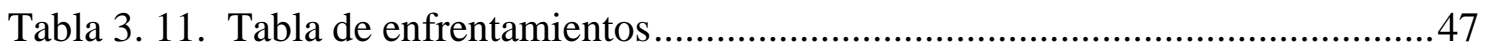

Tabla 3. 12. Escala de calificación Macrolocalización..................................................48

Tabla 3. 13. Tabla de ranking de factores - Macrolocalización..................................... 48

Tabla 3. 14. Distribución de oferta por tipo de inmueble ..............................................49

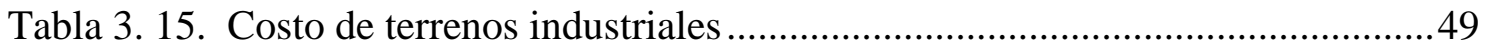

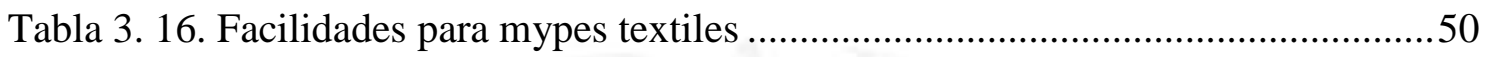

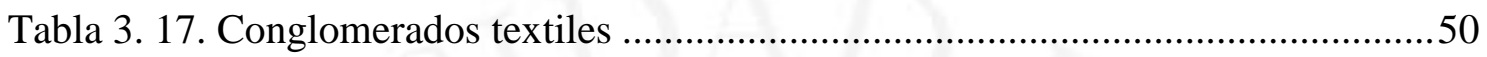

Tabla 3. 18. Tasa de denuncias por comisión de delitos (por cada 10000 habitantes) .51

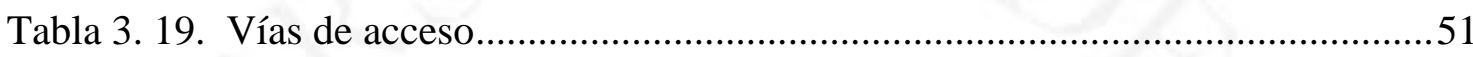

Tabla 3. 20. Importancia de factores para microlocalización ........................................51

Tabla 3. 21. Tabla de enfrentamientos - Microlocalización .........................................52

Tabla 3. 22. Escala de calificación Microlocalización ...............................................52

Tabla 3. 23. Tabla de ranking de factores - Microlocalización .....................................52

Tabla 4. 1. Proyección de venta específica de conjuntos.............................................53

Tabla 4. 2. Relación tamaño-recurso productivo .........................................................54

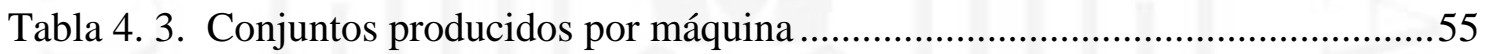

Tabla 4. 4. Tabla resumen de costos y gastos fijos .........................................................56

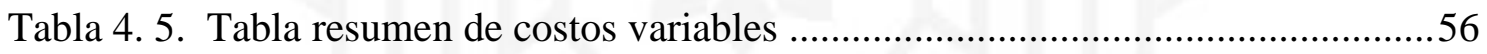

Tabla 4. 6. Tabla resumen punto de equilibrio .........................................................57

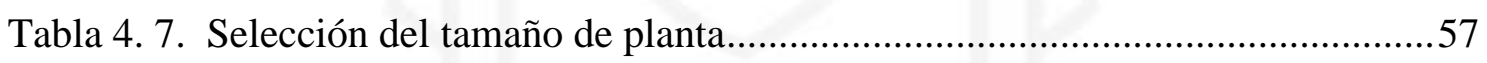

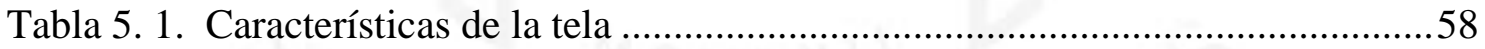

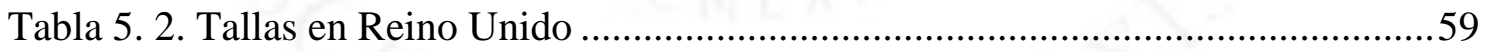

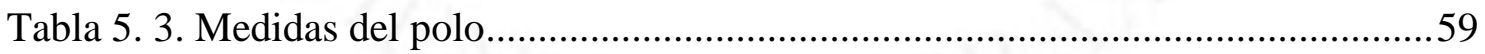

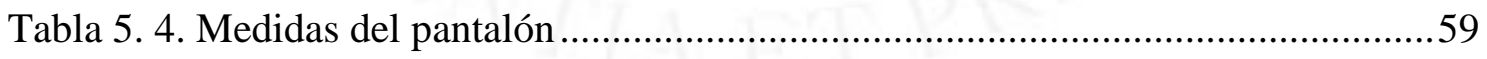

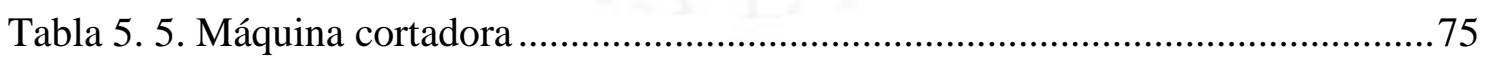

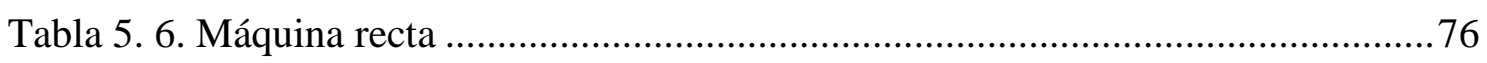

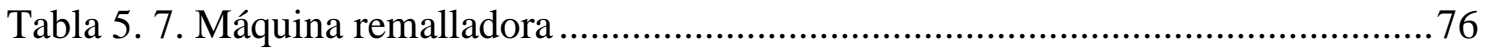

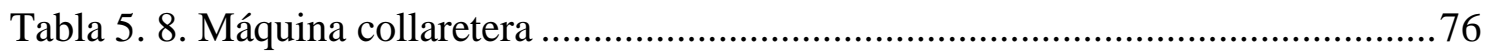

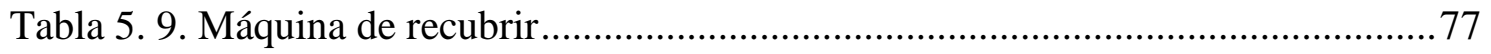

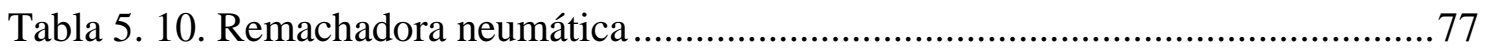

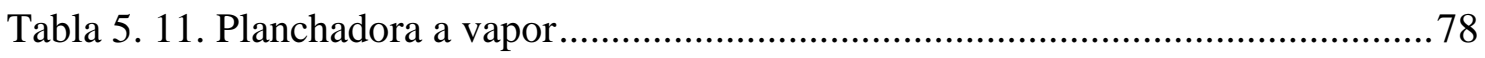




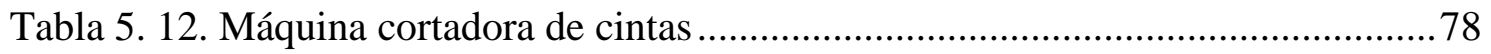

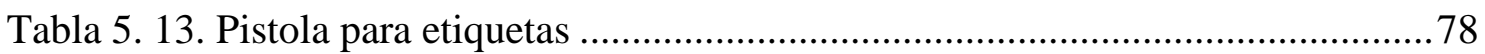

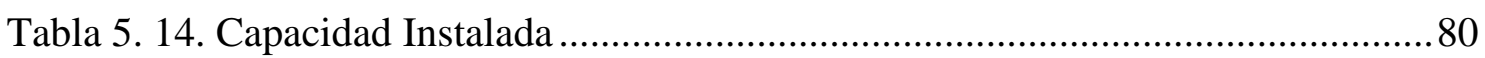

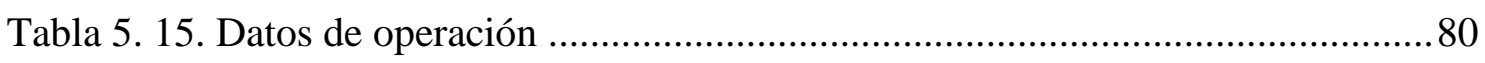

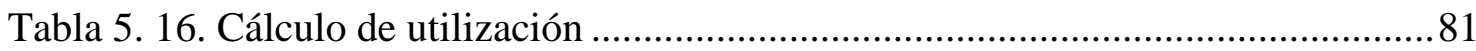

Tabla 5. 17. Cálculo del número de máquinas al 2022 ................................................ 81

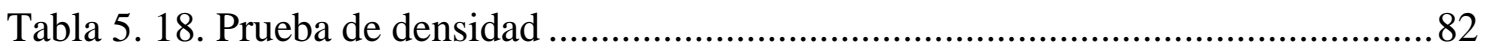

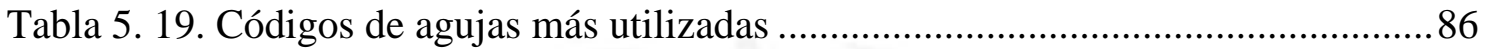

Tabla 5. 20. Tabla maestra para la inspección normal - muestreo único (MIL STD

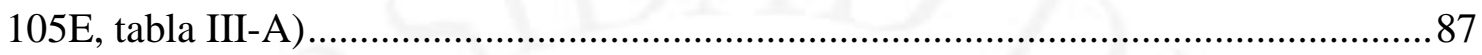

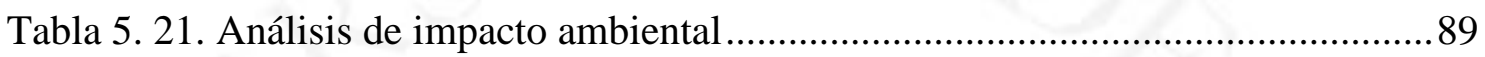

Tabla 5. 22. Criterios para obtener la probabilidad de ocurrencia................................. 89

Tabla 5. 23. Criterio para obtener la severidad del evento ..........................................90

Tabla 5. 24. Criterio para obtener el nivel de riesgo...................................................90

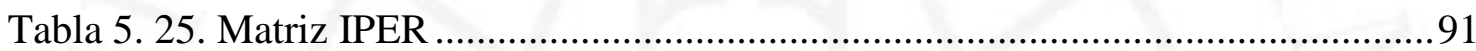

Tabla 5. 26. Costo del Mantenimiento en horas-hombre.............................................93

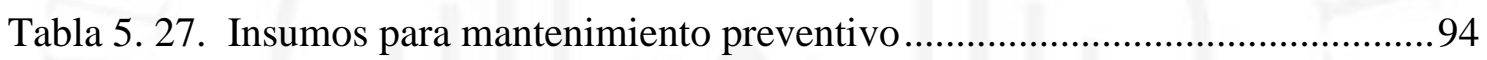

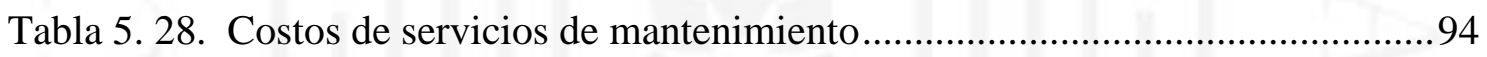

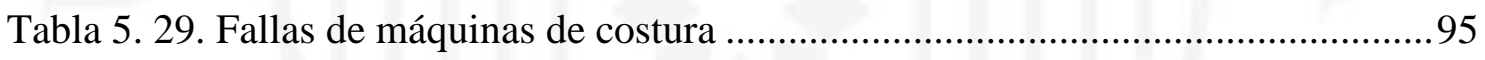

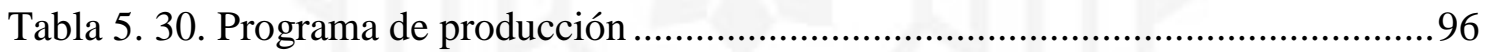

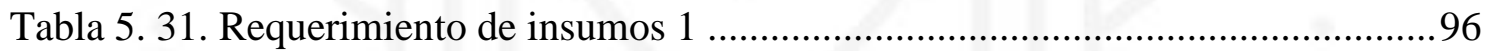

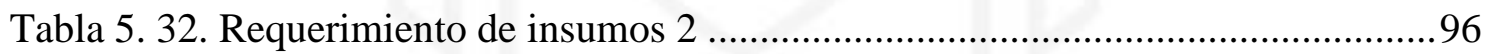

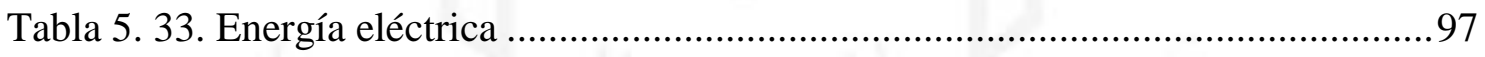

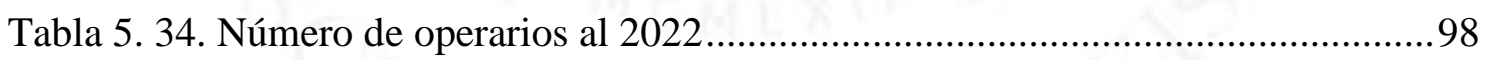

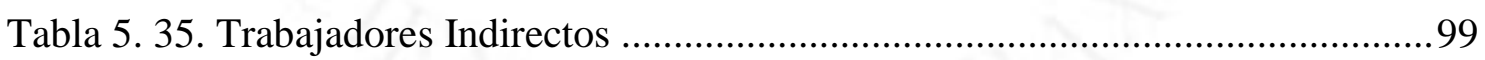

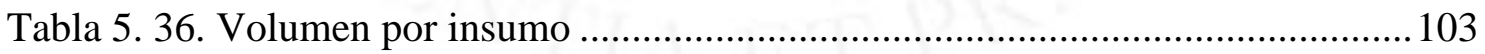

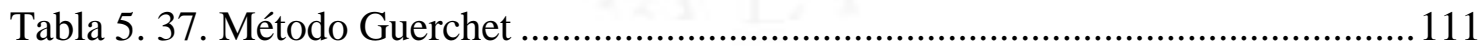

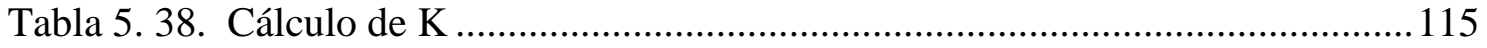

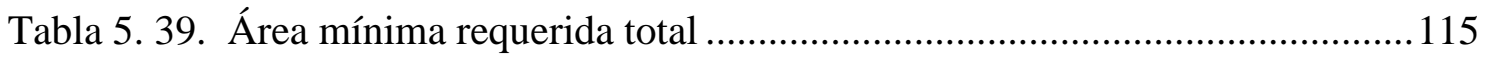

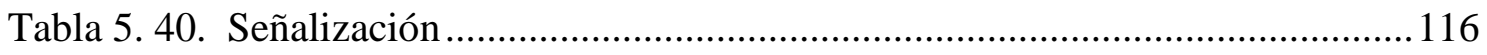

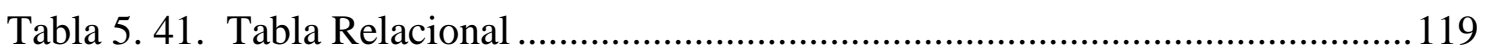

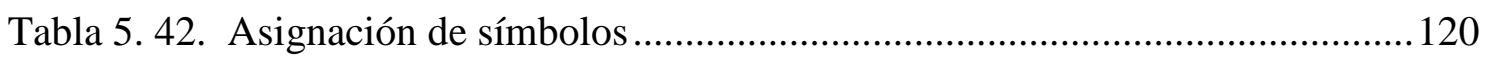

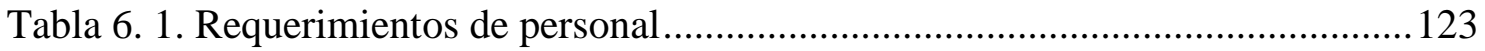


Tabla 7. 1. Activos Tangibles 126

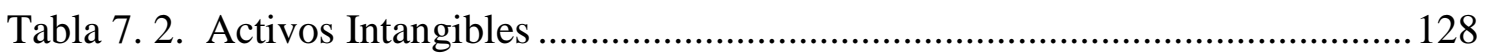

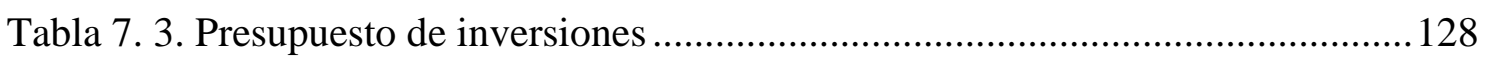

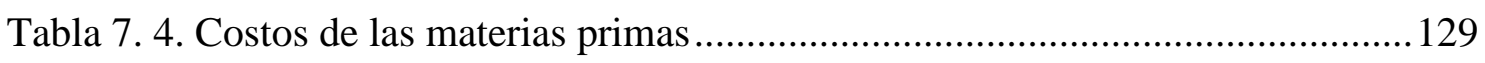

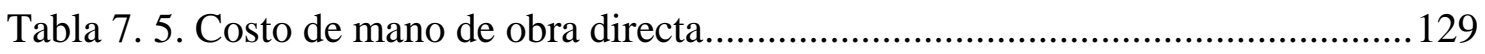

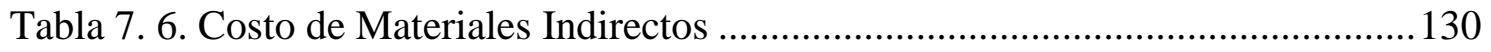

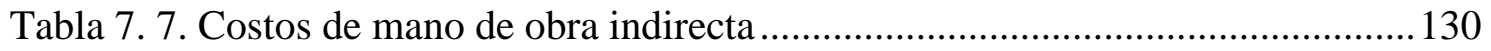

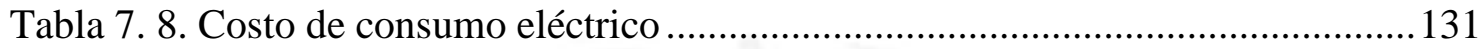

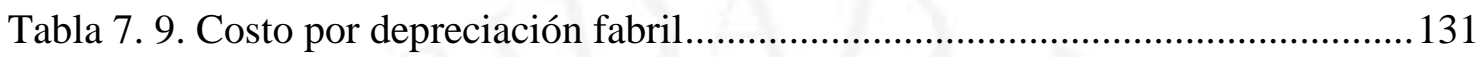

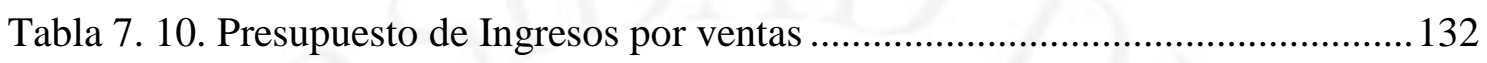

Tabla 7. 11. Tabla resumen de costo de producción..................................................... 132

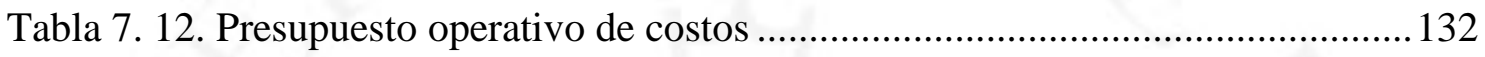

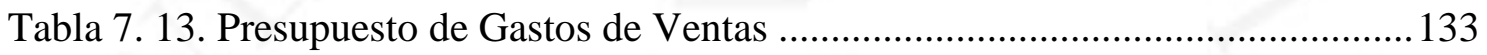

Tabla 7. 14. Presupuesto de Gastos Administrativos..................................................... 133

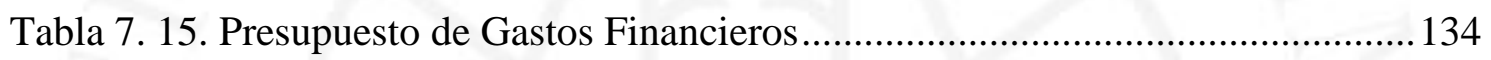

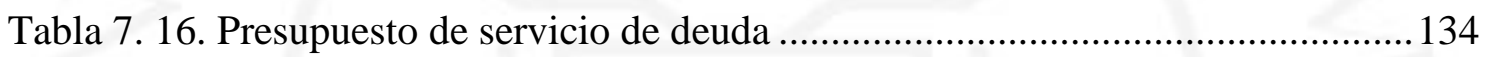

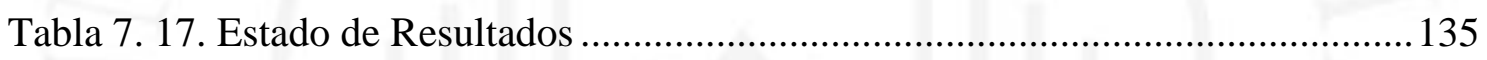

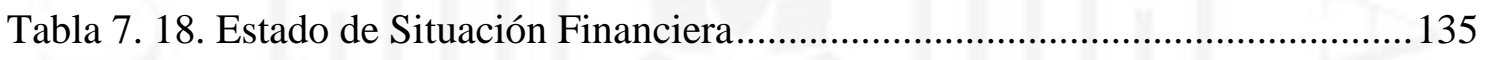

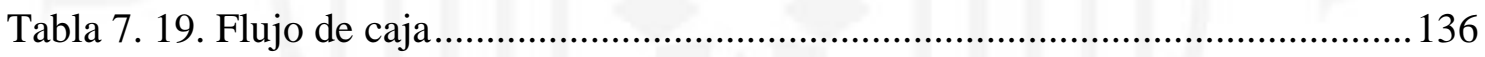

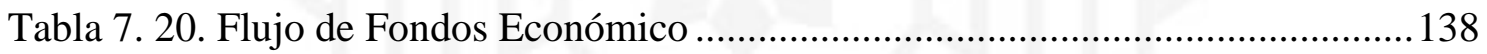

Tabla 7. 21. Flujo de Fondos Financiero .................................................................... 138

Tabla 8. 1. Costo promedio ponderado de capital ...................................................... 139

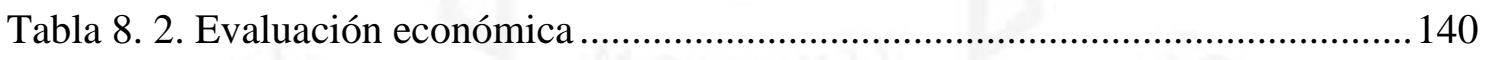

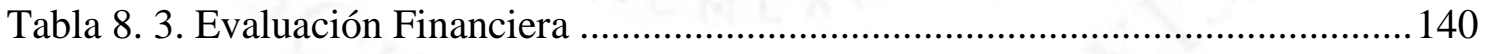

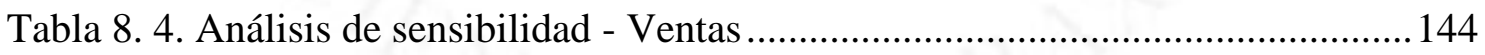

Tabla 8. 5. Análisis de sensibilidad - Costo de ventas .................................................... 144

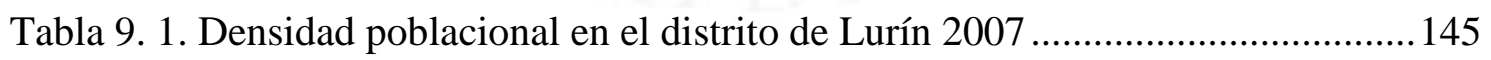

Tabla 9. 2. Población y porcentaje por grandes grupos de edades de Lurín................... 145

Tabla 9. 3. Distrito de zonas APEIM por niveles 2016 - Zona 9 ............................... 146

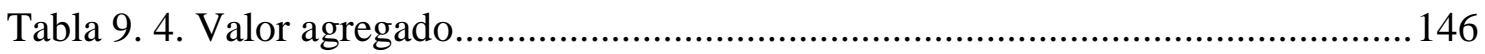




\section{ÍNDICE DE FIGURAS}

Figura 2. 1. Diseño de polo manga larga de color entero ........................................... 14

Figura 2. 2. Diseño de pantalón de color entero ........................................................ 14

Figura 2. 3. Tamaño de mercado, crecimiento y consumo per cápita de ropa de niños en

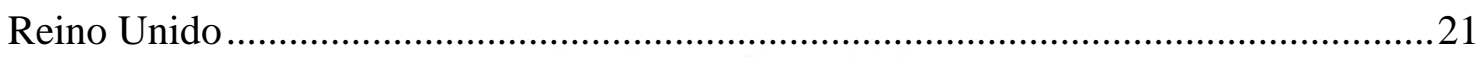

Figura 2. 4. Preferencias de consumidores según grupo socio económico y edad........22

Figura 2. 5. Cálculo de la demanda potencial de ropa de bebé.....................................23

Figura 2. 6. Factores que influyen en la compra de prendas de bebé ...........................26

Figura 2. 7. Tiendas percibidas para comprar ropa para hombre, mujeres y niños .......27

Figura 2. 8. Actitudes de los padres o abuelos al realizar compras de ropa de niños de 0

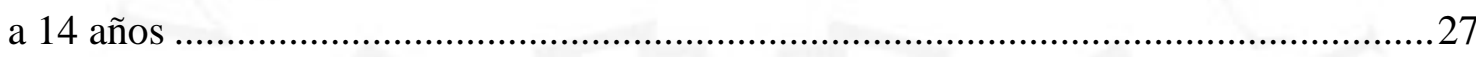

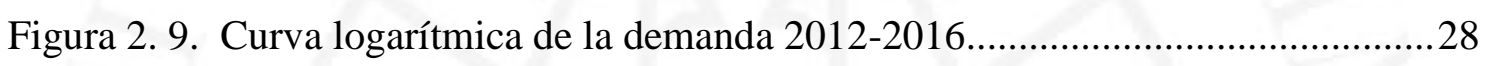

Figura 2. 10. Tendencias en la compra de bebés y niños (porcentaje según encuestas) 32

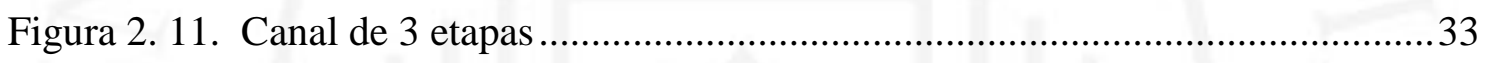

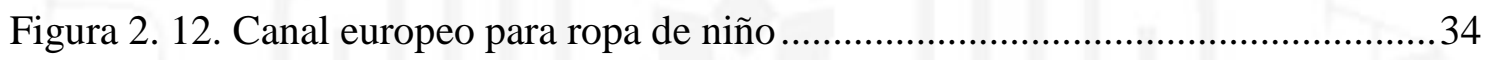

Figura 3. 1. Ubicación de parques industriales en el interior del país ............................44

Figura 3. 2. Parques industriales en la ciudad de Lima ................................................ 45

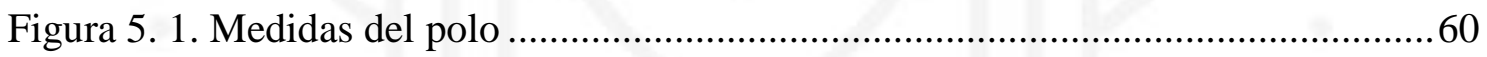

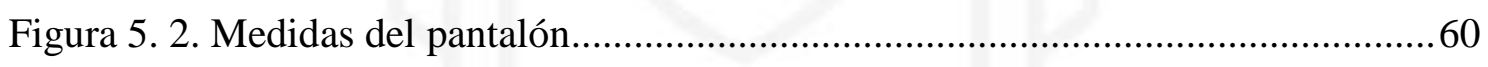

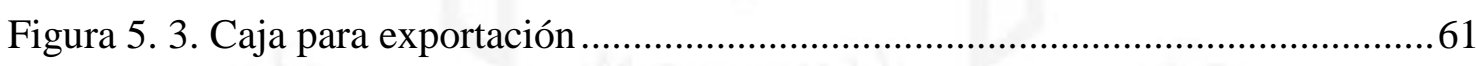

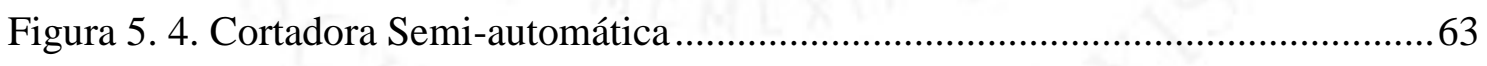

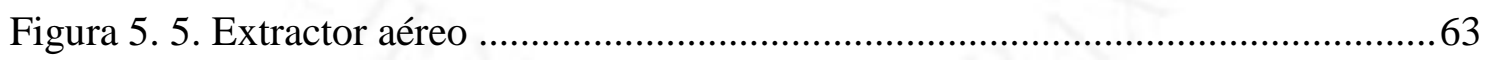

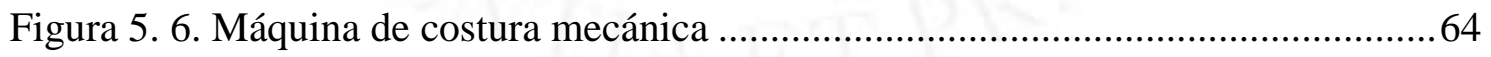

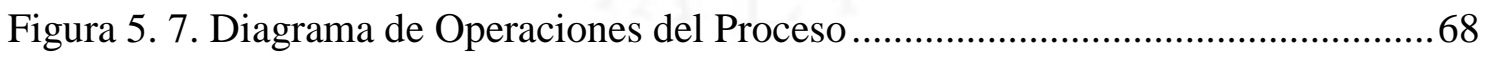

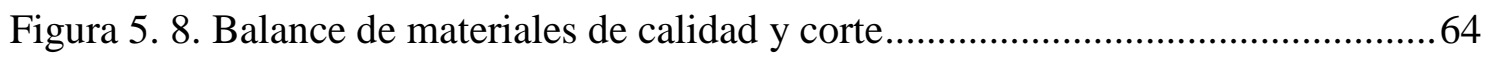

Figura 5. 9. Balance de materiales para la elaboración de un polo................................65

Figura 5. 10. Balance de materiales para la elaboración de un pantalón ........................67

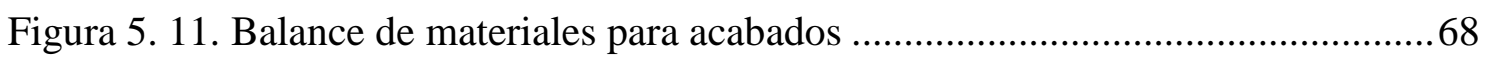

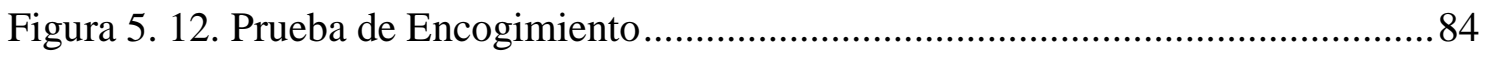

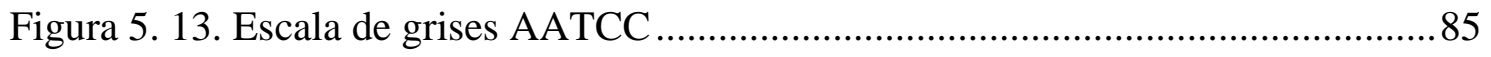

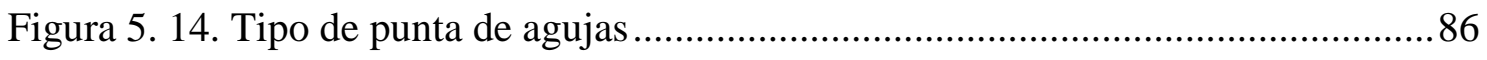




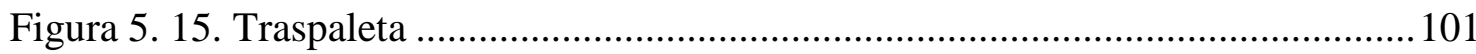

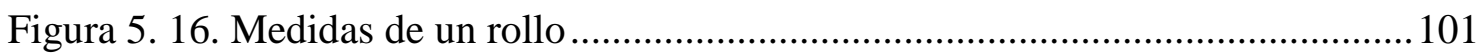

Figura 5. 17. Dimensiones del rack de telas ............................................................. 102

Figura 5. 18. Imagen referencial del rack de telas ..................................................... 102

Figura 5. 19. Estante de principales insumos............................................................ 103

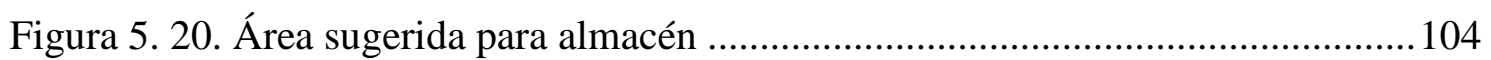

Figura 5. 21. Rack para cajas de producto terminado................................................... 105

Figura 5. 22. Imagen referencial del rack de producto terminado ................................ 105

Figura 5. 23. Área del almacén productos terminados .................................................. 106

Figura 5. 24. Imagen de Camión NQR - Chevrolet ....................................................... 107

Figura 5. 25. Dimensiones del patio de maniobras ........................................................ 108

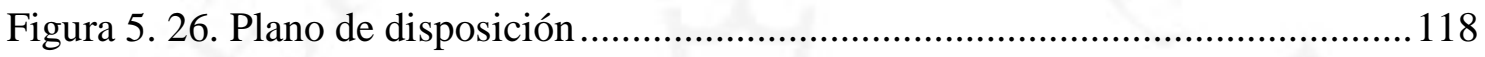

Figura 5. 27. Diagrama relacional de actividades..................................................... 121

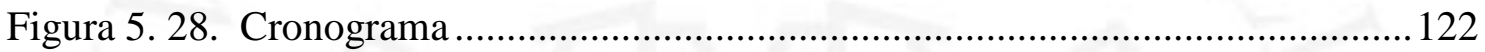

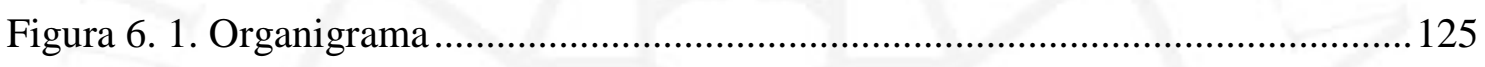

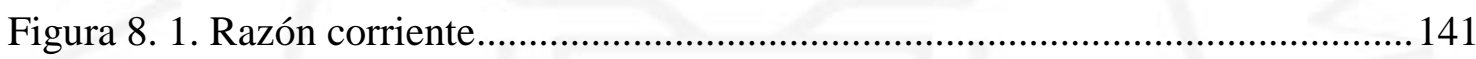

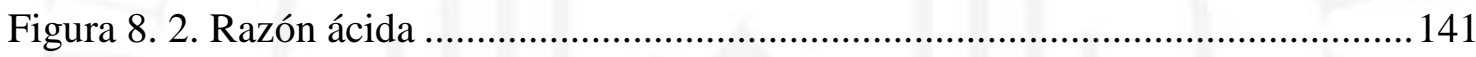

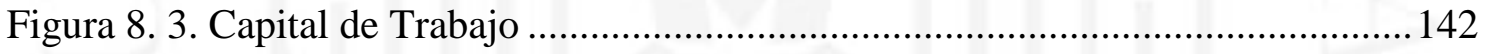

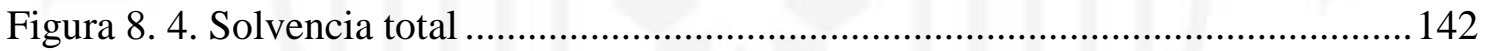

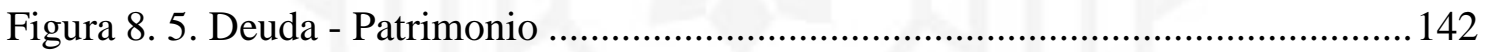

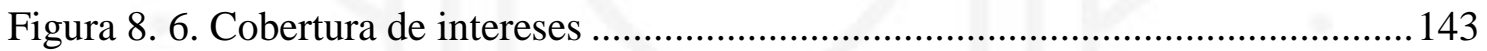

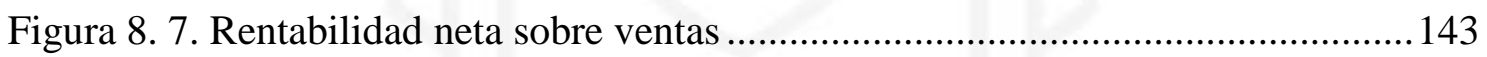

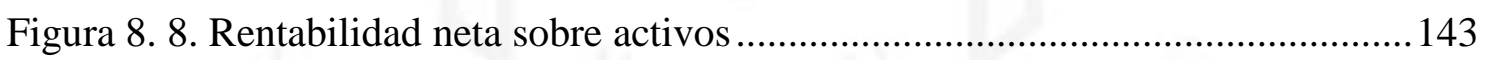

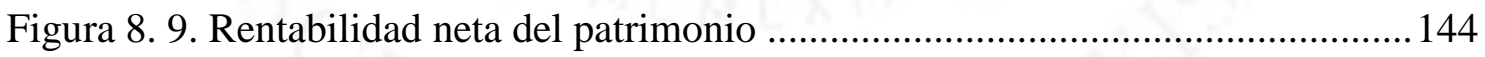




\section{ÍNDICE DE ANEXOS}

Anexo 1: Términos de referencia......................................... 162

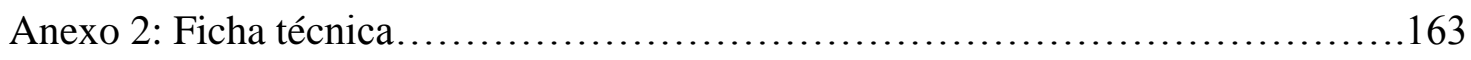

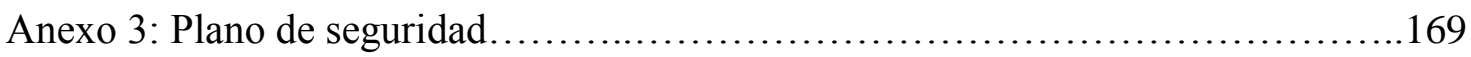

Anexo 4: Índice de reporte Childrenswear (UK) ................................. 170 


\section{RESUMEN EJECUTIVO}

La presente investigación plantea las bases para el estudio preliminar de una empresa de confección de ropa para bebés de algodón al 100\% orgánico para exportación.

Esta investigación tiene el objetivo de determinar la viabilidad de mercado, tecnológica, económica y financiera; para ello, fue necesario seguir una estructura que pueda guiar la evaluación de los principales criterios para el proyecto.

En el capítulo 1, se presenta la problemática, los objetivos que se buscarán alcanzar a lo largo de la investigación, definición de los alcances y límites del mismo, justificación del tema, planteo de hipótesis junto a un marco referencial basado en estudios previos y un marco conceptual.

En el capítulo 2, se presenta el estudio de mercado, que incluye la presentación del producto, un análisis del sector, la determinación de la demanda histórica, potencial y proyectada, análisis de la oferta, identificación del mercado meta para plantear una demanda específica del proyecto, a partir de lo cual se genera el planteamiento de las políticas de comercialización, distribución, publicidad, promoción, análisis de precios y finalmente un análisis de disponibilidad de los principales insumos.

En el capítulo 3, se realiza la identificación y evaluación de la localización de la planta. Se analizan varios departamentos, resultando más favorable el departamento de Lima según el ranking de factores favorables, del cual el distrito de Lurín fue seleccionado como el lugar óptimo para la localización de la planta.

En el capítulo 4, se englobaron los análisis de capítulos anteriores y posteriores para determinar el tamaño de planta, resultando con una restricción por el tamaño del mercado.

El capítulo 5 engloba diversos aspectos de la ingeniería como especificaciones técnicas y composición de la tela, proceso de producción, características de la maquinaria y equipos a utilizar para determinar la capacidad instalada y el número de máquinas necesarias, también se presentan metodologías que permitirán mantener un nivel calidad tanto en el producto, como en la materia prima, los insumos y el proceso; además se incluye un estudio de impacto ambiental, seguridad y salud en el trabajo, sistema de 
mantenimiento, un programa de producción que permite determinar el requerimiento de los insumos, los servicios y el personal; finalmente, se desarrollan los preámbulos para obtener la adecuada disposición de planta junto a un cronograma de implementación del proyecto.

En el capítulo 6, se detalla información acerca de la parte organizacional del proyecto tales como la formación de la organización empresarial, requerimientos de personal administrativo y de servicio; y estructura organizacional.

En el capítulo 7, se realizaron estimaciones de las inversiones a corto y largo plazo, se determinará los costos de producción para poder desarrollar los presupuestos operativos (ingresos por ventas, costos y gastos) y financieros (servicio de deuda, estado de resultado y situación financiera), adicionalmente se presenta el flujo de fondos netos económicos y financieros.

En el capítulo 8, se presenta la evaluación económica y financiera del proyecto usando indicadores como el valor actual neto (VAN), el periodo de recupero, la tasa interna de retorno (TIR) y el beneficio-costo para verificar la viabilidad del proyecto; se incluirá un análisis de ratios de liquidez, solvencia y rentabilidad; así como un análisis de sensibilidad para saber el desempeño del proyecto en un escenario optimista como pesimista.

En el capítulo 9, se explican las zonas y comunidades de influencia del proyecto; junto a un análisis de indicadores social que permitirá observar los beneficios que generaría la implantación del proyecto tanto a los pobladores cercanos como a todo el país. 


\section{EXECUTIVE SUMMARY}

The present investigation raises the bases for the preliminary study of a company for the manufacture of baby clothes made of $100 \%$ organic cotton for export.

This research has the objective of determining the viability of the market, technology, economy and finance; for this, it was necessary to follow a structure that could guide the evaluation of the main criteria for the project.

In chapter 1, we present the problem, the research objectives to achieve by the end of the investigation, the definition of the scope and limits of the same, the justification of the topic, the hypothesis plan together with a referential framework based on previous studies and a conceptual framework.

In chapter 2, the market study is presented, which includes the presentation of the product, the analysis of the sector, the determination of the historical demand, the potential and the project, the analysis of the offer, the identification of the target market to raise a specific demand of the Project, from what refers to the generation of marketing policies, distribution, advertising, price analysis and finally an analysis of availability of the main inputs.

In Chapter 3, the identification and evaluation of the location of the plant is carried out. Several departments are analyzed, resulting as a winner the department of Lima according to the ranking of favorable factors, where the district of Lurin was selected as the optimal place for the location of the plant.

In Chapter 4, the analyzes of previous and subsequent chapters were included to determine the size of the plant, resulting in a restriction for the size of the market.

Chapter 5 covers many aspects of engineering such as technical specifications and composition of the fabric, production process, characteristics of machinery and equipment to determine the appropriate capacity and the number of machines required, methodologies are also presented that must maintain a level of quality both in the product, as in the raw material, the inputs and the process; in addition, an environmental impact study, safety and health at work, maintenance system, a production program that allows determining the requirement of inputs, services and personnel are included; finally, we 
develop the parameters to obtain the appropriate plant layout along with a schedule of project implementation.

In Chapter 6, information about the organizational part of the project is detailed, such as the formation of the business organization, administrative and service staff requirements; and organizational structure.

In chapter 7 , the production costs are determined for the power of the same. financial), additionally the flow of net economic and financial funds is presented.

Chapter 8 presents the economic and financial evaluation of the project, the indicators such as the net real value (NPV), the recovery period, the rate of return (IRR) and the benefit-cost to verify the viability of the project.; it will include an analysis of liquidity, solvency and profitability ratios; as well as a sensitivity analysis to know the performance of the project in an optimistic scenario as a weightlifter.

In chapter 9, the areas and communities of influence of the project are explained; along with an analysis of social indicators that relate to the benefits of the project's writing. 


\section{CAPÍTULO I: ASPECTOS GENERALES}

\subsection{Problemática}

En los últimos años, la preocupación por el tema ambiental ha ido en aumento y va de la mano con las medidas adoptadas por diversos países para preservar el medio ambiente. Es así que diversas industrias se van orientando a lo ecológico. Inicialmente, éstas solo brindaban donaciones para temas ambientales, pero en los últimos años hay un creciente sector que ha optado por utilizar materias primas ecológicas o mejorar sus procesos para disminuir su huella de carbono. (Morgan, 2015)

En este contexto, la industria textil ha sufrido un gran cambio dando como fruto a la moda sostenible o también llamada ecológica. La industria textil es una de las industrias más grandes a nivel mundial y es la segunda industria que mayor contaminación genera al medio ambiente después de la industria petrolera. Es así que la moda ecológica busca crear un sistema de responsabilidad social. (Morgan, 2015)

Según datos extraídos de la Comisión de Promoción del Perú para la Exportación y el Turismo (PromPerú, 2015), los consumidores europeos valoran cada vez más que las prendas que hayan sido producidas con tejidos orgánicos y mediante procesos que disminuyan el impacto ambiental.

Una de las muestras de este cambio es el reto de la alfombra verde en el que diversas celebridades lucen vestimenta de moda sostenible, demostrando así que belleza, elegancia, ecología y ética son más que compatibles. Así mismo, buscan influenciar a sus seguidores y futuras generaciones. (I Feel Dress, 2016)

El Perú no es ajeno a este cambio. "Según la OTA, [Asociación de Comercio Orgánico], el Perú se ubica como el octavo productor orgánico a nivel mundial, aspecto que resulta interesante, ya que también es uno de los principales... [productores] de algodón pima en el mundo" (como se cita en Gestión, 2013). A pesar de que Perú es un gran productor de algodón orgánico, la mayor parte de este es destinado a la exportación (Inga, 2016).

Por otro lado, según los datos extraídos de la página Euromonitor (2016), el mercado de prendas para bebé en Reino Unido aún se encuentra en crecimiento, más 
moderado debido a diferentes factores socioeconómicos y de natalidad, pero que aún no llega a consolidarse. Así mismo, es uno de los mayores consumidores de prendas fabricadas de algodón peruano (orgánico y comercial) y se proyecta un aumento significativo a mediano plazo en el consumo de prendas orgánicas. (PromPerú, 2015)

Es así que la presente investigación plantea las bases para el estudio preliminar de una empresa de confección de ropa para bebés de algodón al 100\% orgánico para exportación. El destino principal del producto será Reino Unido debido a la alta demanda que presenta el mercado por productos de calidad, con variedad de diseños y tallas.

\subsection{Objetivos de la investigación}

- Objetivo general:

Determinar la viabilidad de mercado, tecnológica, económica y financiera para la instalación de una planta de confección de ropa para bebés de algodón orgánico al 100\% para exportación a Reino Unido.

- Objetivos específicos:

- Realizar un estudio de mercado, especificando las características de los clientes y sus preferencias.

- Evaluar a las empresas competidoras y los productos que ofrecen para determinar estrategias de diferenciación.

- Definir el proceso productivo a emplear.

- Analizar la viabilidad económica y financiera

\subsection{Alcance y limitaciones de la investigación}

Para el alcance, el estudio analizará los procesos de confección de un juego de ropa para bebés (polo y pantalón) a partir de tela orgánica, este conjunto va dirigido al segmento infantil de 0 a 3 años de Reino Unido.

En cuanto a las limitaciones, existen pocos proveedores de tela orgánica con certificaciones internacionales, lo que refleja un alto precio en la materia prima. Así 
mismo, existe desconocimiento de parte de los trabajadores en cuanto a la correcta manipulación de prendas orgánicas.

\subsection{Justificación del tema}

\section{- Técnica:}

Según la Asociación de Comercio Orgánico (Organic Trade Association, 2015), el Perú se encuentra como décimo productor de algodón orgánico a nivel mundial. En el año 2011, el pleno Congreso peruano prohibió el ingreso de transgénicos con fines de cultivo o crianza por un periodo de diez años, con la finalidad de preservar la biodiversidad nativa del país (Perú Orgánico, 2011). Esto nos da una ventaja competitiva con respecto a otros países, especialmente asiáticos, que tienen problemas para separar los cultivos orgánicos de los transgénicos.

Una característica importante de la producción orgánica de algodón es el uso de fertilizantes naturales, como se da en los valles de Cañete y Chincha, donde se usa como abono el guano de aves, se cosecha a mano en lugar de maquinarias o químico defoliantes, y se busca conservar los suelos rotando los cultivos de algodón con maíz y frijoles. (Oro Blanco, 2017)

Las diferencias del algodón comercial con el orgánico son casi imperceptibles al tacto (Rodríguez, 2011). Es por ello que se exige un certificado de autenticidad a los productores de algodón orgánico.

La empresa Control Union Certifications explica que para que un producto sea considerado orgánico y se le permita el ingreso al mercado internacional debe tener una certificación que deje constancia de su procedencia. (Chavarri, 2009); bajo este contexto, existe la certificación Global Organic Textile Standart (GOTS), la cual tiene por objetivo asegurar la condición orgánica de los productos textiles desde la fabricación de la materia prima hasta el correcto etiquetado (Círculo de estudios de mercados internacionales, 2013). Actualmente, existen solo cinco empresas peruanas proveedoras de tela orgánica con esta certificación. Será necesario un adecuado control de toda la cadena de producción para poder cumplir con los lineamientos que determina GOTS, por ejemplo: los textiles 
deben contener un mínimo de $70 \%$ de fibra orgánica para poder ser certificada, los insumos químicos deben cumplir con ciertos criterios ambientales y toxicológicos, entre otros (Organic Trade Association, 2017).

Durante la etapa de confección, la materia prima es tratada como el algodón tradicional, pero con el cuidado de evitar las contaminaciones en la planta con suciedad o residuos de otras fibras no orgánicas. Para este proceso no existen maquinarias especializadas sino de manera general maquinaria para confeccionar prendas de algodón en tejido de punto como la máquina recta, remalladora, recubridora, etc.

En resumen, existe en el Perú producción de algodón orgánico que sustenta técnicamente este proyecto.

\section{- Económica:}

La red de acción de alternativas al uso de agroquímicos ha realizado estudios en parcelas peruanas y ha determinado en relación con los rendimientos que el 36,6 por ciento de los agricultores que cambiaron el algodón tradicional por algodón orgánico vieron incrementados sus ingresos. De igual manera, en lo que respecta a la utilidad, el 20 por ciento de los involucrados registró un incremento. Así mismo, el algodón tradicional necesita una gran cantidad de pesticidas y herbicidas para su crecimiento, este ahorro significa un beneficio económico para el agricultor. (Gomero y Velásquez, 2002).

En cuanto al mercado, éste es muy competitivo, y requiere de constante actualización de diseños. El cliente europeo está dispuesto a pagar más el valor agregado de la etiqueta ecológica siempre y cuando vaya de la mano con el confort, diseño y la calidad (Mintel Group Limited, 2014).

Se asume entonces que esto generará beneficios económicos para la empresa.

\section{- Social:}

El “algodón orgánico es mucho más suave que el algodón común, permite a la piel una mayor ventilación y respiración” (Fernández, 2014, pág. 28). Además, 
reduce la posibilidad de presentar reacciones alérgicas y colabora con el cuidado del ecosistema. (Verde Textil, 2017)

El algodón orgánico brinda los siguientes beneficios para los productores, el medio ambiente y el consumidor:

- Beneficios para los productores: el algodón orgánico no es tóxico, con lo cual resguarda la salud de los productores debido a que no se afectan por el contacto o la inhalación de productos químicos que suelen ser empleados en el cultivo del algodón convencional (Centro de Comercio Internacional, 2015).

- Beneficios para el medio ambiente: se respetan los recursos naturales y el ecosistema al evitar el uso de fertilizantes químicos e insecticidas, así como "el uso de algodón no modificado genéticamente (no transgénicos)" (Conciencia ecológica, 2011).

- Beneficios para el consumidor: el uso de algodón orgánico elimina las reacciones alérgicas provocadas por la utilización de productos químicos en prendas. Así mismo, el hecho de que no existan residuos químicos tóxicos contribuye en la suavidad del producto y es beneficiosa para la piel de quienes lo utilizan (Verde Textil, 2009).

\subsection{Hipótesis de trabajo}

La instalación de una planta de confección de ropa para bebés de algodón al 100\% orgánico para exportación a Reino Unido será viable desde el punto de vista del mercado, tecnológico, económico y financiero.

\subsection{Marco referencial de la investigación}

Para el desarrollo del marco referencial, se detallarán las siguientes investigaciones relacionadas al presente trabajo:

- “Análisis y desarrollo de producto para prendas de vestir para exportación”, por Lisbeth Giovanna Urquizo Rivas (2014) de la Pontificia Universidad Católica del Perú. En esta tesis se detalla el proceso desde la parte de desarrollo del color en tintorería hasta la prenda terminada, enfocándose en la parte de gestión de una empresa textil. Como aporte a nuestro trabajo, rescataremos las mejoras en el área 
de gestión de costura y desarrollo de producto. Así mismo, entre las diferencias se encuentran que en este análisis no se detallan los procesos de costura por tipo de prenda, ni se menciona la gestión posterior a la prenda terminada, ya sea de trámites de exportación como estándares de calidad para el producto terminado según el continente al que se quiera exportar.

- "Plan de Negocios para la comercialización vía web de ropa orgánica para bebé", por Miguel Caro Marentes, Henry Cuyubamba López y Audrey Mendoza Díaz (2012) de la Universidad Peruana de Ciencias Aplicadas. En este plan de negocios, se detalla el plan de marketing, el plan financiero la formulación estratégica para el mercado peruano. A diferencia de esta tesis, nuestro proyecto va dirigido a otro mercado y se hace un detallado análisis en la parte de ingeniería del proyecto.

- "Desarrollo de un plan de negocios para la nueva línea de producto confeccionada con algodón orgánico para la empresa Pinto S.A. en el mercado local”, por María Andrea Puertas Carrión y Javier Alejandro Paredes Saltos (2008) de la Escuela Superior Politécnica Del Litoral en Ecuador. Esta tesis brinda un panorama de las oportunidades de negocio para las prendas de bebé hechas de algodón orgánico en Ecuador.

- "Proyecto para la instalación de una planta de confecciones de ropa de bebés", por Silvia Adelma Campos Benites (1995) de la Universidad de Lima. Se tendrá como referencia debido a que se utilizarán las mismas maquinarias y altos estándares de calidad por el enfoque de exportación a Europa. En cuanto a las diferencias, se tiene otro mercado objetivo y enfatiza en los beneficios e inconvenientes de los sistemas modulares y el tradicional. Por lo tanto, no desarrolla el valor agregado del diseño, sino que tiene un enfoque a volumen.

- "Producción y exportación de sábanas de algodón pima para bebés en el Reino Unido”, por Kelly Daniela Hernández Gaspar (2015) de la Universidad de Lima. Se tiene el mismo mercado objetivo y los altos estándares de calidad del producto. Sin embargo, la diferencia radica en que se trata de un producto distinto al planteado y no detalla en proceso de producción de las sábanas.

- "Estudio de pre-factibilidad para la implementación de una planta de estampado textil sobre tejidos de algodón ecológico" (Wasser Burlet, Nicole, 2010). Se tomarán como base los datos recopilados con respecto a las características del 
algodón orgánico, así como las recomendaciones para sus transportes y evitar la contaminación en la planta. El estudio de pre-factibilidad solo trata del proceso de estampado mientras que lo planteado se enfocará en la parte de confección, armado y distribución de la prenda, última etapa del proceso.

- "Proyecto de una planta de tejido, confección y estampado de camisetas de algodón para la exportación”, de Mariano Ibérico Ocampo y Roberto A. Cenzano Duran (1989) de la Universidad Nacional de Ingeniería. Esta tesis brinda un detallado estudio de tiempos y del proceso de producción para prendas de exportación. Sin embargo, al ser un trabajo del año 1989, muchos de los datos que brinda se encuentran desactualizados.

\subsection{Marco conceptual}

Para el marco conceptual, se desarrollarán los conceptos más importantes sobre el estudio.

Según el informe de la web Generalitat de Catalunya, se define "la inscripción 100\% puro, acompañando la denominación de una fibra, como la única expresión permitida para explicar que el producto textil incluye exclusivamente esta fibra" (Generalitat de Catalunya, s.f.). Para este proyecto, se incluirá la etiqueta de $100 \%$ puro algodón.

La definición del algodón orgánico indica que:

Es cultivado y crece en campos de tierra fértil libres de pesticidas, herbicidas y fertilizantes químicos sintéticos, ... es hilado y producido sin químicos tóxicos. Además, la agricultura orgánica respeta los ciclos de la tierra, procurando... mantener un equilibrio y preservar la tierra. Así mismo, un cultivo se considera ecológico cuando ha sido certificado como tal por organismos independientes de inspección y certificación con arreglo a las normativas y disposiciones vigentes en el país [de origen]... o por el mercado al que va dirigido (Conciencia Eco, 2011).

Así mismo, en la revista de la situación mundial del algodón, se señala que el algodón orgánico es un tipo de algodón certificado, cuyo requisito principal es certificar primero su sistema de producción y procesamiento. (Comité Consultivo Internacional del Algodón, 2011) 
Otra definición importante es el Global Organic Textile Standart (GOTS), que indica los siguiente:

La norma líder en el procesamiento de textiles hechos con fibra orgánica. Contiene requisitos claros para el cuidado del medio ambiente a lo largo de la cadena de provisión de textiles orgánicos y sostiene el cumplimiento de criterios sociales. Solo aquellos textiles que contengan un mínimo de $70 \%$ de fibra orgánica pueden certificarse con GOTS (PromPerú, 2015).

Así mismo, existen certificaciones adicionales que significarán una ventaja competitiva como la Oeko Tex Standard 100, certificación de productos que "ofrece a las empresas en la cadena textil un instrumento óptimo y un claro valor añadido que garantiza la calidad de sus productos" (PromPerú, 2015).

Así mismo, se brindarán más detalles en el Anexo 1 acerca de diversos conceptos de apoyo que ayuden a entender este estudio. 


\section{CAPÍTULO II: ESTUDIO DE MERCADO}

\subsection{Aspectos generales del estudio de mercado}

\subsubsection{Definición comercial del producto}

El producto propuesto es ropa para bebés de algodón orgánico, algodón cultivado sin uso de químicos.

La partida arancelaria para este tipo de producto es: “6111200000 - Prendas y complementos de vestir de punto para bebés de algodón" (Superintendencia Nacional de Aduanas y Administración Tributaria, 2018)

En cuanto a la empresa, esta tendría el código CIIU 1810-05 de sección D de industrias manufactureras de fabricación de prendas de vestir para bebés y niños.

La descripción por niveles de producto se presenta a continuación:

- Producto básico: Conjunto de vestir para bebés que brinde abrigo.

- Producto real: Conjunto de vestir para bebés de algodón orgánico que brinde abrigo, que comprende un juego de polo manga larga y un pantalón de color entero en tamaños de acuerdo a las mismas medidas que los principales competidores y de buena calidad. El producto final será comercializado en bolsas transparentes que variarán en medida según las tallas.

- Producto aumentado: Prenda de vestir para bebés de algodón orgánico al $100 \%$ con certificaciones internacionales como GOTS, garantía de devolución en caso de no cumplir con los estándares de calidad como para evitar la irritación de la piel sensible y cubrir el cambio de tallas. Así mismo, se brindará un servicio post-venta mediante la página web de la empresa, permitiendo que los clientes puedan realizar un reclamo, queja, sugerencia o duda de forma directa con respecto al producto o la empresa. 


\subsubsection{Principales características del producto:}

\subsubsection{Usos y características del producto:}

Su principal uso es el de abrigo para vestir y protegerse del clima adverso. Éste se caracteriza por ser de uso diario y biodegradable ${ }^{1}$ (Wolf, 2009).

Su tiempo de biodegradación, es decir el tiempo que demora en descomponerse al ser expuesto a microorganismos (bacterias, protozoos, entre otros), es de aproximadamente de 5 meses. (Pazso, Rey, \& Botero, 2013)

Así mismo, se dará una prioridad a la moda y variedad de diseños en conjunto porque es lo que destaca que demandará el mercado (Mintel Group Limited, 2014).

También, se tendrá en cuenta la clasificación de tallas para estandarizarlas con las marcas más conocidas como Asda, Mothercare, Primark y Tesco.

\section{Figura 2. 1}

Diseño de polo manga larga de color entero

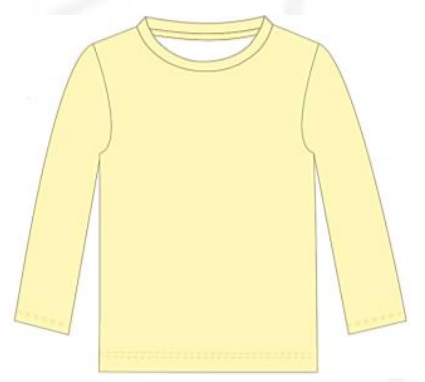

Elaboración propia

Figura 2. 2

Diseño de pantalón de color entero

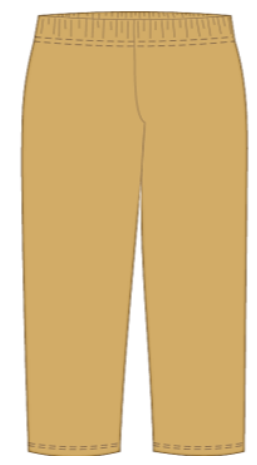

Elaboración propia

\footnotetext{
${ }^{1}$ Según la ISO 14855 y el método estándar EN 14046, los materiales que se denominen biodegradables deben degradarse en un 90\% como mínimo en 6 meses siendo sometidos a un ambiente rico en dióxido carbónico $\left(\mathrm{CO}_{2}\right)$.
} 


\subsubsection{Bienes sustitutos y complementarios:}

- Bienes sustitutos:

Los bienes sustitutos son todas las prendas en general compuestas de distintos materiales como algodón, poliéster, seda, lana, etc. Así mismo, se incluye a las prendas ecológicas como las prendas hechas de bambú y las prendas recicladas de botellas PET's.

La mayoría de éstos son maquiladas en la India, China o Bangladesh bajo las marcas más conocidas como H\&M, Tesco, Primark, Mothercare, entre otros (Morgan, 2015), empresas que suelen tener un bajo control de las condiciones de trabajo de los empleados que trabajan en los países en vías de desarrollo (The Guardian, 2012).

Al cierre del año 2016, se observa en la plataforma de Veritrade a empresas peruanas que exportan a Reino unido bajo la partida - Prendas y complementos de vestir de punto para bebes de algodón - con descripción de prenda orgánico, las cuales son: Manufacturas América E.I.R.L., Jhomi Organic Cotton S.R.L., Peru Cotton Pima S.A.C. y Tejidos Orgánicos S.A.C. (Veritrade, 2017)

- Bienes complementarios:

Los bienes complementarios son los accesorios y demás prendas de vestir como zapatos, medias, casacas, gorros, etc. Éstos complementan el estilo de la persona. Las tiendas de ropa suelen colocar conjuntos que combinan en los maniquíes e incluso asesores de moda en los retails para recomendar el conjunto ideal para el cliente como H\&M y Zara.

\subsubsection{Determinación del área geográfica que abarcará el estudio}

La investigación se centrará en Reino Unido cuya economía ha seguido una tendencia estable en los últimos años. Así mismo, el público abarcará los padres que tengan hijos entre 0 y 3 años que se preocupen por el medio ambiente y la responsabilidad social de la empresa. 


\subsubsection{Análisis del sector}

Para realizar el análisis del sector, se procedió a utilizar el modelo estratégico de las 5 fuerzas de Michael Porter que se detallan a continuación:

\section{- La rivalidad entre las firmas establecidas en el sector:}

Existen diversas empresas dedicadas a la venta de ropa para bebés. Grandes empresas de ropa empiezan a sacar una división para bebés mientras otras sacan una división de línea orgánica. Entre las más importantes empresas con ropa para bebés de algodón orgánico se encuentran H\&M (2015), Mark \& Spencer (2013), Primark (2015), Nike (2009), GAP (2014), etc. Varias de estas empezaron su línea orgánica a raíz del derrumbe del Rana Plaza, el cual mostró al mundo la irresponsabilidad de las grandes marcas de la industria de la moda por sus trabajadores y el medio ambiente. (The Guardian, 2012)

En cuanto a exportadores de prendas de algodón peruano orgánico al 100\%, muy pocas empresas cuentan con certificaciones, siendo la que más destaca por el volumen de exportación a Reino Unido: Manufacturas América E.I.R.L. seguida por Peru Cotton Pima S.A.C., Tejidos Orgánicos S.A.C. y finalmente Jhomi Organic Cotton S.R.L., proveen a empresas como Bebe Bombom Limited, Oeuf Llc C/O Locher Evers International Ltd, Sue Collins, Tatiana And Company Inc (Veritrade, 2017).

En el estricto ámbito de algodón orgánico, la rivalidad aún es media.

\section{- Poder de negociación de proveedores:}

La cantidad de proveedores de materia prima es limitada, debido a la poca producción de algodón orgánico en el Perú y una limitada lista de proveedores certificados. Entre los principales proveedores con certificación GOTS se encuentran: Bergman Rivera S.A.C., Ecotton S.A.C., Eko Peru S.A.C. - Naturtex y Filasur S.A. (Global Organic Textile Standard, 2017).

Razón por la cual, el poder de negociación de proveedores es alto.

\section{- Riesgo de ingreso de competidores potenciales:}

El riesgo es medio a nivel de competidores nacionales, debido a los requisitos legales que se deben cumplir para exportar, la alta inversión y supervisión de este tipo de productos a Europa; mientras que a nivel mundial, este riesgo es alto 
debido al gran impulso de la moda ecológica y a la expansión de una línea de ropa para bebés de diversas empresas exitosas que cuentan ya con una línea de ropa para niños, mujeres embarazadas o ropa de adultos como Mango y Zara, que incursionaron en éste negocio a finales del 2015. (Telva, 2015)

Se concluye entonces que el riesgo de ingreso será alto debido a que el proyecto se enfoca en un mercado internacional.

\section{- Amenaza de productos sustitutos:}

Existen diversos productos de algodón al $100 \%$ así como productos orgánicos de botellas recicladas o prendas de bambú. Sin embargo, la mayoría de éstos son de India, China o Bangladesh. Estos países tienden a abaratar costos brindando un producto de mediana calidad o de limitadas tallas y diseños. (Morgan, 2015) Es así como la amenaza todavía es media en el sector de prendas orgánicas.

\section{- Poder de negociación de los compradores:}

El Reino Unido es el tercer país europeo de mayor consumo de algodón orgánico con un consumo aproximado de 750 toneladas al año. (CCI, 2014)

En el mercado, tiendas como H\&M que presentan ropa orgánica para bebés a un costo muy similar al de la ropa para bebés en general. Sin embargo, el cliente europeo tiende a sospechar de precios muy bajos por vincularlos fácilmente con productos de baja calidad o por sospechar que pueden estar abaratando costos al pagarles un bajo salario a los trabajadores. (Mintel Group Limited, 2014)

Así mismo, según encuestas realizadas por Mintel, un británico promedio está dispuesto a pagar más por un producto de mayor calidad y que brinde comodidad a sus hijos.

En conclusión, el poder de negociación de los compradores es alto.

En resumen, la intensidad de competencia en el sector es alta por lo cual es un mercado poco atractivo, sin embargo, existe una tendencia hacia el consumo responsable que es reciente en este sector debido a que los consumidores están cada vez más preocupados por las consecuencias ambientales y sociales de sus compras (Nassivera, Troiano, Marangon, Sillani, \& Markova Nencheva, 2017). 


\subsubsection{Determinación de la metodología que se empleará en la investigación de mercado}

Las fuentes primarias abarcan entrevistas y videoconferencias con profesionales del sector recopilados de diversos periódicos o revistas y personalmente.

Las fuentes secundarias para el presente estudio utilizan como referencia trabajos de investigación de esta casa de estudio. Por otro lado, también se utilizarán libros y revistas, además páginas de Internet relacionadas a instituciones internacionales como PromPerú, Ipsos, etc.

También informes estadísticos para estudio de mercado de Mintel, Veritrade, Datatrade, Euromonitor, entre otros.

Además, se usará la investigación de mercado para la definición comercial del producto y el área geográfica que abarcará el estudio. Además, se usará la regresión para realizar el análisis de la proyección de la demanda.

\subsection{Análisis de la demanda}

\subsubsection{Demanda histórica}

\subsubsection{Importaciones/Exportaciones}

No se cuenta con una partida arancelaria especifica de productos textiles orgánicos, por lo cual a continuación se muestran cifras de los productos exportados e importados bajo la partida arancelaria: 6111200000 - Prendas y complementos de vestir de punto para bebés de algodón.

\section{Tabla 2.1}

Importaciones de prendas de bebé de Reino Unido (2012 - 2016)

\begin{tabular}{|c|c|c|}
\hline Año & Toneladas & Unidades \\
\hline $\mathbf{2 0 1 2}$ & 15006,89 & 93793083 \\
\hline $\mathbf{2 0 1 3}$ & 16017,64 & 100110234 \\
\hline $\mathbf{2 0 1 4}$ & 17215,00 & 107593780 \\
\hline $\mathbf{2 0 1 5}$ & 15183,62 & 94897645 \\
\hline $\mathbf{2 0 1 6}$ & 15303,52 & 95647023 \\
\hline
\end{tabular}

Fuente: Trademap, (2016) 
Tabla 2.2

Exportaciones de ropa de bebé de Reino Unido (2012-2016)

\begin{tabular}{|c|c|c|}
\hline Año & Toneladas & Unidades \\
\hline $\mathbf{2 0 1 2}$ & 4010,69 & 25066793 \\
\hline $\mathbf{2 0 1 3}$ & 6657,47 & 41609165 \\
\hline $\mathbf{2 0 1 4}$ & 7926,65 & 49541564 \\
\hline $\mathbf{2 0 1 5}$ & 6100,41 & 38127535 \\
\hline $\mathbf{2 0 1 6}$ & 4053,50 & 25334380 \\
\hline
\end{tabular}

Fuente: Trademap, (2016)

\subsubsection{Producción nacional}

La producción nacional de Reino Unido se muestra en la tabla 2.3.

Tabla 2.3

Producción nacional de prendas de bebé de Reino Unido

\begin{tabular}{|c|c|c|}
\hline Año & Toneladas & Unidades \\
\hline $\mathbf{2 0 1 2}$ & 5841,86 & 36511597 \\
\hline $\mathbf{2 0 1 3}$ & 7800,02 & 48750131 \\
\hline $\mathbf{2 0 1 4}$ & 8017,35 & 50108423 \\
\hline $\mathbf{2 0 1 5}$ & 8378,03 & 52362690 \\
\hline $\mathbf{2 0 1 6}$ & 6386,84 & 39917756 \\
\hline
\end{tabular}

Fuente: Trademap, (2016)

\subsubsection{Demanda Interna Aparente (DIA)}

La demanda interna aparente histórica se obtuvo de la página Euromonitor. Ésta es la producción total del país más las importaciones menos las exportaciones (DIA= producción + importaciones - exportaciones).

Tabla 2. 4

DIA de Reino Unido

\begin{tabular}{|c|c|c|}
\hline Año & Toneladas & Unidades \\
\hline $\mathbf{2 0 1 2}$ & 16838,06 & 105237888 \\
\hline $\mathbf{2 0 1 3}$ & 17160,19 & 107251200 \\
\hline $\mathbf{2 0 1 4}$ & 17305,70 & 108160640 \\
\hline $\mathbf{2 0 1 5}$ & 17461,25 & 109132800 \\
\hline $\mathbf{2 0 1 6}$ & 17636,86 & 110230400 \\
\hline
\end{tabular}

Fuente: Euromonitor, (2016) 


\subsubsection{Demanda potencial}

2.2.2.1. Patrones de consumo: incremento poblacional, consumo per cápita, estacionalidad

Incremento poblacional:

En los últimos años, las tasas de nacimiento han ido disminuyendo y Reino Unido se va transformando en una sociedad mayoritariamente de la tercera edad. Sin embargo, se estima que se reduciría ligeramente el crecimiento poblacional debido a la compensación por el aumento de inmigrantes.

Tabla 2.5

Población proyectada de Reino Unido

\begin{tabular}{|c|c|}
\hline Año & $\begin{array}{c}\text { Población total en } \\
\text { Reino Unido } \\
\text { Proyectada }\end{array}$ \\
\hline $\mathbf{2 0 1 2}$ & 63,49 \\
\hline $\mathbf{2 0 1 3}$ & 63,91 \\
\hline $\mathbf{2 0 1 4}$ & 64,35 \\
\hline $\mathbf{2 0 1 5}$ & 64,88 \\
\hline $\mathbf{2 0 1 6}$ & 65,38 \\
\hline $\mathbf{2 0 1 7}$ & 65,81 \\
\hline $\mathbf{2 0 1 8}$ & 66,20 \\
\hline $\mathbf{2 0 1 9}$ & 66,56 \\
\hline $\mathbf{2 0 2 0}$ & 66,91 \\
\hline $\mathbf{2 0 2 1}$ & 67,23 \\
\hline $\mathbf{2 0 2 2}$ & 67,53 \\
\hline
\end{tabular}

Fuente: Oficina Nacional de Estadística de Reino Unido, (2014)

Así mismo, según la tabla 2.6., se puede evidenciar que el ratio de población inicial va a permanecer en aumento, los nacimientos aumentarán de manera moderada mientras los fallecimientos aumentarán a menor magnitud. 
Tabla 2. 6

Millones de personas afectados por variables de nacimientos, muertes y migraciones de Reino Unido

\begin{tabular}{|c|c|c|c|c|c|}
\hline & & & & & Millions \\
\hline & 2014-2019 & $2019-2024$ & $2024-2029$ & 2029-2034 & 2034-2039 \\
\hline Población inicial & 64.6 & 66.9 & 69.0 & 71.0 & 72.7 \\
\hline Nacimientos & 3.9 & 4.0 & 4.0 & 4.0 & 4.1 \\
\hline Muertes & 2.9 & 2.9 & 3.0 & 3.2 & 3.4 \\
\hline Cambio natural & 1.1 & 1.2 & 1.0 & 0.8 & 0.6 \\
\hline Total migraciones & 1.2 & 0.9 & 0.9 & 0.9 & 0.9 \\
\hline Variación total & 2.3 & 2.1 & 2.0 & 1.7 & 1.6 \\
\hline Población final & 66.9 & 69.0 & 71.0 & 72.7 & 74.3 \\
\hline
\end{tabular}

Fuente: Oficina Nacional de Estadística de Reino Unido, (2014)

\section{Consumo per cápita:}

Analizando la data recopilada de Euromonitor, se observa un consumo per cápita de 137,7 dólares en unidades de ropa de niños (bebé y niños) por niño en Reino Unido y un crecimiento de $1,1 \%$ de mercado entre el 2015 y el 2020.

Figura 2. 3

Tamaño de mercado, crecimiento y consumo per cápita de ropa de niños en Reino Unido

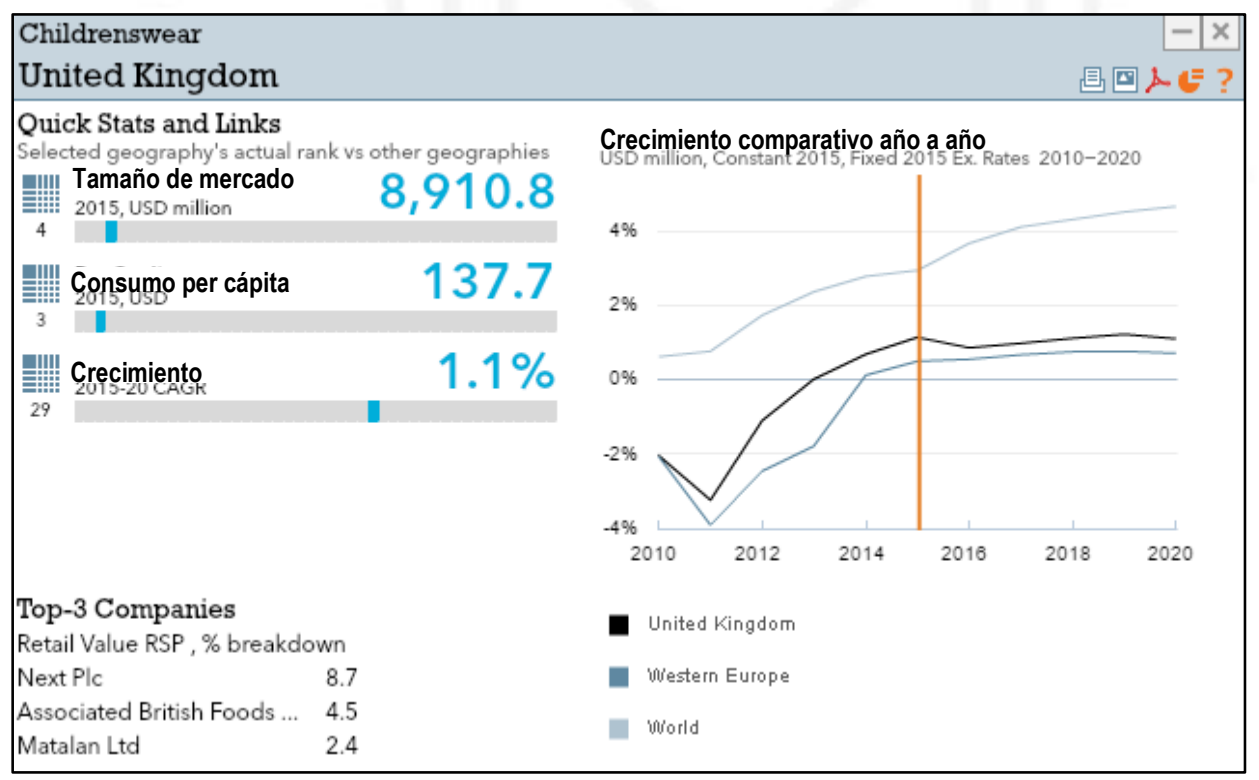

Fuente: Euromonitor, (2016) 


\section{$\underline{\text { Preferencias en los consumidores: }}$}

La figura 2.4 menciona las preferencias de los consumidores según el rango de edad de los padres para comprar ropa para bebés y niños. Se destaca que los padres más jóvenes (31 años) prefieren comprar ropa en tiendas especializadas de niños.

Figura 2. 4

Preferencias de consumidores según grupo socio económico y edad.

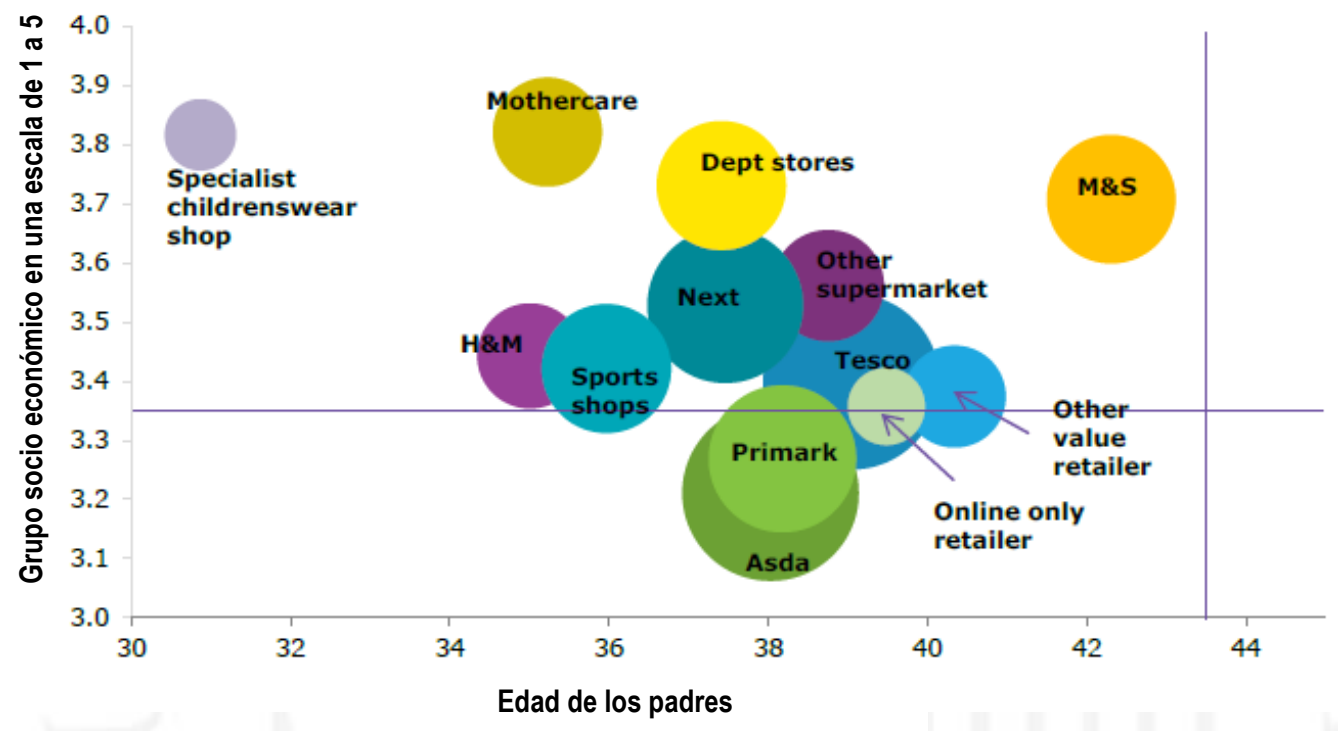

Fuente: Mintel Group Limited, (2014)

\section{Estacionalidad:}

Generalmente, “en Reino Unido se tienen inviernos fríos a medios y veranos cálidos con moderada variación en temperatura durante el año" (La guía, 2017).

Esto influiría en la cantidad de compra de productos de prendas gruesas como chompas. Sin embargo, las prendas de este proyecto se pueden usar en verano y en invierno debajo de las chompas. La estacionalidad influye a la moda en el caso de colores y tendencias, pero no en la demanda que tendrán los productos básicos de este proyecto.

Aspectos culturales:

El derrumbe del Rana Plaza y los altos índices de contaminación de la industria textil han influenciado en el pensamiento de las empresas y los clientes sobre la responsabilidad social en el sector textil. La responsabilidad social (RSE) está aumentando en importancia debido a que logra moldear las políticas de las grandes marcas y los minoristas del sector 
textil y de confecciones. "A medida que las empresas comprenden cómo repercute la producción de algodón convencional en los agricultores y las comunidades agrícolas, comienzan a examinar algodones alternativos para servir a los consumidores y mejorar su imagen pública” (Guía del algodón, 2014).

"Las prendas certificadas como de comercio justo tienen un mercado pequeño pero creciente debido a la conciencia sobre temas éticos asociados con las prendas de bajo costo" (PromPerú, 2015). Según el periódico Business Insurance, los consumidores están dispuestos a pagar $15 \%$ más en promedio para garantizar que los trabajadores no laboren en talleres de esclavitud (Brandon Gaille, 2014). Así mismo, la calidad sigue siendo el principal factor determinante de compra del cliente de prendas de vestir (Mintel Group Limited, 2014)

\subsubsection{Determinación de la demanda potencial}

Uno de los países con un consumo per cápita similar al de Reino Unido de 137,7 dólares por persona (puesto 3) es Noruega con 141,1 dólares por persona (puesto 2). Las temperaturas son muy similares a las de Reino Unido, así como las condiciones económicas de ambos países debido a su cercanía geográfica. Así mismo, los padres noruegos no ahorran ningún gasto cuando se trata de proporcionar a sus hijos la mejor ropa de calidad posible, es por ello que existe una gran demanda por el algodón orgánico (Euromonitor, 2017).

Figura 2. 5

Cálculo de la demanda potencial de ropa de bebé

\begin{tabular}{|c|c|c|}
\hline $\begin{array}{l}\text { Millones de unidades de prendas } \\
\text { de bebé demandadas en Noruega }\end{array}$ & $\begin{array}{c}\text { Número de bebés en } \\
\text { Reino Unido }\end{array}$ & $\begin{array}{c}\text { Millones de unidades de } \\
\text { prendas de bebé que se } \\
\text { esperan sean demandadas } \\
\text { en Reino Unido }\end{array}$ \\
\hline Número de bebés en Noruega
\end{tabular}

Elaboración propia 
Tabla 2.7

Demanda potencial de ropa de bebé

\begin{tabular}{|l|c|c|c|c|}
\hline Año & $\begin{array}{c}\text { Miles de unidades de } \\
\text { prendas de bebé } \\
\text { demandadas en Noruega }\end{array}$ & $\begin{array}{c}\text { Número de } \\
\text { bebés en } \\
\text { Noruega }\end{array}$ & $\begin{array}{c}\text { Número de } \\
\text { bebés en } \\
\text { Reino Unido }\end{array}$ & $\begin{array}{c}\text { Miles de unidades de prendas } \\
\text { de bebé que se espera sean } \\
\text { demandadas en Reino Unido }\end{array}$ \\
\hline $\mathbf{2 0 1 6}$ & $7.401,0$ & 237.238 & 3.971 .780 & 123.906 \\
\hline $\mathbf{2 0 1 7}$ & $7.388,4$ & 239.886 & 3.996 .177 & 123.081 \\
\hline $\mathbf{2 0 1 8}$ & $7.460,1$ & 246.471 & 4.020 .667 & 121.696 \\
\hline $\mathbf{2 0 1 9}$ & $7.563,0$ & 248.953 & 4.111 .236 & 124.896 \\
\hline $\mathbf{2 0 2 0}$ & $7.690,0$ & 255.453 & 4.135 .408 & 124.490 \\
\hline $\mathbf{2 0 2 1}$ & $7.817,7$ & 257.756 & 4.159 .075 & 126.144 \\
\hline $\mathbf{2 0 2 2}$ & $7.928,7$ & 259.945 & 4.114 .848 & 125.509 \\
\hline
\end{tabular}

Fuente: Euromonitor, (2017)

Elaboración propia.

Al obtener un resultado muy similar al consumo real de Reino Unido en el año 2016 de 123,906 miles de unidades, se concluye que nuestra suposición es correcta. Existe un mercado potencial pero no es muy grande, considerando que se estimaron varios valores en el proceso y el panorama de su reciente separación de la Unión Europea (El Comercio, 2016).

Así mismo, se realizó el cálculo de la demanda natural, utilizando el consumo per cápita de prendas de bebés para Reino Unido, obteniendo que se consume en promedio 26.61 prendas por bebé en Reino Unido y un crecimiento del 1.2\% anual (Euromonitor, 2018). Es así que se realiza el cálculo de la demanda, obteniendo la siguiente tabla.

Tabla 2.8

Calculo de la demanda

\begin{tabular}{|l|c|c|c|}
\hline Año & Número de bebés en Reino Unido & Consumo per cápita & Demanda natural \\
\hline $\mathbf{2 0 1 7}$ & 3.996 .177 & 26,61 & 106333055 \\
\hline $\mathbf{2 0 1 8}$ & 4.020 .667 & 26,93 & 108268512 \\
\hline $\mathbf{2 0 1 9}$ & 4.111 .236 & 27,25 & 112035845 \\
\hline $\mathbf{2 0 2 0}$ & 4.135 .408 & 27,58 & 114046895 \\
\hline $\mathbf{2 0 2 1}$ & 4.159 .075 & 27,91 & 116076000 \\
\hline $\mathbf{2 0 2 2}$ & 4.114 .848 & 28,24 & 116219750 \\
\hline
\end{tabular}

Fuente: Euromonitor, (2018) 


\subsubsection{Demanda mediante fuentes primarias.}

\subsubsection{Diseño y aplicación de encuestas u otras técnicas}

Para el diseño de encuestas, se tomó la data extraída de la empresa Mintel. Ésta se realizó teniendo como base a 2000 usuarios de personas que viven en Reino Unido.

Así mismo, se utilizó la prueba chi-cuadrado con un $95 \%$ de intervalo de confianza.

Tabla 2.9

Grupo de personas encuestadas por edad

\begin{tabular}{|c|c|c|c|}
\hline Grupo por edad & Género & Porcentaje $(\mathbf{\%})$ & Número de personas \\
\hline $\mathbf{1 6 - 1 9}$ & Hombre & 3,6 & 72 \\
\hline $\mathbf{1 6 - 1 9}$ & Mujer & 3,4 & 68 \\
\hline $\mathbf{2 0 - 2 4}$ & Hombre & 4,9 & 98 \\
\hline $\mathbf{2 0 - 2 4}$ & Mujer & 4,8 & 95 \\
\hline $\mathbf{2 5 - 3 4}$ & Hombre & 9,4 & 180 \\
\hline $\mathbf{2 5 - 3 4}$ & Mujer & 9,5 & 190 \\
\hline $\mathbf{3 5}-\mathbf{4 4}$ & Hombre & 9,3 & 186 \\
\hline $\mathbf{3 5 - 4 4}$ & Mujer & 9,5 & 190 \\
\hline $\mathbf{4 5 - 5 4}$ & Hombre & 9,3 & 186 \\
\hline $\mathbf{4 5 - 5 4}$ & Mujer & 9,4 & 189 \\
\hline $\mathbf{5 5 - 6 4}$ & Hombre & 7,0 & 140 \\
\hline $\mathbf{5 5 - 6 4}$ & Mujer & 7,2 & 144 \\
\hline $\mathbf{6 5 +}$ & Hombre & 5,7 & 113 \\
\hline $\mathbf{6 5 +}$ & Mujer & 7,0 & 140 \\
\hline & TOTAL & 100 & 2000 \\
\hline
\end{tabular}

Fuente: Mintel Group Limited, (2014)

Tabla 2. 10

Grupo de personas encuestadas por región

\begin{tabular}{|c|c|c|}
\hline Región & Porcentaje (\%) & Número de personas \\
\hline Noreste & 4,2 & 84 \\
\hline Noroeste & 11,5 & 229 \\
\hline Yorkshire y Humber & 8,6 & 172 \\
\hline Midlands del Este & 7,4 & 148 \\
\hline Midlands del Oeste & 9,1 & 182 \\
\hline Gran Londres & 13,4 & 269 \\
\hline Sureste & 23,6 & 473 \\
\hline Suroeste & 8,6 & 172 \\
\hline Gales & 5,0 & 99 \\
\hline Escocia & 8,6 & 172 \\
\hline TOTAL & 100 & 2000 \\
\hline
\end{tabular}

Fuente: Mintel Group Limited, (2014) 
Tabla 2. 11

Grupo de personas encuestadas por nivel socio económico

\begin{tabular}{|c|cc|}
\hline Grupo socio económico & Porcentaje $(\boldsymbol{\%})$ & Número de personas \\
\hline AB & 22,3 & 446 \\
\hline C1 & 30,9 & 618 \\
\hline C2 & 20,9 & 418 \\
\hline DE & 25,9 & 518 \\
\hline Total & 100 & 2000 \\
\hline
\end{tabular}

Fuente: Mintel Group Limited, (2014)

De la encuesta realizada, se pudo obtener la siguiente información:

Figura 2. 6

Factores que influyen en la compra de prendas de bebé

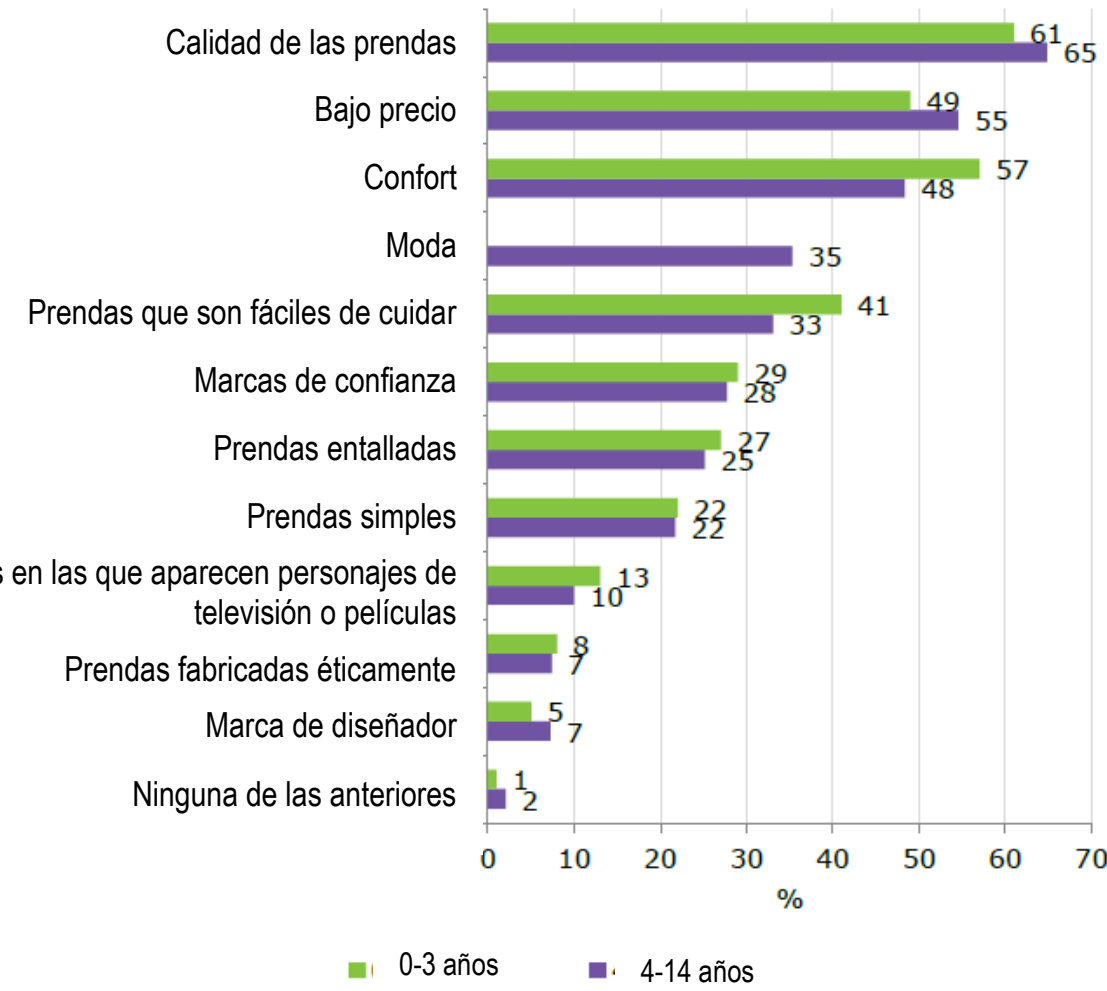

Fuente: Mintel Group Limited, (2014) 
Figura 2.7

Tiendas percibidas para comprar ropa para hombre, mujeres y niños

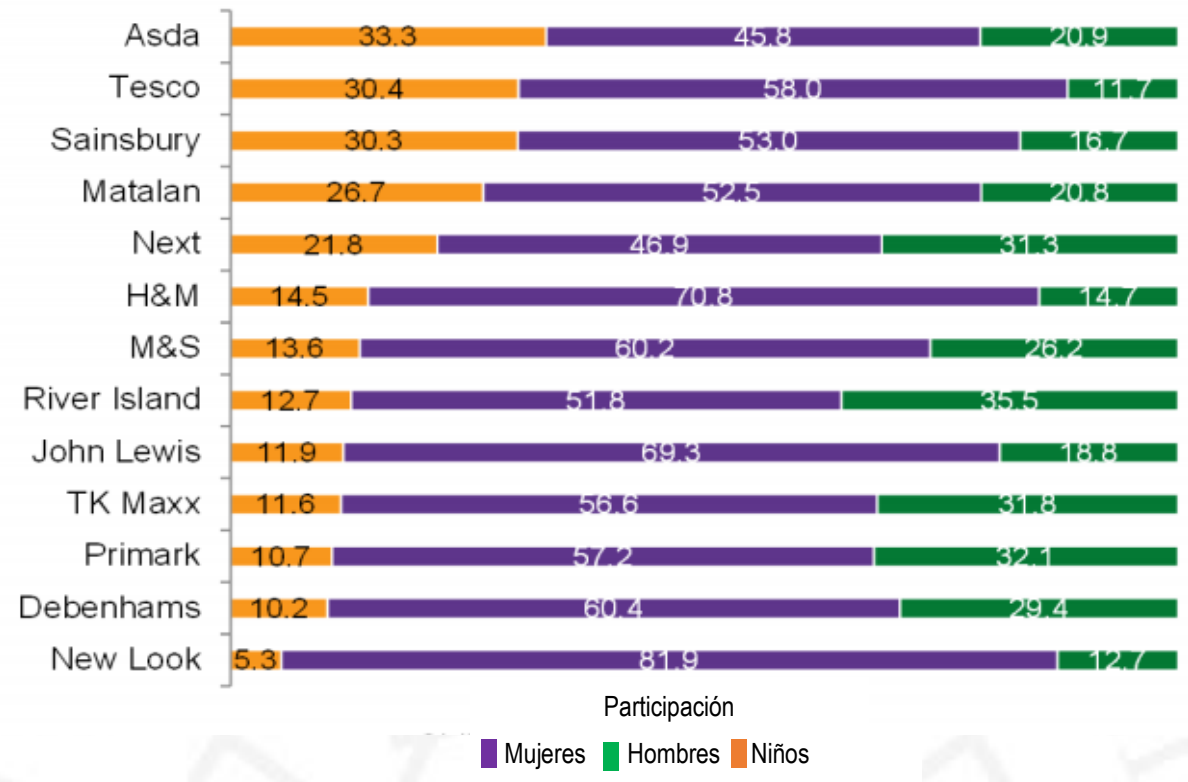

Fuente: Mintel Group Limited, (2014)

Figura 2.8

Actitudes de los padres o abuelos al realizar compras de ropa de niños de 0 a 14 años

Prefiero comprar de las tiendas cuyas tallas conozco

Prefiero comprar prendas a mis hijos de las mismas tiendas donde compro para mí

Prefiero comprar sets o conjuntos de ropa

Ninguno de los anteriores

Prefiero comprar en línea y recoger en tienda

He cambiado a comprar prendas de marcas baratas He usado un dispositivo móvil para ver ropa para mis hijos/nietos

He usado un dispositivo móvil para comprar ropa para mis hijos/nietos

Suelo comprar prendas para mis hijos/nietos que son de un estilo similar al mío

He usado redes sociales/blogs para ver las tendencias en ropa de niños

He tenido problemas para encontrar ropa para niños acorde a la estación del año

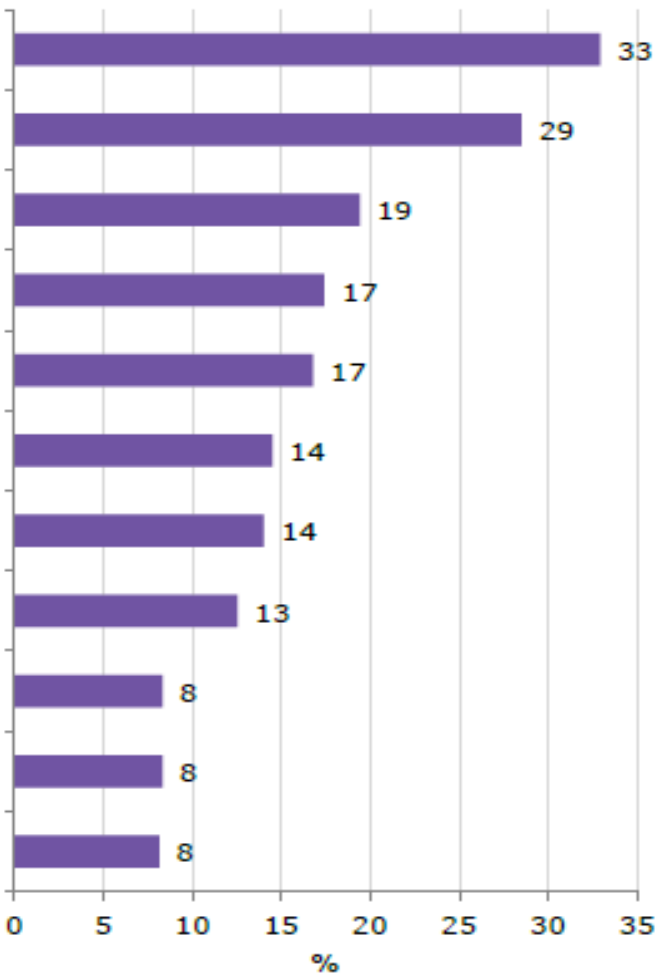

Fuente: Mintel Group Limited, (2014) 


\subsubsection{Determinación de la demanda}

Para la determinación de la demanda, se consideró:

- El 8\% de la población de Reino Unido prefiere ropa hecha de manera ética u orgánica. Así mismo, se deberá tener en consideración que el producto deberá contar con diseños y estándares de calidad dirigidos a un mercado internacional.

Tabla 2. 12

Demanda del proyecto

\begin{tabular}{|c|c|c|c|}
\hline Años & DIA & $\begin{array}{c}\text { Demanda del } \\
\text { proyecto }\end{array}$ & $\begin{array}{c}\text { Preferencia por prendas } \\
\text { fabricadas éticamente } \\
(8 \%)\end{array}$ \\
\hline $\mathbf{2 0 1 7}$ & 111673900 & 106333055 & 8506644 \\
\hline $\mathbf{2 0 1 8}$ & 112860600 & 108268511 & 8661481 \\
\hline $\mathbf{2 0 1 9}$ & 114047300 & 112035844 & 8962868 \\
\hline $\mathbf{2 0 2 0}$ & 115234000 & 114046895 & 9123752 \\
\hline $\mathbf{2 0 2 1}$ & 116420700 & 116076000 & 9286080 \\
\hline $\mathbf{2 0 2 2}$ & 117607400 & 116219750 & 9297580 \\
\hline
\end{tabular}

Fuente: Mintel Group Limited, (2014)

Elaboración propia

\subsubsection{Proyección de la demanda}

La demanda se proyectó según la tendencia lineal por ser la que se adaptaba mejor a la tendencia del consumidor británico.

Figura 2.9

Curva logarítmica de la demanda 2012-2016

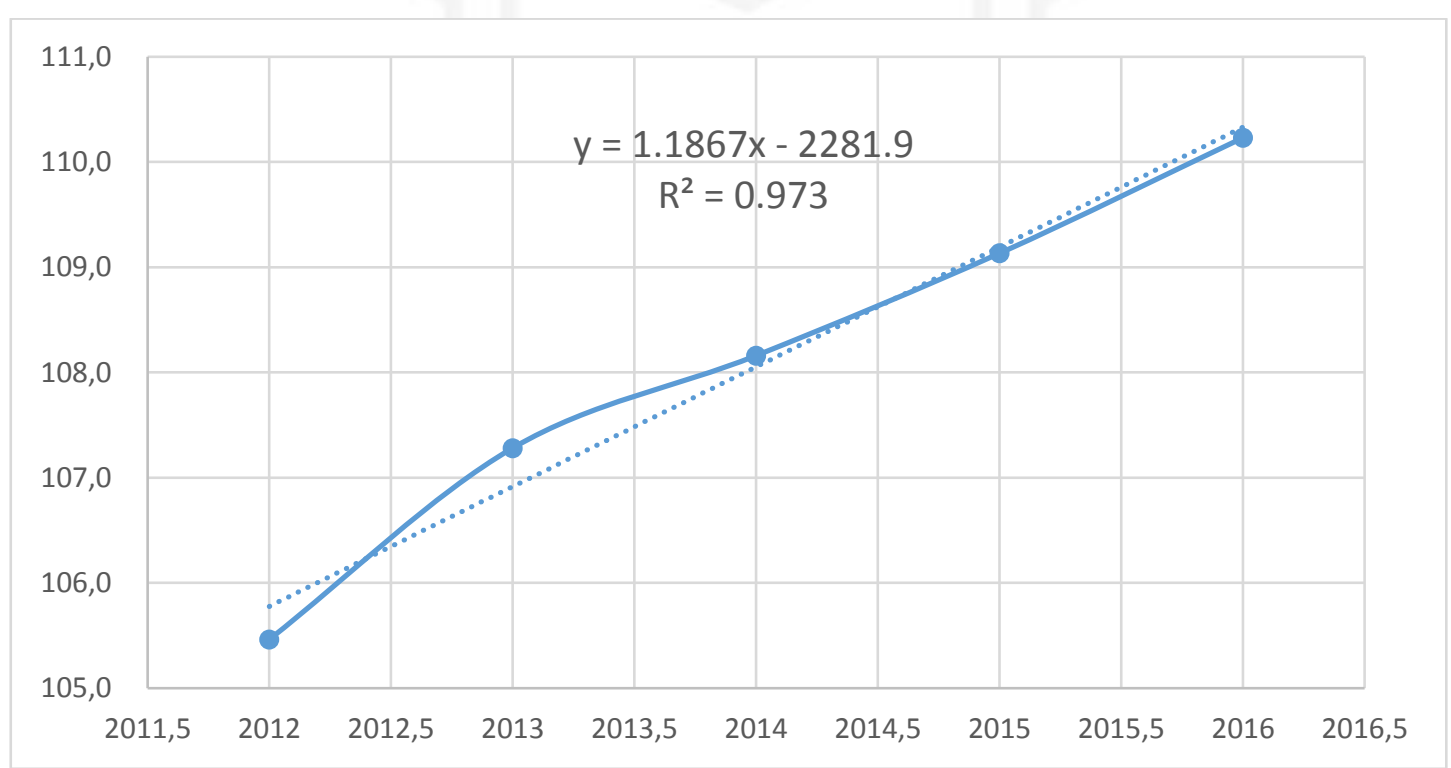

Elaboración propia 
Tabla 2. 13

Demanda proyectada 2017-2022 en millones de unidades

\begin{tabular}{|c|c|c|c|c|c|c|}
\hline Millones de unidades & $\mathbf{2 0 1 7}$ & $\mathbf{2 0 1 8}$ & $\mathbf{2 0 1 9}$ & $\mathbf{2 0 2 0}$ & $\mathbf{2 0 2 1}$ & $\mathbf{2 0 2 2}$ \\
\hline Ropa de bebés (0-3 años) & 112 & 113 & 114 & 115 & 116 & 118 \\
\hline
\end{tabular}

Elaboración propia

\subsubsection{Consideraciones sobre la vida útil del proyecto}

Se considerará un total de cinco años de vida útil debido a que es el período en el que varios de los activos se deprecian en su totalidad y deberá tener en cuenta para realizar compra de maquinaria al final del quinto año con las utilidades generadas hasta esa fecha.

Así mismo, al tratarse de un estudio de pre-factibilidad, el horizonte está dentro del plazo establecido en el que se espera obtener resultados.

\subsection{Análisis de la oferta}

\subsubsection{Empresas productoras, importadoras y comercializadoras}

En cuanto a las empresas productoras a nivel nacional, destacan las siguientes: Jhomi Organic Cotton S.A.C, Manufacturas América EIRL, Perú Cotton Pima SAC y Tejidos Orgánicos S.A.C.

Las empresas importadoras de Reino Unido son: Tatiana And Company Inc., Lotus London Limited, Sue Collins, Lemon Loves Lime, Marie Chantal Ltd, Iza Minkiewicz, Oeuf Llc C/O Ceewhy Vancouver Ltd, Cashmirino London Limited, Arte Perú Limited.

La mayoría de estas prendas son importadas por tiendas de diseñador (boutiques). Así mismo, solo dos empresas se dedican constantemente a exportar productos orgánicos.

Empresas comercializadoras en Reino Unido: Asda Stores Ltd, Next Plc, Tesco Plc, Primark Stores Ltd, J SainsburyPlc, Matalan Ltd, Mothercare Plc, New Look Retailers Ltd, Nike (UK) Ltd, Adidas (UK) Ltd, River Island Clothing Ltd, BhS Ltd, H\&M Hennes \& Mauritz (UK) Ltd, Inditex UK Ltd, Peacock Group Plc, Marks \& Spencer Plc, Pumpkin Patch Ltd, Gap Inc, Fat Face Group Ltd, Pentland Group Plc, 
Hackett Ltd, Puma UK Ltd, All Saints Retail Ltd, Adams Childrenswear Ltd, Woolworths Group Plc (Great Britain).

\subsubsection{Competidores actuales y potenciales}

La composición del mercado se compone según la tabla 2.14 .

Tabla 2.14

Participación de mercado (porcentaje)

\begin{tabular}{|c|c|c|c|c|c|}
\hline Empresas & 2012 & 2013 & 2014 & 2015 & 2016 \\
\hline Asda Stores Ltd & 13,5 & 13,5 & 13,7 & 13,4 & 13,2 \\
\hline Next Plc & 9,4 & 8,8 & 8,7 & 8,6 & 8,5 \\
\hline Primark Stores Ltd & 4,2 & 4,4 & 4,6 & 4,5 & 4,5 \\
\hline J Sainsbury Plc & 2,4 & 2,5 & 2,7 & 2,7 & 2,7 \\
\hline Matalan Ltd & 2,4 & 2,4 & 2,4 & 2,4 & 2,4 \\
\hline Mothercare Plc & 2,6 & 2,4 & 2,2 & 2,1 & 2,1 \\
\hline Lidl Ltd & 1,4 & 1,4 & 1,4 & 1,4 & 1,4 \\
\hline New Look Retailers Ltd & 1,2 & 1,3 & 1,3 & 1,3 & 1,3 \\
\hline $\begin{array}{c}\text { H\&M Hennes\& Mauritz (UK) } \\
\text { Ltd }\end{array}$ & 0,7 & 0,7 & 0,7 & 0,7 & 1,2 \\
\hline Nike (UK) Ltd & 0,7 & 0,7 & 0,9 & 1,1 & 1,2 \\
\hline adidas (UK) Ltd & 1,1 & 0,9 & 1,0 & 1,0 & 1,1 \\
\hline River Island Clothing Ltd & 0,9 & 0,9 & 0,9 & 0,9 & 0,9 \\
\hline BhSLtd & 0,8 & 0,8 & 0,8 & 0,8 & 0,7 \\
\hline Inditex UK Ltd & 0,7 & 0,7 & 0,7 & 0,7 & 0,7 \\
\hline Peacock Group Plc, The & 0,7 & 0,6 & 0,6 & 0,6 & 0,5 \\
\hline Pumpkin Patch Ltd & 0,6 & 0,5 & 0,4 & 0,4 & 0,4 \\
\hline Fat Face Group Ltd & 0,3 & 0,3 & 0,3 & 0,3 & 0,3 \\
\hline Gap UK Holdings Ltd & 0,4 & 0,4 & 0,3 & 0,3 & 0,3 \\
\hline Pentland Group Plc & 0,1 & 0,1 & 0,2 & 0,3 & 0,3 \\
\hline Decathlon UK Ltd & 0,1 & 0,1 & 0,2 & 0,2 & 0,2 \\
\hline Hugo Boss UK Ltd & 0,2 & 0,1 & 0,1 & 0,1 & 0,1 \\
\hline Puma UK Ltd & 0,1 & 0,1 & 0,1 & 0,1 & 0,1 \\
\hline Ralph Lauren UK Ltd & 0,1 & 0,1 & 0,1 & 0,1 & 0,1 \\
\hline Hackett Ltd & 0,2 & 0,2 & 0,1 & 0,1 & 0,1 \\
\hline Tesco Plc & 5,8 & 6,0 & 6,1 & 6,0 & 0,1 \\
\hline Marks \& Spencer Plc & 6,2 & 6,0 & 5,7 & 5,4 & 0,1 \\
\hline All Saints Retail Ltd & 0,0 & 0,0 & - & - & - \\
\hline Other Private Label & 5,6 & 5,6 & 5,6 & 5,5 & 5,5 \\
\hline Others & 37,7 & 38,4 & 38,3 & 38,9 & 50,0 \\
\hline Total & 100,0 & 100,0 & 100,0 & 100,0 & 100,0 \\
\hline
\end{tabular}

Fuente: Euromonitor, (2017)

En los últimos años, las condiciones de esclavitud en las fábricas textiles, explotación infantil y daños en el medio ambiente han obligado a varias empresas a plantearse objetivos de responsabilidad social y ética (Morgan, 2015).Entre ellas, H\&M plantea que el total de sus productos de algodón sean orgánicos o reciclado para el 2020; Nike tiene como norma que todos sus productos se compongan de un 5\% como mínimo 
de algodón orgánico; Mark \& Spencer cumplieron la meta de tener el $50 \%$ de sus productos elaborados de manera sostenible y responsable para el 2015 y plantean llegar al 100\% para el 2020 (Cottoned On, 2016).

No se ha encontrado información acerca de potenciales competidores que ingresen al mercado bajo reconocidas marcas. Sin embargo, se presenta una fuerte tendencia a la compra en línea, especialmente para productos de 0 a 3 años, para aquellos que ofrecen sus productos en eBay y Amazon (Mintel Group Limited, 2014). Estas dos empresas del comercio digital tienen sus mercados más grandes en Reino Unido (Lester, 2011), por ejemplo, Amazon UK tiene un mercado de \$298.956.307 (Minderest, 2017); según el Logistics Performance Index (LPI), publicado por el Banco Mundial en el 2016, Reino Unido, considerado como nodo económico para Europa y todo el mundo, “ocupa el octavo puesto en desempeño logístico a nivel mundial, con un puntaje de 4.07 (PromPerú, 2017)", que le permite tener cobertura en todas sus ciudades.

\subsection{Determinación de la demanda para el proyecto.}

\subsubsection{Segmentación del mercado.}

El mercado objetivo tomará en cuenta solo a las personas con intención de compra de prendas de vestir éticamente producidas.

Para la segmentación demográfica, se considerará a todos los padres mayores de 16 años que tengan hijos entre 0 y 3 años.

Para la segmentación geográfica, se considerará a todos aquellos que radiquen en Reino Unido, independientemente de su nacionalidad; debido al alto desempeño logístico de este país que permite la cobertura a nivel nacional (PromPerú, 2017).

Para la segmentación psicográfica, se considerarán los grupos socio económicos A, B, C1 y C2, cuyas características se describirán en la tabla 2.15. 
Tabla 2. 15

Segmentación por grupos socio-económicos

\begin{tabular}{|c|c|}
\hline Grupo socio económico & \begin{tabular}{c} 
Descripción de las ocupaciones \\
\hline A
\end{tabular} \\
\hline B & Gerentes, administrativos o profesionales de rango alto. \\
\hline C1 & Gerentes, administrativos o profesionales de rango medio. \\
\hline C2 & $\begin{array}{c}\text { Supervisor o ejecutivo, y administrativos o profesionales de bajo } \\
\text { rango. }\end{array}$ \\
\hline D & Trabajadores calificados. \\
\hline E & $\begin{array}{c}\text { Trabajadores medios y no calificados. } \\
\text { largos debido a enfermedades, desempleo, edad avanzada u otro } \\
\text { motivo. }\end{array}$ \\
\hline
\end{tabular}

Fuente: Mintel Group Limited, (2014)

\subsubsection{Selección de mercado meta}

Para la demanda específica del proyecto se consideró lo siguiente:

- Se considerará un $74,1 \%$ del total de la población debido a que el proyecto se dirigirá a los sectores A, B, C1 y C2.

- Para hallar el número de conjuntos se multiplicó por 19\%, que es el consumo del mercado según encuestas (Mintel Group Limited, 2014).

Figura 2. 10

Tendencias en la compra de bebés y niños (porcentaje según encuestas)

Prefiero comprar de los retail cuyas tallas conozco

Prefiero comprar ropa de los retail donde compro mi ropa

Suelo comprar conjuntos

Ninguna

Suelo comprar online y recoger en tienda

He cambiado a comprar prendas de marcas más baratas

He usado un celular para investigar sobre prendas para mi hijo/nieto

He usado un celular para comprar prendas para mi hijo/nieto

Suelo comprar prendas para mi hijo/nieto similares a la mía

He usado redes sociales / blogs para leer comentarios sobre retailers de ropa de niños

Ha sido difícil encontrar prendas que estén acorde a la temporada / clima

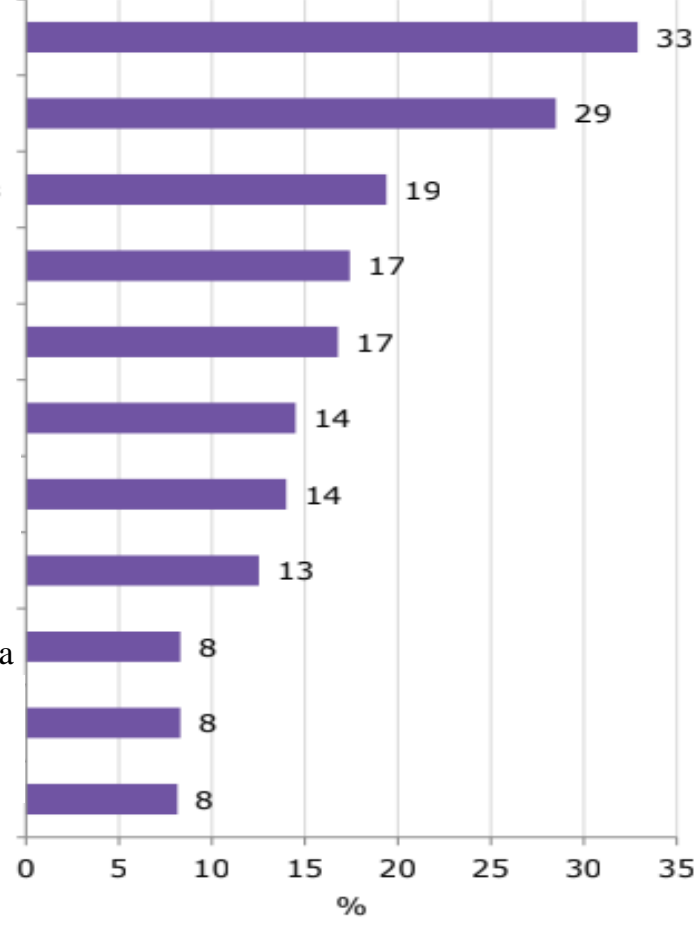

Fuente: Mintel Group Limited, (2014) 
- Se considerará un $11,17 \%$ de participación de mercado debido a que se reemplazará una parte de la oferta de algodón orgánico de Bangladesh (Market Access Map, 2018). Iniciaremos el proyecto con una participación de mercado de $3 \%$ que irá ascendiendo hasta un $5.4 \%$ en el quinto año.

\subsubsection{Demanda específica para el proyecto}

Tabla 2. 16

Demanda Específica

\begin{tabular}{|c|c|c|c|c|c|c|}
\hline & Años & Demanda & $\begin{array}{c}\text { Responsa } \\
\text { bilidad } \\
\text { Social } \\
\mathbf{( 8 \% )}\end{array}$ & $\begin{array}{c}\text { Nivel } \\
\text { socioeconómico } \\
\mathbf{( 7 4 , 1 \% )}\end{array}$ & $\begin{array}{c}\text { Participación } \\
\text { de mercado } \\
(\mathbf{3 \%} \mathbf{- 5 , 4 \% )}\end{array}$ & $\begin{array}{c}\text { Conjuntos } \\
\text { (unidades) }\end{array}$ \\
\hline $\mathbf{1 9 \%}$
\end{tabular}

Elaboración propia

\subsection{Definición de la Estrategia de Comercialización}

\subsubsection{Políticas de comercialización y distribución}

Se plantea una distribución mediante un canal de 3 etapas.

Figura 2. 11

Canal de 3 etapas

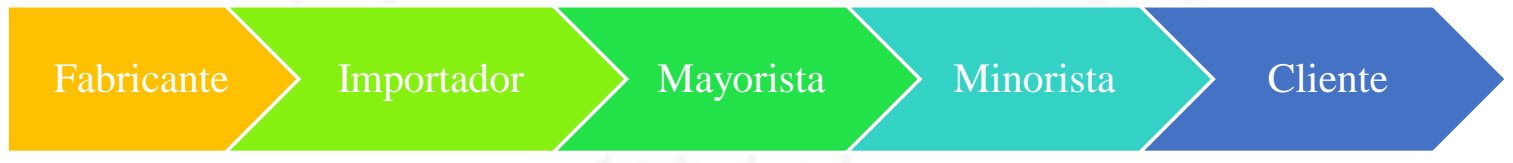

Fuente: Martínez, E. y Vásquez, A., (2006).

La comercialización se realizará a través de un agente comercial, el cual se encargará de ofrecer el producto dentro de su cartera de clientes de Reino Unido; la comisión que se ofrecerá es de un 10\% sobre el precio de venta (Domínguez, 2012). 
Figura 2. 12

Canal europeo para ropa de niño

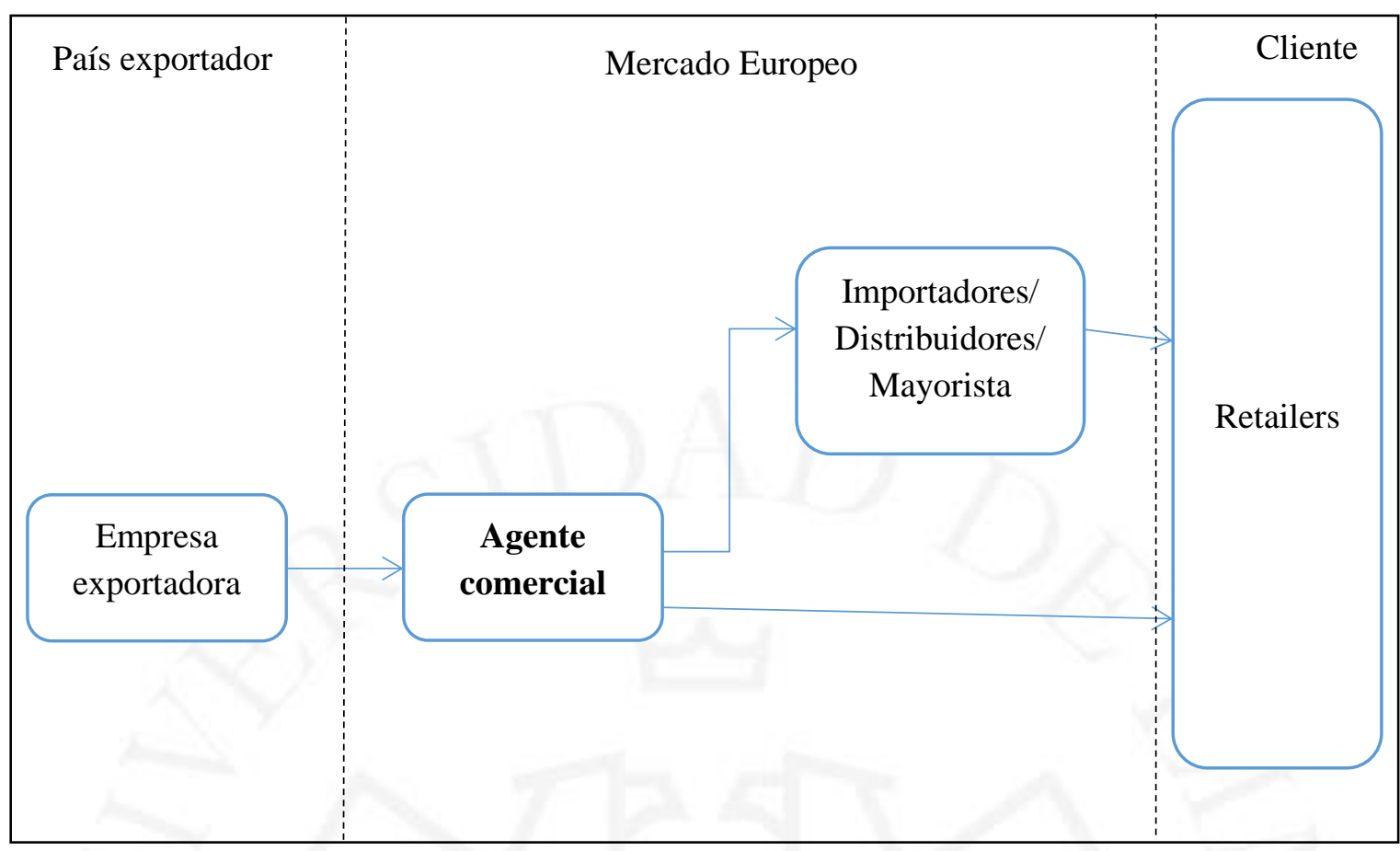

Fuente: Ministry of Foreign Affairs, (2016)

Los retailers están conformados por tiendas de marca, tienda de ropa especializada, hipermercados, supermercados, tiendas en línea, mercados, etc.

\subsubsection{Publicidad y promoción}

Nuestro plan de promoción consistirá en participar de misiones comerciales, que nos permitirá tener un acercamiento directo a potenciales clientes y conocer las nuevas tendencias del mercado británico, su costo es de aproximadamente de 20033 soles ; las principales entidades organizadoras son la Cámara de Comercio de Lima (CCL), ADEX, la embajada del Perú en Reino Unido y PromPerú (SIICEX, 2015). También se participará de ferias internacionales, como las que se detallan en la Tabla 2. 17., la inversión en ferias internaciones tiene un costo aproximado de 33656 soles que incluye gastos en alquiler de stand, acondicionamiento del stand, gastos de viajes, entre otros (Emprendedores, 2017). 
Tabla 2. 17

Ferias en Reino Unido para exportadores

\begin{tabular}{|c|c|c|}
\hline Feria & Fecha & Descripción \\
\hline Pure \& Premier & Febrero y Julio & $\begin{array}{l}\text { Exposición en feria de moda líder del Reino } \\
\text { Unido para las marcas de moda de ropa de } \\
\text { gama alta y media. }\end{array}$ \\
\hline Bubble London & Febrero & Feria de productos para niños. \\
\hline The Baby Show & Marzo & $\begin{array}{l}\text { Feria de moda y productos para niños, padres } \\
\text { y embarazadas. }\end{array}$ \\
\hline F\&A show & Octubre - Noviembre & $\begin{array}{l}\text { Feria de ideas, diseños e innovaciones en el } \\
\text { mundo de la costura, artes textiles y } \\
\text { suministros necesarios para proyectos de } \\
\text { costura. }\end{array}$ \\
\hline
\end{tabular}

Fuente: Comisión de Promoción del Perú para la Exportación y el Turismo, PromPerú, (2015)

Elaboración propia

Para la publicidad, se plantea contar con una página web que nos permita informar sobre la procedencia de nuestros productos, puntos de venta, números de contacto entre otros datos que permitan generar confianza con respecto a la marca; el costo de creación de una página web es de 849.6 soles y el costo anual de hosting es de 335 soles (IntimediaExpress, 2018).

\subsubsection{Análisis de precios}

\subsubsection{Tendencia histórica de los precios}

La tendencia histórica se obtuvo de Veritrade (2018) para el valor promedio de las empresas exportadoras de conjuntos de ropa de bebé de algodón orgánico. Se debe tener en cuenta que la mayor parte de producción orgánica peruana se destina a boutiques que importan las prendas a un precio inferior del que las venden.

Tabla 2. 18

Exportaciones peruanas de conjuntos de ropa para bebés de algodón orgánico en libras

\begin{tabular}{|c|c|c|c|c|c|c|c|c|}
\hline $\begin{array}{c}\text { Precio (FOB) } \\
\text { Precio FOB en }\end{array}$ & $\mathbf{2 0 1 2}$ & $\mathbf{2 0 1 3}$ & $\mathbf{2 0 1 4}$ & $\mathbf{2 0 1 5}$ & $\mathbf{2 0 1 6}$ & $\mathbf{2 0 1 7}$ & $\mathbf{2 0 1 8} *$ & Promedio \\
\hline $\begin{array}{c}\text { dólares de empresas } \\
\text { peruanas de ropa } \\
\text { orgánica }\end{array}$ & 8,94 & 9,08 & 9,22 & 9,21 & 9,15 & 9,14 & 9,15 & 9,13 \\
\hline Precio en libras & 5,74 & 5,80 & 5,59 & 6,22 & 6,79 & 7,54 & 7,57 & 6,54 \\
\hline
\end{tabular}

Nota: El año 2018 fue proyectado

Fuente: Veritrade, (2018) 


\subsubsection{Precios actuales}

Los precios de un conjunto de ropa de exportación son en promedio 6,5 libras que equivalen a 29 nuevos soles, las variaciones de precios entre las empresas exportadoras son muy pequeñas.

También consideraremos en el proyecto los precios a los cuales se ofrecen las prendas en el mercado, por variedad de modelos; con la finalidad de demostrar un ingreso monetario cada vez mayor según el grado de posicionamiento de la marca en Reino Unido que permita ingresar boutiques propias.

Tabla 2. 19

Precios y modelos de los productos disponibles en el mercado

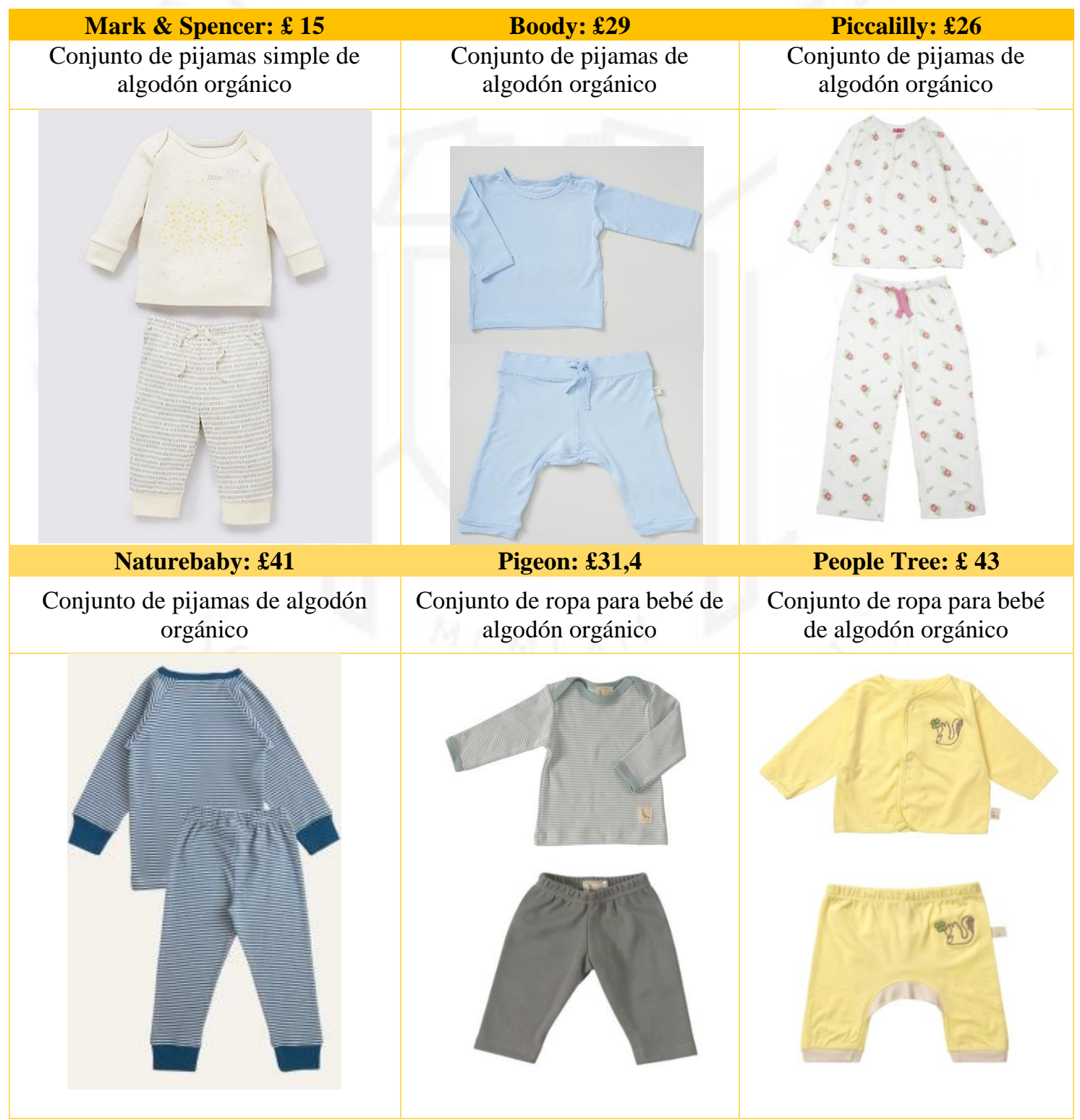

Fuente: Ebay, (2017)

Elaboración propia 
En general, los precios son mucho más altos en las boutiques que en las tiendas por departamentos debido a que los diseños son mucho más personalizados y complejos, también, el canal de comercialización es más amplio.

\subsection{Análisis de Disponibilidad de los insumos principales}

\subsubsection{Características principales de la materia prima}

El algodón orgánico permite obtener telas más suaves y agradables al tacto, se caracteriza por sus semillas no tratadas, libres de transgénicos. Existe un control total del ciclo de producción de tela: desde el cultivo, pasando por la hilatura y su tejido. Los colores que presenta son naturales de la tierra y no se le aplica tratamiento químico, sólo el lavado, por lo que al final se obtiene tejidos completamente puros y biodegradables. (Ribes \& Casals, 2015)

Con respecto a la tela, existen algunos tintes naturales, realizados con extractos de plantas que nos brindan una mayor gama de tonos de colores (Universidad Mayor de San Marcos, 2011). En el Perú, una de las empresas más reconocidas por esta práctica es Ecotintes S.A.C. (Ecotintes, s.f.), aliado de Bergman \& Rivera, quien nos proporcionará la tela ya terminada.

En cuanto a la tela, sus características se detallan en el siguiente cuadro.

Tabla 2. 20

Características de la tela

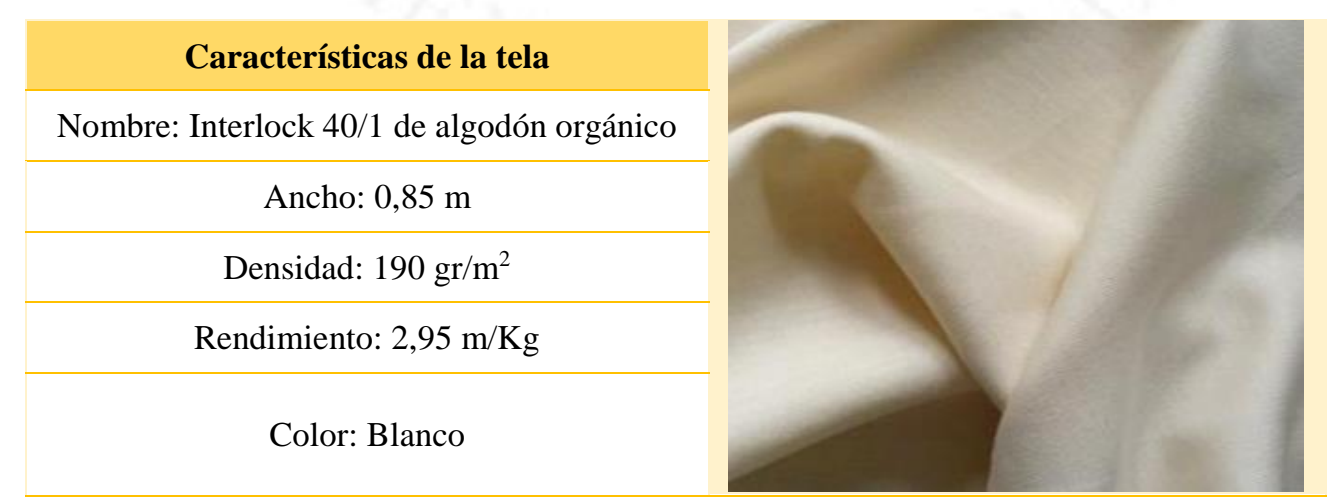

Fuente: Bergman \& Rivera, (2017) 


\subsubsection{Disponibilidad de la materia prima}

En cuanto a la disponibilidad de algodón a nivel nacional para el año 2016 fue de 479.225 kilos de algodón orgánico (Textile Exchange, 2016). Luego, para convertir esa cantidad de algodón a tela se pierde un 5\% como merma y contaminación (Creditex, 2016). Es así como se obtienen 455.263 kilos de tela de algodón orgánico disponible a nivel nacional.

Así mismo, se cuenta con la siguiente cartera de proveedores de algodón orgánico a nivel nacional: Bergman Rivera S.A.C., Ecotton S.A.C., Eko Perú S.A.C Naturtex y Filasur S.A.

Según la Superintendencia Nacional de Aduanas y de Administración Tributaria (Sunat), el mayor exportador de tela orgánica es Bergman Rivera, el cual exportó 25.313 kilos en fibra y tela orgánica durante el año 2017, y 18.904 kilos en el 2016. Esto nos asegura la disponibilidad de materia prima necesaria para el proyecto, la cual es una cifra menor a lo exportado en ambos años.

\subsubsection{Costo de la materia prima}

En el presente proyecto se considerará un costo de materia prima de $\$ 15,5$ por kilogramo para abastecimiento al por menor de algodón orgánico sin incluir I.G.V. (Bergman \& Rivera, 2017).

Se cuenta con una limitada cartera de proveedores, los cuales son: Bergman Rivera S.A.C., Ecotton S.A.C., Eko Perú S.A.C - Naturtex y Filasur S.A. Los proveedores a los que se hará referencia durante el desarrollo de este proyecto serán Bergman Rivera S.A.C. y Eko Perú S.A.C. (Naturtex) porque ofrecen la mejor calidad de materia prima, rápida respuesta para el abastecimiento y amplia gama de colores con teñidos orgánicos (Global Organic Textile Standard, 2017). 


\section{CAPÍTULO III: LOCALIZACIÓN DE PLANTA}

\subsection{Identificación y análisis detallado de los factores de localización}

Según Díaz, Jarufe y Noriega en el libro Disposición de planta, indican que: "los elementos más importantes para la localización de planta son la suma de los costos de transporte de las materias primas hacia la planta y el traslado de los productos acabados hacia el mercado; la disponibilidad y los costos relativos a los insumos"; entre otros. (Díaz, Jarufe y Noriega,2007)

Para nuestro estudio de localización tendremos en cuenta mantener la calidad de los productos, con la finalidad de promover una marca; y ahorro de costos, para generar mayores utilidades que beneficiaran tanto a la empresa como a los trabajadores.

Por lo cual los factores de la macrolocalización serán:

- Proximidad con proveedores de materia prima:

Existen pocos proveedores de tela orgánica certificada a nivel nacional, por lo cual se buscará estar cerca de la mayor cantidad de empresas certificadas ya sean sus depósitos, sedes productivas u oficinas administrativas; para garantizar que contaremos con la cantidad necesaria de materia prima en el tiempo adecuado.

Los principales departamentos con proveedores certificados son: Ica, Lima y Lambayeque.

- Disponibilidad y bajo costo de energía eléctrica:

La energía eléctrica es el suministro principal para la operatividad de nuestro negocio debido a que la tecnología a emplearse está compuesta de equipos especialmente consumidores de esta energía; adicionalmente será importante evaluar su costo para poder ofrecer precios más competitivos. 
- Disponibilidad de terrenos industriales:

Será importante considerar la disponibilidad de los terrenos industriales ya que en nuestro proyecto se invertirá en la construcción de una planta, y la oferta de terrenos industriales en algunas zonas es escasa por el déficit que el país presenta en infraestructura industrial según comenta la ministra Lieneke Schol (El Comercio, 2018).

- Condiciones de puertos marítimos:

Será necesario contar con una adecuada infraestructura de puertos marítimos que nos permita atender de una manera eficaz a nuestros clientes, lo cual además nos brindará una mayor competitividad en el mercado internacional.

- Disponibilidad de mano de obra:

La mayoría de nuestros trabajadores serán parte del proceso de confección, puestos para los cuales no es necesario una educación superior o técnica, sin embargo, es un factor a tener en consideración ya que son nuestra principal fuerza de trabajo.

- Nivel de desarrollo humano

Se evaluará el IDH (Índice de Desarrollo Humano), que nos indica la vida sana y saludable, conocimientos y nivel de vida decoroso de la población evaluada (Ministerio de Economía y Finanzas, 2018); lo cual nos permitirá ser una empresa más atractiva para profesionales calificados.

\subsection{Identificación y descripción de las alternativas de localización}

Basándonos en el factor más importante que es la cercanía de materia prima, se han identificado tres alternativas de localización para la macrolocalización:

- Ica

La industria textil y de confecciones en el departamento de Ica tiene una alta representatividad por la presencia de plantas destinadas a la fabricación de hilados, telas y confección de prendas de vestir de alto valor 
agregado. La calidad de esta industria ha permitido que parte importante de la producción se destine a la exportación, principalmente a los mercados de Estados Unidos y Europa, colocando productos de marcas reconocidas a nivel mundial, en nichos de mercado de precios altos" (Banco Central de Reserva, 2010).

Entre sus empresas más importantes se encuentran: "Textil del Valle S.A, Southern Textile Network S.A.C, Central de Comercio Algodonero S.A.C, Textiles del Sur S.A.C, Creditex S.A.A. y Western Cotton S.A”, entre otras (Consejo Nacional de Ciencia, Tecnología e Innovación Tecnológica, 2014, pág. 71). Según el Censo de Empresas Manufactureras del año 2007 del Ministerio de la Producción: "el número de empresas dedicadas a fabricar productos textiles en Ica ascendió a 29, mientras que el número de empresas dedicadas a fabricar prendas de vestir, adobo y teñido de pieles fue de 168" (Banco Central de Reserva, 2010).

- Lima

En Lima, la industria textil y de confecciones involucra actividades que van desde el tratamiento de las fibras textiles para elaborar hilos, hasta la confección de prendas de vestir y otros artículos. Las empresas dedicadas a dichas actividades integran diferentes procesos productivos, otorgando un mayor nivel agregado a sus productos (Asociación Peruana de Técnicos Textiles, 2016).

Según la SUNAT, [Superintendencia Nacional de Administración Tributaria]: el total de empresas operativas registradas a diciembre del 2000 del subsector de preparación de fibras, fabricación de hilados e hilos y tejidos, asciende a 728 unidades productivas en todo el Perú. Cabe resaltar que la información proporcionada está referida al total de empresas manufactureras y de servicios relacionadas con esta rama industrial de diferente escala de producción (micro, pequeñas, medianas y grandes empresas). Según su distribución geográfica, en Lima se hallan establecidas 472 empresas (64.8\%) (Centrum Católica Graduate Business School, 2010). 
- Lambayeque

Lambayeque es considerada una región de riquísimas tradiciones textiles. Existen zonas como la caleta de San José, Monsefú o Etén, familias enteras se encargan de confeccionar prendas que se usan para ceremonias de antiguo origen o célebres sombreros de chalán. En una publicación hecha por Cristina Gutiérrez, la autora menciona lo siguiente: "Este departamento es quizás el único de la costa que no se dejó sojuzgar por la cultura criolla y que conserva intacta su textilería artesanal basada en algodón” (RPP, 2016).

En declaraciones a la Agencia Andina, Zoeger (2014) comentó que el 90\% de gorras deportivas del Perú se hacen en el distrito chiclayano de Eten. "Esas cifras no hacen ver que Lambayeque produce textilería mucho más de La Libertad, región que antes nos llevaba una amplia ventaja", anotó tras agregar que lo que falta es esa organización tipo clúster para poder en conjunto no sólo uniformizar la producción, sino mejorar y ser, junto con la agricultura, el turismo y la construcción, un sector económico muy productivo y que genere mano de obra (Andina, 2014).

\subsection{Evaluación y selección de localización}

\subsubsection{Evaluación y selección de la macro localización}

Se identificarán los factores más importantes de los tres departamentos y se realizará la evaluación. Cabe resaltar que se considerará al Callao como parte de los puertos de Lima.

- Proximidad con proveedores de materia prima:

Los departamentos con mayor presencia de proveedores certificados son: Lima, Ica y Lambayeque. Este será el factor más importante.

Consideraremos establecimientos como oficinas administrativas, sedes productivas y almacenes. 
Tabla 3. 1

Proximidad con proveedores de materia prima

\begin{tabular}{|c|c|c|c|c|c|}
\hline \multirow{2}{*}{ Departamento } & \multicolumn{5}{|c|}{ Empresas } \\
& $\begin{array}{c}\text { Bergman Rivera } \\
\text { SAC }\end{array}$ & $\begin{array}{c}\text { Ecotton } \\
\text { SAC }\end{array}$ & $\begin{array}{c}\text { Eko Peru } \\
\text { SAC }\end{array}$ & Filasur SA & Total \\
\hline Ica & 3 & 8 & & & 11 \\
\hline Lambayeque & 1 & 1 & & 5 & 2 \\
\hline Lima & 4 & 2 & 1 & 5 & 25 \\
\hline
\end{tabular}

Fuente: Razón Social Perú, (2017)

- Disponibilidad y bajo costo de energía eléctrica:

La energía eléctrica será un factor importante después de la proximidad con proveedores de materia prima, ya que es un recurso indispensable para la producción al igual que el desarrollo de áreas industriales.

Tabla 3.2

Disponibilidad de energía eléctrica

\begin{tabular}{|c|cc}
\hline Departamento & Producción $(\mathbf{G w}-\mathbf{h})$ & Precio $(\mathbf{S} /$. / mes $)$ \\
\hline Ica & 910 & 6,55 \\
\hline Lima & 24987 & 9,46 \\
\hline Lambayeque & 83,3 & 7,56 \\
\hline
\end{tabular}

Fuente: Ministerio de Energía y Minas, MEM. (2015)

- Desarrollo de áreas industriales:

Evaluaremos este factor considerando los parques industriales existentes y los que se encuentran en proyectos; ya que nos permitirá conocer los departamentos con mayor inversión en la extensión del sector industrial.

Tabla 3.3

Número de parques industriales por cada departamento

\begin{tabular}{|c|c|} 
Departamento & $\begin{array}{c}\text { Número de parques } \\
\text { industriales }\end{array}$ \\
\hline Ica & 1 \\
\hline Lima & 8 \\
\hline Lambayeque & 1 \\
\hline
\end{tabular}

Fuente: Ministerio de la Producción, PRODUCE. (2014) 
Tabla 3.4

Número de proyectos de parques industriales en comercialización

\begin{tabular}{|c|c|}
\hline Departamentos & Proyectos de parques de industriales \\
\hline Ica & 0 \\
\hline Lima & 6 \\
\hline Lambayeque & 0 \\
\hline
\end{tabular}

Fuente: Colliers International, (2017)

Figura 3. 1

Ubicación de parques industriales en el interior del país

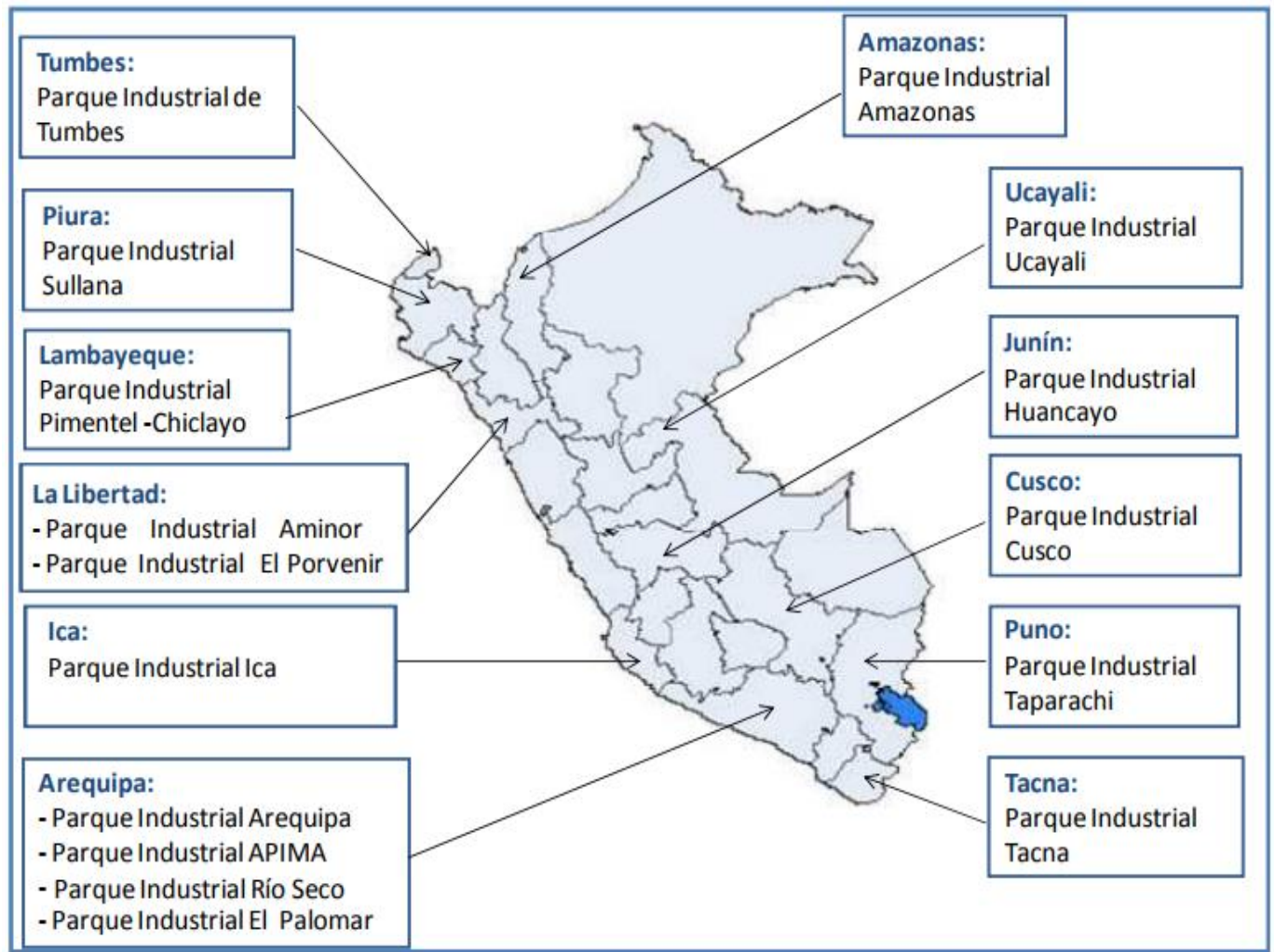

Fuente: Ministerio de la Producción, PRODUCE. (2014) 
Figura 3.2

Parques industriales en la ciudad de Lima

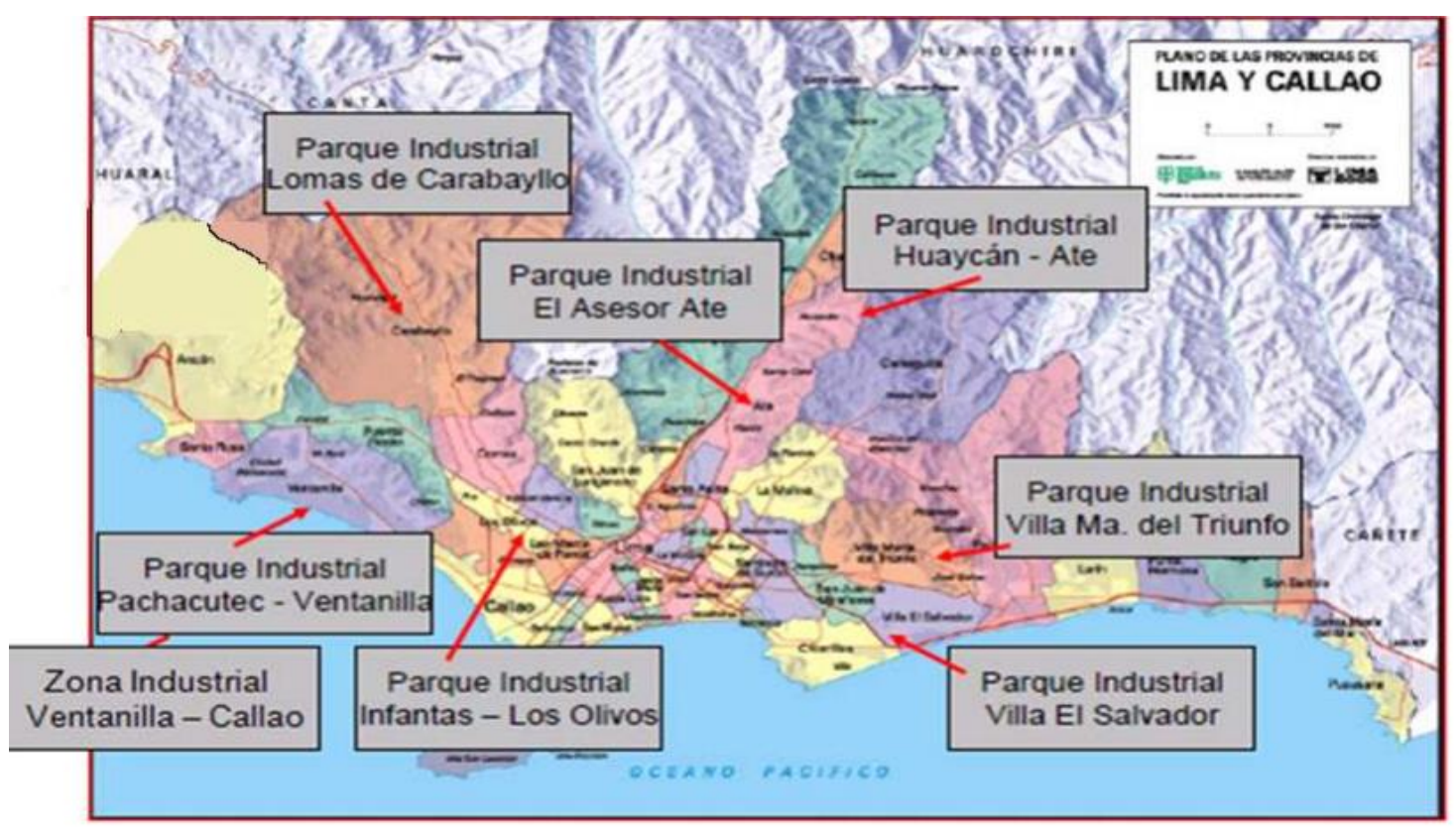

Fuente: Ministerio de la Producción, PRODUCE. (2014)

Tabla 3.5

Proyectos de Parques Industriales en Comercialización

\begin{tabular}{|c|c|c|}
\hline Proyecto & Ubicación & Comercializa \\
\hline La Chutana & Lima & Colliers \\
\hline Sector 62 & Chilca & Inmobiliaria Triana \\
\hline Macrópolis & Lurín & Inversiones Centenario \\
\hline Huachipa Este & Huachipa & Bryson Hills \\
\hline Indurpark & Chilca & Indurpark \\
\hline Piura Futura & Piura & Piura Futura \\
\hline Lúcumo & Lurín & Inversiones El Pino \\
\hline
\end{tabular}

Fuente: Colliers International, (2017)

- Condiciones de puertos marítimos:

Este será un factor de menos importancia que el desarrollo de áreas industriales, pero más importantes que el nivel de desarrollo humano. Lima es el único departamento con un aeropuerto internacional llamado "Jorge Chávez"; con respecto a los puertos, se brindará mayor información en las siguientes tablas. Así mismo, se precisa que se considerará al Callao como parte del departamento de Lima. 
Tabla 3.6

Número de puertos

\begin{tabular}{|c|c|}
\hline Departamento & Puerto \\
\hline \multirow{2}{*}{ Ica } & Pisco \\
\cline { 2 - 2 } & Gral. San Martín \\
\cline { 2 - 2 } & San Nicolás \\
\cline { 2 - 2 } Lambayeque & San Juan \\
\hline \multirow{2}{*}{ Lima } & Eten \\
\hline \multirow{2}{*}{ Pimentel } \\
\cline { 2 - 2 } & Callao \\
\hline & Supe \\
\cline { 2 - 2 } & Chancay \\
\hline
\end{tabular}

Fuente: Instituto Nacional de Estadística e Informática, INEI. (2017)

Tabla 3. 7.

Proyectos de desarrollo en puertos

\begin{tabular}{c|c|c|c|} 
Departamento & $\begin{array}{c}\text { Número de } \\
\text { talleres } \\
\text { realizados }\end{array}$ & $\begin{array}{c}\text { Monto de los proyectos ejecutados en } \\
\text { puertos en el 2017 }\end{array}$ & $\begin{array}{c}\text { Monto de las iniciativas } \\
\text { de inversión en puerto }\end{array}$ \\
\hline Ica & 1 & Terminal de Pisco $(\$ 249$ millones $)$ & \$485 millones \\
\hline Lambayeque & 0 & 0 & \$232 millones \\
\hline Lima & 6 & $\begin{array}{c}\text { Terminal Chancay }(\$ 372 \text { millones }) \\
\text { Terminal Callao }(\$ 13.9 \text { millones })\end{array}$ & 0 \\
\hline
\end{tabular}

Fuente: Autoridad Portuaria Nacional, (2017)

- Disponibilidad de mano de obra:

El proceso si bien no necesitará la participación de mucha mano de obra especializada, sí es intensivo en mano de obra directa. Por lo tanto, este factor es menos importante que las condiciones de puertos marítimos.

Tabla 3. 8.

Disponibilidad de mano de obra

\begin{tabular}{|c|c|c|}
\hline Departamento & $\begin{array}{c}\text { PEA con educación secundaria } \\
\text { (porcentaje) }\end{array}$ & $\begin{array}{c}\text { PEA desempleada } \\
\text { (porcentaje) }\end{array}$ \\
\hline Ica & 46,3 & 3,3 \\
\hline Lima & 47,5 & 4,6 \\
\hline Lambayeque & 45,7 & 4,7 \\
\hline
\end{tabular}

Fuente: Instituto Nacional de Estadística e Informática, INEI. (2014) 
- $\quad$ Nivel de desarrollo humano:

Adicionalmente, se considerará como factor el nivel de desarrollo humano debido a que se debe tener en cuenta el nivel de los aspectos básicos de la población con el fin de generar empleo y mejores condiciones de vida para la población habitante, es por ello que tendrá la misma importancia que la disponibilidad de mano de obra.

Tabla 3.9

Nivel de desarrollo humano

\begin{tabular}{|c|c|c|}
\hline Departamento & Ranking a nivel nacional & Valor IDH \\
\hline Ica & 7 & 0,5351 \\
\hline Lima & 1 & 0,6340 \\
\hline Lambayeque & 10 & 0,4617 \\
\hline
\end{tabular}

Fuente: Actualidad Gubernamental,(2014)

Tabla 3. 10

Importancia de factores macrolocalización

\begin{tabular}{c|c|c} 
Factor & Descripción & Importancia \\
\hline F1 & Proximidad con proveedores de materia prima & 1 \\
\hline F2 & Disponibilidad y bajo costo de energía eléctrica & 2 \\
\hline F3 & Desarrollo de áreas industriales & 2 \\
\hline F4 & Condiciones de puertos marítimos & 3 \\
\hline F5 & Disponibilidad de mano de obra & 4 \\
\hline F6 & Nivel de desarrollo humano & 4
\end{tabular}

Fuente: Díaz, B. y Noriega, M., (2017)

Elaboración propia

Tabla 3.11

Tabla de enfrentamientos

\begin{tabular}{|c|c|c|c|c|c|c|c|}
\hline & $\mathrm{F} 1$ & $\mathrm{~F} 2$ & F3 & F4 & F5 & F6 & TOTAL \\
\hline $\mathrm{F} 1$ & - & 1 & 1 & 1 & 1 & 1 & 5 \\
\hline $\mathrm{F} 2$ & 0 & - & 1 & 1 & 1 & 1 & 4 \\
\hline F3 & 0 & 1 & - & 1 & 1 & 1 & 4 \\
\hline F4 & 0 & 0 & 0 & - & 1 & 1 & 2 \\
\hline F5 & 0 & 0 & 0 & 0 & - & 1 & 1 \\
\hline F6 & 0 & 0 & 0 & 0 & 1 & - & 1 \\
\hline & & & & & & & 17 \\
\hline
\end{tabular}

Fuente: Díaz, B. y Noriega, M., (2017)

Elaboración propia 
Tabla 3. 12

Escala de calificación Macrolocalización

\begin{tabular}{|c|c|}
\hline Bueno & 6 \\
\hline Regular & 4 \\
\hline Malo & 2 \\
\hline
\end{tabular}

Fuente: Díaz, B. y Noriega, M., (2017)

Elaboración propia

Tabla 3.13

Tabla de ranking de factores - Macrolocalización

\begin{tabular}{c|c|c|c|c|c|c|c|}
\multirow{2}{*}{ Fact. } & \multirow{2}{*}{ Pond. } & \multicolumn{2}{|c|}{ Lima } & \multicolumn{2}{c|}{ Ica } & \multicolumn{2}{c|}{ Lambayeque } \\
\cline { 3 - 9 } & & Calif. & Puntaje & Calif. & Puntaje & Calif. & Puntaje \\
\hline F1 & $29,41 \%$ & 6 & 1,76 & 6 & 1,76 & 2 & 0,59 \\
\hline F2 & $23,53 \%$ & 6 & 1,41 & 6 & 1,41 & 2 & 0,47 \\
\hline F3 & $23,53 \%$ & 6 & 1,41 & 2 & 0,47 & 2 & 0,47 \\
\hline F4 & $11,76 \%$ & 6 & 0,71 & 6 & 0,71 & 4 & 0,47 \\
\hline F5 & $5,88 \%$ & 6 & 0,35 & 4 & 0,24 & 6 & 0,35 \\
\hline F6 & $5,88 \%$ & 2 & 0,12 & 4 & 0,24 & 4 & 0,24 \\
\hline TOTAL & $100,00 \%$ & & $\mathbf{5 , 7 6}$ & & 4,82 & & 2,59 \\
\hline
\end{tabular}

Fuente: Díaz, B. y Noriega, M., (2017)

Elaboración propia

El departamento elegido en el que se localizará la planta es Lima debido a que cuenta con el mayor puntaje: 5,76

\subsubsection{Evaluación y selección de la micro localización}

- Disponibilidad de terrenos industriales:

En este factor evaluaremos la oferta de terrenos que se presentan en las zonas de mayor actividad industrial de Lima, desarrollados en el reporte del primer semestre del 2017 de la inmobiliaria Colliers International. Este será uno de los factores más importantes al igual que los costos de terrenos. 
Tabla 3.14

Distribución de oferta por tipo de inmueble

\begin{tabular}{|c|c|c|}
\hline Distritos & Terrenos & Locales \\
\hline Zona Este 1 (Ate) & $10 \%$ & $90 \%$ \\
\hline Zona Sur 2 (Chilca) & $61 \%$ & $39 \%$ \\
\hline Zona Sur 1 (Lurín) & $44 \%$ & $56 \%$ \\
\hline Fuente: Colliers International, $(2017)$ & \\
\hline
\end{tabular}

Fuente: Colliers International, (2017)

- Costos de terrenos:

Teniendo en consideración los cuadros comparativos previos, se analizarán los distritos de Ate, por su cercanía a San Juan de Lurigancho; Chilca, por su cercanía al distrito de Quilmaná y Lurín, por la presencia de parques industriales y su cercanía a los distritos de Chorrillos y Villa El Salvador, donde también se ubican proveedores de materia prima. Este será uno de los factores más importantes.

Tabla 3. 15

Costo de terrenos industriales

\begin{tabular}{|c|c|}
\hline Distritos & Precios promedios $\left(\$ / \mathrm{m}^{2}\right)$ \\
\hline Zona Este 1 (Ate) & 1053 \\
\hline Zona Sur 2 (Chilca) & 97,5 \\
\hline Zona Sur 1 (Lurín) & 207.5 \\
\hline
\end{tabular}

Fuente: Colliers International, (2017)

- $\quad$ Facilidades municipales

Se considerará como un factor las facilidades municipales de cada distrito, siendo más importante que los conglomerados del sector textil pero menos importantes que la disponibilidad de terrenos industriales. Este se medirá según la cantidad de mypes registradas del sector textil durante un año debido a que muestra lo atractiva que es esa municipalidad y la capacidad de atención de sus registros, así como la cantidad de personal dedicado exclusivamente a la promoción de mypes dentro de cada municipalidad. 
Tabla 3. 16

Facilidades para mypes textiles

\begin{tabular}{|c|c|c|}
\hline Distritos & $\begin{array}{c}\text { Cantidad de mypes textiles } \\
\text { registradas en el 2016 }\end{array}$ & $\begin{array}{c}\text { Cantidad de personal laborando en la } \\
\text { promoción de las mypes durante 2014 }\end{array}$ \\
\hline Ate & 14 & 1 \\
\hline Chilca & 4 & 1 \\
\hline Lurín & 1 & 0 \\
\hline
\end{tabular}

Fuente: Instituto Nacional de Estadística e Informática, INEI. (2016)

- Conglomerados del sector textil

Un factor importante que influirá en el desempeño de este proyecto son los conglomerados textiles debido a que nos proporcionarán un soporte para la obtención de insumos en casos de incumplimientos por parte de proveedores o sobredemandas. Este factor será más importante que la seguridad pública pero menos importante que los costos de terrenos.

Tabla 3.17

Conglomerados textiles

\begin{tabular}{|c|c|c|}
\hline Distritos de conglomerados textiles & $\begin{array}{c}\text { Densidad empresarial } \\
\left.\text { (Empresas } / \mathbf{~ k m}^{\mathbf{2}}\right)\end{array}$ & Ubicación \\
\hline La Victoria & 7167,7 & Lima Centro \\
\hline Cercado Lima & 3926,2 & Lima Centro \\
\hline Villa EI Salvador & 893,3 & Lima Sur \\
\hline Ate & 628,8 & Lima Este \\
\hline San Juan de Lurigancho & 519,2 & Lima Este \\
\hline
\end{tabular}

Fuente: Universidad Señor de Sipán, (2018); Gonzáles, M., (2018); Gonzales, L. y Aguirre, S., (2005); Ministerio de la Producción, PRODUCE. (2017) e Instituto Nacional de Estadística e Informática, INEI. (2017).

Según el cuadro anterior, se colocará una puntuación mayor a Ate y Lurín, por tener cercanía a distritos de conglomerados textiles, mientras que Chilca tendrá una menor puntuación.

- Seguridad pública:

Se considerará este factor debido a que la seguridad afectará tanto a la empresa en pérdidas económicas y costos de protección, así como al personal que labora en la empresa (Expansión, 2016). Este factor será igual de importante que las vías de acceso, pero menos importante que los conglomerados textiles. 
Tabla 3.18

Porcentaje de denuncias por comisión de delitos (cada 10000 habitantes)

\section{Distritos Porcentaje de denuncias por comisión de delitos}

\begin{tabular}{|cc|}
\hline Ate & 45,6 \\
\hline Chilca & 128 \\
\hline Lurín & 76,6 \\
\hline
\end{tabular}

Fuente: Instituto Nacional de Estadística e Informática, INEI. (2017)

- Vías de acceso

Este factor influirá en el acceso hacia la planta, tanto para el personal que labore en la empresa como para los proveedores de materiales y salidas de la mercadería. Este factor será igual de importante que la seguridad pública.

Tabla 3. 19

Vías de acceso

\begin{tabular}{c|c|c|}
\hline Distritos & Rutas nacionales & $\begin{array}{c}\text { Líneas de metro (en } \\
\text { proyecto) }\end{array}$ \\
\hline \multirow{2}{*}{ Ate } & PE-22 (Puente Huachipa, Óvalo santa anita, Santa & Línea 2 \\
& Clara), PE-1N (vía de evitamiento) & \\
\hline \multirow{2}{*}{ Chilca } & LM-720, LM-114, LM-718 & - \\
\hline \multirow{2}{*}{ Lurín } & PE-1S (I.V. Pucusana, Chilca) & \\
\hline & LM-808, LM-809, LM-806, LM_807, LM-810, LM- & 811, LM-812, LM-814 \\
\hline
\end{tabular}

Fuente: Ministerio de Transportes y Comunicaciones, MTC. (2018)

Finalmente, con los datos recopilados, se procede a realizar el Ranking de Factores.

Tabla 3. 20

Importancia de factores para microlocalización

\begin{tabular}{c|c|c|}
\hline Factor & Descripción & Importancia \\
\hline F1 & Disponibilidad de terrenos industriales & 1 \\
\hline F2 & Costos de terrenos & 1 \\
\hline F3 & Facilidades municipales & 2 \\
\hline F4 & Conglomerados del sector textil & 3 \\
\hline F5 & Seguridad pública & 4 \\
\hline F6 & Vías de acceso & 4 \\
\hline
\end{tabular}

Fuente: Díaz, B. y Noriega, M., (2017)

Elaboración propia 
Tabla 3.21

Tabla de enfrentamientos - Microlocalización

\begin{tabular}{cccc|c|c|c|c|} 
& F1 & F2 & F3 & F4 & F5 & F6 & TOTAL \\
\hline & - & 1 & 1 & 1 & 1 & 1 & 5 \\
\hline F2 & 1 & - & 1 & 1 & 1 & 1 & 5 \\
\hline F3 & 0 & 0 & - & 1 & 1 & 1 & 3 \\
\hline F4 & 0 & 0 & 0 & - & 1 & 1 & 2 \\
\hline F5 & 0 & 0 & 0 & 0 & - & 1 & 1 \\
\hline F6 & 0 & 0 & 0 & 0 & 1 & - & 1 \\
\hline & & & & & & & 17 \\
\hline
\end{tabular}

Fuente: Díaz, B. y Noriega, M., (2017)

Elaboración propia

Tabla 3.22

Escala de calificación Microlocalización

\begin{tabular}{|c|c|}
\hline Bueno & 6 \\
\hline Regular & 4 \\
\hline Malo & 2 \\
\hline
\end{tabular}

Fuente: Díaz, B. y Noriega, M., (2017)

Elaboración propia

Tabla 3.23

Tabla de ranking de factores - Microlocalización

\begin{tabular}{c|c|c|c|c|c|c|c|}
\hline \multirow{2}{*}{ Fact. } & \multirow{2}{*}{ Pond. } & \multicolumn{2}{c}{ Ate } & \multicolumn{2}{c}{ Chilca } & \multicolumn{2}{c}{ Lurín } \\
\hline & & Calif. & Puntaje & Calif. & Puntaje & Calif. & Puntaje \\
\hline F1 & $29,41 \%$ & 2 & 0,59 & 6 & 1,76 & 6 & 1,76 \\
\hline F2 & $29,41 \%$ & 2 & 0,59 & 6 & 1,76 & 6 & 1,76 \\
\hline F3 & $17,65 \%$ & 4 & 0,71 & 4 & 0,71 & 2 & 0,35 \\
\hline F4 & $11,76 \%$ & 6 & 0,71 & 2 & 0,24 & 4 & 0,47 \\
\hline F5 & $5,88 \%$ & 4 & 0,24 & 2 & 0,12 & 4 & 0,24 \\
\hline F6 & $5,88 \%$ & 6 & 0,35 & 2 & 0,12 & 4 & 0,24 \\
\hline TOTAL & $100,00 \%$ & & 3,18 & & 4,71 & & $\mathbf{4 , 8 2}$ \\
\hline
\end{tabular}

Fuente: Díaz, B. y Noriega, M., (2017)

Elaboración propia

El distrito elegido para localizar la planta es Lurín, debido a que cuenta con el mayor puntaje: 4,82 


\section{CAPÍTULO IV: TAMAÑO DE PLANTA}

En el presente capítulo se determinará cuál de los siguientes factores: mercado, recurso productivo, tecnología, inversión o punto de equilibrio; definirá el tamaño de planta de nuestro proyecto.

\subsection{Relación tamaño-mercado}

Se estima que la demanda proyectada del producto para el año 2018 será de 41156 conjuntos de ropa de bebé, según el análisis que se realizó en el punto 2.4.

Tabla 4. 1

Proyección de venta específica de conjuntos

\begin{tabular}{|c|c|}
\hline Año & Conjuntos (unidades) \\
\hline $\mathbf{2 0 1 7}$ & 35930 \\
\hline $\mathbf{2 0 1 8}$ & 41156 \\
\hline $\mathbf{2 0 1 9}$ & 47912 \\
\hline $\mathbf{2 0 2 0}$ & 54869 \\
\hline $\mathbf{2 0 2 1}$ & 62825 \\
\hline $\mathbf{2 0 2 2}$ & 70766 \\
\hline
\end{tabular}

Elaboración propia

\subsection{Relación tamaño-recurso productivo}

Para el cálculo del tamaño - recurso productivo se tomará en cuenta los kilos de tela e hilo orgánico que exporta nuestro principal proveedor, Bergman \& Rivera S.A.C., para evidenciar la capacidad productiva del proveedor y asegurar nuestro abastecimiento de materia prima.

De esta manera, se evidencia que la capacidad de esta empresa es suficiente para abastecer el mercado nacional, recurriendo a la exportación para obtener mayores ingresos. 
Tabla 4. 2

Relación tamaño-recurso productivo

\begin{tabular}{|c|c|c|}
\hline Año & Exportación $(\mathbf{k g})$ & Conjuntos \\
\hline $\mathbf{2 0 1 7}$ & 37022,25 & 204799 \\
\hline $\mathbf{2 0 1 8}$ & 34864,90 & 217773 \\
\hline $\mathbf{2 0 1 9}$ & 37073,60 & 230747 \\
\hline $\mathbf{2 0 2 0}$ & 39282,30 & 243721 \\
\hline $\mathbf{2 0 2 1}$ & 41491,00 & 256695 \\
\hline $\mathbf{2 0 2 2}$ & 43699,70 & 204799 \\
\hline
\end{tabular}

Fuente: Veritrade, (2018)

El consumo se calculó multiplicando la densidad por la cantidad de metros en los que entran los moldes de una prenda multiplicado por el ancho del rollo de la tela.

Consumo $M P=190 \mathrm{gr} / \mathrm{m} 2 \times 1.60 \mathrm{~m} \times 0,56 \mathrm{~m}=170,24 \mathrm{gr}$ de tela $/$ conjunto

La disponibilidad es mayor a la cantidad requerida por lo que el proyecto es viable.

\subsection{Relación tamaño-tecnología.}

El tamaño de planta se encuentra en función de la cantidad de máquinas, equipos y mano de obra disponibles.

A continuación, calcularemos la capacidad de producción de cada estación del proceso productivo. 
Tabla 4. 3

Conjuntos producidos por máquina

\begin{tabular}{|c|c|c|c|c|c|c|c|c|c|}
\hline Operación & $\begin{array}{c}\mathbf{P} \\
(\text { conj/h-m) }\end{array}$ & $\mathbf{M}$ & $\mathbf{S} / \mathbf{A}$ & $\mathbf{D} / \mathrm{S}$ & T/D & $\mathbf{H} / \mathbf{T}$ & $\mathbf{U}$ & $\mathbf{E}$ & $\begin{array}{c}\text { CO } \\
\text { (conj/año) }\end{array}$ \\
\hline $\begin{array}{c}\text { Tender y verificar calidad } \\
\text { y cantidad }\end{array}$ & 55 & 1 & 52 & 6 & 1 & 8 & $94 \%$ & $80 \%$ & 103425 \\
\hline Tizar tela & 80 & 1 & 52 & 6 & 1 & 8 & $100 \%$ & $80 \%$ & 159744 \\
\hline Cortar tela & 70 & 1 & 52 & 6 & 1 & 8 & $94 \%$ & $80 \%$ & 131215 \\
\hline Habilitar, cortar y pegar & 55 & 1 & 52 & 6 & 1 & 8 & $100 \%$ & $80 \%$ & 108916 \\
\hline Cortar collareta y elástico & 95 & 1 & 52 & 6 & 1 & 8 & $94 \%$ & $80 \%$ & 178286 \\
\hline Coser con recta & 48 & 1 & 52 & 6 & 1 & 8 & $94 \%$ & $80 \%$ & 89856 \\
\hline Coser con remalladora & 12 & 4 & 52 & 6 & 1 & 8 & $94 \%$ & $80 \%$ & 92635 \\
\hline Coser con recubridora & 15 & 4 & 52 & 6 & 1 & 8 & $94 \%$ & $80 \%$ & 115200 \\
\hline Coser con collaretera & 86 & 1 & 52 & 6 & 1 & 8 & $94 \%$ & $80 \%$ & 160457 \\
\hline Colocar snaps & 200 & 1 & 52 & 6 & 1 & 8 & $94 \%$ & $80 \%$ & 374400 \\
\hline $\begin{array}{l}\text { Verificar calidad de } \\
\text { costura y limpiar hilos }\end{array}$ & 47 & 2 & 52 & 6 & 1 & 8 & $100 \%$ & $80 \%$ & 187200 \\
\hline Planchar & 67 & 1 & 52 & 6 & 1 & 8 & $100 \%$ & $80 \%$ & 133120 \\
\hline $\begin{array}{c}\text { Colocar Hang Tag, doblar, } \\
\text { embolsar y embalar }\end{array}$ & 57 & 1 & 52 & 6 & 1 & 8 & $100 \%$ & $80 \%$ & 114536 \\
\hline
\end{tabular}

Elaboración propia

Se puede apreciar que la operación de remallado es el cuello de botella del proyecto con 89856 conjuntos.

\subsection{Relación tamaño-inversión}

La cantidad de dinero que necesitamos financiarnos para la compra de terreno, construcción, maquinaria y capital de trabajo del proyecto es de aproximadamente $240.408,63$ soles.

El mercado nos ofrece opciones para poder obtener este monto requerido para la implementación del negocio; el BBVA Continental (BBVA Continental, 2018) presenta el préstamo Contilocal, el cual nos permite acceder a un monto de hasta 250000 soles con cuotas de interés de 19,5\% para negocios en los que exista la compra de un terreno; y Prestamype presta de 20000 hasta 300000 soles con una tasa de costo efectivo anual (TCEA) de $28 \%$ a $40 \%$ (Prestamype, 2018).

Por lo tanto, el financiamiento del proyecto es viable dentro del mercado peruano. 


\subsection{Relación tamaño-punto de equilibrio}

Para recuperar el dinero invertido en la empresa, es necesario generar utilidades en la planta, es decir, que los ingresos por la venta de productos sean mayores a los costos y gastos respectivos.

Se considera como punto de equilibrio al nivel de venta en unidades físicas y en unidades monetarias dado que los ingresos son iguales a los egresos y las utilidades tienen un valor nulo (Didier, 2006).

Las unidades físicas se calculan con la siguiente fórmula:

$$
\text { Punto de Equilibrio }=\frac{\text { Costos fijos }}{(\text { Precio de Venta Unitario }- \text { Costos Variables Unitarios })}
$$

Para determinar nuestro punto de equilibrio, consideraremos como costos fijos: los sueldos de la mano de obra indirecta, así como gastos indirectos: la cuota anual del préstamo y la depreciación de la maquinaria; para el costo variable unitario consideraremos la materia prima, el transporte y sueldos del personal operativo para la demanda del año 2022: 70766 unidades.

Tabla 4.4

Tabla resumen de costos y gastos fijos

\begin{tabular}{|c|r|}
\hline Ítems & Costo / Gasto fijo (Soles) \\
\hline Gastos operativos & 382147,6 \\
\hline Gasto financiero & 46879,7 \\
\hline Gastos indirectos & 11320,6 \\
\hline TOTAL & 440347,9 \\
\hline
\end{tabular}

Elaboración propia

Tabla 4. 5

Tabla resumen de costos variables

\begin{tabular}{|c|r|}
\hline Ítems & Costo variable (Soles) \\
\hline Materia prima & 362022,9 \\
\hline Material indirecto & 14639,8 \\
\hline Costos de Exportación & 34157,3 \\
\hline Mano de obra directa & 326400,0 \\
\hline Comisión de bróker & 123057,7 \\
\hline TOTAL & 860277,7 \\
\hline
\end{tabular}

Elaboración propia 
El costo variable unitario (cvu) se obtiene de la división del costo variable total entre la cantidad a producir, que este caso se considera a la demanda del 2022.

Adicionalmente, se considerará como un ingreso la obtención del drawback, el cual significa el $4 \%$ del valor total FOB de las exportaciones, el cual aumentaría el ingreso de las ventas unitarias (Superintendencia Nacional de Aduanas y de Administración Tributaria, 2014).

$$
\text { Punto de Equilibrio }=\frac{\text { Costos fijos }}{(\text { Precio de Venta U. }+ \text { Drawback U. -Costos Variables U. })}
$$

Tabla 4. 6

Tabla resumen punto de equilibrio

\begin{tabular}{|l|l|}
\hline Costos / gastos fijos & S/. $440 ~ 347,9$ \\
\hline Pvu & S/. 31 \\
\hline Drawback unitario & S/. 1,24 \\
\hline Costos variables unitarios & S/. 20,90/conjunto \\
\hline Punto de equilibrio sin incluir Drawback & $\mathbf{4 3 ~ 6 1 1 ~ c o n j u n t o s / a n ̃ o ~}$ \\
\hline Punto de equilibrio incluyendo Drawback & $\mathbf{3 8 ~ 8 4 1}$ conjuntos/año \\
\hline
\end{tabular}

Elaboración propia

Considerando un precio de venta de 31 soles ( 7 libras esterlinas), el punto de equilibrio en unidades físicas sería de 43611 conjuntos de ropa al año sin incluir el Drawback y 38841 conjuntos de ropa al año incluyéndolo.

\subsection{Selección del tamaño de planta.}

A continuación, determinaremos el tamaño de planta del proyecto hasta el año 2022.

Tabla 4.7

Selección del tamaño de planta

\begin{tabular}{|c|c|}
\hline Tamaño & Unidades de conjuntos \\
\hline Recursos productivos & 204799 \\
\hline Mercado & 70766 \\
\hline Tecnología & 89856 \\
\hline Punto de equilibrio & 38841 \\
\hline Elaboración propia & \\
\hline
\end{tabular}

El tamaño de planta es de 70766 unidades de conjunto, limitado por el mercado. 


\section{CAPÍTULO V: INGENIERÍA DEL PROYECTO}

\subsection{Definición técnica del producto}

\subsubsection{Especificaciones técnicas del producto}

El conjunto de ropa de bebé consta de:

- Un polo manga larga con un broche de presión (snap) en el hombro.

- Un pantalón con elástico en la cintura.

El conjunto será elaborado con tela de algodón orgánico Interlock 40/1.

\subsubsection{Composición del producto}

Así mismo, las características de la tela se detallan en el siguiente cuadro

Tabla 5. 1

Características de la tela

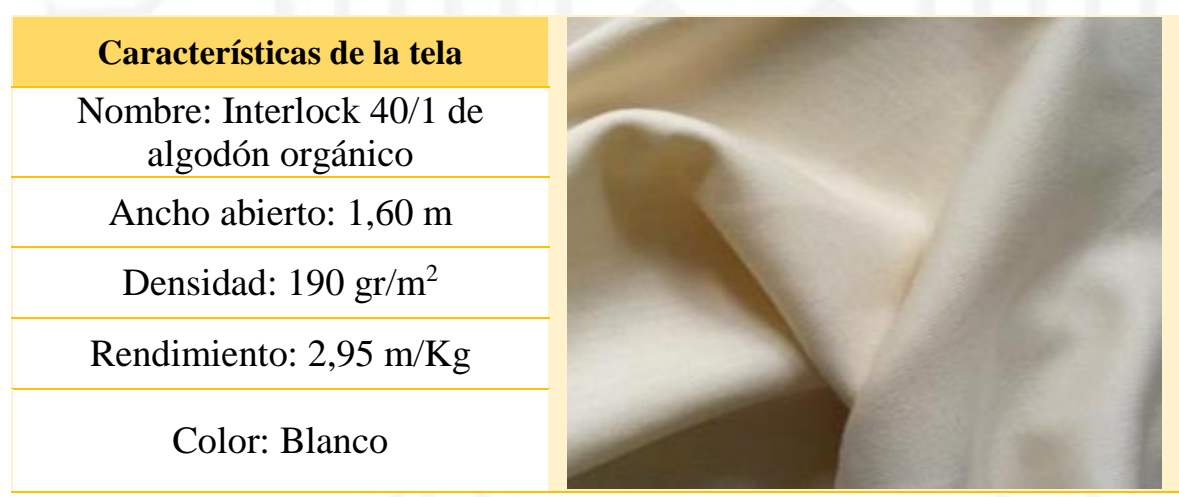

Fuente: Bergman \& Rivera, (2017)

\subsubsection{Diseño gráfico del producto}

Se tomará como base la talla de 6-9 meses debido a que la demanda de ropa en bebés es constante por cada talla y esta es la más representativa en consumo de recursos. 
Tabla 5. 2

Tallas en Reino Unido

\begin{tabular}{|c|c|c|c|c|}
\hline $\begin{array}{c}\text { Tallas en Reino } \\
\text { Unido }(\text { edad) }\end{array}$ & Altura $(\mathbf{c m s})$ & Pecho(cms) & Cintura(cms) & Cadera(cms) \\
\hline Recién nacido & $\mathbf{5 0}$ & 37 & - & - \\
\hline $\mathbf{1}$ mes & $\mathbf{5 6}$ & $38-40$ & - & - \\
\hline $\mathbf{1 - 3}$ meses & $\mathbf{6 2}$ & $40-43$ & - & - \\
\hline $\mathbf{3 - 6}$ meses & $\mathbf{6 8}$ & $43-46$ & - & - \\
\hline $\mathbf{6 - 9}$ meses & $\mathbf{7 4}$ & $46-48$ & - & - \\
\hline $\mathbf{9 - 1 2}$ meses & $\mathbf{7 6}$ & $48-50$ & - & - \\
\hline $\mathbf{1 2 - 1 8}$ meses & $\mathbf{8 3}$ & $50-51$ & $50-51$ & $52-54$ \\
\hline $\mathbf{1 8 - 2 4}$ meses & $\mathbf{9 0}$ & $51-53$ & $51-52$ & $54-56$ \\
\hline $\mathbf{2 - 3}$ años & $\mathbf{9 8}$ & $53-55$ & $52-53$ & $56-58$ \\
\hline
\end{tabular}

Fuente: Next, (2017)

Tabla 5. 3

Medidas del polo

\begin{tabular}{|c|c|c|}
\hline \multicolumn{3}{|c|}{ Polo } \\
\hline Letra & Parte & Medida (pulgadas) \\
\hline $\mathbf{A}$ & Largo & $133 / 4$ \\
\hline B & Ancho a media pulgada de sisa & $11 \frac{1}{2}$ \\
\hline $\mathbf{C}$ & Abertura de faldón & $121 / 4$ \\
\hline D & Largo de manga & $101 / 2$ \\
\hline $\mathbf{E}$ & Sisa & $43 / 4$ \\
\hline $\mathbf{F}$ & Abertura de manga & 3 \\
\hline $\mathbf{G}$ & Abertura de escote & $41 / 4$ \\
\hline $\mathbf{H}$ & Profundidad de escote delantero & 2 \\
\hline I & Profundidad de escote espalda & 1 \\
\hline $\mathbf{J}$ & Ancho de hombros & $95 / 8$ \\
\hline $\mathbf{K}$ & Largo de tapete & $3 / 4$ \\
\hline $\mathbf{L}$ & Cuello a broche & 1 \\
\hline
\end{tabular}

Elaboración propia

Tabla 5.4

Medidas del pantalón

\begin{tabular}{ccc}
\multicolumn{3}{c}{ Pantalón } \\
\hline Letra & Parte & Medida (pulgadas) \\
\hline $\mathbf{M}$ & Ancho de cintura & $8^{1 / 4}$ \\
\hline $\mathbf{N}$ & Tiro delantero & 7 \\
\hline $\mathbf{O}$ & Tiro espalda & $93 / 4$ \\
\hline $\mathbf{P}$ & Cadera & $10^{3 / 4}$ \\
\hline $\mathbf{Q}$ & Largo & $18^{1 / 4}$ \\
\hline $\mathbf{R}$ & Ancho del muslo & 6 \\
\hline $\mathbf{S}$ & Boca pie & $31 / 4$ \\
\hline $\mathbf{T}$ & Ancho de elástico & 2 \\
\hline
\end{tabular}

Elaboración propia 
Figura 5. 1

Medidas del polo

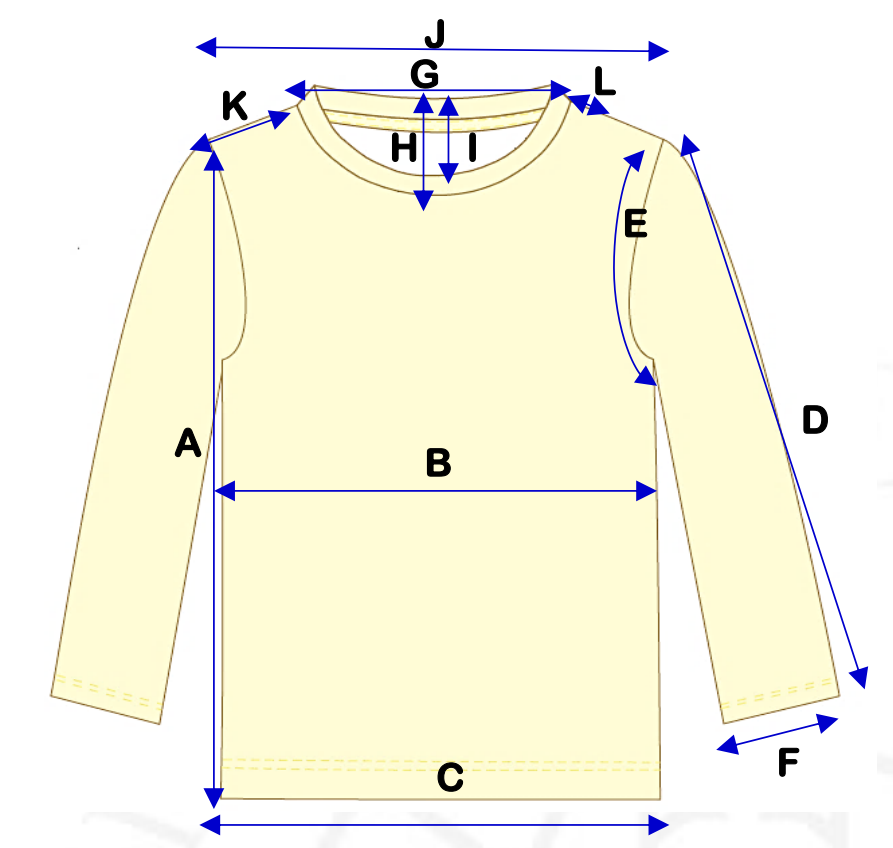

Elaboración propia

Figura 5. 2

Medidas del pantalón

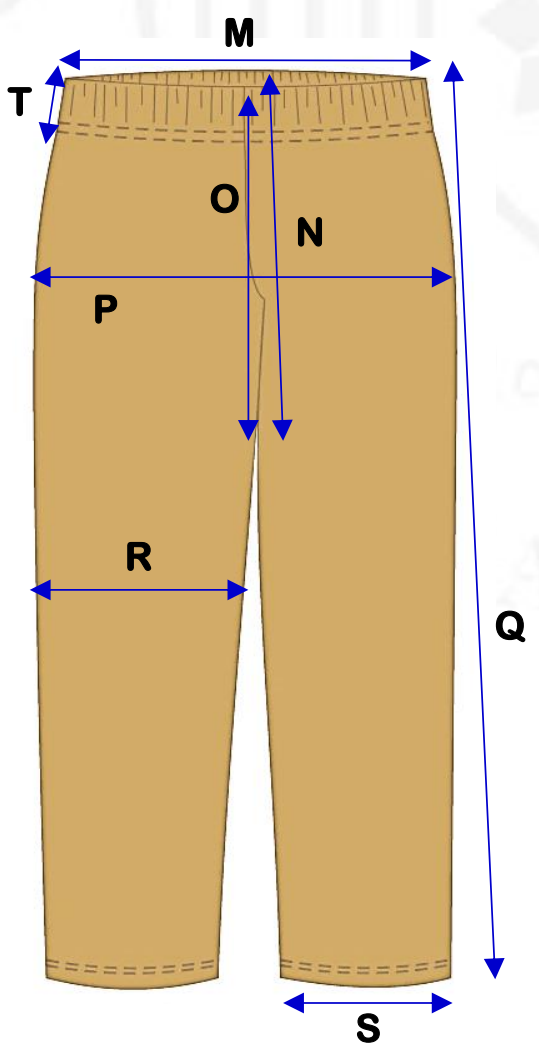

Elaboración propia 
Para exportar los conjuntos, se utilizarán cajas de cartón con las dimensiones: 40 cm x $60 \mathrm{~cm}$ x $40 \mathrm{~cm}$, que tendrán una capacidad de almacenamiento de 100 conjuntos de ropa de bebé. Esta capacidad ha sido determinada considerando la demanda para el último año del proyecto.

Figura 5.3

Caja para exportación

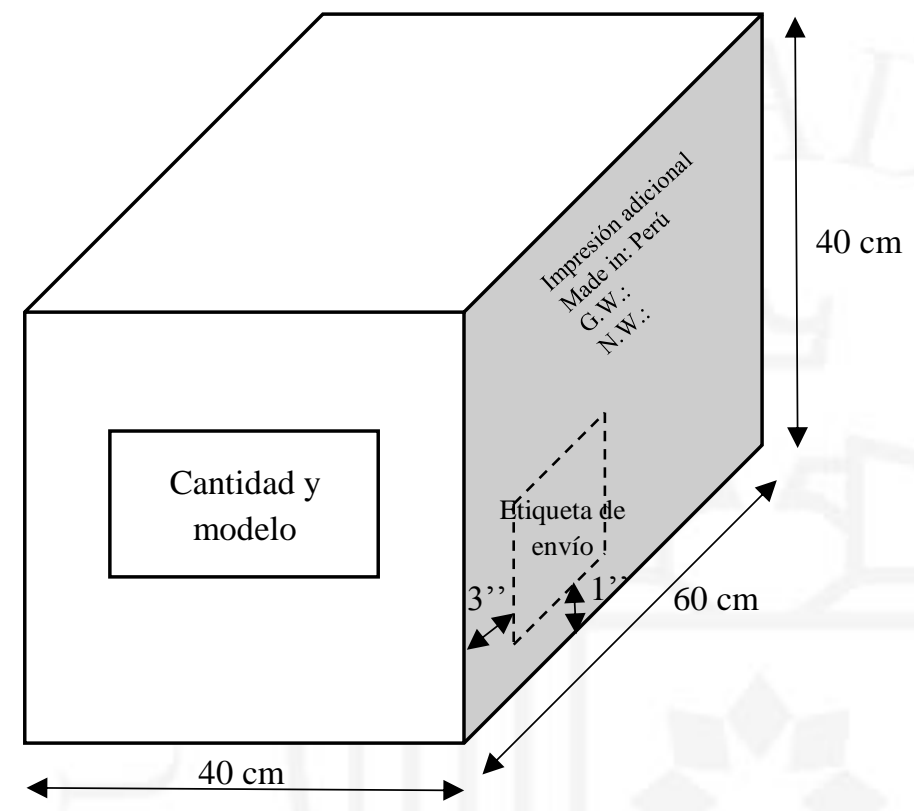

Elaboración propia

\subsubsection{Regulaciones técnicas al producto}

Existen normas técnicas peruanas obligatorias como:

- $\quad$ NTP-ISO 3758:2006 TEXTILES. “Código de los símbolos de cuidado para el etiquetado" (PromPerú, 2017).

- NTP-ISO 231.400:2006 TEXTILES. "Etiquetado para prendas de vestir y ropa para el hogar" (PromPerú, 2017).

- NTP-ISO 3635:2006. "Designación de talla para prendas de vestir. Definiciones y procedimientos de medición del cuerpo humano" (PromPerú, 2017). 
Adicionalmente, será necesario considerar las normas dispuestas por el país destino:

- Reglamento (EU) N 1007/2011, "relativo a las denominaciones de las fibras textiles y al etiquetado y marcado de la composición en fibras de los productos textiles “(PromPerú, 2017). A continuación, algunos extractos del documento:

$\checkmark$ “Art.7.1 Solo podrán etiquetarse o marcarse como «100 \%», «puro» o «todo» los productos que se compongan exclusivamente de una misma fibra" (Parlamento Europeo, 2001).

$\checkmark$ “Art.14.1 El etiquetado y marcado de productos textiles será duradero, legible, visible y accesible con facilidad y, en el caso de las etiquetas, estas irán fijadas de modo seguro" (Parlamento Europeo, 2001).

Los controles que se aplican al comercio textil según el reglamento son pruebas de conformidad de composición, inflamabilidad y toxicidad (Parlamento Europeo, 2001); con la finalidad de cumplir con la Ley general para la seguridad de los productos, que responsabiliza sobre la seguridad de los productos distribuidos en Reino Unido a los productores e importadores. (PromPerú, 2017)

\subsection{Tecnologías existentes y procesos de producción.}

\subsubsection{Naturaleza de la tecnología requerida.}

\subsubsection{Descripción de las tecnologías existentes.}

Para confeccionar una prenda, se necesitan de diversas operaciones que se pueden realizar de forma manual, semi-automatizada o automatizada.

A continuación, se detallarán solo las tecnologías de las operaciones que se encuentran semi-automatizados debido a que involucran una menor inversión que las automatizadas (Mundo Costuras, 2017):

- Corte:

Máquina de corte semi-automática: Entre las más utilizadas, se encuentra la cortadora vertical de 5 a 10 pulgadas de luz para corte. 
Figura 5.4

Cortadora Semi-automática

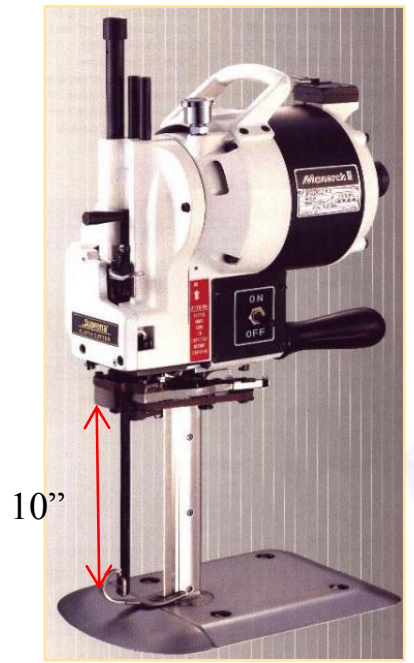

Fuente: Detextiles, (2016)

- Condiciones ambientales:

Extractor aéreo de techo: Permite extraer el aire con polvillo en el medio ambiente para evitar que sea aspirado por las personas que laboran en el área de corte y/o contamina la tela.

Figura 5. 5

Extractor aéreo

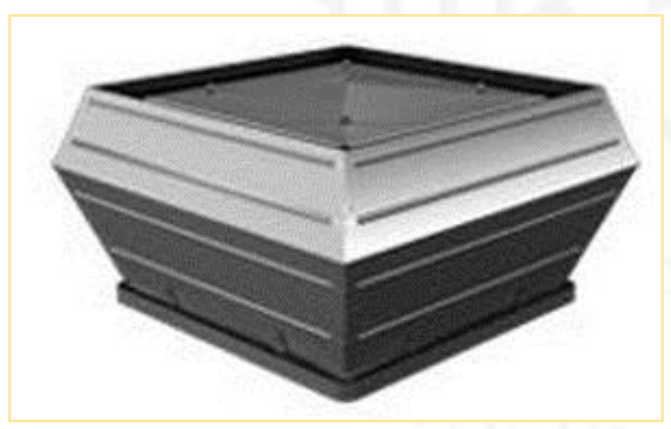

Fuente: Archiexpo, (2016)

- Costura:

Máquinas de coser mecánicas: Las máquinas de coser mecánicas llevan un pedal que se conecta a la corriente para coser.

Estas máquinas seleccionan las puntadas mediante diales en forma de rueda o palanca. Estos diales conectan directamente con el mecanismo de la 
máquina para la selección del tipo, largo y ancho de la puntada (Saucedo, 2014).

Figura 5. 6

Máquina de costura mecánica

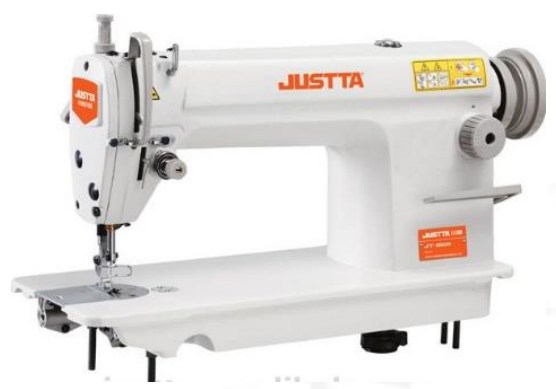

Fuente: Alibaba, (2016)

\subsubsection{Selección de la tecnología.}

Se contará con las tecnologías anteriormente mencionadas en el punto 5.2.1.1.:

- Corte: Máquina de corte semi-automática

- Condiciones ambientales: Extractor de aire.

- Costura: Máquinas de coser mecánicas

\subsubsection{Proceso de producción.}

\subsubsection{Descripción del proceso.}

$\underline{\text { Recepción y control de calidad }}$

Al llegar los rollos de tela interlock, pasan por un estricto control de calidad, que está conformado por pruebas de densidad, para corroborar que la tela es del grosor adecuado; y de encogimiento, para conocer el porcentaje que se encoje la tela y de solidez del color y se contrastan con las especificaciones brindadas por el proveedor.

Posteriormente, se tiende cada uno de los rollos mientras un operario identifica los defectos con stickers de diferentes colores, según el tipo de defecto. Si se observa una notable cantidad de stickers de un defecto mayor, el rollo es devuelto al proveedor. En esta etapa, también se selecciona un rollo del que se cortarán las cintas para elaborar la collareta. 
Paralelamente, se recepciona la entretela y los rollos de elástico. Estos materiales pasan por un control de calidad con un límite de control más amplio que el de la materia prima.

\section{$\underline{\text { Tendido, tizado y corte }}$}

Luego, los rollos de tela interlock son tendidos, colocando una capa de tela sobre otra, para que reposen y recuperen sus dimensiones iniciales, comúnmente el reposo se realiza durante la noche.

A la mañana siguiente, se traza el contorno de los moldes con tizas y se corta según las tallas y cantidades requeridas.

Paralelamente, se cortan los rollos previamente seleccionados con la máquina cortadora de cintas para elaborar la collareta.

En cuanto a la tela plana, se corta en tiras con la cortadora vertical, obteniendo al final una merma que es desechada del proceso.

Los rollos de elástico se cortan en tiras según la talla del pantalón a confeccionar.

\section{$\underline{\text { Verificar medidas y habilitar }}$}

Previo al habilitado, se coloca la entretela en el delantero y la espalda mediante una plancha para que se adhiera. Luego, cada una de las piezas, collareta, piernas, mangas, espalda, delantero y cinta de hombro, es habilitada; es decir, es marcada con un sticker según la talla y tipo de pieza. Así mismo, se realiza un control de calidad de las medidas de las piezas tales como doblar el delantero y la espalda por la mitad para verificar que las piezas son simétricas o superponer las mangas para asegurarse que ambas piezas son iguales.

\section{Confección - polo manga larga}

Para la confección de un polo manga larga, se tienen las siguientes piezas: delantero, espalda, cintas de cuello, mangas y las cintas de hombro. Primero, se realizan costuras previas como el recubierto de bastas de las mangas debido a que, al tratarse de una prenda de pequeñas dimensiones, esta operación sería más compleja si se realizara en una etapa posterior.

Una vez finalizada la etapa de operaciones previas, se procede a unir el delantero y la espalda mediante un remalle por el hombro derecho. Luego, se realiza la costura del 
cuello de la prenda y las etiquetas de talla con la máquina collaretera. Después, se realiza un atraque de la cinta de cuello para darle un mejor acabado y se fija el hombro abierto para tener mayor facilidad durante el pegado de mangas. Ambas operaciones se realizan con la máquina recta.

Las mangas con basta recubierta, se unen al delantero y la espalda mediante un remalle; luego, se cierran los costados de la prenda colocando la etiqueta de composición en el lado izquierdo. Ambas operaciones se realizan con la máquina remalladora.

La última operación de costura consiste en el recubierto de la basta faldón con la máquina recubridora. Seguidamente, se utiliza la máquina remachadora para pegar los snaps en el hombro izquierdo de la prenda.

\section{Confección - pantalón}

Para la confección de un pantalón, se tienen las siguientes piezas: pierna derecha e izquierda y las cintas de elástico. Primero, se realizan costuras previas, tales como el recubierto de bastas de cada pierna y el cerrado de las cintas de elástico con la máquina recta. Posteriormente, se marca el elástico por el centro para facilitar las operaciones de costura.

Las piernas con basta recubierta se remallan por el tiro y el fundillo, para luego ser remalladas por la entrepierna. Todas estas operaciones se realizan con la máquina remalladora. Para darle un mejor acabado, se realiza un atraque en las bastas, donde se oculta la costura sobrante del recubierto.

Luego, se procede a coser el elástico, donde se utiliza la máquina remalladora y se realiza el recubierto de cintura en la que se colocan las etiquetas de talla y composición.

\section{$\underline{\text { Acabados }}$}

Una vez terminado el proceso de confección, se procede a realizar la inspección de prendas terminadas y limpieza mediante el corte o retiro de hilos sobrantes. Las prendas que no aprueban la inspección, siendo el 5\% del total que ingresa, son clasificadas y aquellas que aprueban la inspección son enviadas de regreso al área de confección para su recuperación. Este reproceso no se detalla en el análisis debido a que es influenciado por varios factores como el tipo de defecto y los estándares de calidad de cada cliente. 
Las prendas aptas son planchadas utilizando una planchadora a vapor y se coloca el hang-tag con información variable de acuerdo a lo solicitado por el cliente.

\section{Empaquetado}

En el área de embolsado, los polos y pantalones se doblan y embolsan como conjunto utilizando bolsas transparentes y cinta masking tape. Para finalizar el proceso, se embalan y se cuentan las cajas embaladas. Se sabe que en cada caja de $60 \mathrm{~cm}$ x $40 \mathrm{~cm}$ x $40 \mathrm{~cm}$ se colocan 100 conjuntos de ropa para bebés y se estima una producción de 59 cajas al mes. 


\subsubsection{Diagrama de proceso: DOP}

Figura 5.7

Diagrama de Operaciones del Proceso

\section{DIAGRAMA DE OPERACIONES DEL PROCESO PARA LA ELABORACIÓN UNA CAJA DE 100 CONJUNTOS DE ROPA PARA BEBÉS DE ALGODÓN AL 100\% ORGÁNICO}

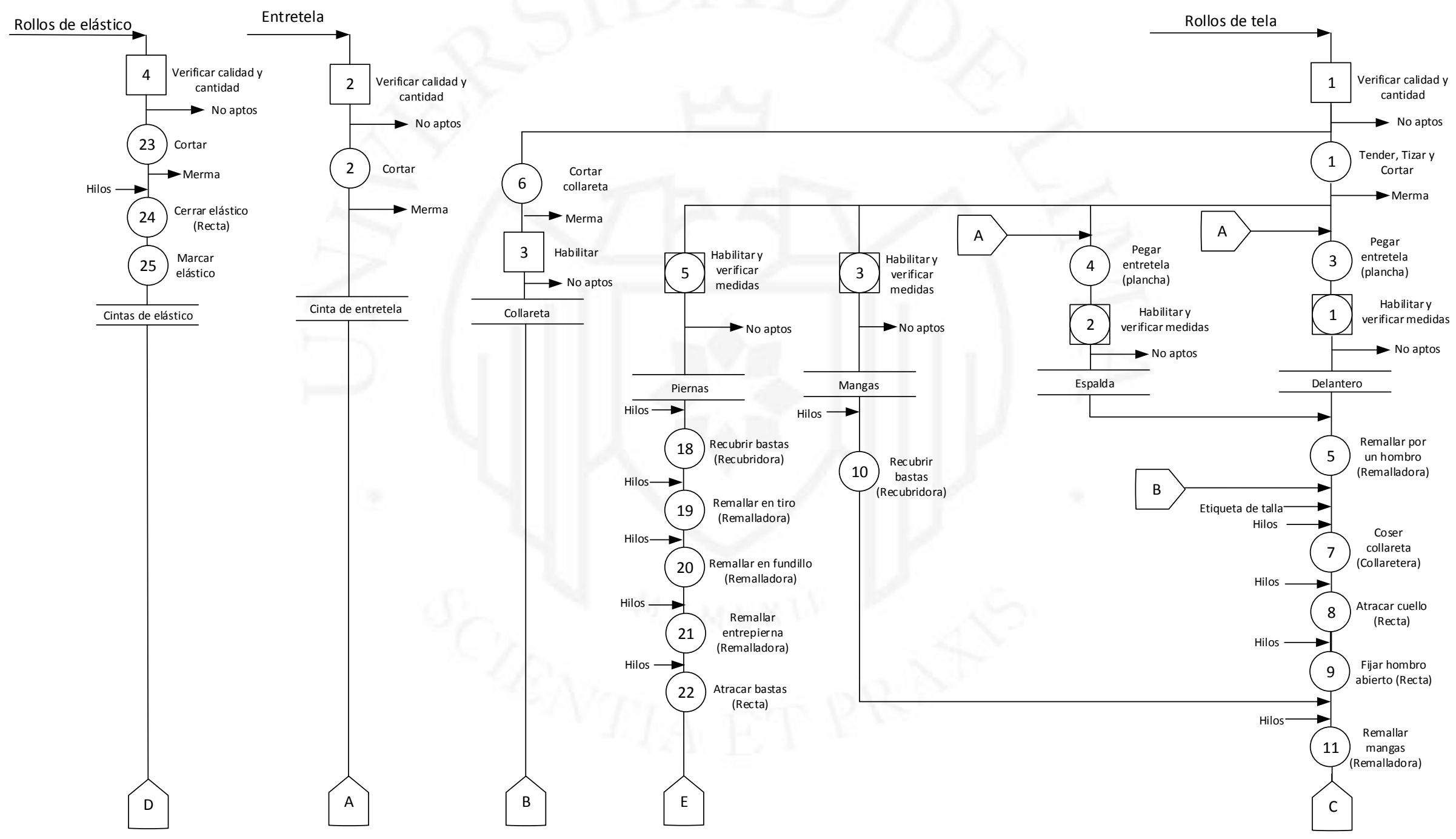



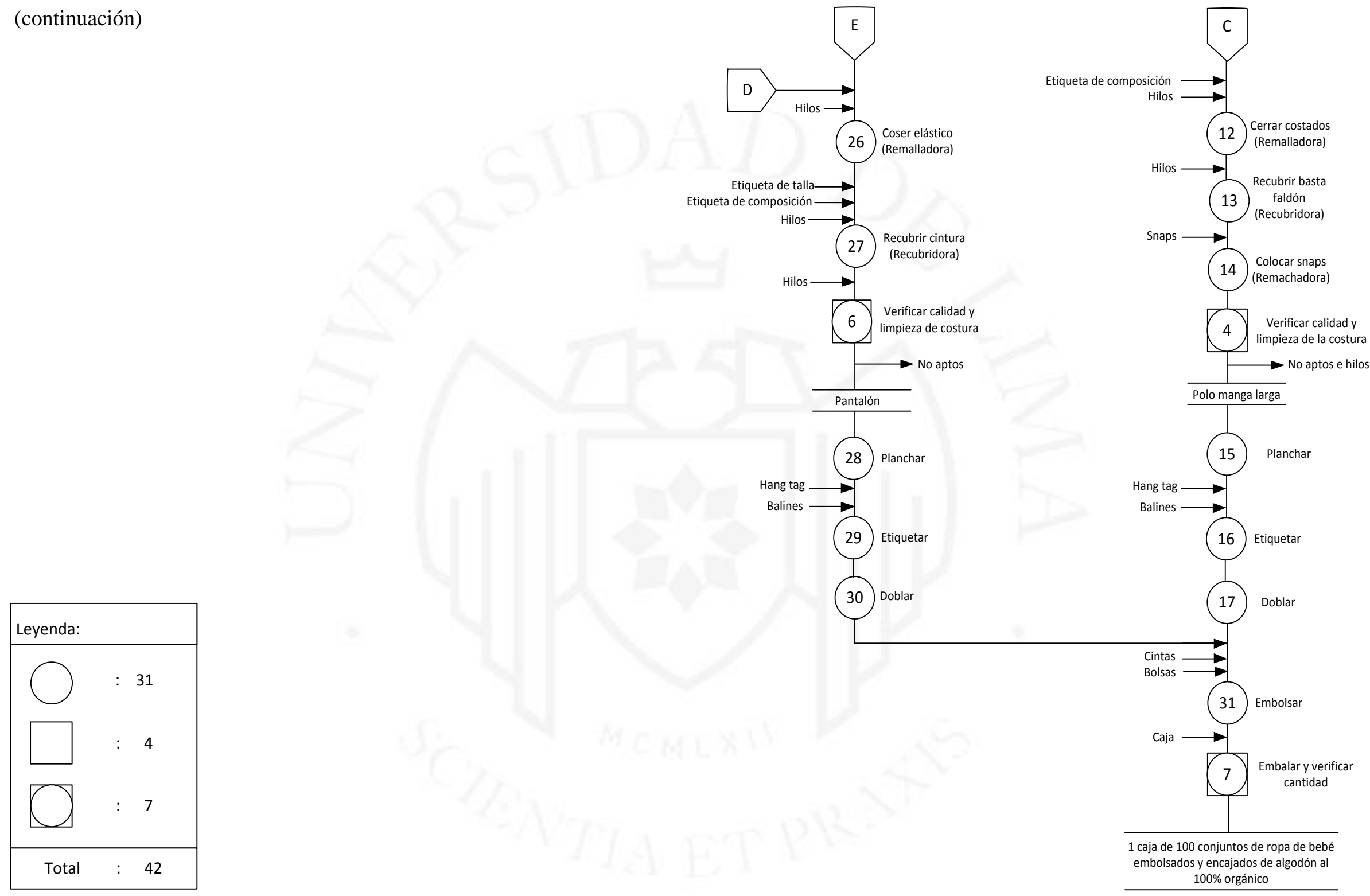

Elaboración propia 


\subsubsection{Balance de materiales}

Figura 5.8

Balance de materiales de calidad y corte

Unidad Base: 59 cajas de 100 conjuntos / mes

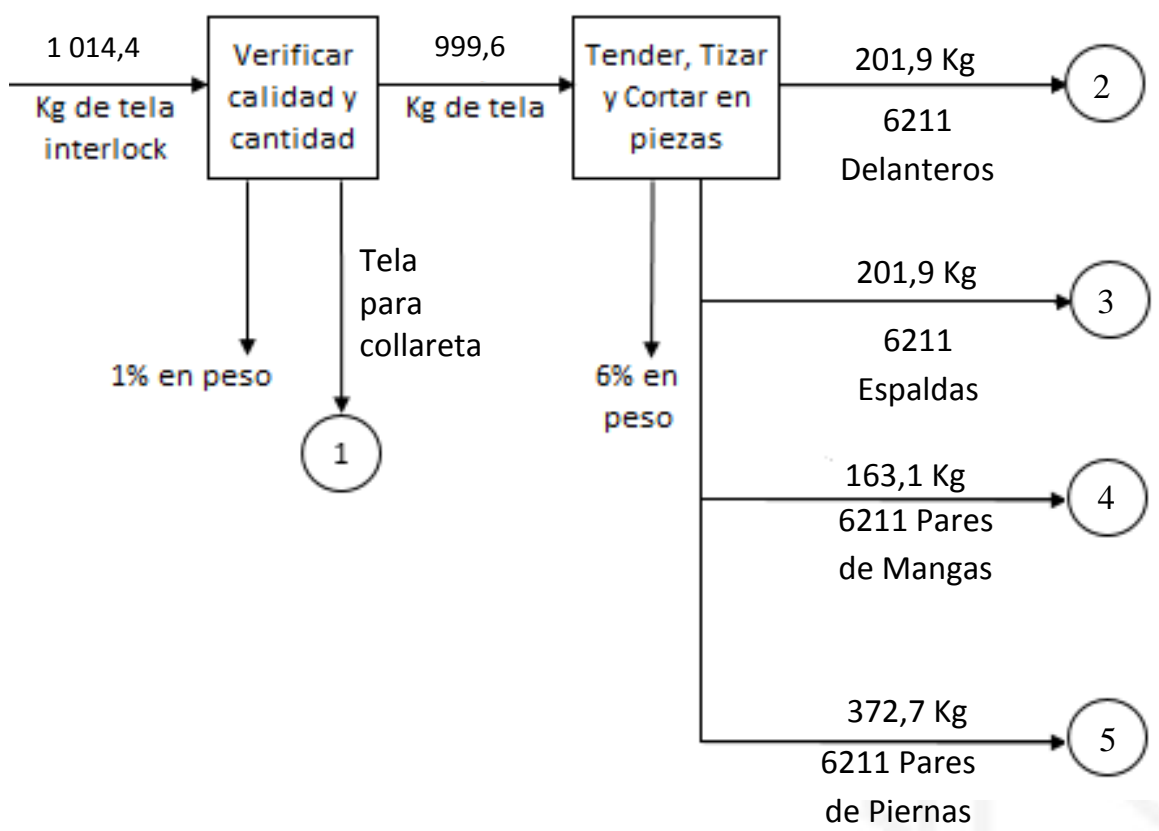

Elaboración propia 
Figura 5. 9

Balance de materiales para la elaboración de un polo

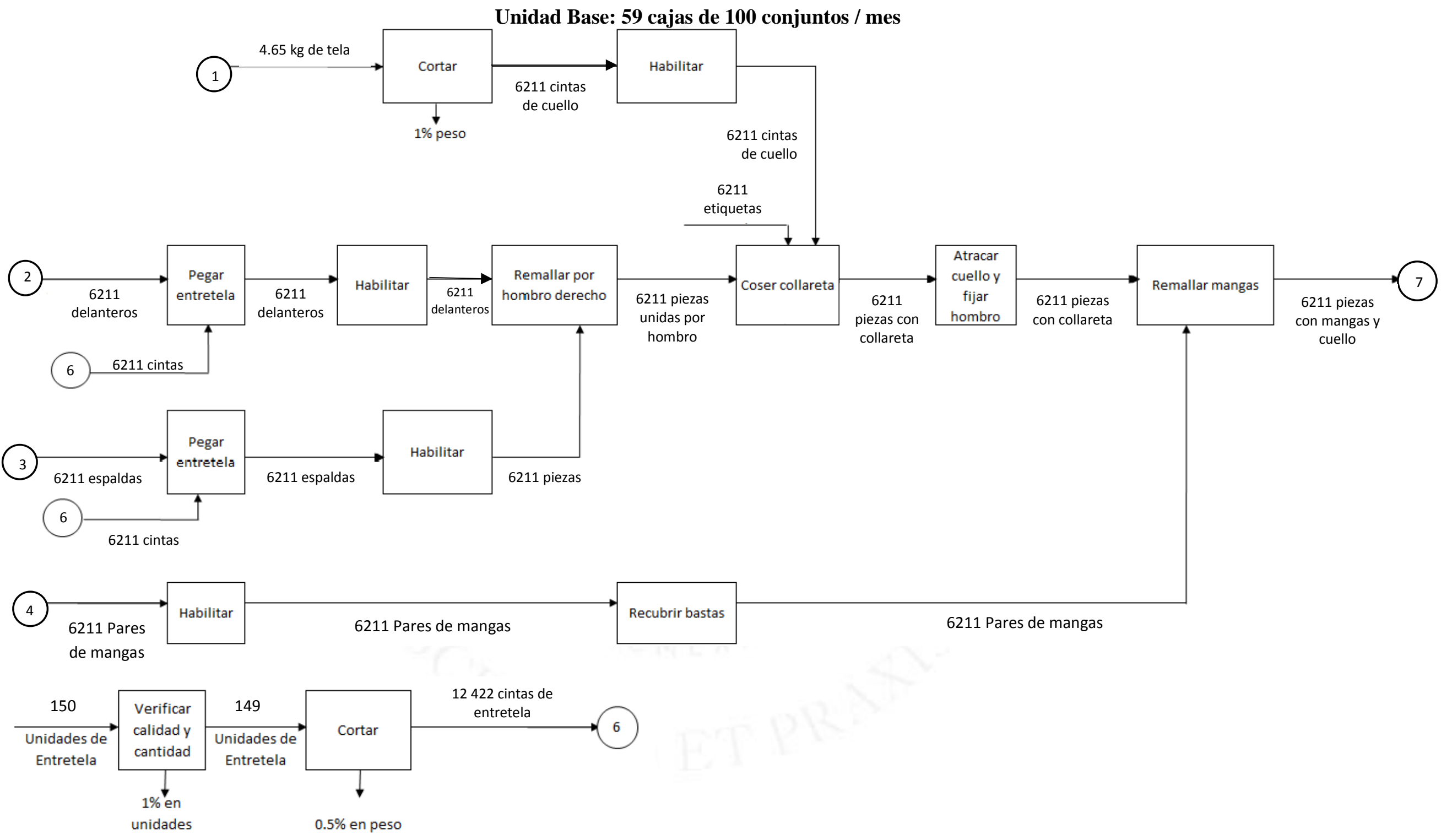




\section{(continuación)}

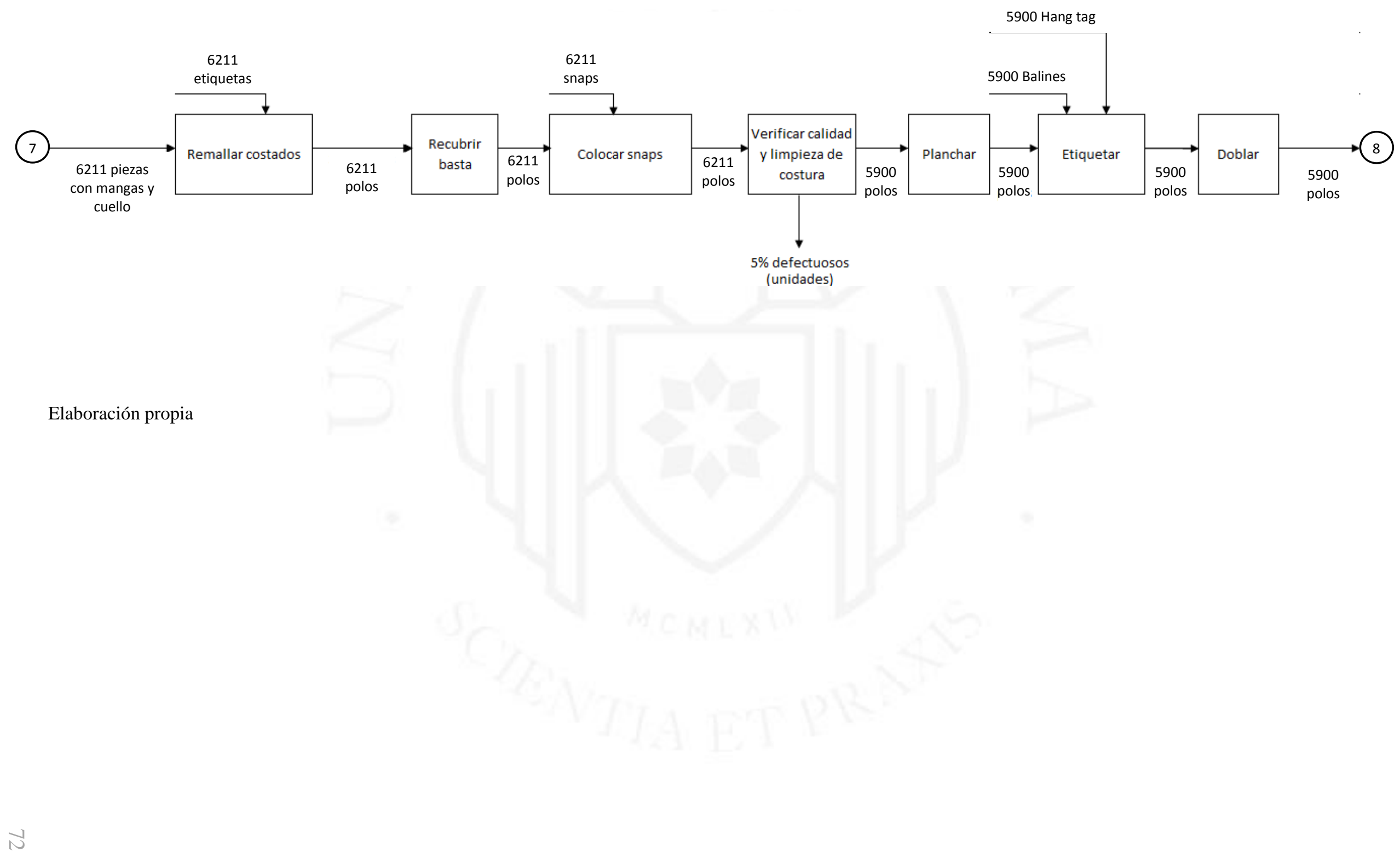


Figura 5. 10

Balance de materiales para la elaboración de un pantalón

Unidad Base: 59 cajas de 100 conjuntos / mes

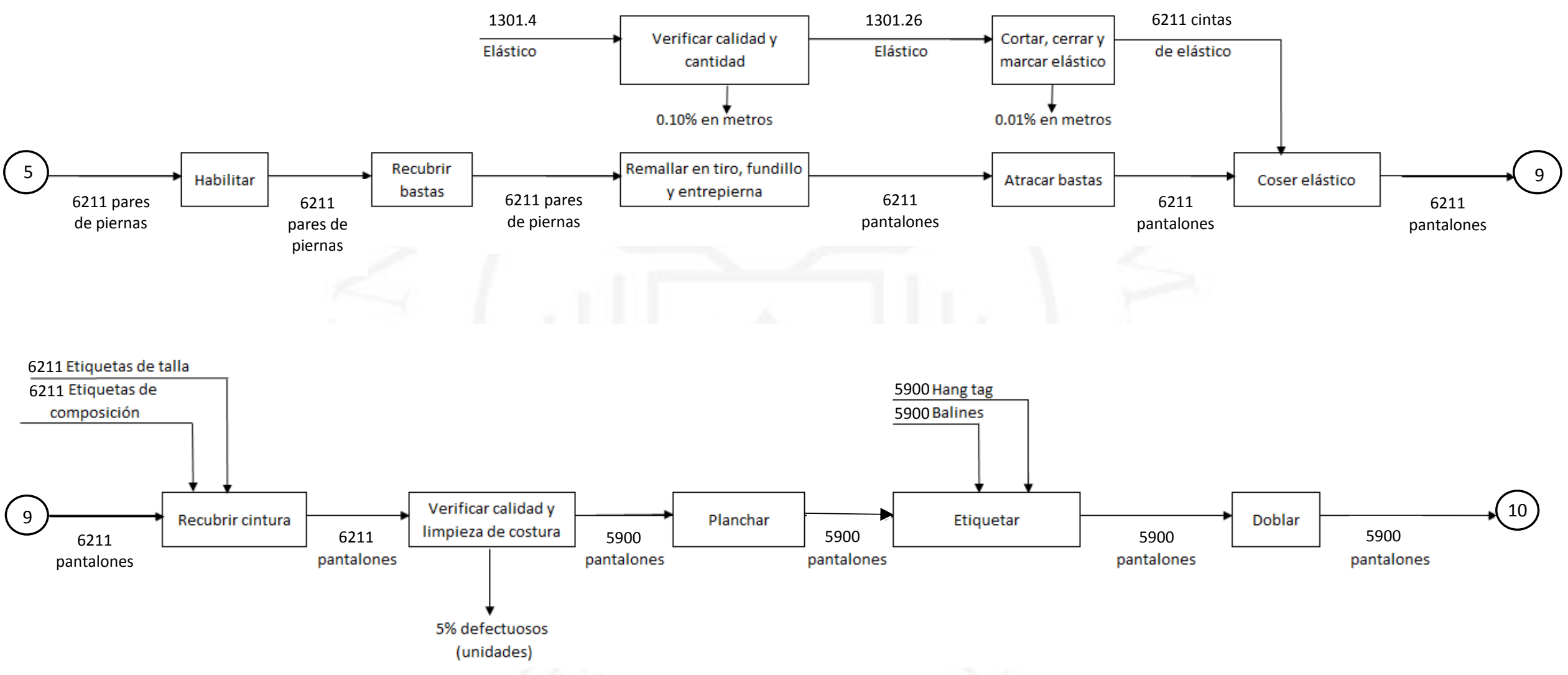

Elaboración propia 
Figura 5. 11

Balance de materiales para acabados

Unidad Base: 59 cajas de 100 conjuntos / mes

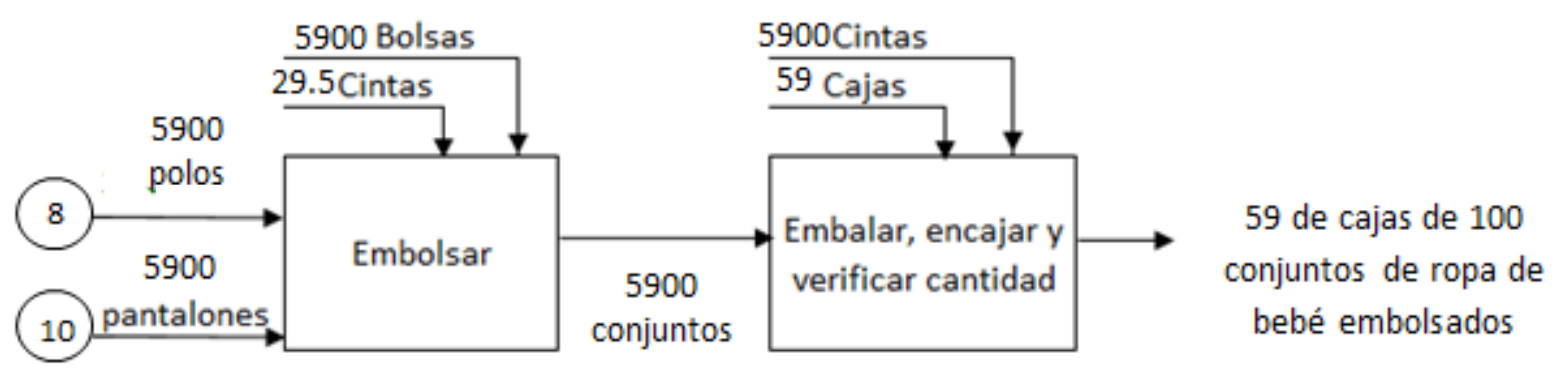

Elaboración propia 


\subsection{Características de las instalaciones y equipos.}

\subsubsection{Selección de la maquinaria y equipos.}

Las máquinas necesarias para el área de producción son:

- Máquina cortadora semi-automática

- Máquina de costura recta

- Máquina de costura overlock o remalladora

- Máquina recubridora.

- Máquina collaretera

- Máquina remachadora neumática

- Planchadora a vapor.

- Máquina cortadora de cintas

\subsubsection{Especificaciones de la maquinaria.}

Las especificaciones técnicas se detallarán en las siguientes tablas.

Tabla 5.5

Máquina cortadora

\begin{tabular}{|l|} 
Fabricante: Mack \\
Sección: Corte \\
Nombre: Cortadora de cuchilla vertical \\
Modelo: KS-AV \\
Tensión: $220 \mathrm{~V}$ \\
Intensidad de Corriente (A): 2,6 \\
Potencia: $0,37 \mathrm{KW}$ \\
Largo: $0,29 \mathrm{~m}$ \\
Ancho: $0,20 \mathrm{~m}$ \\
Altura: $0,45 \mathrm{~m}$
\end{tabular}

Fuente: Alibaba, (2016) 
Tabla 5. 6

Máquina recta

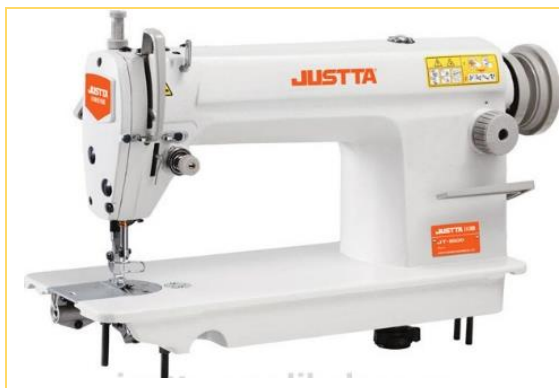

Fabricante: Justta

Sección: Costura

Nombre: Máquina de costura recta

Modelo: JT8500

Tensión: $220 \mathrm{~V}$

Potencia: 0,6 KW

Velocidad de costura máxima: 5.000 ppm

Largo: $1,2 \mathrm{~m}$

Ancho: 0,55 m

Altura: $0,68 \mathrm{~m}$

Fuente: Alibaba, (2016)

Tabla 5.7

Máquina remalladora

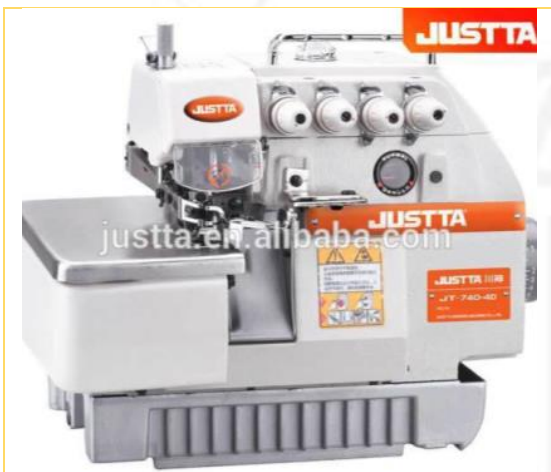

Fabricante: Justta

Sección: Costura

Nombre: Máquina de costura overlock

Modelo: JT747

Tensión: $220 \mathrm{~V}$

Potencia: $0.50 \mathrm{KW}$

Velocidad de costura máxima: 6.000 ppm

Largo: 1,2 m

Ancho: $0,55 \mathrm{~m}$

Altura: $0,70 \mathrm{~m}$

Fuente: Alibaba, (2016)

Tabla 5.8

Máquina collaretera

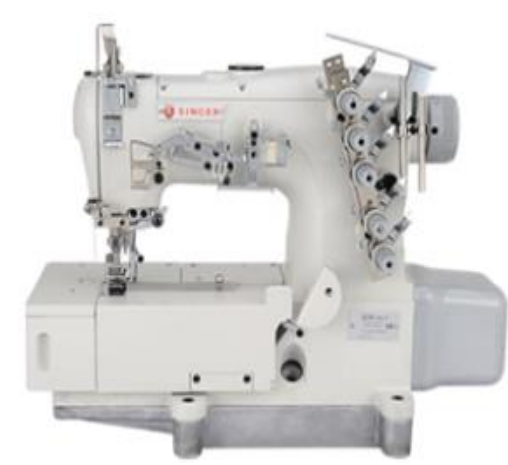

Fabricante: Singer

Sección: Costura

Nombre: Máquina collaretera

Modelo: 522D-364-03

Tensión: $220 \mathrm{~V}$

Potencia: $0.50 \mathrm{KW}$

Velocidad de costura máxima: 6.000 ppm

Largo: $0.61 \mathrm{~m}$

Ancho: 0,41 m

Altura: $0,63 \mathrm{~m}$

Fuente: Maquina Singer Perú, (2018) 
Tabla 5. 9

Máquina de recubrir

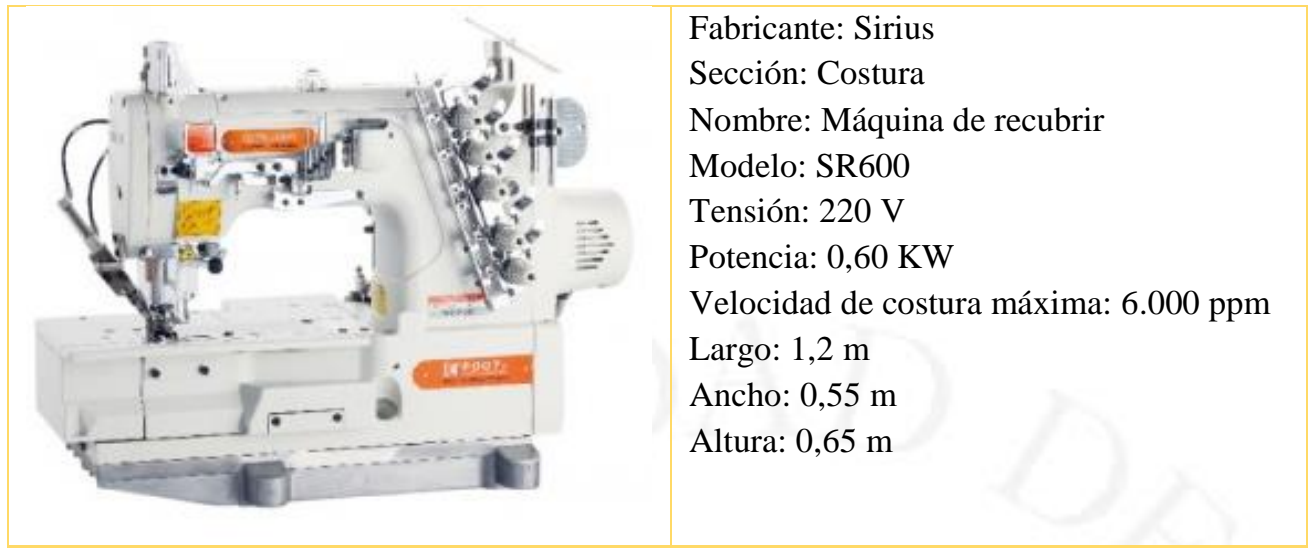

Fuente: Maquitex, (2017)

Tabla 5. 10

Remachadora neumática

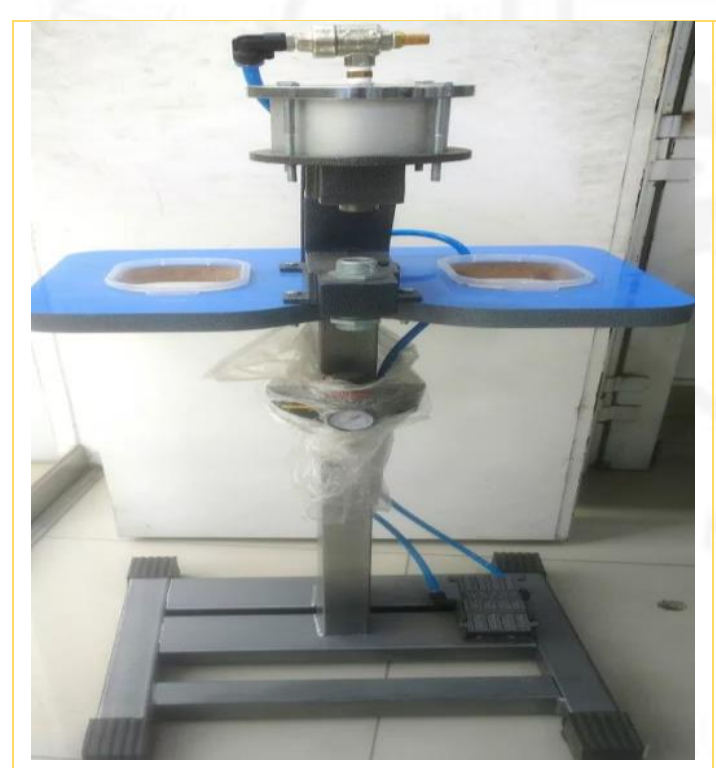

Fabricante: Empresa BACSF E.I.R.L.

Sección: Acabados

Nombre: Remachadora neumática

Modelo: Estándar

Presión: 120 libras

Largo: 0,40 m

Ancho: 0,30 m

Altura: 0,80-Regulable

Fuente: Alibaba, (2016) 
Tabla 5. 11

Planchadora a vapor

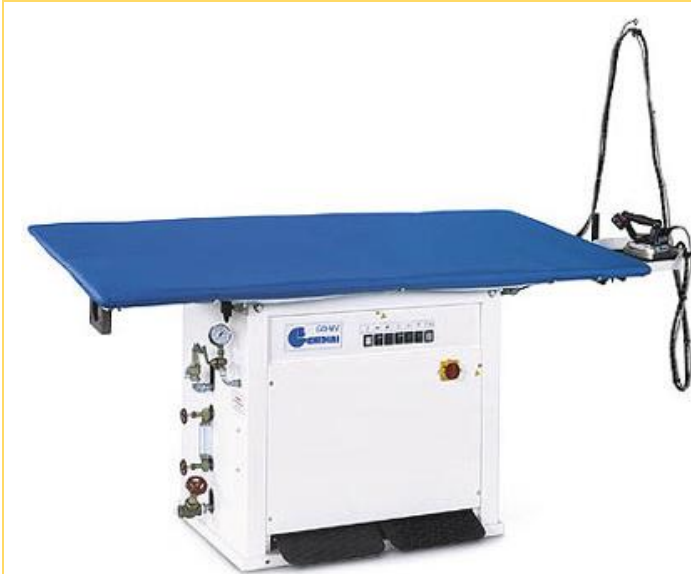

Fabricante: Monti Antonio s.p.a.

Sección: Planchado

Nombre: Planchadora a vapor

Modelo: 100

Tensión: $220 \mathrm{~V}$

Potencia: 1,60 KW

Producción de vapor: $26 \mathrm{~kg} / \mathrm{h}$

Consumo eléctrico promedio: $3,5 \mathrm{KW} / \mathrm{h}$

Largo: $1,50 \mathrm{~m}$

Ancho: $0,80 \mathrm{~m}$

Altura: 1,04 m

Fuente: Monti, (2016)

Tabla 5. 12

Máquina cortadora de cintas

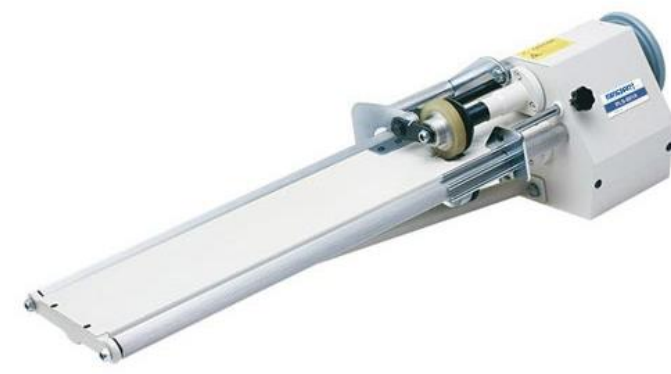

Fabricante: Mingjian

Sección: Acabados

Nombre: Máquina cortadora de cintas

Modelo: MJ-801A

Tensión: $220 \mathrm{~V}$

Potencia: 1400 R.p.m.

Consumo eléctrico promedio: $250 \mathrm{~W}$

Largo: 0,82 m

Ancho: $0,35 \mathrm{~m}$

Altura: $0,65 \mathrm{~m}$

Fuente: Alibaba, (2016)

Tabla 5. 13

Pistola para etiquetas

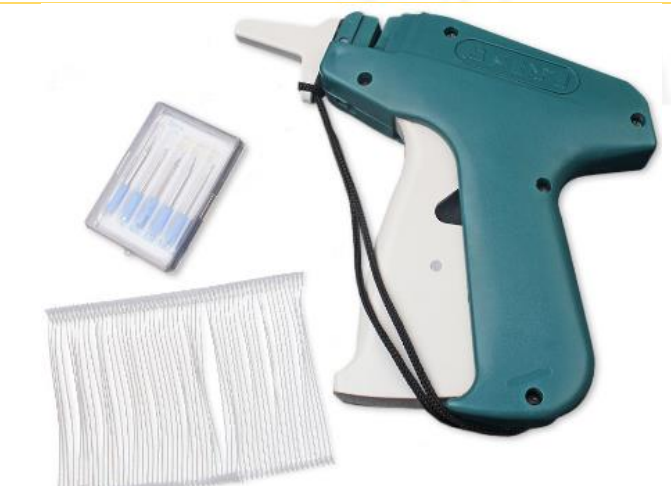

Fabricante: Siyipai

Sección: Acabados

Nombre: Pistola para etiquetas

Modelo: GT-HT20161213

Largo: 0,15 m

Ancho: $0,08 \mathrm{~m}$

Altura: 0,20 m

Fuente: Aliexpress, (2017) 


\subsection{Capacidad instalada.}

\subsubsection{Cálculo de la capacidad instalada}

Nuestra capacidad instalada está determinada por un turno de 8 horas al día, 6 días a la semana y 52 semanas al año; a continuación, presentamos la fórmula para determinar la capacidad de la planta:

Capacidad Instalada (unid /año) = PH(unid/hr) x NH (\# máq x hr/año-máq x u) x CE

PH= Producción horaria de la máquina

$\mathrm{NH}=$ Número de horas productivas

$\mathrm{CE}=$ Coeficiente de eficiencia de la máquina

- Factor de utilización:

$\mathrm{U}=\mathrm{NHP} / \mathrm{NHR}=7.5 \mathrm{hrs} / 8 \mathrm{hrs}=93,75 \%$

NHR: Hora reales de jornada, para nuestro caso es de 8 horas.

NHP: Número de horas productivas. Es el número de horas reales menos el tiempo de limpieza, 15 min y mantenimiento, 15 minutos.

- Factor de eficiencia:

$\mathrm{E}=80 \%$

Nos muestra la desviación que existe entre las horas estándar y las horas productivas para un mismo producto, en el sector textil consideramos un promedio de 80\% (Cabrejos \& Mejía, 2013). 
Tabla 5. 14

Capacidad Instalada

\begin{tabular}{|c|c|c|c|c|c|c|c|c|c|}
\hline Operación & $\begin{array}{c}\text { P } \\
(\text { Conj/HH) }\end{array}$ & $\mathbf{H}$ & S/A & $\mathrm{D} / \mathrm{S}$ & T/D & H/T & $\mathbf{U}$ & $\mathbf{E}$ & $\begin{array}{c}\text { CO } \\
(\text { conj/año) }\end{array}$ \\
\hline $\begin{array}{l}\text { Tender y verificar } \\
\text { calidad y cantidad }\end{array}$ & 55 & 1 & 52 & 6 & 1 & 8 & $94 \%$ & $80 \%$ & 103,425 \\
\hline Tizar tela & 80 & 1 & 52 & 6 & 1 & 8 & $100 \%$ & $80 \%$ & 159,744 \\
\hline Cortar tela & 70 & 1 & 52 & 6 & 1 & 8 & $94 \%$ & $80 \%$ & 131,215 \\
\hline $\begin{array}{l}\text { Habilitar, cortar y pegar } \\
\text { entretela }\end{array}$ & 55 & 1 & 52 & 6 & 1 & 8 & $100 \%$ & $80 \%$ & 108,916 \\
\hline $\begin{array}{l}\text { Cortar collareta y } \\
\text { elástico }\end{array}$ & 95 & 1 & 52 & 6 & 1 & 8 & $94 \%$ & $80 \%$ & 178,286 \\
\hline Coser con recta & 48 & 1 & 52 & 6 & 1 & 8 & $94 \%$ & $80 \%$ & 89,856 \\
\hline Coser con remalladora & 12 & 4 & 52 & 6 & 1 & 8 & $94 \%$ & $80 \%$ & 92,635 \\
\hline Coser con recubridora & 15 & 4 & 52 & 6 & 1 & 8 & $94 \%$ & $80 \%$ & 115,200 \\
\hline Coser con collaretera & 86 & 1 & 52 & 6 & 1 & 8 & $94 \%$ & $80 \%$ & 160,457 \\
\hline Colocar snaps & 200 & 1 & 52 & 6 & 1 & 8 & $94 \%$ & $80 \%$ & 374,400 \\
\hline $\begin{array}{l}\text { Verificar calidad de } \\
\text { costura y } \\
\text { limpiar hilos }\end{array}$ & 47 & 2 & 52 & 6 & 1 & 8 & $100 \%$ & $80 \%$ & 187,200 \\
\hline Planchar & 67 & 1 & 52 & 6 & 1 & 8 & $100 \%$ & $80 \%$ & 133,120 \\
\hline $\begin{array}{l}\text { Colocar Hang Tag, } \\
\text { doblar, } \\
\text { embolsar y embalar }\end{array}$ & 57 & 1 & 52 & 6 & 1 & 8 & $100 \%$ & $80 \%$ & 114,536 \\
\hline
\end{tabular}

La capacidad de la planta es de 89856 conjuntos anuales, definido por la operación coser con recta.

\subsubsection{Cálculo detallado del número de máquinas requeridas}

Para determinar el número de máquinas se considerarán lo siguientes datos de operación:

Tabla 5. 15

Datos de operación

\begin{tabular}{|l|r|}
\hline Horas/Turno & $\mathbf{8}$ \\
\hline Turno/Días & 1 \\
\hline Días/Semana & 6 \\
\hline Semanas/Año & 52 \\
\hline Horas/Año & 1572 \\
\hline Utilización & $79 \%$ \\
\hline Eficiencia & $80 \%$ \\
\hline
\end{tabular}

Elaboración propia

La utilización se obtuvo de la división de la producción anual entre la capacidad instalada. 
Tabla 5. 16

Cálculo de utilización

\begin{tabular}{|l|r|}
\hline Ítem & Conjuntos \\
\hline Producción anual & 70766 \\
\hline Capacidad instalada & 89856 \\
\hline Utilización & $79 \%$ \\
\hline
\end{tabular}

Elaboración propia

Para obtener la cantidad de máquinas por operación se realizó una división entre la capacidad requerida (Demanda anual/ (1- defectuoso) x Tiempo Estándar) y la capacidad disponible (Número de horas productivas x U x E).

Tabla 5. 17

Cálculo del número de máquinas al 2022

\begin{tabular}{|c|c|c|c|c|c|c|c|}
\hline \multirow{2}{*}{ Máquinas } & \multicolumn{9}{|c}{ Cap. Requerida } & $\begin{array}{c}\text { Cap. } \\
\text { No }\end{array}$ \\
Dolos/Años & Hrs/Polo & Pantalón/Año & Hrs/Pantalón & Disponible & Máquinas \\
\hline Cortadora & 79567 & 0.008 & 79567 & 0.007 & 1571 & 1 \\
\hline Cortadora de cintas & 74491 & 0.001 & - & 0.000 & 1571 & 1 \\
\hline Recta & 74491 & 0.010 & 74491 & 0.011 & 1571 & 1 \\
\hline Remalladora & 74491 & 0.040 & 74491 & 0.041 & 1571 & 4 \\
\hline Recubridora & 74491 & 0.032 & 74491 & 0.033 & 1571 & 4 \\
\hline Collaretera & 74491 & 0.012 & - & 0.000 & 1571 & 1 \\
\hline Remachadora & 74491 & 0.005 & - & 0.000 & 1571 & 1 \\
\hline Planchadora & 70766 & 0.008 & 70766 & 0.008 & 1571 & 1 \\
\hline
\end{tabular}

Elaboración propia

El número de máquinas necesarias para dar soporte a la producción es de 14 en total.

\subsection{Resguardo de la calidad y/o inocuidad del producto.}

\subsubsection{Calidad de la materia prima, de los insumos, del proceso y del producto.}

- Calidad de la materia prima:

Durante la recepción de los lotes de tela se tomará una muestra por lote para determinar si está cumple las especificaciones de calidad que el producto demanda.

A continuación, se describirán las pruebas físicas: 


\section{Prueba de Densidad:}

Según la norma técnica peruana NTP 231.002 "TELAS. Método de determinación del peso de piezas, rollos o cortes", de acuerdo al número de rollos que componen al lote, la cantidad mínima de especímenes a extraer al azar, para efectuar la determinación del peso es la que se detalla en la tabla 5.18.

Tabla 5. 18

Prueba de densidad

\begin{tabular}{|c|c|}
\hline $\begin{array}{l}\text { Número de piezas, } \\
\text { rollos o cortes del lote }\end{array}$ & $\begin{array}{l}\text { Número mínimo de } \\
\text { especímenes a extraer }\end{array}$ \\
\hline 1 & 1 \\
\hline 2 a 10 & 2 \\
\hline 11 a 30 & 3 \\
\hline 31 a 65 & 4 \\
\hline 66 a 125 & 5 \\
\hline 126 a 200 & 6 \\
\hline Más de 200 & $\begin{array}{l}\text { 3\% hasta un máximo de } 10 \\
\text { especímenes }\end{array}$ \\
\hline
\end{tabular}

El aparato necesario para realizar los ensayos es una balanza que asegure una exactitud de $\pm 0,25 \%$ del peso del espécimen.

Procedimiento:

Se mide la longitud y el ancho de los especímenes extraídos según los procedimientos descritos en la NTP 231.017 "TELAS. Método manual para determinar la longitud” y NTP 231.001 "TELAS. Métodos para determinar el ancho"

Se pesan los especímenes.

El peso por metro lineal de la tela se calcula promediando los pesos por metro lineal de los especímenes.

El peso por metro cuadrado de cada espécimen se calcula mediante la ecuación siguiente:

$$
\mathrm{Gm}=\frac{\mathrm{G}}{1 \times \mathrm{a}}
$$


Donde:

$\mathrm{Gm}=$ el peso por metro cuadrado, expresado en gramos .

$\mathrm{G}=$ el peso del espécimen, expresado en gramos.

1 = la longitud del espécimen, expresados en metros.

$\mathrm{a}=$ el ancho del espécimen, expresado en metros.

El peso por metro cuadrado de la tela se calcula promediando los pesos por metro cuadrado de los especímenes.

\section{$\underline{\text { Prueba al Encogimiento }}$}

La Norma Técnica Peruana "NTP 231.138:1985. TELAS. Determinación de la estabilidad dimensional (encogimiento o alargamiento)", establece lo siguiente:

La prueba de ensayo debe tener preferentemente el ancho de la tela y por lo menos $60 \mathrm{~cm}$. de largo.

Esta se coloca sin tensión sobre una superficie plana suave, se eliminan sus quiebres y arrugas y se hacen tres marcas equidistantes paralelas a la trama y tres paralelas a la urdimbre.

Las marcas paralelas a la urdimbre deben tener por lo menos $50 \mathrm{~cm}$. de longitud y estar separadas por lo menos $5 \mathrm{~cm}$. de cualquier orilla de la muestra. Si el ancho de la tela lo permite deben estar separadas entre sí por lo menos $15 \mathrm{~cm}$.

Las marcas paralelas a la trama deben ser tan largas como el ancho de la tela lo permita y estar separadas por lo menos $5 \mathrm{~cm}$. de cualquier orilla de la muestra. Deben estar separadas entre sí por lo menos $15 \mathrm{~cm}$.

Las marcas deben hacerse con tinta insoluble y una pluma de punta fina o cualquier otro método adecuado.

Con respecto al lavado y enjuague, se colocan las muestras individualmente en la lavadora, hasta pesar entre $5 \mathrm{~kg}$ y $8 \mathrm{~kg}$ al aire de tela seca por metro cúbico del volumen del tambor, este peso se puede completar con otras muestras u otras telas similares. Posteriormente, se añade el bicarbonato de sodio y el jabón en las medidas indicadas en la norma técnica y se procede al lavado durante 40 minutos. Luego, se escurre el agua y se procede a volverlo a llenar, realizando el segundo lavado durante 55 minutos. Finalmente, se extraen las muestras y se colocan en el secador para remover el exceso de agua. 
Figura 5. 12

Prueba de Encogimiento

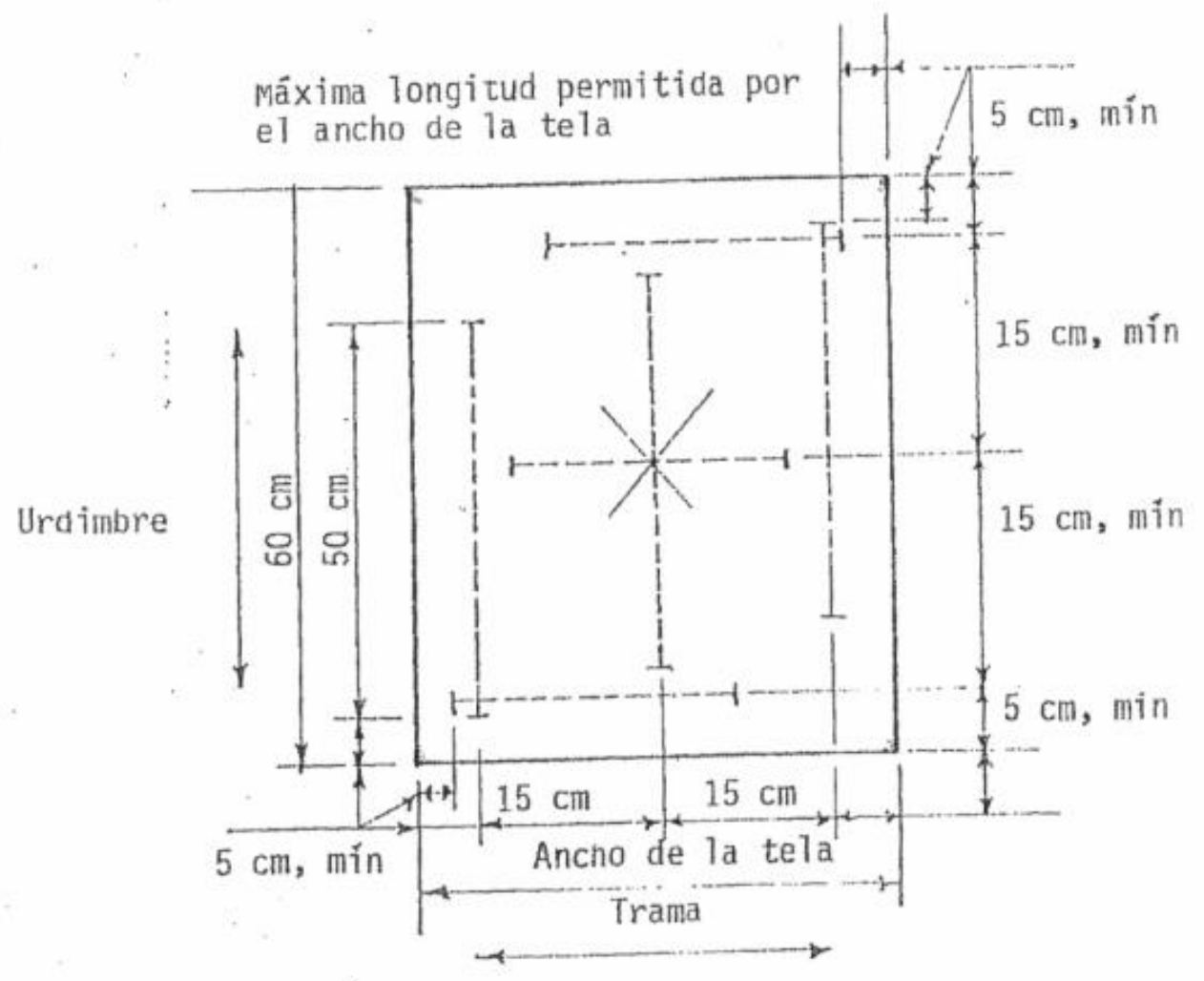

Fuente: Instituto Nacional de Defensa de la Competencia y de la Protección de la Propiedad Intelectual, Indecopi. (2018)

El cambio dimensional se calcula tanto para la urdimbre como para la trama a través de la siguiente fórmula:

$$
C d=\frac{L-L_{1}}{L} \times 100 \%
$$

Donde:

$\mathrm{Cd}=$ Cambio dimensional

$\mathrm{L}=$ Longitud del trazo inicial previo lavado y secado de la urdimbre o trama $(\mathrm{mm})$.

$\mathrm{L}_{1}=$ Longitud del trazo final después del lavado y secado de la urdimbre o trama $(\mathrm{mm})$.

$\underline{\text { Prueba de solidez del color }}$

La Norma técnica peruana NTP 231.006 TEXTILES. "Método de ensayo de la solidez del color al agua", indica que la pieza textil a ensayar se debe sumergir en 
agua en contacto con los tejidos testigos blancos; luego, se escurre y se coloca en un perspirómetro (u otro aparato similar) o entre dos vidrios. El espécimen y los tejidos testigos se secan por separado. El cambio de color del espécimen y la transferencia de color sobre los tejidos testigos se evalúan de acuerdo a las respectivas escalas grises.

Figura 5. 13

Escala de grises AATCC

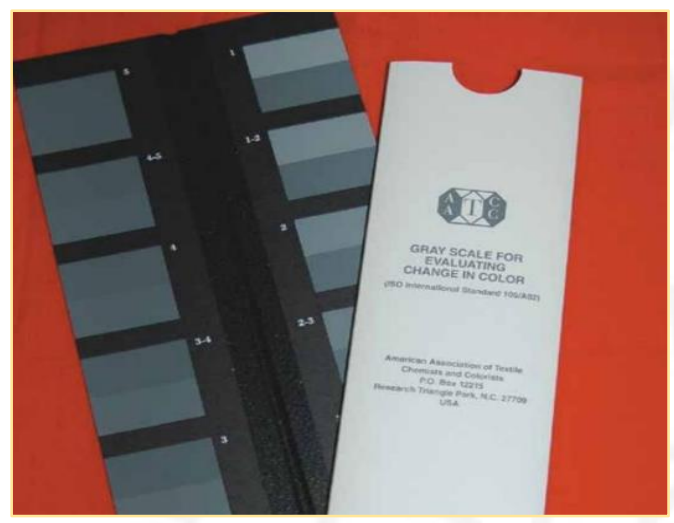

Fuente: Association of Textile, (2017)

- Calidad de los insumos:

En los hilos de costura:

El tipo de hilo a utilizar será de poliéster de título 40/2, y se deberá elegir el color que coincida con el color de la tela que se va a coser.

En las agujas:

La elección correcta del grosor y tipo de punta de la aguja es muy importante para el buen rendimiento durante la costura. (Martínez, 2012)

Los códigos de aguja utilizados para este tipo de prendas son: DBX1, DPX5, DPX7, DCX27, DMX13, DBX63, B63 y V63.

En cuanto al tipo de punta, se recomienda el uso del tipo SUK, punta de bola mediana, y tipo R, punta redonda normal. El primero es ideal para costuras en tejidos de punto de peso medio, mientras que el segundo es considerado para los tejidos más comunes. (Coats Industrial, 2018) 
Figura 5. 14

Tipo de punta de agujas

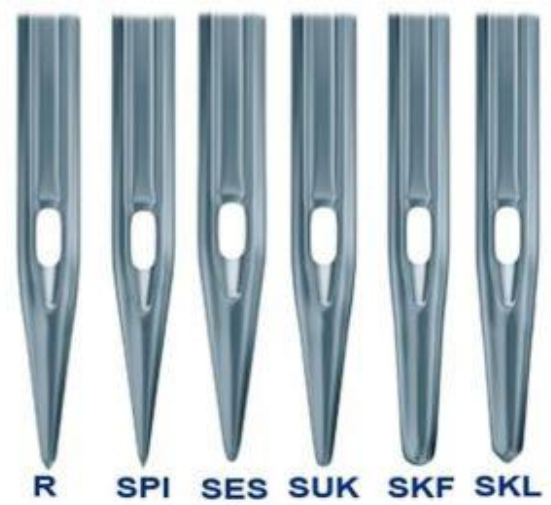

Fuente: Coats industrial, (2018)

Tabla 5. 19

Códigos de agujas más utilizadas

\begin{tabular}{|c|c|c|c|c|c|c|c|}
\hline MÁQUINA & $\begin{array}{l}\text { NOMBRE DE } \\
\text { PUNTADA }\end{array}$ & CLASE & TIPO/SERIE & HILO & AGUJA & COD. AGUJA & USOS \\
\hline \multirow{2}{*}{ RECTA } & \multirow{2}{*}{ LOCKSTITCH } & \multirow{2}{*}{300} & \multirow{2}{*}{301} & \multirow{2}{*}{2} & \multirow{2}{*}{1} & DBX1 & Cerrar costuras, realizar pespuntes, \\
\hline & & & & & & DPX5, DPX7 (CG) & varios, etc. \\
\hline OJALADORA & & 300 & 304 & 2 & 1 & DPX5, DPX7 (CG) & Ojales de camisas, pantalones, blusas \\
\hline ATRACADORA & & 300 & $306 / 301-304$ & 2 & 1 & DPX5, DPX7 (CG) & Atraques de seguridad: Pasadores 0 \\
\hline BOTONERA & EVERLOCK & 700 & 701 & 1 & 1 & TQX1, TQX7 & Pegar botones de 2 ó 4 orificios \\
\hline REMALLADORA & OVERLOCK & 500 & 504 & 3 & 1 & DCX27, DMX13 & Unir piezas, cerrar costuras \\
\hline REMALLADORA & OVERLOCK & 500 & 505 & 3 & 1 & DCX27, DMX13 & Orillar cantos \\
\hline REMALLADORA & $\begin{array}{l}\text { POINT DE } \\
\text { SURETE }\end{array}$ & 500 & $\begin{array}{c}516 \\
402-504\end{array}$ & 5 & 2 & $\mathrm{DCX} 27, \mathrm{DMX} 13$ & Remalle con puntada de seguridad \\
\hline RECUBRIDORA & INTERLOCK & 400 & 406 & 3 & 2 & DBX63, B63, V63 & Bastas, costuras centradas \\
\hline RECUBRIDORA & INTERLOCK & 400 & 407 & 4 & 3 & DBX63, B63, V63 & Bastas, costuras triples \\
\hline RECUBRIDORA & FLATLOCK & 600 & 605 & 4 & 2 & DBX63, B63, V63 & Costuras ornamentales \\
\hline RECUBRIDORA & FLATLOCK & 600 & 607 & 5 & 3 & DBX63, B63, V63 & Costuras ornamentales \\
\hline RECUBRIDORA & INTERLOCK & 400 & 402 & 2 & 1 & DBX63, B63, V63 & Ribetear bordes (Bsb 2x 402) \\
\hline
\end{tabular}

Fuente: Universidad Nacional Mayor de San Marcos, UNMSM. (2014)

- Calidad del proceso

El aseguramiento de la calidad se dará a través de inspecciones al 100\% para las estaciones de corte y costura.

El objetivo de las inspecciones es reducir la cantidad de productos defectuosos en el tiempo, por ello se plantea que uno de los operarios con mayor experiencia se dedique a determinar si un producto en proceso es aceptable o no para continuar con las demás estaciones, tendrá en cuenta las siguientes especificaciones: 
dimensiones de corte, marcas con elementos inapropiados, tensión de puntada, secuencia de puntada, elasticidad, distorsión de costura y verificar que las dimensiones de la talla se encuentra dentro de los parámetros establecidos en los cuadros de especificaciones 5.4 y 5.5. (Fernández, 2013)

- Calidad del producto

Para mantener la calidad del producto se realizará un plan de muestreo a través del cual se determinará que la prenda final cumpla con las especificaciones técnicas del producto (Anexo 1).

Se establecerán parámetros de control, para ello, se tendrá en cuenta el nivel de calidad aceptable (NCA) con el que trabajará la empresa.

A continuación, se presentarán los pasos para realizar la auditoría:

- Escoger el nivel de inspección.

- Determinar el tamaño del lote.

- Encontrar la letra de código para el tamaño de la muestra, dependiendo de la tabla MIL STD 105E y de acuerdo con el tamaño del lote.

- Decisión en cuanto a aceptar o rechazar el lote (Ruiz-Falcó, 2006).

Tabla 5. 20

Tabla maestra para la inspección normal - muestreo único (MIL STD 105E, tabla III-A)

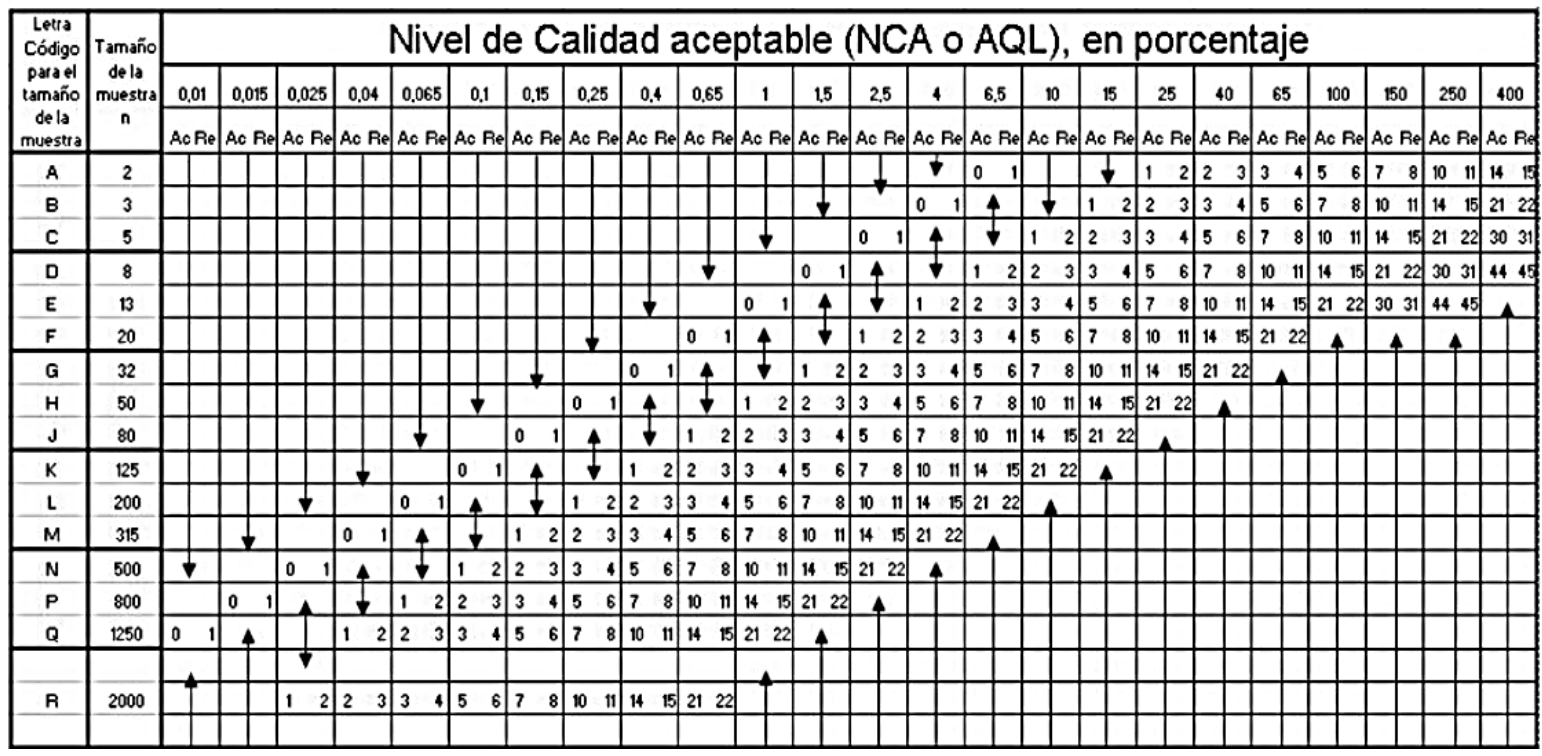

Fuente: Universidad de La Laguna, (2018) 


\subsubsection{Estrategias de mejora}

Al ser una empresa exportadora, se plantea como estrategia de mejora la certificación ISO debido a que brindaría mayor prestigio a nivel internacional. De esta manera, la implementación de la ISO 9001 otorgará los requisitos para obtener un sistema de gestión de calidad en la empresa. (Organización Internacional para la Estandarización, 2015)

Los beneficios de la ISO 9001.2015 son:

- Enfatizar la necesidad de contar con un proceso de planeación estratégica, que permita a la empresa anticipar las acciones de los competidores.

- Efectuar un seguimiento de procesos en lugar de funciones y actividades aisladas.

- Identificar los riesgos del negocio para evaluar sus niveles de impacto.

- Buscar el bienestar equilibrado de las organizaciones a través del conjunto de normas ISO.

- Generar un valor agregado que los distingue en el mercado. (Grupo Albe Consultoría, 2016)

\subsection{Estudio de impacto ambiental.}

Para nuestra empresa será importante contar con un estudio de impacto ambiental para tener en cuenta los posibles daños que se podría causar a nuestro entorno, en base a los aspectos e impactos ambientales; con la finalidad de reducir el posible deterioro del medio ambiente y poder considerar medidas preventivas o correctivas. 
Tabla 5. 21

Análisis de impacto ambiental

\begin{tabular}{|c|c|c|c|c|}
\hline ENTRA & PROCESO & SALE & ASPECTO & IMPACTO \\
\hline Rollos de tela & Corte & Piezas de ropa & $\begin{array}{c}\text { Cosechos no orgánicos } \\
\text { (retazos de tela, } \\
\text { polvillos de algodón) }\end{array}$ & $\begin{array}{c}\text { Coninación } \\
\text { de suelos } \\
\text { Contaminación } \\
\text { de aire }\end{array}$ \\
\hline Piezas de tela & Habilitado & $\begin{array}{c}\text { Piezas de tela } \\
\text { verificadas }\end{array}$ & $\begin{array}{c}\text { Desechos no orgánicos } \\
\text { (piezas de tela } \\
\text { defectuosas) }\end{array}$ & $\begin{array}{c}\text { Contaminación } \\
\text { de suelos }\end{array}$ \\
\hline Piezas de tela & Remallado & $\begin{array}{c}\text { Piezas de telas } \\
\text { remalladas }\end{array}$ & $\begin{array}{c}\text { Desechos no orgánicos } \\
\text { (agujas rotas) }\end{array}$ & $\begin{array}{c}\text { Contaminación } \\
\text { de suelos }\end{array}$ \\
\hline $\begin{array}{c}\text { Conjunto de } \\
\text { bebé }\end{array}$ & $\begin{array}{c}\text { Verificado de } \\
\text { calidad }\end{array}$ & $\begin{array}{c}\text { Polo de bebé } \\
\text { verificado }\end{array}$ & $\begin{array}{c}\text { Desechos no orgánicos } \\
\text { (productos finales } \\
\text { defectuosos) }\end{array}$ & $\begin{array}{c}\text { Contaminación } \\
\text { de suelos }\end{array}$ \\
\hline
\end{tabular}

Fuente: Cotán, S. (2007)

Elaboración propia

Según el cuadro anterior los impactos que se darían serían de aire y suelo, se buscará reducir la contaminación de aire con el uso de extractores que eviten que el polvillo genere enfermedades entre los trabajadores y contamine el producto final; con respecto a la contaminación de suelos, la empresa puede donar sus productos defectuosos a entidades que puedan reutilizarlos y las agujas deberán ser botadas en depósitos adecuados.

\subsection{Seguridad y salud ocupacional.}

Tabla 5. 22

Criterios para obtener la probabilidad de ocurrencia

\begin{tabular}{|c|c|c|c|c|}
\hline Índice & $\begin{array}{l}\text { Personas } \\
\text { Expuestas } \\
\text { (PE) }\end{array}$ & $\begin{array}{l}\text { Procedimiento de } \\
\text { trabajo (PT) }\end{array}$ & Capacitación (C) & $\begin{array}{l}\text { Exposición al } \\
\text { Riesgo (ER) }\end{array}$ \\
\hline 1 & De 1 a 3 & $\begin{array}{l}\text { Existen, son } \\
\text { satisfactorios y } \\
\text { suficientes }\end{array}$ & $\begin{array}{l}\text { Personal entrenado, conoce } \\
\text { el peligro y lo previene }\end{array}$ & $\begin{array}{l}\text { Al menos una vez } \\
\text { al año (S) } \\
\text { Esporádicamente } \\
\text { (SO) }\end{array}$ \\
\hline 2 & De 4 a 12 & $\begin{array}{l}\text { Existen parcialmente y } \\
\text { no son satisfactorios ni } \\
\text { suficientes }\end{array}$ & $\begin{array}{c}\text { Personal parcialmente } \\
\text { entrenado, conoce el peligro, } \\
\text { pero no toma acciones de } \\
\text { control }\end{array}$ & $\begin{array}{l}\text { Al menos una vez } \\
\text { al mes }(\mathrm{S}) \\
\text { Eventualmente } \\
(\mathrm{SO})\end{array}$ \\
\hline 3 & Más de 12 & No existen & $\begin{array}{c}\text { Personal no entrenado, no } \\
\text { conoce el peligro y no toma } \\
\text { acciones de control }\end{array}$ & $\begin{array}{l}\text { Al menos una vez } \\
\text { al día }(\mathrm{S}) \\
\text { Permanentemente } \\
\text { (SO) }\end{array}$ \\
\hline
\end{tabular}

Fuente: Generalitat de Catalunya, (2006).

Elaboración propia 
Tabla 5. 23.

Criterio para obtener la severidad del evento

\begin{tabular}{|c|c|}
\hline Índice & Severidad (Consecuencia) \\
\hline 1 & Lesión sin incapacidad (S) \\
\hline 2 & Incomodidad (SO) \\
\hline 3 & Lesión con incapacidad temporal $(\mathbf{S})$ \\
\hline \multirow{2}{*}{ Daño a la salud reversible (SO) } \\
\hline
\end{tabular}

Fuente: Generalitat de Catalunya, (2006).

Elaboración propia

Tabla 5. 24

Criterio para obtener el nivel de riesgo

\begin{tabular}{|c|c|c|}
\hline Nivel de Riesgo & Grado de riesgo & Criterio de significancia \\
\hline 4 & Trivial (T) & No significativo \\
\hline 5 a 8 & Tolerable (TO) & \\
\hline 9 a 16 & Moderado (MO) & No significativo \\
\hline 17 a 24 & Importante (IM) & Significativo \\
\hline 25 a 36 & Intolerable (IT) & \\
\hline
\end{tabular}

Fuente: Generalitat de Catalunya, (2006).

Elaboración propia 
Tabla 5. 25

Matriz IPER

\begin{tabular}{|c|c|c|c|c|c|c|c|c|c|c|c|}
\hline Tarea & Peligro & Riesgo & $\begin{array}{l}\text { Personas } \\
\text { Expuestas }\end{array}$ & $\begin{array}{l}\text { Procedimientos } \\
\text { Existentes }\end{array}$ & $\begin{array}{c}\text { Índice } \\
\text { Capacitación }\end{array}$ & $\begin{array}{l}\text { Exposición } \\
\text { al Peligro }\end{array}$ & Prob & Severidad & Riesgo & $\begin{array}{l}\text { Nivel } \\
\text { Riesgo }\end{array}$ & $\begin{array}{l}\text { Medidas De } \\
\text { Control }\end{array}$ \\
\hline Recepción & $\begin{array}{l}\text { Carga de Rollo } \\
\text { Pesada }\end{array}$ & $\begin{array}{l}\text { Lesión } \\
\text { Muscular }\end{array}$ & 1 & 1 & 1 & 2 & 5 & 3 & 15 & Mo & Instructivos Visuales \\
\hline $\begin{array}{c}\text { Verificar } \\
\text { Calidad de Tela }\end{array}$ & Ponchadora & Cortes o Golpes & 1 & 1 & 1 & 2 & 5 & 1 & 5 & To & Procedimiento Establecido \\
\hline Corte de la Tela & $\begin{array}{l}\text { Máquina de } \\
\text { Corte }\end{array}$ & Corte de Dedos & 1 & 1 & 1 & 2 & 5 & 3 & 15 & Mo & $\begin{array}{c}\text { Seguir el Procedimiento y uso } \\
\text { de EPPs (Guantes) }\end{array}$ \\
\hline \multirow{2}{*}{ Costura } & $\begin{array}{l}\text { Máquina de } \\
\text { Costura }\end{array}$ & $\begin{array}{c}\text { Dedo Atravesado por } \\
\text { La Aguja }\end{array}$ & 2 & 1 & 1 & 3 & 7 & 3 & 21 & $\operatorname{Im}$ & $\begin{array}{l}\text { Procedimiento establecido } \\
\text { para evitar las Pérdidas de } \\
\text { fragmentos de Agujas }\end{array}$ \\
\hline & Polvo de Tela & $\begin{array}{l}\text { Enfermedades } \\
\text { Respiratorias: } \\
\text { Neumoconiosis }\end{array}$ & 2 & 1 & 1 & 3 & 7 & 3 & 21 & $\mathrm{IM}$ & $\begin{array}{c}\text { Uso adecuado } \\
\text { de EPP (Mascarilla, Lentes) }\end{array}$ \\
\hline Desmanche & $\begin{array}{c}\text { Químico Toxico } \\
\text { e } \\
\text { Inflamable }\end{array}$ & $\begin{array}{l}\text { Lesión de Órganos } \\
\text { Internos y Externos }\end{array}$ & 1 & 1 & 1 & 2 & 5 & 3 & 15 & Mo & $\begin{array}{l}\text { Procedimiento Establecido Y } \\
\text { EPPs (Mascarillas y Guantes) }\end{array}$ \\
\hline Planchado & $\begin{array}{l}\text { Plancha a altas } \\
\text { Temperaturas }\end{array}$ & $\begin{array}{l}\text { Quemaduras en la } \\
\text { Mano }\end{array}$ & 1 & 1 & 1 & 3 & 6 & 2 & 12 & Mo & $\begin{array}{c}\text { Procedimiento } \\
\text { Definidos de uso de la } \\
\text { maquina }\end{array}$ \\
\hline $\begin{array}{l}\text { Embolsar } \\
\text { y Empacar }\end{array}$ & Estante Móvil & Golpe & 1 & 1 & 1 & 2 & 5 & 1 & 5 & To & $\begin{array}{c}\text { Procedimiento establecido } \\
\text { para adecuada } \\
\text { manipulación } \\
\text { del estante }\end{array}$ \\
\hline $\begin{array}{c}\text { Almacenamiento } \\
\text { de } \\
\text { Producto }\end{array}$ & $\begin{array}{l}\text { Unidad de } \\
\text { Carga Pesada }\end{array}$ & $\begin{array}{c}\text { Lesión en la Carga } \\
\text { Muscular }\end{array}$ & 1 & 1 & 1 & 2 & 5 & 3 & 15 & Mo & $\begin{array}{c}\text { Procedimiento establecido } \\
\text { para adecuada } \\
\text { Manipulación de carga }\end{array}$ \\
\hline
\end{tabular}

Fuente: Generalitat de Catalunya, (2006).

Elaboración propia 


\subsection{Sistema de mantenimiento.}

- Mantenimiento preventivo:

\section{- Máquina cortadora:}

Se realizará un control visual sobre el estado de la maquinaria para la inspección de limpieza: Carcasa, carril de la cuchilla, rodillos de la placa principal, ventilador - motor y la cuchilla. Así mismo, se realizará una inspección del nivel de aceite y una verificación del desgaste de componentes (lija y cuchilla), siendo esta última la verificación más importante debido a que es el principal aditamento.

- Máquinas de costura:

Antes de poner en marcha la máquina al inicio de la jornada o después de haber estado parada por cierto tiempo, deben realizarse los siguientes trabajos: limpie el polvo, compruebe el nivel de aceite y, si es necesario, lubríquela.

Lubrique el garfio y limpie el aceite sobrante, haga una prueba de costura, y cosa algunos segundos a una velocidad baja y después a la velocidad máxima admisible.

Conforme al tipo de máquina y al régimen de trabajo, también deben realizarse lubricaciones intermedias, por ejemplo, antes o después del descanso del mediodía. (Martínez G., 2012)

- Máquina cortadora de cintas:

El mantenimiento de esta máquina consiste en una verificación visual del correcto estado de sus aditamentos, realizando una inspección de limpieza y de componentes por desgaste. Así mismo, se debe tener en cuenta y precaución durante la inspección de la lubricación interna y cerciorarse de contar con el aceite adecuado para la máquina.

\section{- Máquina vaporizadora:}

La vaporizadora cuenta con un generador de vapor autónomo que recibirá vapor mediante el consumo de agua destilada y un aspirador interno. 
Se realizará una inspección profunda de limpieza y operatividad de cada una de sus partes: Mueble, plancha, manguera, cables y pedal.

La operatividad de la vaporizadora depende principalmente del caldero, por lo cual será necesaria una inspección y limpieza de al menos una vez a la semana.

Así mismo, se inspeccionará y realizará la limpieza superficial del compresor eléctrico de aire.

- Máquina remachadora:

Para la máquina remachadora se realizan os siguientes controles: inspección de limpieza mediante un control visual; el drenado del líquido cumulado; la revisión de lubricación de la máquina, el cambio de aceite, y la inspección de componentes por desgaste.

En la siguiente tabla se muestra el costo en horas-hombre invertidas por el personal en actividades de mantenimiento preventivo.

Tabla 5. 26

Costo del Mantenimiento en horas-hombre

\begin{tabular}{|c|c|c|c|}
\hline Área & $\begin{array}{c}\text { horas / } \\
\text { año }\end{array}$ & $\begin{array}{c}\mathbf{N}^{\circ} \\
\text { Máquinas }\end{array}$ & $\begin{array}{c}\text { Total } \\
\text { anual (S/) }\end{array}$ \\
\hline Lubricación de partes móviles y limpieza & 17,3 & 1 & 11,0 \\
\hline Limpieza del motor y ajustes eléctricos & 3,0 & 1 & 1,9 \\
\hline Cambio de piedra de afilar & 0,7 & 1 & 0,4 \\
\hline Costura & & & \\
\hline Máquina remachadora & 41,8 & 1 & 26,6 \\
\hline Máquina remalladora & 36,4 & 4 & 92,7 \\
\hline Compresora & 33,8 & 1 & 21,5 \\
\hline Máquina Cortadora de Cintas & 7,8 & 1 & 5,0 \\
\hline Máquina Collaretera & 8,5 & 1 & 5,4 \\
\hline Máquina Recubridora & 22,1 & 4 & 56,3 \\
\hline Máquina Recta & 41,6 & 1 & 26,5 \\
\hline Acabados & & & \\
\hline Revisión de máquinas & 31,2 & 1 & 19,9 \\
\hline
\end{tabular}

Fuente: Rodriguez, R.y Tarazona, L., (2011)

Elaboración propia 
Tabla 5. 27

Insumos para mantenimiento preventivo

\begin{tabular}{c|rr}
\hline Materiales Indirectos & Mensual & Anual (S/) \\
\hline Franelas(paquetes 2 unidades) & 64 & 768 \\
\hline Piedras de afilar & 30 & 90 \\
\hline Mascarillas & 25 & 100 \\
\hline Aceite Blanco (1gl) & 33,3 & 400 \\
\hline Lubricante(unid*90 ml) & 30 & 360 \\
\hline Agujas (paquetes 8 unidades) & 37 & 442 \\
\hline Tapón oído & 76 & 228 \\
\hline TOTAL & 295,1 & 2387,6
\end{tabular}

Elaboración propia

Tabla 5. 28

Costos de servicios de mantenimiento

\begin{tabular}{|c|c|c|c|}
\hline Área & Tipo de servicio & Periodo & $\begin{array}{l}\text { Total del servicio } \\
\text { (S/) }\end{array}$ \\
\hline \multicolumn{4}{|l|}{ Corte } \\
\hline $\begin{array}{l}\text { Máquina de } \\
\text { Corte y tijeras }\end{array}$ & Afilar cuchillas y tijeras & Bimensual & 60 \\
\hline $\begin{array}{l}\text { Máquina de } \\
\text { Corte y tijeras }\end{array}$ & $\begin{array}{l}\text { Mantenimiento preventivo y cambio de } \\
\text { cuchilla }\end{array}$ & Bimensual & 900 \\
\hline \multicolumn{4}{|l|}{ Costura } \\
\hline $\begin{array}{l}\text { Máquina } \\
\text { remachadora }\end{array}$ & Mantenimiento preventivo y limpieza & Semestral & 90 \\
\hline $\begin{array}{l}\text { Máquina } \\
\text { remalladora }\end{array}$ & Mantenimiento preventivo y limpieza & $\begin{array}{c}\text { Cada } 4 \\
\text { meses }\end{array}$ & 540 \\
\hline Compresora & Mantenimiento preventivo y limpieza & Mensual & 720 \\
\hline $\begin{array}{c}\text { Máquina } \\
\text { Cortadora de } \\
\text { Cintas }\end{array}$ & Mantenimiento preventivo y limpieza & Trimestral & 180 \\
\hline $\begin{array}{c}\text { Máquina } \\
\text { Collaretera }\end{array}$ & Mantenimiento preventivo y limpieza & $\begin{array}{c}\text { Cada } 4 \\
\text { meses }\end{array}$ & 135 \\
\hline $\begin{array}{l}\text { Máquina } \\
\text { Recubridora }\end{array}$ & Mantenimiento preventivo y limpieza & $\begin{array}{c}\text { Cada } 4 \\
\text { meses }\end{array}$ & 540 \\
\hline Máquina Recta & Mantenimiento preventivo y limpieza & Trimestral & 180 \\
\hline \multicolumn{4}{|l|}{ Acabados } \\
\hline $\begin{array}{c}\text { Máquina } \\
\text { Vaporizadora }\end{array}$ & $\begin{array}{l}\text { Arreglo de líneas de vapor y retorno de } \\
\text { condensado }\end{array}$ & Trimestral & 200 \\
\hline \multirow[t]{2}{*}{$\begin{array}{c}\text { Máquina } \\
\text { Vaporizadora }\end{array}$} & Mantenimiento de la mesa de vaporizado & Anual & 300 \\
\hline & & TOTAL & 3845 \\
\hline
\end{tabular}

Fuente: Rodriguez, R. y Tarazona, L., (2011)

Elaboración propia 
- Mantenimiento reactivo:

El mantenimiento reactivo se da cuando se presentan fallas que detienen el proceso de producción.

Ver la siguiente tabla con la información de las fallas comunes de las máquinas de costura.

Tabla 5. 29

Fallas de máquinas de costura

\begin{tabular}{|c|c|}
\hline Falla & Causas posibles \\
\hline $\begin{array}{l}\text { Roturas del hilo } \\
\text { superior }\end{array}$ & $\begin{array}{l}\text {-Aguja mal colocada. } \\
\text {-Hilo con nudos. } \\
\text {-Tensión muy apretada del hilo superior. } \\
\text {-Muelle de tensión vencido o roto. } \\
\text {-Resorte tira hilo roto. }\end{array}$ \\
\hline Rotura del hilo inferior & $\begin{array}{l}\text {-Bobina sucia o deformada. } \\
\text {-Carrete deformado o con rebabas. } \\
\text {-Tensión muy apretada de la bobina }\end{array}$ \\
\hline $\begin{array}{l}\text { Tensión desigual en las } \\
\text { puntadas }\end{array}$ & $\begin{array}{l}\text {-Bobina sucia. } \\
\text {-Carrete deformado. } \\
\text {-Muelle de tensión de bobina sucia. }\end{array}$ \\
\hline Rotura de aguja & $\begin{array}{l}\text {-La tensión demasiado fuerte del hilo flexiona la aguja. } \\
\text {-La aguja es desviada por partes duras de los tejidos. } \\
\text {-La aguja es desviada por tirar o empujar la prendar. }\end{array}$ \\
\hline
\end{tabular}

Fuente: Martínez, G., (2013)

\subsection{Programa de Producción}

\subsubsection{Factores para la programación de la producción}

El factor que influye en nuestro programa de producción es la demanda anual debido a que se utilizará el sistema de producción de fabricación por pedido. Sin embargo, durante el proceso de producción de cada prenda existen diferentes defectos de calidad que se estiman en un 5\% para cada prenda. Este porcentaje de prendas reemplazará a la producción defectuosa.

\subsubsection{Programa de producción}

Según el punto 5.9.1., el programa de producción será igual a la demanda. 
Tabla 5. 30

Programa de producción

\begin{tabular}{|l|c|c|}
\hline Año & C. Requerida (conjuntos) & C. Producida (conjuntos) \\
\hline $\mathbf{2 0 1 8}$ & 41156 & \\
\hline $\mathbf{2 0 1 9}$ & 47912 & 41156 \\
\hline $\mathbf{2 0 2 0}$ & 54869 & 47912 \\
\hline $\mathbf{2 0 2 1}$ & 62825 & 54869 \\
\hline $\mathbf{2 0 2 2}$ & 70766 & 62825 \\
\hline
\end{tabular}

Elaboración propia

\subsection{Requerimiento de insumos, servicios y personal}

\subsubsection{Materia prima, insumos y otros materiales}

Tabla 5. 31

Requerimiento de insumos 1

\begin{tabular}{|c|c|c|c|c|c|c|}
\hline & $\begin{array}{c}\text { C. } \\
\text { Año }\end{array}$ & $\begin{array}{c}\text { Tela } \\
\text { Requerida } \\
\text { (conjuntos) }\end{array}$ & $\begin{array}{c}\text { Hilos de } \\
\text { interlock } \\
\text { poliéster }\end{array}$ & $\begin{array}{c}\text { Entretela } \\
\text { (conos) }\end{array}$ & $\begin{array}{c}\text { Snaps } \\
\text { (ciento) }\end{array}$ & Elástico (m) \\
\hline $\mathbf{2 0 1 8}$ & 41156 & 7077 & 812 & 1090 & 434 & 9100 \\
\hline $\mathbf{2 0 1 9}$ & 47912 & 8238 & 946 & 1269 & 505 & 10600 \\
\hline $\mathbf{2 0 2 0}$ & 54869 & 9434 & 1083 & 1453 & 578 & 12150 \\
\hline $\mathbf{2 0 2 1}$ & 62825 & 10802 & 1240 & 1664 & 662 & 13900 \\
\hline $\mathbf{2 0 2 2}$ & 70766 & 12167 & 1396 & 1874 & 745 & 15650 \\
\hline
\end{tabular}

Elaboración propia

Tabla 5. 32

Requerimiento de insumos 2

\begin{tabular}{|c|c|c|c|c|c|c|c|c|}
\hline Año & $\begin{array}{c}\text { Etiquetas } \\
\text { de talla } \\
\text { (ciento) }\end{array}$ & $\begin{array}{l}\text { Etiquetas de } \\
\text { composición } \\
\text { (ciento) }\end{array}$ & $\begin{array}{c}\text { Hang } \\
\text { Tag } \\
\text { (ciento) }\end{array}$ & $\begin{array}{l}\text { Balines } \\
\text { (ciento) }\end{array}$ & $\begin{array}{c}\text { Bolsas } \\
\text { (ciento) }\end{array}$ & $\begin{array}{l}\text { Cintas } \\
1 / 2^{\prime \prime} \\
\text { (und) }\end{array}$ & $\begin{array}{c}\text { Cintas } \\
2^{\prime \prime} \\
\text { (und) }\end{array}$ & $\begin{array}{l}\text { Cajas } \\
\text { (und) }\end{array}$ \\
\hline 2018 & 867 & 867 & 823 & 824 & 412 & 206 & 46 & 823 \\
\hline 2019 & 1009 & 1009 & 958 & 959 & 480 & 240 & 54 & 958 \\
\hline 2020 & 1156 & 1156 & 1097 & 1098 & 549 & 274 & 61 & 1097 \\
\hline 2021 & 1323 & 1323 & 1257 & 1257 & 629 & 314 & 70 & 1257 \\
\hline 2020 & 1490 & 1490 & 1415 & 1416 & 708 & 354 & 79 & 1415 \\
\hline
\end{tabular}

Elaboración propia 


\subsubsection{Servicios: Energía eléctrica, agua, vapor, combustible, etc.}

- Energía eléctrica

En el siguiente cuadro se detallarán los consumos anuales según cada máquina. Además, se tomará como referencia los datos proporcionados por una MyPyme textil con características similares a nuestro proyecto para los consumos administrativos, teniendo un promedio de 266 soles mensuales en consumo en energía eléctrica de la parte administrativa. Esto representa alrededor del 55\% del total que se paga al mes.

Tabla 5.33

Energía eléctrica

\begin{tabular}{|c|c|c|c|c|}
\hline Ítem & $\begin{array}{c}\text { Conjuntos } \\
\text { por } \\
\text { máquina }\end{array}$ & $\begin{array}{c}\text { Tiempo } \\
\text { (h/año) }\end{array}$ & $\begin{array}{c}\text { Potencia } \\
(\mathbf{K W})\end{array}$ & $\begin{array}{c}\text { Consumo eléctrico } \\
\text { (KW-h) }\end{array}$ \\
\hline Cortadora & 46088 & 658 & 0,37 & 243 \\
\hline Remalladora & 43323 & 3502 & 0,5 & 1751 \\
\hline Recubridora & 43323 & 2816 & 0,6 & 1690 \\
\hline Vaporizadora & 41156 & 617 & 1,6 & 988 \\
\hline Compresora & 43323 & 217 & 5,5 & 1191 \\
\hline Recta & 43323 & 903 & 0,6 & 542 \\
\hline $\begin{array}{c}\text { Cortadora de } \\
\text { cintas }\end{array}$ & 43323 & 58 & 0,5 & 29 \\
\hline Collaretera & 43323 & 505 & 0,5 & 253 \\
\hline $\begin{array}{c}\text { Extractor de } \\
\text { aire }\end{array}$ & 46088 & 658 & 0,37 & 243 \\
\hline Focos & - & 2304 & 0,08 & 184 \\
\hline
\end{tabular}

Fuente: Organismo Supervisor de la Inversión en Energía y Minería, Osinergmin. (2016)

Elaboración propia.

- Telecomunicaciones

Se estima que se consumiría 1800 soles anuales por conceptos de internet y telefonía fija de movistar con una velocidad máxima de 5 Mbps y 4000 soles anuales en total por telefonía móvil con Entel para los ejecutivos de ventas y producción. Estos datos se obtuvieron analizando el consumo promedio de una Mypyme textil de prendas de exportación.

- Agua

Se tomarán los servicios de la empresa Sedapal. Si bien el proceso productivo no involucra al agua como un insumo, se debe considerar para el consumo de los operarios, personal administrativo y para labores de limpieza. Según referencias 
de una tesis de estudio de prefactibilidad para la instalación de una planta de confección de ropa deportiva para el mercado local de José Fernández, se obtiene que el consumo promedio sea de 400 soles al mes.

- $\quad$ Agua destilada

Según los tiempos estándar de vaporizado, y considerando el precio de 95 soles por cada 80 litros de agua destilada, se considera un total de 8906,3 soles anuales en agua destilada.

\subsubsection{Determinación del número de operarios y trabajadores indirectos.}

Se terminó el número de operarios de la misma forma en que se obtuvo el número de máquinas, que se encuentra en el punto 5.4.2. consideramos el año 2022 para el cálculo ya que es el año en el que se presenta la mayor demanda.

Tabla 5. 34

Número de operarios al 2022

\begin{tabular}{|c|c|c|c|c|c|c|}
\hline \multicolumn{7}{|c|}{ Cap. Requerida } \\
\hline & Polos/Años & Hrs/Polo & Pantalón/Año & Hrs/Pantalón & Cap. Disponible & Operarios \\
\hline $\begin{array}{l}\text { Tender y verificar } \\
\text { calidad y cantidad }\end{array}$ & 80420 & 0,0098 & 80420 & 0,0083 & 1571 & 1 \\
\hline Tizar tela & 79567 & 0,0067 & 79567 & 0,0058 & 1571 & 1 \\
\hline Cortar tela & 79567 & 0,0076 & 79567 & 0,0067 & 1571 & 1 \\
\hline $\begin{array}{l}\text { Habilitar, cortar y } \\
\text { pegar entretela }\end{array}$ & 79567 & 0,0117 & 79567 & 0,0067 & 1571 & 1 \\
\hline $\begin{array}{l}\text { Cortar collareta y } \\
\text { elástico }\end{array}$ & 74491 & 0,0013 & 74491 & 0,0092 & 1571 & 1 \\
\hline Coser con recta & 74491 & 0,0100 & 74491 & 0,0108 & 1571 & 1 \\
\hline $\begin{array}{l}\text { Coser con } \\
\text { remalladora }\end{array}$ & 74491 & 0,0400 & 74491 & 0,0408 & 1571 & 4 \\
\hline $\begin{array}{l}\text { Coser con } \\
\text { recubridora }\end{array}$ & 74491 & 0,0317 & 74491 & 0,0333 & 1571 & 4 \\
\hline Coser con collaretera & 74491 & 0,0117 & 0 & 0,0000 & 1571 & 1 \\
\hline Colocar snaps & 74491 & 0,0050 & 0 & 0,0000 & 1571 & 1 \\
\hline $\begin{array}{l}\text { Verificar calidad de } \\
\text { costura y limpiar } \\
\text { hilos }\end{array}$ & 74491 & 0,0117 & 74491 & 0,0097 & 1571 & 2 \\
\hline Planchar & 70766 & 0,0075 & 70766 & 0,0075 & 1571 & 1 \\
\hline $\begin{array}{l}\text { Colocar Hang Tag, } \\
\text { doblar, embolsar y } \\
\text { embalar }\end{array}$ & 70766 & 0,0091 & 70766 & 0,0083 & 1571 & 1 \\
\hline
\end{tabular}


El siguiente cuadro muestra a todo el personal indirecto de la empresa por turno de trabajo:

Tabla 5. 35

Trabajadores Indirectos

\begin{tabular}{|c|c|c|}
\hline Personal Administrativo & Cantidad & Requisitos \\
\hline Gerente General & 1 & $\begin{array}{l}\text { Experiencia de } 8 \text { años en el rubro liderando proyectos } \\
\text { relacionados. }\end{array}$ \\
\hline Asistente administrativo & 1 & Experiencia de 1 años en el puesto o estudios superiores. \\
\hline Coordinador de ventas & 1 & Experiencia de 4 años en el rubro. \\
\hline Coordinador de Logística & 1 & Experiencia de 4 años en el rubro y estudios superiores. \\
\hline Supervisor de operaciones & 1 & Experiencia de 4 años en el rubro y estudios superiores. \\
\hline Modelista & 1 & Experiencia de 2 años en el rubro o estudios. \\
\hline Almacenero & 1 & Experiencia de 2 años en el rubro. \\
\hline
\end{tabular}

Elaboración propia.

En total, se deberán tener en la parte operativa a 20 operarios (14 para trabajos en máquina y 6 para trabajos manuales) y como personal indirecto a 7 personas.

\subsubsection{Servicios de terceros}

Uno de los servicios a terceros que se podría considerar es el lavado en prenda. Para este proyecto, se mencionará este proceso, pero no se costeará el servicio debido a que no se concreta para todos los clientes.

El lavado en prenda consiste en lavar todas las prendas del lote en una lavadora industrial, lo cual afecta las dimensiones de la prenda. Esta operación se ubicaría después de cortar los hilos y antes de pegar snaps.

El transporte privado del producto final al aeropuerto Jorge Chávez será brindado por una empresa privada, que tendrá un costo de 120 soles, el cual incluye una garantía en caso de robo, pérdida o deterioro.

Así mismo, se tercerizará el servicio de limpieza, donde se contrata este servicio por tres días a la semana a un costo de 90 soles por día (Fernando, Córdova, Flores y Ortiz, 2017).

El servicio de vigilancia será uno de los servicios más altos debido a que habrá un vigilante en la empresa durante las 24 horas del día, siendo pagado este servicio a la empresa contratada con 3900 soles mensuales. 


\subsection{Disposición de planta}

\subsubsection{Características físicas del proyecto.}

El proyecto presenta un sistema de producción por lotes - taller, por lo cual el tipo de distribución de planta que debe tener es por proceso. Las ventajas que este tipo de distribución nos ofrece son: una mejor utilización de la maquinaria, adaptabilidad a gran cantidad de productos, cambios de la secuencia de operaciones y a las variaciones del programa de producción. (Bonilla, Díaz, Kleeberg y Noriega, 2010)

\subsubsection{Determinación de las zonas físicas requeridas.}

- Almacén de materia prima e insumos

En esta zona se realizará la recepción de tela y demás insumos necesarios para la producción. Está compuesta por la zona de recepción y la zona de almacenamiento.

La zona de recepción está destinada para el material que se descarga y se mantiene cierto tiempo en ella, para verificar que las cantidades concuerden con los documentos que la acompañan (Díaz y Noriega, 2017).

Se contará con un escritorio de dimensiones: $0,7 \mathrm{~m} \mathrm{x} 0,5 \mathrm{~m}$ x 0,8 m, que permita registrar los ingresos y salidas de productos; un pasadizo de $2 \mathrm{~m}$ que permita realizar las maniobras necesarias con la traspaleta de $500 \mathrm{~kg}$ y un espacio de estacionamiento. 
Figura 5. 15

Traspaleta

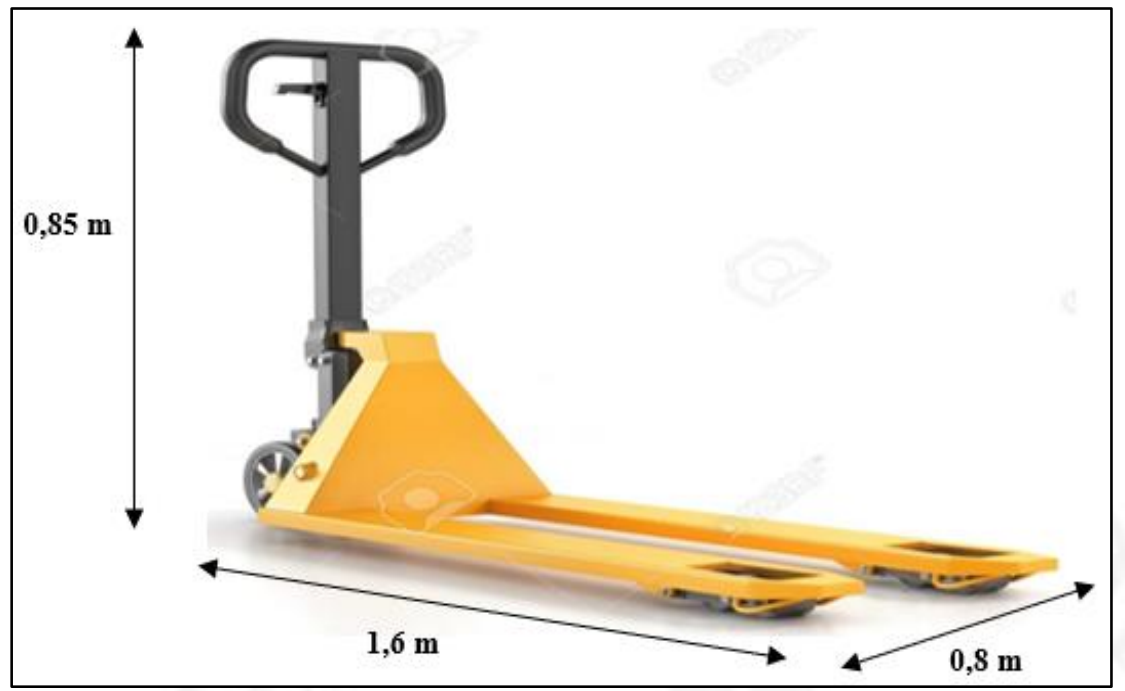

Fuente: Alibaba, (2018)

La zona de almacenamiento es el espacio disponible para resguardar los grupos de materiales (Díaz y Noriega, 2017). Definiremos sus dimensiones en base racks que nos permitirán aprovechar el espacio cúbico.

El número de rollos de tela de algodón de $42.5 \mathrm{~m}^{2}$, que necesitaremos para un requerimiento anual de $7077 \mathrm{~kg}$ de tela y un tiempo de almacenamiento de 30 días es de 73 rollos.

$\frac{7077 \mathrm{~kg} \text { tela }}{\text { año }} \frac{\mathrm{X} \text { año }}{364 \text { días }} \times \quad 30$ días $X \frac{1 \mathrm{~m}^{2}}{0,19 \mathrm{~kg}} \times \frac{1 \text { rollo }}{42,5 \mathrm{~m}^{2}}=73$ rollos

Las métricas necesarias del estante para 73 rollos de tela de dimensiones 1,6 $\mathrm{m}$ de ancho y $20 \mathrm{~cm}$ de diámetro, son:

Volumen necesario: 73 rollos x $0,2 \mathrm{~m} \times 0,2 \mathrm{~m} \times 1,6 \mathrm{~m}=4,67 \mathrm{~m}^{3}$

Figura 5. 16

Medidas de un rollo

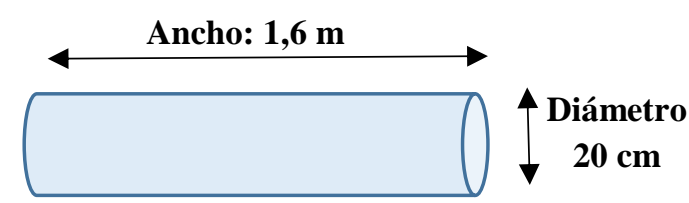

Elaboración propia 
Dimensiones sugeridas del estante:

Figura 5. 17

Dimensiones del rack de telas

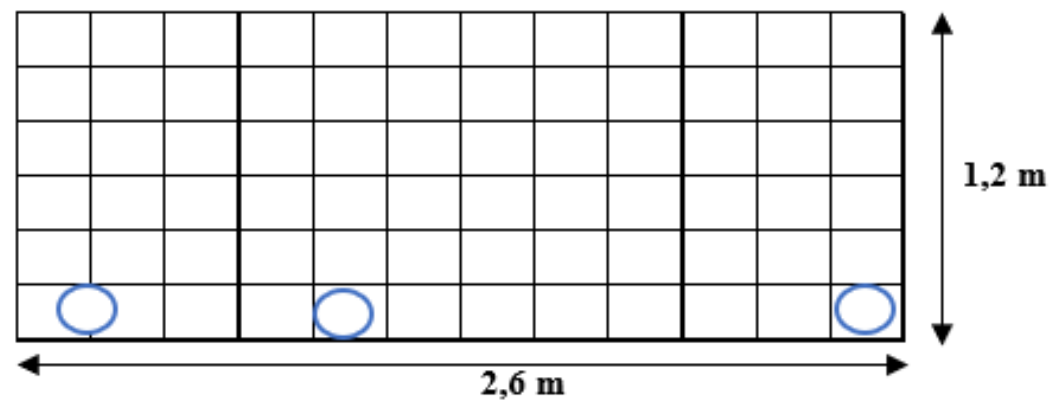

Elaboración propia

Volumen del estante de telas $=1,2 \mathrm{~m} \mathrm{x} \mathrm{2,6} \mathrm{m} \times 2 \mathrm{~m}=6.24 \mathrm{~m}^{3}$

Figura 5. 18

Imagen referencial del rack de telas

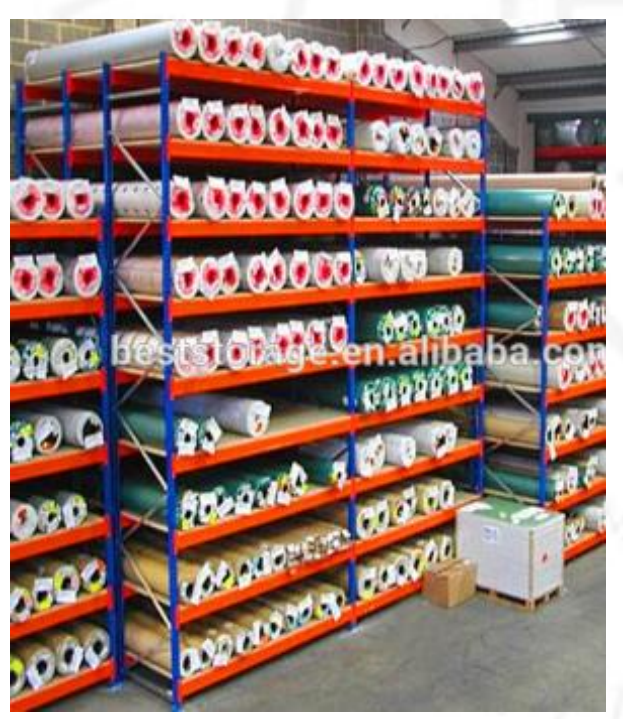

Fuente: Alibaba, (2018)

A continuación, evaluaremos las dimensiones del estante de los principales insumos. 
Tabla 5. 36

Volumen por insumo

\begin{tabular}{|c|c|c|c|c|}
\hline Insumos & Unidades & $\begin{array}{l}\text { Cantidad } \\
\text { requerida* }\end{array}$ & Dimensiones & $\begin{array}{c}\text { Volumen } \\
\text { Requerido }\left(\mathbf{m}^{3}\right)\end{array}$ \\
\hline Hilos & Cono $(4000 \mathrm{~m})$ & 67 & $0,07 \mathrm{~m} \times 0,07 \mathrm{~m} \times 0,1 \mathrm{~m}$ & 0,033 \\
\hline Entretela & Unidad & 90 & $0,2 \mathrm{~m} \times 0,3 \mathrm{~m} \times 0,001 \mathrm{~m}$ & 0,005 \\
\hline Elástico & Rollo (156 m) & 750 & $0,08 \mathrm{~m} \times 0,08 \mathrm{~m} \times 0,12 \mathrm{~m}$ & 0,576 \\
\hline Snaps & Ciento & 36 & $0,2 \mathrm{~m} \times 0,16 \mathrm{~m} \times 0,05 \mathrm{~m}$ & 0,058 \\
\hline Hang Tag & Ciento & 36 & $0,07 \mathrm{~m} \times 0,1 \mathrm{~m} \times 0,04 \mathrm{~m}$ & 0,010 \\
\hline Balines & Ciento & 68 & $0,1 \mathrm{~m} \times 0,07 \mathrm{~m} \times 0,04 \mathrm{~m}$ & 0,019 \\
\hline Bolsas & Ciento & 34 & $0,15 \mathrm{~m} \times 0,1 \mathrm{~m} \times 0,03 \mathrm{~m}$ & 0,015 \\
\hline Cintas 1/2" & Unidad & 17 & $0,013 \mathrm{~m} \times 0,1 \mathrm{~m} \times 0,1 \mathrm{~m}$ & 0,002 \\
\hline Cintas 2" & Unidad & 4 & $0,051 \mathrm{~m} \times 0,1 \mathrm{~m} \times 0,1 \mathrm{~m}$ & 0,002 \\
\hline Cajas (sin armar) & Unidad & 68 & $1 \mathrm{~m} \mathrm{x} 0,8 \mathrm{~m} \mathrm{x} 0,01 \mathrm{~m}$ & 0,544 \\
\hline \multicolumn{4}{|c|}{ TOTAL } & 1,265 \\
\hline
\end{tabular}

Elaboración propia.

En la figura 5.19 se detallan las dimensiones sugeridas para el estante de insumos.

Figura 5. 19

Estante de principales insumos

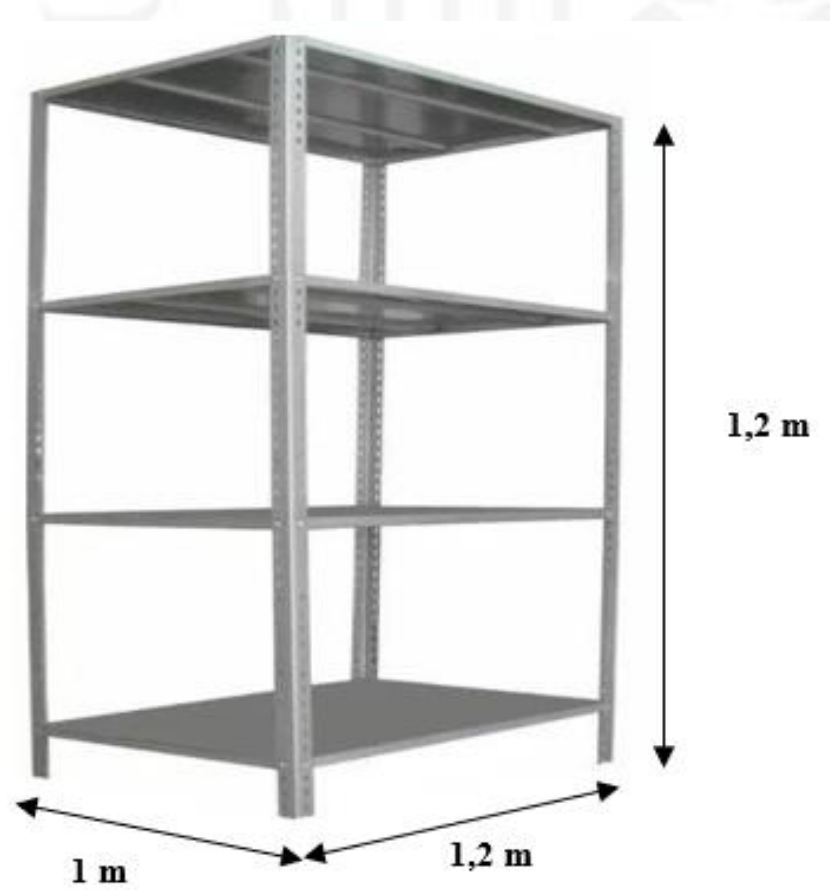

Fuente: Alibaba, (2018)

Elaboración propia

Volumen requerido: $1,2 \mathrm{~m}$ x $1 \mathrm{~m} \mathrm{x} \mathrm{1,2} \mathrm{m}=1,44 \mathrm{~m}^{3}$ 
El área necesaria para el almacén de materia prima e insumos sería:

Área Total $=$ Zona de recepción + Zona de almacenamiento

Área Total $=(2 \mathrm{~m} \times 0,7 \mathrm{~m}+2 \mathrm{~m} \times 1,6 \mathrm{~m}+1,6 \mathrm{~m} \times 0,8 \mathrm{~m})+(2,6 \mathrm{~m} \times 2 \mathrm{~m}+1,2$ $\mathrm{m} \times 1 \mathrm{~m}+1,2 \mathrm{~m} \times 2 \mathrm{~m}+2,6 \mathrm{~m} \times 2 \mathrm{~m}+1,6 \mathrm{~m} \times 0,8 \mathrm{~m})=21,16 \mathrm{~m}^{2}$

Figura 5. 20

Área sugerida para almacén

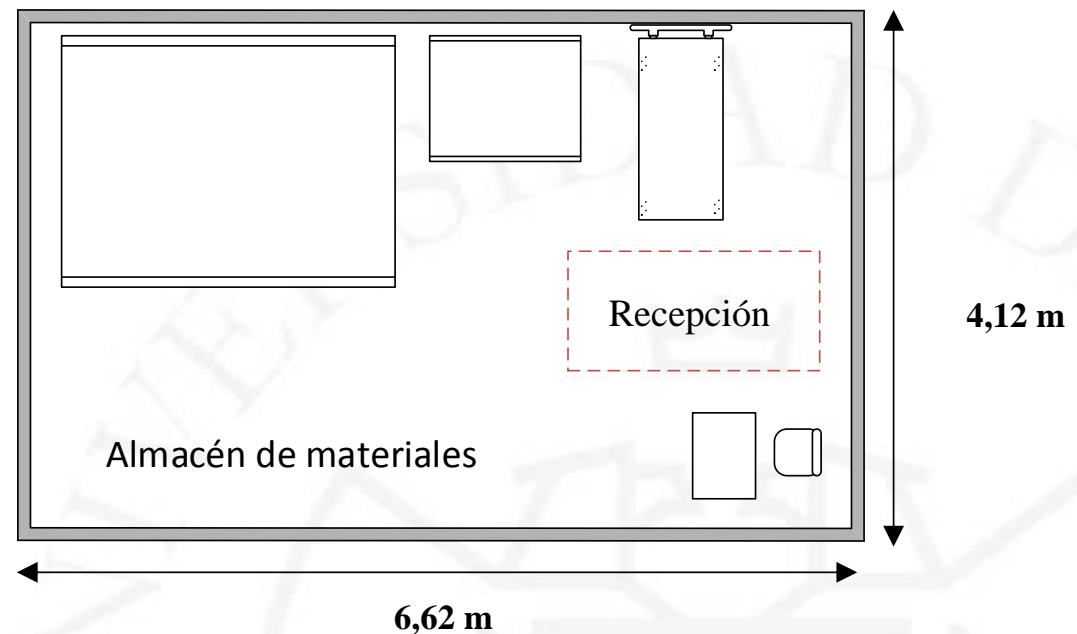

Elaboración propia

Área sugerida para el almacén: 4,12 x 6,62 =27,27 $\mathrm{m}^{2}$

- Almacén de productos terminados

Para determinar las dimensiones de la zona de almacenamiento del producto terminado, tendremos en cuenta las dimensiones de la caja del producto terminado: 0,40 m x 0,60 m x 0,40 m. Cada mes se producen 59 cajas y se estima un período de almacenamiento de 30 días.

Volumen necesario $=0,4 \mathrm{~m} \times 0,6 \mathrm{~m} \times 0,4 \mathrm{~m} \times 59$ cajas $/ \mathrm{mes}=4,8 \mathrm{~m}^{3}$

Se recomienda un rack de capacidad de 60 cajas, de las dimensiones de la figura 5.21 . 
Figura 5. 21

Rack para cajas de producto terminado

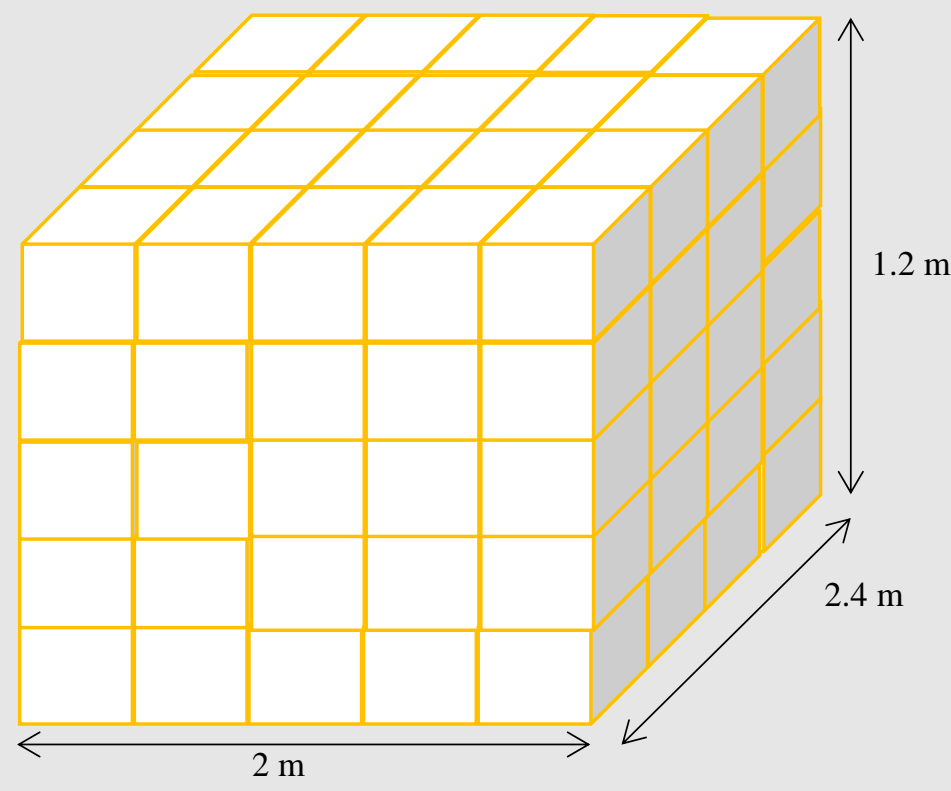

Elaboración propia

Figura 5. 22

Imagen referencial del rack de producto terminado

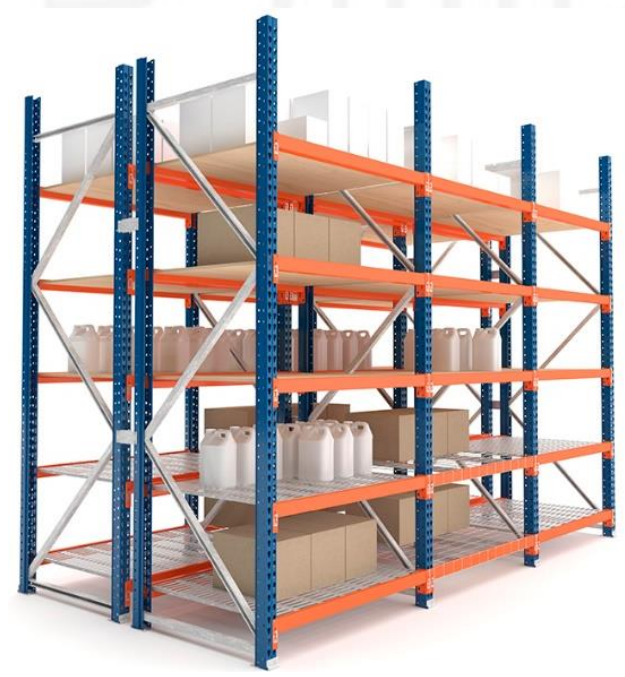

Fuente: Racks del pacifico, (2018)

Adicionalmente, se considerará un área adicional que permita el desplazamiento de la traspaleta.

El área necesaria para el almacén de productos terminados será:

$$
\text { Área Total }=\left(2 \mathrm{~m} \mathrm{x} \mathrm{2,4} \mathrm{m)}+(2,4 \mathrm{~m} \mathrm{x} 4 \mathrm{~m})=14,4 \mathrm{~m}^{2}\right.
$$


Figura 5. 23

Área del almacén productos terminados

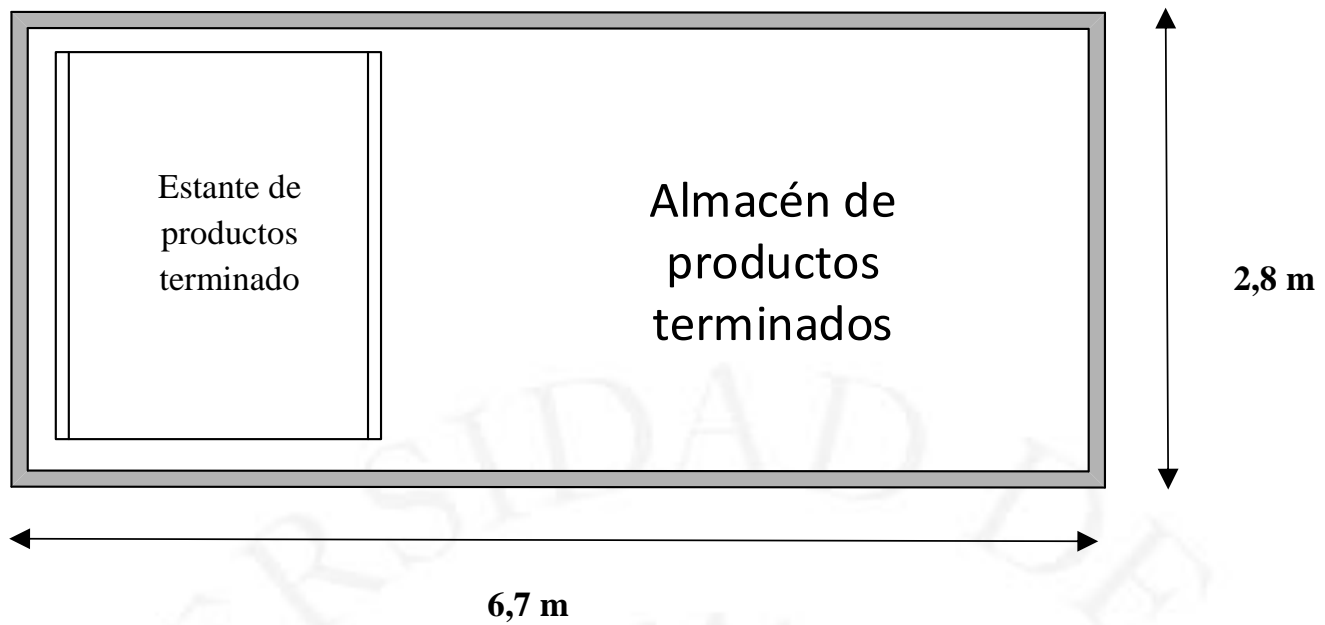

Elaboración propia

Área sugerida para el almacén: 2,8 x 6,7 =18,76 $\mathrm{m}^{2}$

- Área de Desarrollo de Producto

En esta zona se encontrará un modelista, quien se encarga de elaborar los moldes y las fichas técnicas. Para el buen desempeño de sus funciones consideraremos 4,5 $\mathrm{m}^{2}$ de espacio, sugerido por Sule. En esta área se contará con una mesa acondicionada para elaborar moldes con dimensiones de $1 \mathrm{~m}$ x 1,5 m x $1 \mathrm{~m}$. Adicionalmente, esta persona contará con una computadora y un estante para guardar prototipos. Se considerará un estante de $1,5 \mathrm{~m}$ x $1 \mathrm{~m}$ x 1,7 m y una mesa en la que se ubicará la computadora de $1,5 \mathrm{~m}$ x 0,8 m x 0,65 m.

Área de desarrollo $=4,5+1 \times 1,5+1,5 \times 1+1,5 \times 0,8=8,7 \mathrm{~m}^{2}$

- Laboratorio de control de calidad

En el laboratorio de control de calidad, se llevará acabo las pruebas de densidad y encogimiento. Consideraremos una estación de trabajo mínima de $4,5 \mathrm{~m}^{2}$ (Sule, 2001). Las principales máquinas del área de control de calidad son la balanza electrónica y la lavadora automática. Considerando que la balanza electrónica se 
encuentra ubicada en una mesa de $1,2 \mathrm{~m}$ x 0,55 $\mathrm{m}$ x 0,78 $\mathrm{m}$ y las dimensiones de la lavadora son $0,55 \mathrm{~m}$ x 0,59 m x 0,84 m. Así mismo, se tendrá un estante para guardar muestras o guardar instrumentos de $2 \mathrm{~m}$ x 0,6 m x 1,5 m. Adicionalmente, se cuenta con un lavabo de $0,6 \mathrm{~m}$ x $0,3 \mathrm{~m}$.

Área de control de calidad $=4,5+1,2 \times 0,55+0,55 \times 0,59+2 \times 0,6+0,18=6,86 \mathrm{~m}^{2}$

- $\quad$ Patio de maniobra

Zona que permitirá la atención de los vehículos que traen los materiales o que llevan los productos terminados. (Díaz \& Noriega, Manual para el diseño de instalaciones manufactureras y de servicios, 2017)

Para determinar su área consideraremos un espacio que permita el buen desenvolvimiento de las tareas de carga y descarga: uso de rampa (2,4 m x 1,6 m) $\mathrm{y}$ viales que permitan el transporte del carrito (ancho: 0,80 m y largo:1,6 m) y operarios (ancho: 0,90 m).

Figura 5. 24

Imagen de Camión NQR - Chevrolet

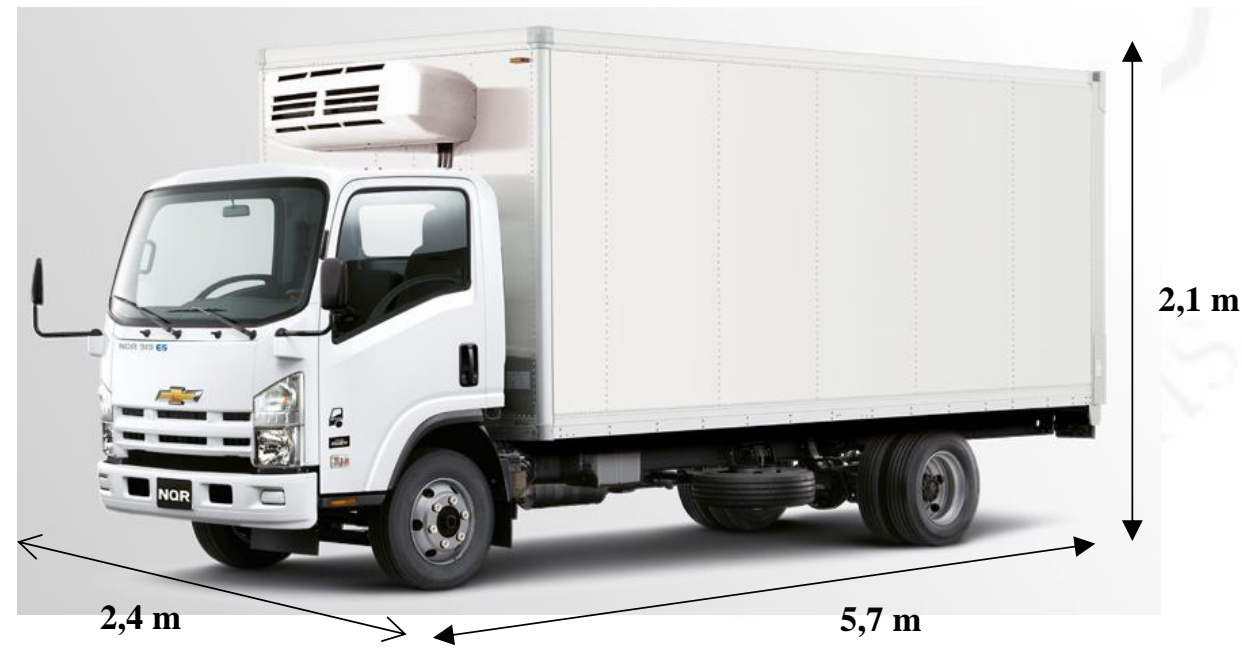

Fuente: Chevrolet, (2018) 
Figura 5. 25

Dimensiones del patio de maniobras

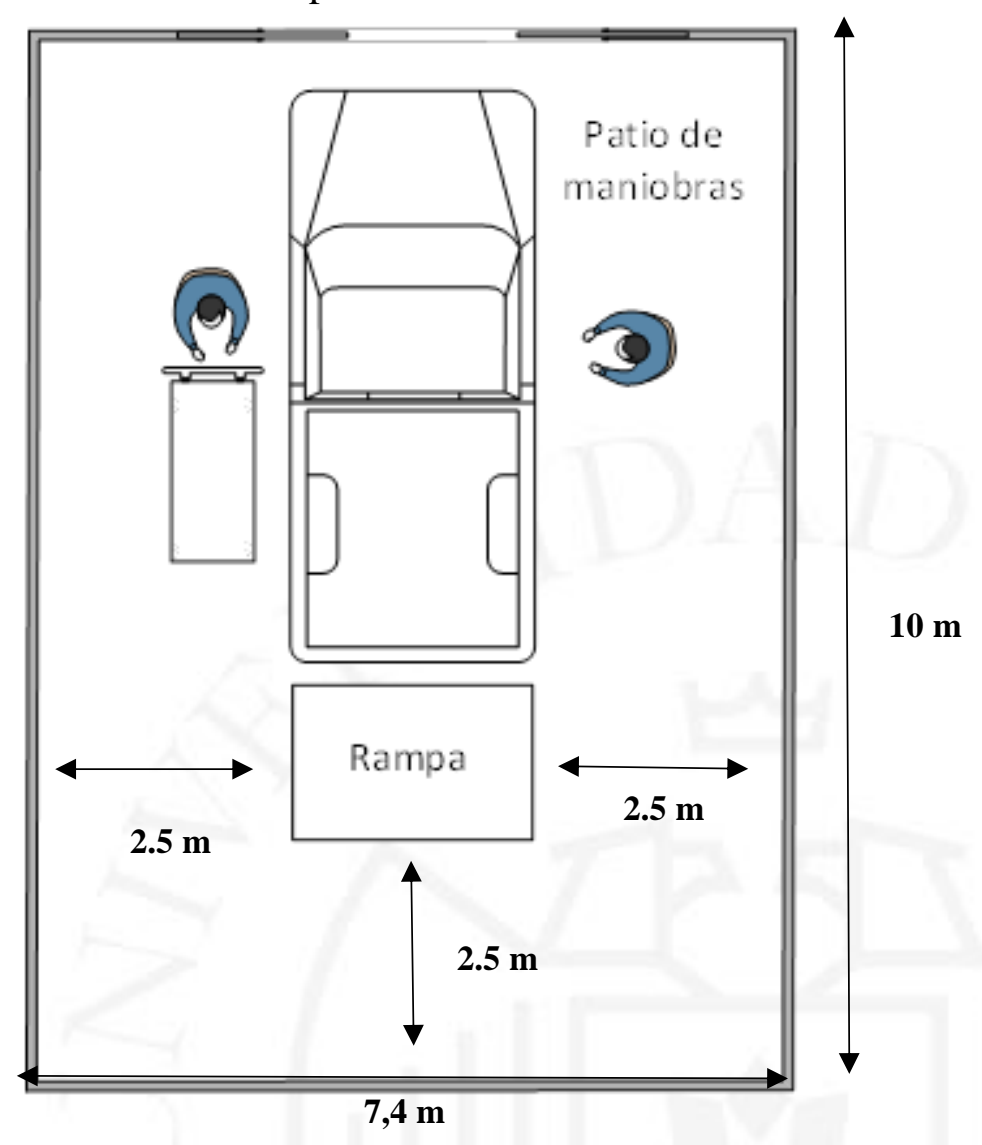

Elaboración propia

Área del patio de maniobras $=10 \mathrm{~m} \times 7,4 \mathrm{~m}=74 \mathrm{~m}^{2}$

- Zona administrativa

Sus dimensiones se determinarán según el número de empleados que se tienen para esta zona, nos guiaremos del libro "Instalaciones de Manufactura" de Sule:

- Ejecutivo principal: de 23 a $46 \mathrm{~m}^{2}$

- Mando medio: de 7,5 a $14 \mathrm{~m}^{2}$

- Oficinista: de 4,5 a $9 \mathrm{~m}^{2}$ (D.R. Sule., 2001)

Para nuestro, caso serían las siguientes dimensiones:

- Gerente general: $23 \mathrm{~m}^{2}$

- 3 mandos medios: $33 \mathrm{~m}^{2}$ (11 $\mathrm{m}^{2}$ para cada supervisor o coordinador) 
- Asistente administrativo: $7 \mathrm{~m}^{2}$

Esto resulta en un total de $63 \mathrm{~m}^{2}$ para la zona administrativa.

- Área de control y seguridad:

Es una oficina donde se encuentra el personal de seguridad, que controlará el ingreso y salida de personas o vehículos a las instalaciones.

Consideraremos la dimensión mínima recomendada por Sule para un oficinista: $4,5 \mathrm{~m}^{2}$.

- Showroom

Ambiente destinado para la exposición de nuestros productos a clientes o potenciales compradores; se contará con dos estantes ( $3.5 \mathrm{~m}$ x $0.8 \mathrm{~m} \times 1 \mathrm{~m})$, un sillón (1.4 m x $0.8 \mathrm{~m}$ x $0.6 \mathrm{~m})$ y una mesa pequeña $(0.7 \mathrm{~m}$ x $0.7 \mathrm{~m}$ x $0.4 \mathrm{~m})$.

- Comedor

Según el libro "Instalaciones de Manufactura" para el comedor a cada operario se le considera $1,58 \mathrm{~m}^{2}$; se tendrán dos horarios de almuerzo por lo cual las dimensiones del comedor lo definiremos en base al número de colaborares de la zona de confección, que incluyen 20 operarios y 2 administrativos,

- 22 personas $\mathrm{x} 1,58 \mathrm{~m}^{2} /$ persona $=34,8 \mathrm{~m}^{2}$

- Servicios higiénicos y vestidores

Según el Reglamento Nacional de Edificaciones (2005), el número de servicios higiénicos depende del número de trabajadores.

En la operación contamos con 20 colaboradores por lo cual según el artículo 22, contaremos con un servicio para hombres (1 lavatorio, 1 urinario y 1 lavadero), y otro para mujeres (1 lavatorio y 1 inodoro); para los cuales se considerará un espacio de $1,5 \mathrm{~m}$ por $2 \mathrm{~m}$ por cada uno. 
Adicionalmente, se considerará por cada servicio higiénico una ducha de $1 \mathrm{~m}^{2}$ y vestuarios a razón de $1,5 \mathrm{~m}^{2}$ por trabajador. (Reglamento Nacional de Edificaciones, 2005).

Para el área administrativa se dispondrán de un servicio higiénico de $3 \mathrm{~m}^{2}$ por género.

Área de servicios higiénicos y vestidores (operativa) $=2 \times 3 \mathrm{~m}^{2}+2 \times 1 \mathrm{~m}^{2}+$ $1,5 \mathrm{~m}^{2} \times 19=34.5 \mathrm{~m}^{2}$

Área de servicios higiénicos y vestidores (administrativa) $=2 \times 3 \mathrm{~m}^{2}=6 \mathrm{~m}^{2}$ 


\subsubsection{Cálculo de áreas para cada zona}

Tabla 5. 37

Método Guerchet

\begin{tabular}{|c|c|c|c|c|c|c|c|c|c|c|c|c|c|}
\hline \multirow{2}{*}{\multicolumn{3}{|c|}{ Elementos }} & \multicolumn{3}{|c|}{ Dimensiones (m) } & \multirow[b]{2}{*}{$\mathbf{N}$} & \multirow[b]{2}{*}{$\mathbf{n}$} & \multirow[b]{2}{*}{ Ss } & \multirow[b]{2}{*}{$\mathrm{Sg}$} & \multirow[b]{2}{*}{ Se } & \multirow[b]{2}{*}{ St } & \multicolumn{2}{|c|}{ Cálculo de k } \\
\hline & & & $\mathbf{L}$ & $\mathbf{A}$ & $\mathbf{h}$ & & & & & & & Ss $\times n \times h$ & Ss $\times \mathrm{n}$ \\
\hline \multirow{19}{*}{ Estáticos } & \multirow{4}{*}{ Zona de corte } & $\begin{array}{c}\text { Mesa de corte (cortadora semi } \\
\text { automática) }\end{array}$ & 10 & 2 & 1,25 & 2 & 1 & 20 & 40 & 39,39 & 99,39 & 25 & 20,00 \\
\hline & & Almacén temporal (carga) & 1,6 & 0,5 & 1,45 & & 1 & 0,80 & & 0,53 & 1,33 & 1 & 0,80 \\
\hline & & Máquina de cortadora de cintas & 0,82 & 0,35 & 0,65 & 1 & 1 & 0,29 & 0,3 & 0,38 & 0,95 & 0,19 & 0,29 \\
\hline & & Mesa de habilitado (control de calidad) & 1,5 & 0,7 & 0,8 & 2 & 1 & 1,05 & 2,1 & 2,07 & 5,22 & 1 & 1,05 \\
\hline & \multirow{15}{*}{ Zona de confección } & Máquina remalladora & 1,2 & 0,55 & 1,2 & 1 & 4 & 0,66 & 0,66 & 0,89 & 8,84 & 3,17 & 2,64 \\
\hline & & Mesas auxiliares (carga) & 0,55 & 0,41 & 0,6 & & 4 & 0,23 & & 0,15 & 1,51 & 0,54 & 0,90 \\
\hline & & Mesas auxiliares (descarga) & 0,55 & 0,41 & 0,6 & & 4 & 0,23 & & 0,15 & 1,51 & 0,54 & 0,90 \\
\hline & & Máquina recta & 1,2 & 0,55 & 1,1 & 1 & 1 & 0,66 & 0,66 & 0,87 & 2,19 & 0,73 & 0,66 \\
\hline & & Mesas auxiliares (carga) & 0,55 & 0,41 & 0,6 & & 1 & 0,23 & & 0,15 & 0,37 & 0,14 & 0,23 \\
\hline & & Mesas auxiliares (descarga) & 0,55 & 0,41 & 0,6 & & 1 & 0,23 & & 0,15 & 0,37 & 0,14 & 0,23 \\
\hline & & Máquina recubridora & 1,2 & 0,55 & 1,1 & 1 & 4 & 0,66 & 0,66 & 0,89 & 8,84 & 2,90 & 2,64 \\
\hline & & Mesas auxiliares (carga) & 0,55 & 0,41 & 0,6 & & 4 & 0,23 & & 0,15 & 1,51 & 0,54 & 0,90 \\
\hline & & Mesas auxiliares (descarga) & 0,55 & 0,41 & 0,6 & & 4 & 0,23 & & 0,15 & 1,51 & 0,54 & 0,90 \\
\hline & & Máquina collaretera & 0,61 & 0,41 & 1,2 & 1 & 1 & 0,25 & 0,25 & 0,33 & 0,83 & 0,30 & 0,25 \\
\hline & & Mesas auxiliares (carga) & 0,55 & 0,41 & 0,6 & & 1 & 0,23 & & 0,15 & 0,37 & 0,14 & 0,23 \\
\hline & & Mesas auxiliares (descarga) & 0,55 & 0,41 & 0,6 & & 1 & 0,23 & & 0,15 & 0,37 & 0,14 & 0,23 \\
\hline & & Remachadora neumática & 0,4 & 0,3 & 1,1 & 1 & 1 & 0,12 & 0,12 & 0,16 & 0,40 & 0,13 & 0,12 \\
\hline & & Mesas auxiliares (carga) & 0,55 & 0,41 & 0,6 & & 1 & 0,23 & & 0,15 & 0,37 & 0,14 & 0,23 \\
\hline & & Mesas auxiliares (descarga) & 0,55 & 0,41 & 0,6 & & 1 & 0,23 & & 0,15 & 0,37 & 0,14 & 0,23 \\
\hline
\end{tabular}


(continuación)

\begin{tabular}{|c|c|c|c|c|c|c|c|c|c|c|c|c|}
\hline \multirow{2}{*}{\multicolumn{2}{|c|}{ Elementos }} & \multicolumn{3}{|c|}{ Dimensiones (m) } & \multirow[b]{2}{*}{$\mathbf{N}$} & \multirow[b]{2}{*}{$\mathbf{n}$} & \multirow[b]{2}{*}{ Ss } & \multirow[b]{2}{*}{$\mathbf{S g}$} & \multirow[b]{2}{*}{ Se } & \multirow[b]{2}{*}{ St } & \multicolumn{2}{|c|}{ Cálculo de $\mathbf{k}$} \\
\hline & & $\mathbf{L}$ & A & $\mathbf{h}$ & & & & & & & Ss $\times n \times h$ & Ss $\mathbf{x} n$ \\
\hline & Mesa de control de calidad & 1,5 & 0,7 & 0.8 & 2 & 1 & 1,05 & 2,10 & 2,07 & 5,22 & 0,84 & 1,05 \\
\hline \multirow{4}{*}{ Zona de acabados } & Plancha de vapor & 1,82 & 0,94 & 1,04 & 1 & 1 & 1,71 & 1,71 & 2,25 & 5,67 & 2 & 1,71 \\
\hline & Mesas auxiliares (carga) & 0,55 & 0,41 & 0,6 & & 1 & 0,23 & & 0,15 & 0,37 & 0,14 & 0,23 \\
\hline & Mesas auxiliares (descarga) & 0,55 & 0,41 & 0,6 & & 1 & 0,23 & & 0,15 & 0,37 & 0,14 & 0,23 \\
\hline & Mesas para etiquetar, doblar y embolsar & 1,5 & 0,7 & 0,8 & 1 & 2 & 1,05 & 1,05 & 1,38 & 6,95 & 2 & 2,10 \\
\hline \multirow{2}{*}{ Móviles } & Operarios & $X$ & $X$ & 1,65 & & 20 & 0,50 & & & & 17 & 10,00 \\
\hline & Carrito de plataforma & 1.6 & 0,8 & 0,85 & & 1 & 0,50 & & & & 0,43 & 0,50 \\
\hline & & & & & & & & & TOTAL & 156,20 & & \\
\hline
\end{tabular}

Elaboración propia 
Análisis del 30\% para los posibles elementos independientes:

- Zona de corte

Sg de la mesa de corte: $2 \times 10 \mathrm{~m} \times 2 \mathrm{~m}=40 \mathrm{~m}^{2}$

Ss del almacenamiento temporal (carga): $1,6 \mathrm{~m} \times 0,5 \mathrm{~m}=0,8 \mathrm{~m}^{2}$

$\%=0,8 / 40 \times 100=2 \%<30 \%$, no se debe considerar como elemento independiente según el análisis del 30\%, sin embargo, lo consideramos como elementos independientes por la necesidad de espacio para las operaciones de tendido y corte.

- Zona de confección

Sg de la máquina remalladora: $1 \times 1,2 \times 0,55 \mathrm{~m}=0,66 \mathrm{~m}$

Ss de la mesa auxiliar (carga): $0,55 \times 0,41 \mathrm{~m}=0,23 \mathrm{~m}$

Ss de la mesa auxiliar (descarga): $0,55 \times 0,41 \mathrm{~m}=0,23 \mathrm{~m}$

$\%=(0,23+0,23) / 0,66 \times 100=70 \%>30 \%$, se consideran a las mesas auxiliares de carga y descarga como elemento independiente.

Sg de la máquina de recta: 1 x 1,2 x 0,55 m =0,66 m

Ss de la mesa auxiliar (carga): 0,55 x 0,41 $\mathrm{m}=0,23 \mathrm{~m}$

Ss de la mesa auxiliar (descarga): $0,55 \times 0,41 \mathrm{~m}=0,23 \mathrm{~m}$

$\%=(0,23+0,23) / 0,66 \times 100=70 \%>30 \%$, se consideran a las mesas auxiliares de carga y descarga como elementos independientes.

Sg de la máquina de recubridora: $1 \times 1,2 \times 0,55 \mathrm{~m}=0,66 \mathrm{~m}$

Ss de la mesa auxiliar (carga): 0,55 x 0,41 $\mathrm{m}=0,23 \mathrm{~m}$

Ss de la mesa auxiliar (descarga): $0,55 \times 0,41 \mathrm{~m}=0,23 \mathrm{~m}$ 
$\%=(0,23+0,23) / 0,66 \times 100=70 \%>30 \%$, se consideran a las mesas auxiliares de carga y descarga como elementos independientes.

Sg de la máquina collaretera: 1 x $0,61 \times 0,41 \mathrm{~m}=0,25 \mathrm{~m}$

Ss de la mesa auxiliar (carga): 0,55 x 0,41 $\mathrm{m}=0,23 \mathrm{~m}$

Ss de la mesa auxiliar (descarga): $0,55 \times 0,41 \mathrm{~m}=0,23 \mathrm{~m}$

$\%=(0,23+0,23) / 0,25 \times 100=184 \%>30 \%$, se consideran a las mesas auxiliares de carga y descarga como elementos independientes.

Sg de la remachadora neumática: 1 x 0,4 x $0,3 \mathrm{~m}=0,12 \mathrm{~m}$

Ss de la mesa auxiliar (carga): 0,55 x 0,41 $\mathrm{m}=0,23 \mathrm{~m}$

Ss de la mesa auxiliar (descarga): $0,55 \times 0,41 \mathrm{~m}=0,23 \mathrm{~m}$

$\%=(0,23+0,23) / 0,12 \times 100=383 \%>30 \%$, se consideran a las mesas auxiliares de carga y descarga como elemento independiente.

- Zona de acabados

Sg de la plancha de vapor: 1 x 1,5 x 0,8 $\mathrm{m}=1,2 \mathrm{~m}^{2}$

Ss de la mesa auxiliar (carga): 0,55 x 0,41 $\mathrm{m}=0,23 \mathrm{~m}$

Ss de la mesa auxiliar (descarga): $0,55 \times 0,41 \mathrm{~m}=0,23 \mathrm{~m}$

$\%=(0,23+0,23) / 1,2 \times 100=38.3 \%>30 \%$, se consideran a las mesas auxiliares de carga y descarga como elemento independiente. 
Tabla 5. 38

Cálculo de K

\begin{tabular}{|c|r|}
\hline hee & 1,20 \\
\hline hem & 1,61 \\
\hline $\mathbf{k}$ & 0,67 \\
\hline
\end{tabular}

Elaboración propia

Tabla 5. 39

Área mínima requerida total

\begin{tabular}{|c|r|}
\hline \multicolumn{2}{|c|}{ Área mínima requerida } \\
\hline Área de producción (Guerchet) & $156,20 \mathrm{~m}^{2}$ \\
\hline Área de almacén de materia prima e insumos & $27,7 \mathrm{~m}^{2}$ \\
\hline Área de almacén de productos terminados & $18,76 \mathrm{~m}^{2}$ \\
\hline Área de desarrollo de producto & $8,7 \mathrm{~m}^{2}$ \\
\hline Área de patio de maniobras & $74 \mathrm{~m}^{2}$ \\
\hline Área administrativa & $63 \mathrm{~m}^{2}$ \\
\hline Área de control y seguridad & $4,50 \mathrm{~m}^{2}$ \\
\hline Área de servicios & $73,7 \mathrm{~m}^{2}$ \\
\hline Área de control de calidad & $6,86 \mathrm{~m}^{2}$ \\
\hline Área de Showroom & $22,2 \mathrm{~m}^{2}$ \\
\hline TOTAL & $455,62 \mathrm{~m}^{2}$ \\
\hline
\end{tabular}

Elaboración propia

Para determinar las dimensiones del terreno asumiremos uno de dimensiones L x L/2.

$\mathrm{L} \times \mathrm{L} / 2=455,62$

Es recomendable un terreno de $30 \mathrm{~m}$ x $31 \mathrm{~m}$ (valores ajustados).

\subsubsection{Dispositivos de seguridad industrial y señalización}

- Dispositivos de protección colectiva:

Se consideran métodos de protección colectiva a aquellas que protegen simultáneamente a más de una persona. Para nuestro proyecto se presentarán las siguientes:

-Interruptores diferenciales: sistema de protección automático que se coloca en las instalaciones eléctricas, que "tiene la función de proteger la instalación de derivaciones a tierra y a las personas de contactos directos o indirectos" (cortocircuito) (Universitat Politécnica de Valencia, 2012). 
-Extintores manuales de incendio: Generalmente se usa el extintor de polvo químico seco, ya que no son conductores de electricidad (Expower, 2015)

- $\quad$ Sistemas de protección individual:

Los equipos de protección personal a utilizar son:

-Protectores de oídos: protectores auditivos tipos tampones.

-Protectores de vías respiratorias: mascarillas filtrantes de partículas.

-Protectores de manos: guantes de metal (Castillo y Pilco, 2014).

- Señalización:

Tabla 5.40

Señalización

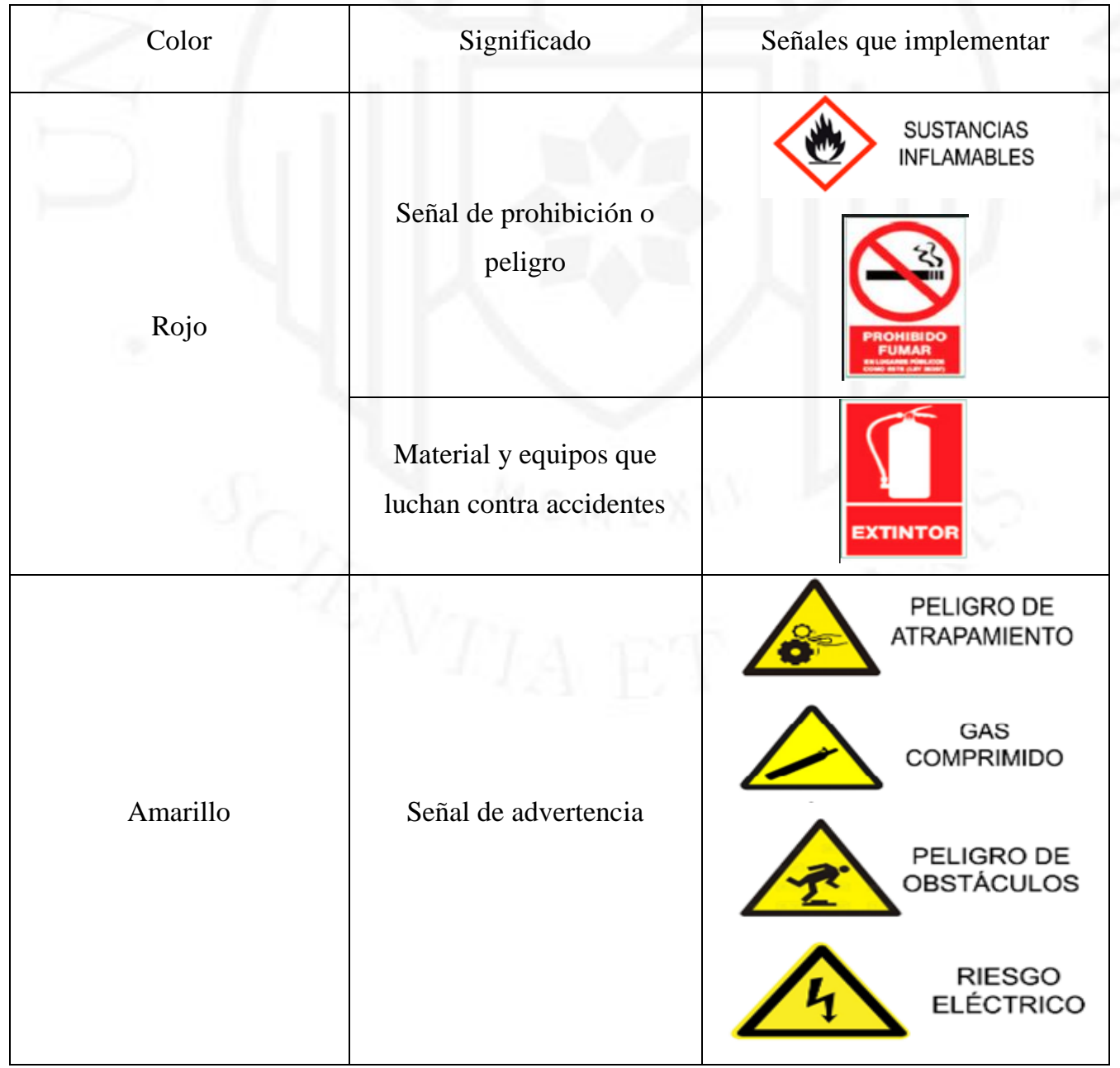

(continúa) 
(continuación)

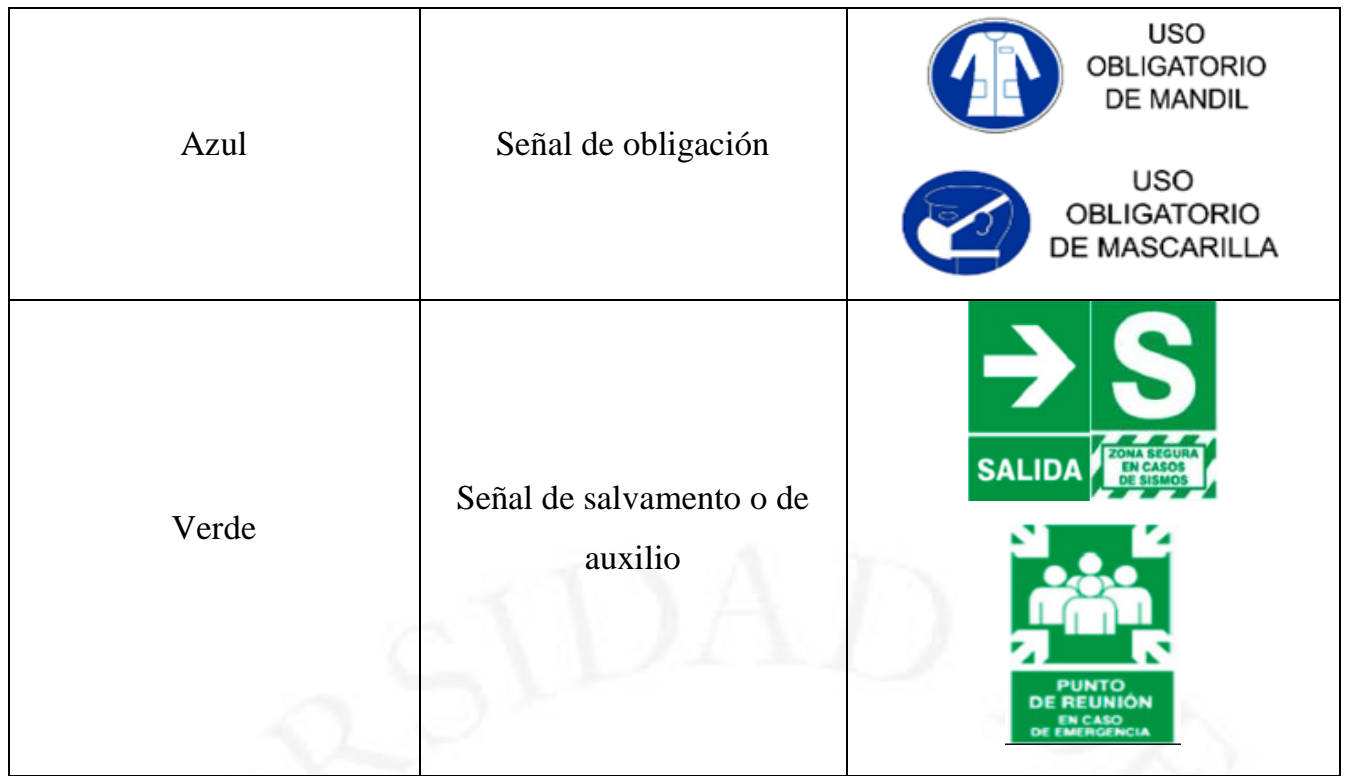

Fuente: Seguridad en plantas, (2013)

Elaboración propia. 


\subsubsection{Disposición general}

Figura 5. 26

Plano de disposición

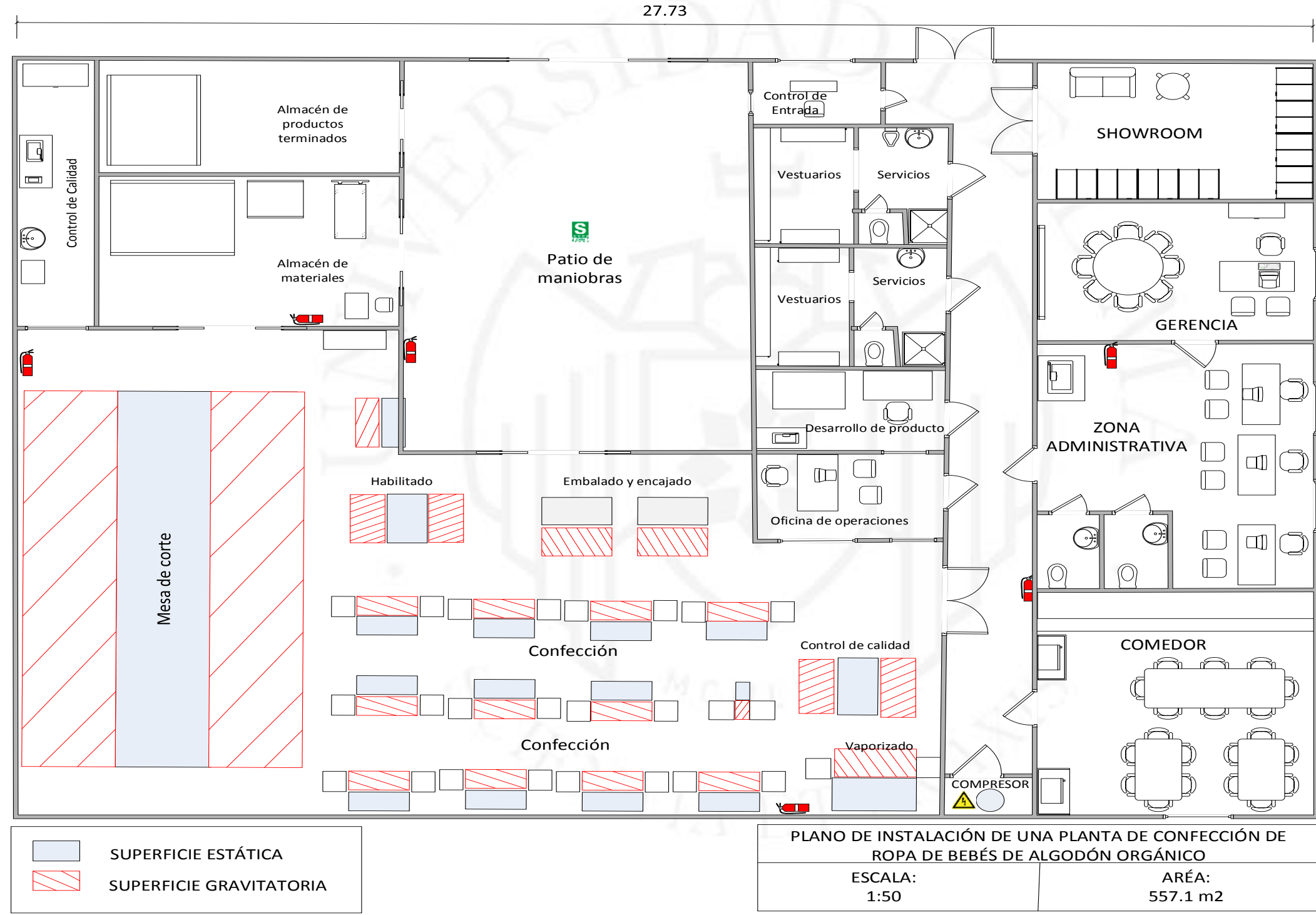




\subsubsection{Disposición de detalle}

Para poder obtener la disposición detallada de la zona productivas realizaremos un análisis relacional que consiste en una tabla relacional, diagrama relacional y diagrama relacional de espacios.

- Tabla relacional

Lista de motivos:

1. Flujo de proceso

2. Control

3. Importancia de los contactos administrativos

4. Atención de clientes y proveedores

5. Posible contaminación

6. Servicios para el personal

Tabla 5. 41

Tabla Relacional

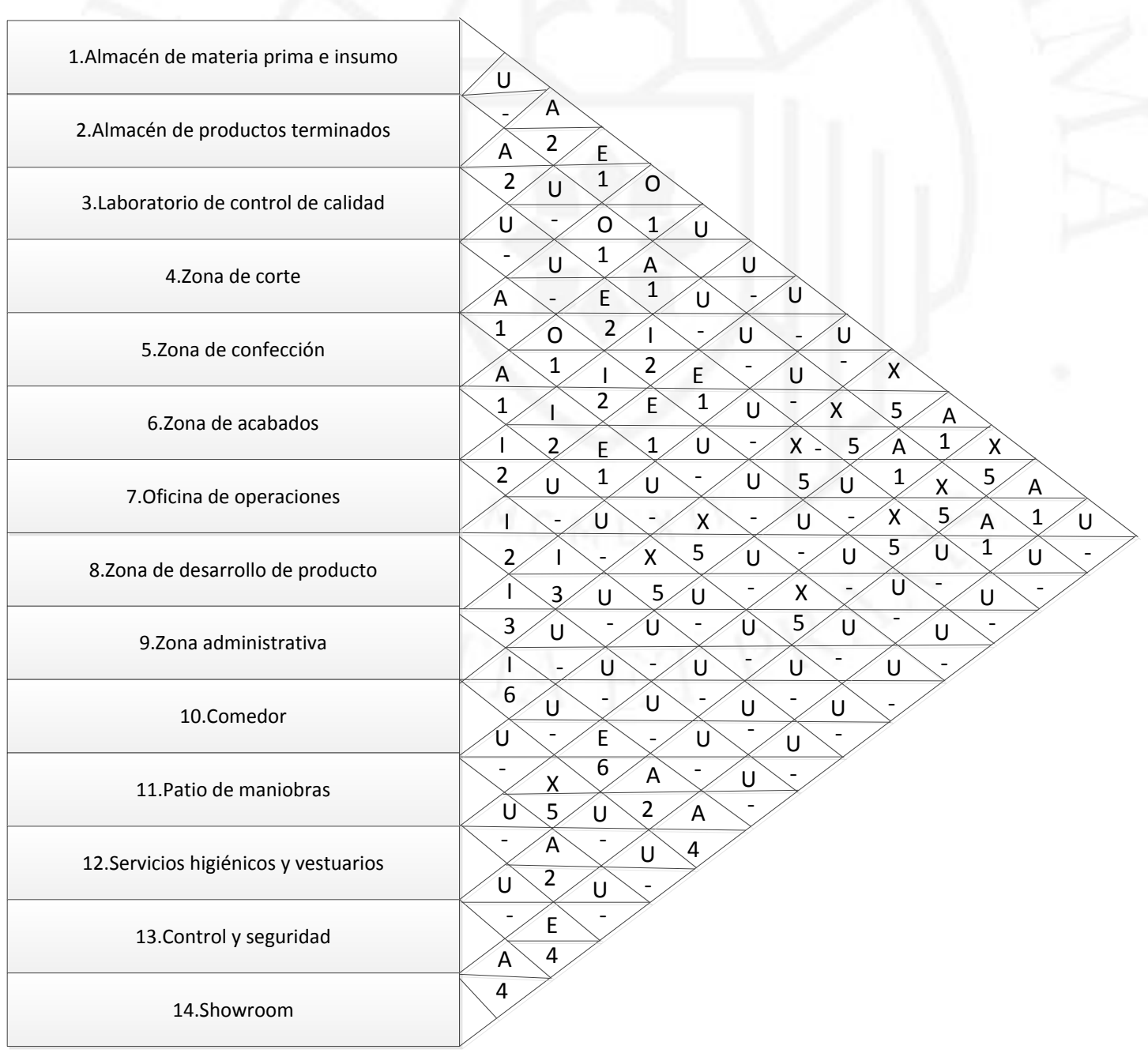

Elaboración propia 
- Diagrama relacional:

Tabla 5.42

Asignación de símbolos

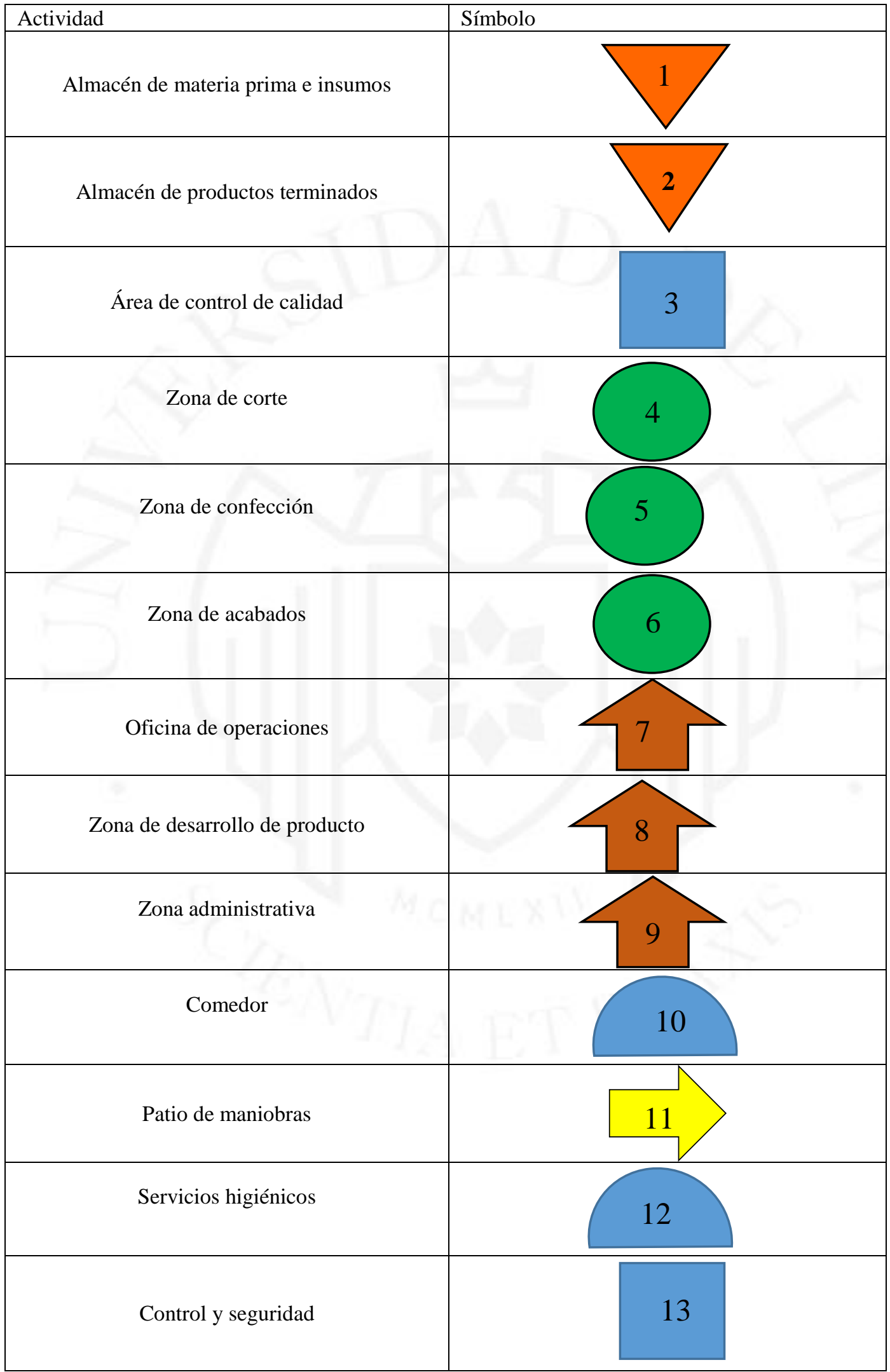

(continúa) 
(continuación)

\begin{tabular}{|c|l|}
\hline Actividad & Símbolo \\
\hline Showroom & \\
& \\
\hline
\end{tabular}

Elaboración propia

Figura 5. 27

Diagrama relacional de actividades

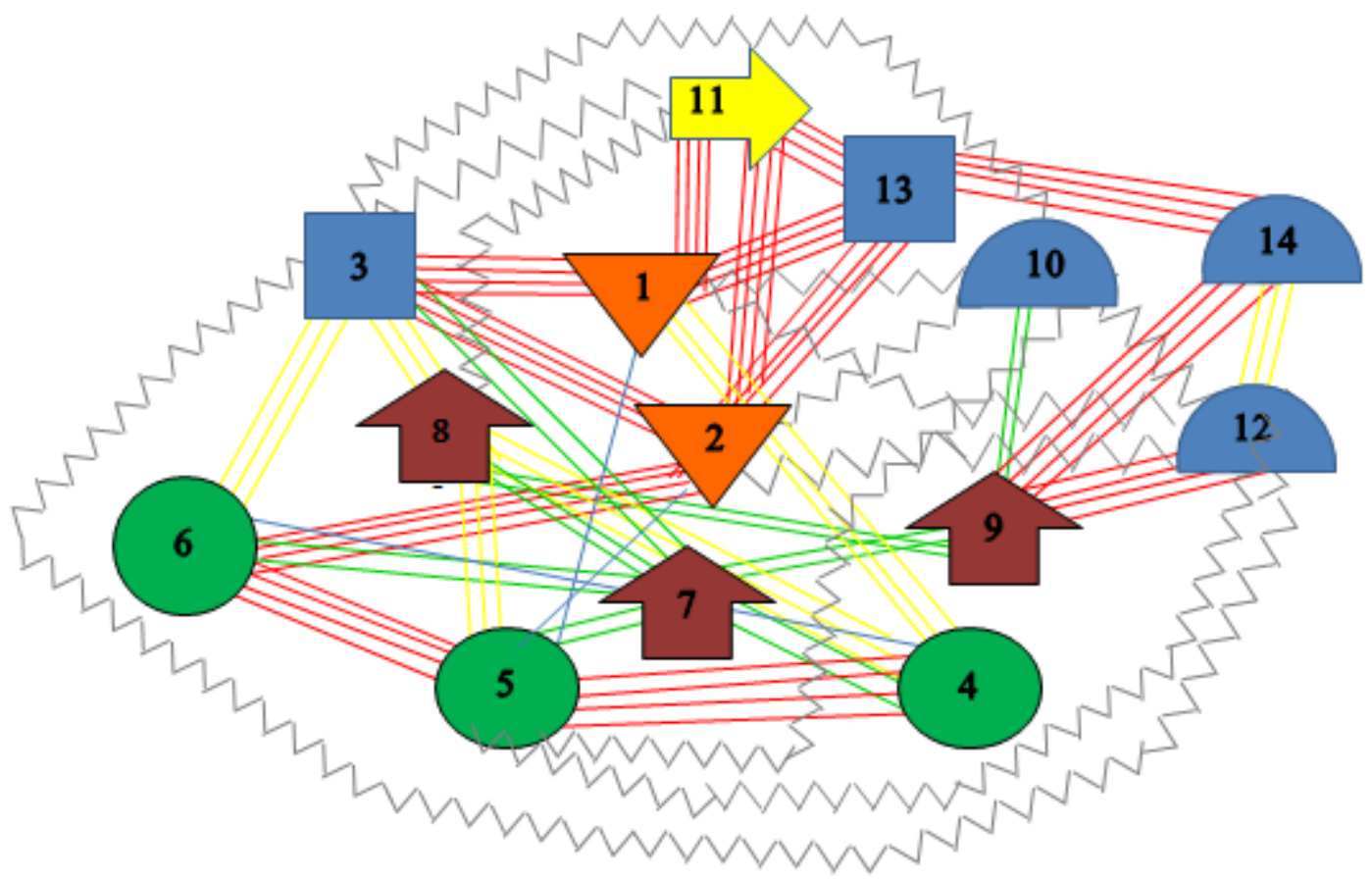

Elaboración propia 


\subsection{Cronograma de implementación del proyecto}

Figura 5. 28

Cronograma

\begin{tabular}{|c|c|c|c|c|c|c|c|c|c|c|c|c|c|c|c|c|c|c|}
\hline \multirow[t]{2}{*}{ ACTIVIDAD } & \multirow[t]{2}{*}{ INICIO DEL PLAN } & \multirow[t]{2}{*}{ DURACIÓN DEL PLAN } & \multicolumn{16}{|c|}{ MESES } \\
\hline & & & 1 & 2 & 3 & 4 & 5 & 6 & 7 & 8 & 9 & 10 & 11 & 12 & 13 & 14 & 15 & $16 \quad 17$ \\
\hline PLAN DE IMPLEMENTACIÓN & 1 & 17 & & & & & & & & & & & & & & & & \\
\hline Actividades Previas & 1 & 7 & & & & & & & & & & & & & & & & \\
\hline Estudios previos & 1 & 2 & & & & & & & & & & & & & & & & \\
\hline Organización, diseño y constitución de la empresa & 3 & 2 & & & & & & & & & & & & & & & & \\
\hline Solicitud de Financiemiento & 5 & 1 & & & & & & & & & & & & & & & & \\
\hline Búsqueda de terreno y acondicionamiento & 6 & 2 & & & & & & & & & & & & & & & & \\
\hline Compra de maquinaria y equipos & 8 & 4 & & & & & & & & & & & & & & & & \\
\hline Proceso de compra y diseño & 8 & 2 & & & & & & & & & & & & & & & & \\
\hline Instalaciones y verificación de buen funcionamiento & 10 & 1 & & & & & & & & & & & & & & & & \\
\hline Compra de accesorios y repuestos & 11 & 1 & & & & & & & & & & & & & & & & \\
\hline Compra de materia prima e insumos & 12 & 2 & & & & & & & & & & & & & & & & \\
\hline Proceso de compra de materia prima e insumos & 12 & 1 & & & & & & & & & & & & & & & & \\
\hline $\begin{array}{l}\text { Realización de pruebas y procedimientos en cuanto a } \\
\text { formulación }\end{array}$ & 13 & 1 & & & & & & & & & & & & & & & & \\
\hline Contratación de personal & 14 & 1 & & & & & & & & & & & & & & & & \\
\hline Inducción y capacitación del personal & 14 & 1 & & & & & & & & & & & & & & & & \\
\hline Pruebas previas a la puesta en marcha & 15 & 2 & & & & & & & & & & & & & & & & \\
\hline Actividades complementarias & 17 & 1 & & & & & & & & & & & & & & & & \\
\hline
\end{tabular}

Fuente: Díaz, B. y Noriega, M., (2017)

Elaboración propia 


\section{CAPÍTULO VI: ORGANIZACIÓN Y ADMINISTRACIÓN}

\subsection{Formación de la organización empresarial}

Nuestra empresa será una sociedad anónima cerrada ya que, al ser una empresa nueva, hay riesgo de tener pérdidas; y en este caso los accionistas no tendrán la responsabilidad de las deudas y daños a terceros (la empresa es una entidad independiente de los accionistas), el riesgo de pérdida de dinero se limita a sus aportes y sus acciones pueden ser transferibles (Ramírez, 2015).

\subsection{Requerimientos de personal directivo, administrativo y de servicios}

Tabla 6. 1

Requerimientos de personal

\begin{tabular}{|c|c|c|c|}
\hline Puesto & Objetivo & Funciones principales & $\begin{array}{l}\text { Requerimientos } \\
\text { principales }\end{array}$ \\
\hline \multirow{4}{*}{$\begin{array}{l}\text { Gerente } \\
\text { general }\end{array}$} & \multirow{4}{*}{$\begin{array}{l}\text { Dirigir, planificar y } \\
\text { controlar las } \\
\text { actividades } \\
\text { administrativas, } \\
\text { operativas y de } \\
\text { comercialización. }\end{array}$} & $\begin{array}{l}\text { Representar legalmente a la empresa. } \\
\text { Revisar los términos de contrato internacional. } \\
\text { Revisar los términos de la carta crédito y/o } \\
\text { características de los documentos de cobranza. }\end{array}$ & \multirow{4}{*}{$\begin{array}{c}\text { Instrucción: } \\
\text { Ingeniero o } \\
\text { Administrador } \\
\text { con } 8 \text { años de } \\
\text { experiencia en el } \\
\text { rubro. } \\
\text { Idiomas: } \\
\text { español, inglés }\end{array}$} \\
\hline & & $\begin{array}{c}\text { Analizar y aprobar presupuestos. } \\
\text { Establecer alianzas con proveedores } \\
\text { Analizar la situación de los estados financieros }\end{array}$ & \\
\hline & & $\begin{array}{c}\text { Supervisar el pago de planillas. } \\
\text { Convocar y dirigir reuniones mensuales de } \\
\text { planificación } \\
\text { Elaborar la política de compensación e incentivos. }\end{array}$ & \\
\hline & & $\begin{array}{l}\text { Realizar un plan estratégico anualmente en conjunto } \\
\text { con todos los jefes de área. } \\
\text { Evaluar el cumplimiento de los objetivos de todas las } \\
\text { áreas de la empresa. }\end{array}$ & \\
\hline $\begin{array}{c}\text { Asistente } \\
\text { administrativo }\end{array}$ & $\begin{array}{l}\text { Realizar actividades de } \\
\text { apoyo administrativo } \\
\text { para facilitar la } \\
\text { información requerida } \\
\text { por la gerencia. } \\
\end{array}$ & $\begin{array}{l}\text { Elaborar del flujo de caja diario. } \\
\text { Controlar presupuestos por áreas. } \\
\text { Coordinar requerimientos de las áreas. } \\
\text { Realizar el pago de planillas. }\end{array}$ & $\begin{array}{l}\text { Instrucción: } \\
\text { Técnico de } \\
\text { administración }\end{array}$ \\
\hline \multirow{3}{*}{$\begin{array}{l}\text { Coordinador } \\
\text { de ventas }\end{array}$} & \multirow{3}{*}{$\begin{array}{l}\text { Planificar, coordinar y } \\
\text { atender todas las } \\
\text { actividades } \\
\text { relacionadas a la } \\
\text { estrategia de } \\
\text { comercialización y } \\
\text { promoción de los } \\
\text { productos. }\end{array}$} & $\begin{array}{c}\text { Realizar la inteligencia comercial de la empresa } \\
\text { Realizar el plan de marketing internacional de la } \\
\text { empresa. } \\
\text { Analizar las tendencias de mercado y la } \\
\text { adaptabilidad del producto. }\end{array}$ & \multirow{3}{*}{$\begin{array}{c}\text { Instrucción: } \\
\text { Administrador } \\
\text { de empresas } \\
\text { especializado en } \\
\text { comercio } \\
\text { internacional con } \\
4 \text { años de } \\
\text { experiencia en el } \\
\text { rubro. } \\
\text { Idiomas: inglés, } \\
\text { español }\end{array}$} \\
\hline & & $\begin{array}{c}\text { Coordinar la elaboración de catálogos y cotizaciones. } \\
\text { Enviar muestras. } \\
\text { Gestionar la atención post-venta }\end{array}$ & \\
\hline & & $\begin{array}{c}\text { Asistir a ferias y/o misiones comerciales. } \\
\text { Asistir a charlas, cursos y seminarios especializados. } \\
\text { Coordinar el mantenimiento y actualización de la } \\
\text { página web }\end{array}$ & \\
\hline
\end{tabular}




\begin{tabular}{|c|c|c|c|}
\hline Puesto & Objetivo & Funciones principales & $\begin{array}{l}\text { Requerimientos } \\
\text { principales }\end{array}$ \\
\hline \multirow{5}{*}{$\begin{array}{l}\text { Supervisor de } \\
\text { operaciones }\end{array}$} & \multirow{5}{*}{$\begin{array}{l}\text { Planificar, coordinar y } \\
\text { controlar el } \\
\text { cumplimiento de los } \\
\text { programas de } \\
\text { producción, seguridad y } \\
\text { nivel de calidad. }\end{array}$} & $\begin{array}{l}\text { Definir y asegurar el cumplimiento de las metas de } \\
\text { producción } \\
\text { Desarrollar y analizar los indicadores de gestión }\end{array}$ & \multirow{5}{*}{$\begin{array}{c}\text { Instrucción: } \\
\text { Ingeniero Textil } \\
\text { o Ingeniero } \\
\text { Industrial con } \\
\text { experiencia de } 4 \\
\text { años en el rubro } \\
\text { Idiomas: español } \\
\text { e inglés }\end{array}$} \\
\hline & & $\begin{array}{l}\text { Garantizar la calidad del producto en todo el proceso } \\
\text { de producción }\end{array}$ & \\
\hline & & $\begin{array}{l}\text { Asegurar que el personal utilice los implementos de } \\
\text { seguridad proporcionados. }\end{array}$ & \\
\hline & & $\begin{array}{l}\text { Coordinar la ejecución de los correctos } \\
\text { mantenimientos de las máquinas. }\end{array}$ & \\
\hline & & Supervisar los costos de producción & \\
\hline \multirow[t]{2}{*}{$\begin{array}{l}\text { Coordinador } \\
\text { de logística }\end{array}$} & \multirow[t]{2}{*}{$\begin{array}{l}\text { Coordinar y controlar la } \\
\text { logística de } \\
\text { operaciones. }\end{array}$} & $\begin{array}{l}\text { Coordinar y ejecutar las compras según los } \\
\text { estándares de la empresa. } \\
\text { Ejecutar la logística de ventas. } \\
\text { Elaborar presupuestos de operaciones y asignar } \\
\text { recursos. } \\
\text { Llevar en la práctica el diseño del producto. }\end{array}$ & \multirow{2}{*}{$\begin{array}{c}\text { Instrucción: } \\
\text { Ingeniero Textil } \\
\text { o Ingeniero } \\
\text { Industrial con } \\
\text { experiencia de } 4 \\
\text { años en el rubro } \\
\text { Idiomas: español } \\
\text { e inglés }\end{array}$} \\
\hline & & $\begin{array}{c}\text { Gestionar la compra de insumos } \\
\text { Controlar el reabastecimiento de stock de } \\
\text { inventarios. }\end{array}$ & \\
\hline \multirow[b]{2}{*}{ Modelista } & \multirow{2}{*}{$\begin{array}{l}\text { Asegurar la entrega de } \\
\text { moldes y escalados de } \\
\text { los productos a los } \\
\text { clientes internos. }\end{array}$} & $\begin{array}{l}\text { Elaborar los moldes y las fichas técnicas para el área } \\
\text { de producción }\end{array}$ & \multirow{2}{*}{$\begin{array}{l}\text { Instrucción: } \\
\text { Estudios técnicos } \\
\text { o experiencia de } \\
2 \text { años en el } \\
\text { puesto }\end{array}$} \\
\hline & & Realizar el control de calidad de los prototipos & \\
\hline Almacenero & $\begin{array}{l}\text { Controlar el inventario } \\
\text { de materiales y } \\
\text { productos terminados } \\
\text { de la empresa. }\end{array}$ & $\begin{array}{l}\text { Elaborar y revisar las guías de remisión. } \\
\text { Registrar el ingreso y salida de productos. } \\
\text { Realizar el control de inventario mensual. }\end{array}$ & $\begin{array}{c}\text { Instrucción: } \\
\text { Secundaria } \\
\text { completa y } \\
\text { experiencia de } 2 \\
\text { años en el puesto }\end{array}$ \\
\hline Maquinista & $\begin{array}{l}\text { Confeccionar prendas } \\
\text { utilizando máquinas y } \\
\text { utensilios de coser de } \\
\text { diferentes } \\
\text { tipos, conforme a los } \\
\text { procesos de confección. }\end{array}$ & $\begin{array}{c}\text { Ejecutar procesos de costura } \\
\text { Manejar máquinas de costura. } \\
\text { Manejar tiempos y cumplimiento de metas } \\
\text { productivas. }\end{array}$ & $\begin{array}{l}\text { Instrucción: } \\
\text { Estudios técnicos } \\
\text { o experiencia de } \\
2 \text { años en el } \\
\text { puesto }\end{array}$ \\
\hline
\end{tabular}

Fuente: Ministerio del Interior, MININTER. (2013)

Elaboración propia 


\subsection{Estructura organizacional.}

Figura 6. 1

Organigrama

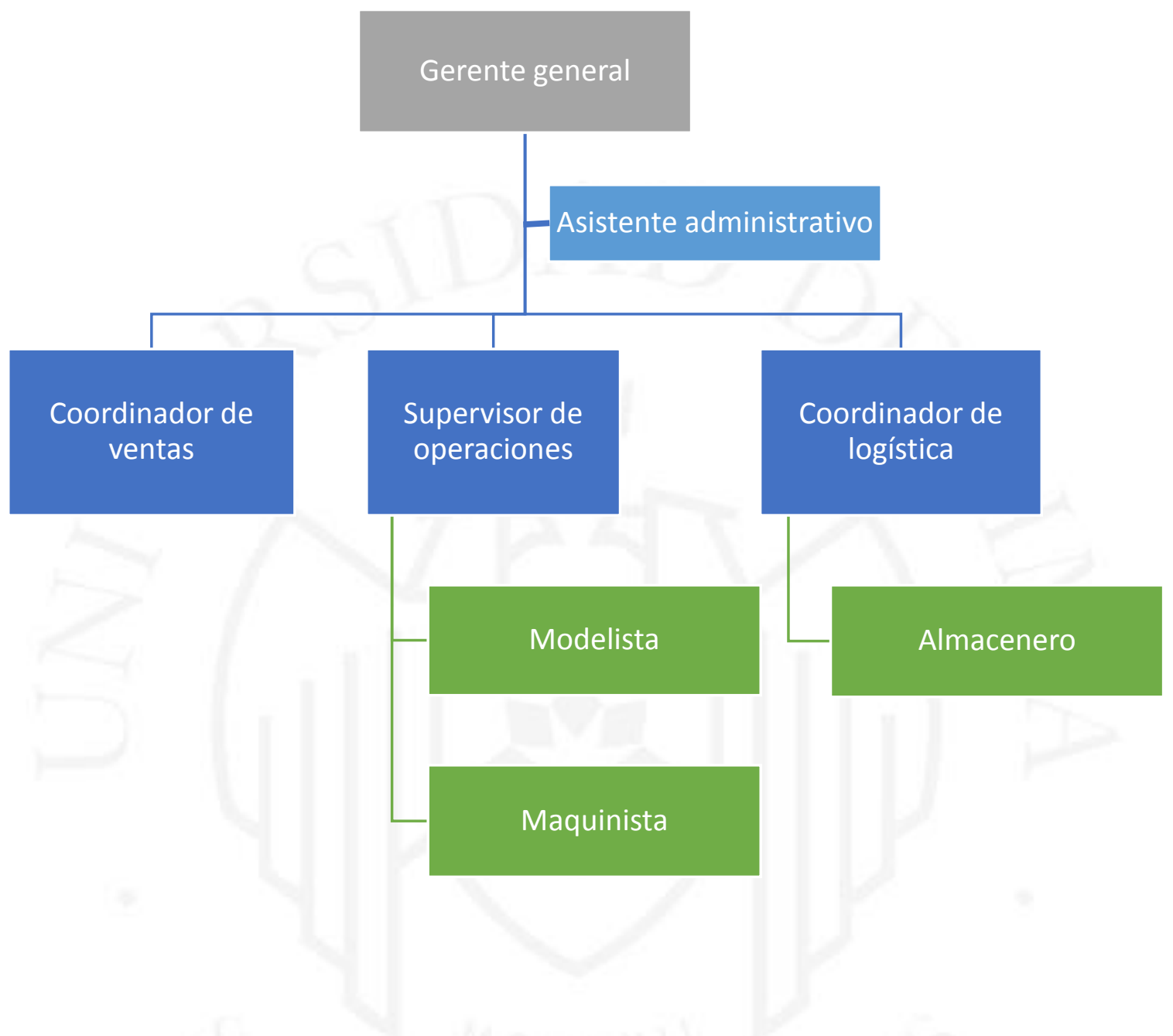

Elaboración propia 


\section{CAPÍTULO VII: ASPECTOS ECONÓMICOS Y FINANCIEROS}

\subsection{Inversiones.}

\subsubsection{Estimación de las inversiones de largo plazo (tangibles e intangibles).}

Las inversiones de largo plazo comprenden los activos tangibles como la infraestructura, las obras civiles, las maquinarias y muebles; además de los activos intangibles como los estudios, trámites legales, certificaciones y puesta en marcha.

Los montos descritos en la tabla de activos tangibles obtenidos de cotizaciones, consulta a profesionales, páginas de proveedores nacionales, etc.

Tabla 7.1

Activos Tangibles

\begin{tabular}{|c|c|c|c|}
\hline Activo Tangible & Cantidad & Precio unitario & $\operatorname{Monto}(\mathrm{S} /)$. \\
\hline \multicolumn{4}{|l|}{ Infraestructura } \\
\hline Terreno (m2) & 557,1 & 270 & 150370 \\
\hline Construcción & 1 & 90000 & 90000 \\
\hline Instalaciones eléctricas & 1 & 2000 & 2000 \\
\hline $\begin{array}{l}\text { Montaje aire acondicionado y aire } \\
\text { comprimido }\end{array}$ & 1 & 2000 & 2000 \\
\hline Montaje sanitario & 1 & 2500 & 2500 \\
\hline Imprevistos & 1 & 7000 & 8000 \\
\hline Transformador & 1 & 150 & 150 \\
\hline \multicolumn{4}{|l|}{ Acondicionamiento } \\
\hline Extintores & 8 & 120 & 960 \\
\hline Aire Acondicionado & 1 & 2542 & 3000 \\
\hline Extractor de aire & 1 & 1618 & 1618 \\
\hline Focos(planta) & 30 & 130 & 3900 \\
\hline Focos(oficina) & 20 & 90 & 1800 \\
\hline \multicolumn{4}{|l|}{ Instalaciones higiénicas } \\
\hline Retrete & 4 & 143 & 572 \\
\hline Lavaderos & 4 & 40 & 160 \\
\hline Lockers & 6 & 150 & 900 \\
\hline \multicolumn{4}{|l|}{ Comedor } \\
\hline Mesas de comedor & 4 & 100 & 400 \\
\hline Mesas para microondas & 2 & 50 & 100 \\
\hline Microondas & 2 & 150 & 300 \\
\hline Sillas de comedor & 20 & 45 & 900 \\
\hline \multicolumn{4}{|l|}{ Laboratorio } \\
\hline Balanza de precisión & 1 & 424 & 424 \\
\hline Lavatorio & 1 & 246 & 246 \\
\hline Lavadora & 1 & 449 & 449 \\
\hline Cronómetros & 1 & 85 & 85 \\
\hline
\end{tabular}


(continuación)

\begin{tabular}{|c|c|c|c|}
\hline Activo Tangible & Cantidad & Precio unitario & Monto (S/.) \\
\hline Escala de grises AATCC & 1 & 974 & 974 \\
\hline \multicolumn{4}{|l|}{ Diseño } \\
\hline Escritorio & 1 & 85 & 85 \\
\hline Computadora & 1 & 2119 & 2119 \\
\hline Silla & 1 & 85 & 85 \\
\hline Mesa de diseño & 1 & 381 & 381 \\
\hline Estantes para prototipos & 1 & 127 & 127 \\
\hline \multicolumn{4}{|l|}{ Confección } \\
\hline Cortadora semi-automática & 1 & 847 & 847 \\
\hline Cortadora de cintas & 1 & 826 & 826 \\
\hline Remalladora & 4 & 1525 & 6102 \\
\hline Recubridora & 4 & 2373 & 9492 \\
\hline Remachadora & 1 & 1525 & 1525 \\
\hline Collaretera & 1 & 1695 & 1695 \\
\hline Vaporizadora & 1 & 1102 & 1102 \\
\hline Recta & 1 & 1102 & 1102 \\
\hline Compresor & 1 & 1271 & 1271 \\
\hline Mesas auxiliares & 24 & 140 & 3356 \\
\hline Mesa de corte & 1 & 1186 & 1186 \\
\hline Tachos & 10 & 25 & 254 \\
\hline Sillas para la zona de operación & 20 & 85 & 1695 \\
\hline \multicolumn{4}{|l|}{ Acabados } \\
\hline Tijeras corta hilos & 2 & 7,78 & 16 \\
\hline Mesa para acabados & 1 & 250 & 250 \\
\hline Pistola de balines & 1 & 50 & 50 \\
\hline \multicolumn{4}{|l|}{ Almacenes } \\
\hline Bastidores de telas & 1 & 1097 & 1097 \\
\hline Anaqueles para materiales & 1 & 271 & 271 \\
\hline Estantes para pt & 1 & 593 & 593 \\
\hline Escritorios pequeños & 1 & 127 & 127 \\
\hline Sillas de escritorio & 1 & 85 & 85 \\
\hline Carrito de plataforma & 1 & 144 & 144 \\
\hline \multicolumn{4}{|l|}{ Oficinas administrativas } \\
\hline Escritorios & 5 & 170 & 850 \\
\hline Laptop & 1 & 2119 & 2119 \\
\hline Computadoras & 5 & 1300 & 6500 \\
\hline Tachos & 5 & 25 & 127 \\
\hline Estantes de oficina & 4 & 127 & 509 \\
\hline Red telefónica & 1 & 576 & 576 \\
\hline Impresoras & 2 & 1017 & 1200 \\
\hline Sillas de escritorio & 5 & 127 & 1200 \\
\hline Útiles & 1 & 424 & 1200 \\
\hline TOTAL & & & 321970 \\
\hline
\end{tabular}

Elaboración propia

Los montos descritos en los activos intangibles fueron obtenidos de cotizaciones, consulta a profesionales, páginas de proveedores nacionales, etc. 
Tabla 7. 2

Activos Intangibles

\begin{tabular}{|l|c|}
\hline \multicolumn{1}{|c|}{ Activo intangible } & Monto (S/.) \\
\hline Estudios & 2500 \\
\hline Trámites burocráticos & 2000 \\
\hline Ingeniería de supervisión & 6000 \\
\hline Puesta en marcha & 10000 \\
\hline Contingencias & 2500 \\
\hline Paquete de office - empresa & 579 \\
\hline Certificaciones internacionales (anual) & 6269 \\
\hline TOTAL & 29848 \\
\hline
\end{tabular}

Elaboración propia

\subsubsection{Estimación de las inversiones de corto plazo (capital de trabajo).}

El ciclo de caja de la empresa es de 50 días por ser el promedio del sector.

Tabla 7. 3

Presupuesto de inversiones

\begin{tabular}{|c|c|c|}
\hline Inversión total & $\mathbf{4 0 0} \mathbf{6 8 1 , 0 5}$ & \\
\hline Inversiones tangibles & 321969,75 & \multirow{2}{*}{351817,50} \\
\hline Inversiones intangibles & 29847,75 & \\
\hline Capital de trabajo & 48863,54 & \\
\hline Elaboración propia & & \\
\hline
\end{tabular}

De la inversión total consideraremos un aporte propio del 40\%, calculado en 160 272,42 soles; siendo la suma restante financiada por un monto de 240408,63 soles.

\subsection{Costos de producción.}

\subsubsection{Costos de las materias primas.}

Los montos descritos en la tabla de costos de materia prima fueron obtenidos de cotizaciones, consulta a profesionales, páginas de proveedores nacionales, etc. 
Tabla 7.4

Costos de las materias primas

\begin{tabular}{|c|c|c|c|}
\hline \multicolumn{4}{|c|}{ MD } \\
\hline Insumos & $\begin{array}{l}\text { Precio / } \\
\text { cantidad }\end{array}$ & $\begin{array}{c}\text { Cantidad / } \\
\text { conjunto }\end{array}$ & $\begin{array}{c}\text { S/. / } \\
\text { conjunto }\end{array}$ \\
\hline Tela $(\mathrm{kg})$ & 50,065 & 0,17 & 8,6089 \\
\hline Entretela (und) & 0,833 & 0,0265 & 0,0221 \\
\hline Elástico (m) & 0,003 & 0,22 & 0,0007 \\
\hline Bolsas (und) & 0,05 & 0,01 & 0,0005 \\
\hline Cintas 1/2" (und) & 1,75 & 0,01 & 0,0088 \\
\hline Cintas 2" (und) & 4,25 & 0,001 & 0,0048 \\
\hline Cajas (und) & 7,25 & 0,02 & 0,1450 \\
\hline Hang Tag (und) & 0,09 & 0,02 & 0,0018 \\
\hline Balines (und) & 0,01 & 0,02 & 0,0002 \\
\hline Snaps (und) & 0,05 & 0,01 & 0,0005 \\
\hline Etiquetas de talla (und) & 0,06 & 0,02 & 0,0013 \\
\hline Etiquetas de composición (und) & 0,08 & 0,02 & 0,0017 \\
\hline Hilos de algodón (m) & 0,008 & 0,02 & 0,0002 \\
\hline \multicolumn{3}{|c|}{ TOTAL } & 8,7963 \\
\hline
\end{tabular}

Elaboración propia

\subsubsection{Costo de la mano de obra directa.}

La cantidad de operarios fue obtenida en el capítulo de capacidad de planta, mientras que el sueldo fue colocado acorde al mercado. (Ministerio de Trabajo y Promoción del Empleo, 2010)

Así mismo, con respecto al cálculo total, se consideraron los beneficios sociales tales como las gratificaciones (dos sueldos al año), vacaciones, compensación por tiempo de servicio (dos veces al año), aportes a Essalud por parte de la empresa (9\%), seguro complementario de trabajo de riesgo y aportes a Senati (0,75\%). (Ministerio de Trabajo y Promoción del Empleo, 2014)

Tabla 7. 5

Costo de mano de obra directa

\section{MOD}

Cantidad Sueldo TOTAL (incluyendo beneficios, seguros y aportes a senati)

$\begin{array}{llll}\text { Operarios } & 20 & 1100 & 326400\end{array}$

Elaboración propia 


\subsubsection{Costo indirecto de fabricación (materiales indirectos, mano de obra indirecta}

y costos generales de planta)

Los precios fueron obtenidos de las páginas web de tiendas especializados en el rubro. Así mismo, este costo de materiales indirectos representa un costo en materiales para realizar mantenimiento preventivo.

Tabla 7. 6

Costo de Materiales Indirectos

\begin{tabular}{|l|c|c|}
\hline \multicolumn{1}{|c|}{ Materiales Indirectos } & Mensual & Anual \\
\hline Franelas(paquetes 2 unidades) & 64 & 768 \\
\hline Aceite Blanco (1gl) & 33 & 400 \\
\hline Lubricante(unid*90 ml) & 30 & 360 \\
\hline Agujas (paquetes 8 unidades) & 37 & 442 \\
\hline Mascarillas & 25 & 100 \\
\hline Piedras de afilar & 30 & 90 \\
\hline Tapón oído & 76 & 228 \\
\hline \multicolumn{1}{|c|}{ TOTAL } & 295,1 & 2387,6 \\
\hline
\end{tabular}

Elaboración propia

Los sueldos mensuales fueron colocados de acuerdo al mercado peruano.

Tabla 7.7

Costos de mano de obra indirecta

\begin{tabular}{|c|c|c|}
\hline Mano de obra indirecta & Mensual & $\begin{array}{c}\text { Anual } \\
\text { (incluyendo } \\
\text { beneficios) }\end{array}$ \\
\hline Supervisor de producción & 3200 & 51840 \\
\hline Modelista & 1350 & 21870 \\
\hline TOTAL & 4550 & 73710 \\
\hline
\end{tabular}

Elaboración propia

Los montos descritos en la tabla superior fueron obtenidos de cotizaciones, consulta a profesionales, páginas de proveedores nacionales, etc. 
Tabla 7.8

Costo de consumo eléctrico

\begin{tabular}{|l|cc|}
\hline Uso tarifa MT3 & kw-hr & Anual (s/.) \\
\hline Carga fija mensual & & 207,8 \\
\hline Extractor de aire & 243,28 & 54,1 \\
\hline Cortadora & 243,28 & 54,1 \\
\hline Remalladora & 1750,95 & 389,4 \\
\hline Recubridora & 1689,58 & 375,8 \\
\hline Vaporizadora & 987,75 & 219,7 \\
\hline Compresor & 1191,37 & 265,0 \\
\hline Recta & 541,53 & 120,4 \\
\hline Collareta & 252,71 & 56,2 \\
\hline Cortadora de cintas & 28,88 & 6,4 \\
\hline Focos & 403 & 1076,1 \\
\hline TOTAL (1) & 6929,4 & 2617,1 \\
\hline Cargo adicional por acondicionamiento de máquinas & - & 444,9 \\
\hline TOTAL (2) & & 3269,9 \\
\hline Elaboración propia & & \\
\hline
\end{tabular}

Tabla 7.9

Costo por depreciación fabril

\begin{tabular}{|c|c|c|}
\hline Depreciaciones fabriles & Anual & $\begin{array}{c}\text { Depreciación } \\
\text { anual (\%) }\end{array}$ \\
\hline Construcción & 4500 & $5 \%$ \\
\hline Instalaciones eléctricas & 100 & $5 \%$ \\
\hline Montaje aire acondicionado y aire comprimido & 100 & $5 \%$ \\
\hline Montaje sanitario & 125 & $5 \%$ \\
\hline Imprevistos & 800 & $10 \%$ \\
\hline Transformador & 15 & $10 \%$ \\
\hline Extractor de aire & 161,8 & $10 \%$ \\
\hline Focos(planta) & 390 & $10 \%$ \\
\hline Cortadora semi-automática & 85 & $10 \%$ \\
\hline Cortadora de cintas & 83 & $10 \%$ \\
\hline Remalladora & 610 & $10 \%$ \\
\hline Recubridora & 949 & $10 \%$ \\
\hline Remachadora & 153 & $10 \%$ \\
\hline Collaretera & 169 & $10 \%$ \\
\hline Vaporizadora & 110 & $10 \%$ \\
\hline Recta & 110 & $10 \%$ \\
\hline Compresor & 127 & $10 \%$ \\
\hline Mesas auxiliares & 336 & $10 \%$ \\
\hline Mesa de corte & 119 & $10 \%$ \\
\hline Tachos & 25 & $10 \%$ \\
\hline Sillas para la zona de operación & 169 & $10 \%$ \\
\hline Tijeras corta hilos & 2 & $10 \%$ \\
\hline Mesa para acabados & 25 & $10 \%$ \\
\hline Pistola de balines & 5 & $10 \%$ \\
\hline
\end{tabular}

Fuente: Superintendencia Nacional de Aduanas y de Administración Tributaria, SUNAT. (2018)

Elaboración propia 
El porcentaje de depreciación se obtiene de la página de Sunat, y se considera un tiempo de vida igual al proyecto de 5 años. (Bernal, 2010)

Adicionalmente, consideraremos el costo invertido en agua destilada para el funcionamiento de la vaporizadora que anualmente es 8 906,3 soles.

\subsection{Presupuesto operativo.}

\subsubsection{Presupuesto de ingreso por ventas.}

Para este presupuesto consideraremos la proyección de la demanda calculada anteriormente y el precio fue obtenido según el cálculo del punto de equilibrio considerando una utilidad del $4 \%$.

Tabla 7. 10

Presupuesto de Ingresos por ventas

\begin{tabular}{|c|c|c|c|c|c|}
\hline & 2018 & 2019 & 2020 & 2021 & 2022 \\
\hline Unidades & 41156 & 47912 & 54869 & 62825 & 70766 \\
\hline Precio de Venta & 31 & 31 & 31 & 31 & 31 \\
\hline Ingreso & 1275849 & 1485275 & 1700927 & 1947589 & 2193751 \\
\hline
\end{tabular}

Elaboración propia

\subsubsection{Presupuesto operativo de costos.}

Tabla 7. 11

Tabla resumen de costo de producción

\begin{tabular}{|c|c|c|} 
Descripción & $\begin{array}{c}\text { Costo de } \\
\text { Producción }\end{array}$ & Unidades \\
\hline MD & 8,80 & Soles/prenda \\
\hline MOD & 326400 & Soles/anual \\
\hline CIF & 100338 & Soles/anual \\
\hline
\end{tabular}

Elaboración propia

Tabla 7. 12

Presupuesto operativo de costos

\begin{tabular}{|l|c|c|c|c|c|}
\hline \multirow{2}{*}{ Costo de Ventas } & $\mathbf{2 0 1 8}$ & $\mathbf{2 0 1 9}$ & $\mathbf{2 0 2 0}$ & $\mathbf{2 0 2 1}$ & $\mathbf{2 0 2 2}$ \\
\hline & 788761,29 & 848185,80 & 909377,36 & 979367,64 & 1049216,22 \\
\hline
\end{tabular}

Elaboración propia 


\subsubsection{Presupuesto operativo de gastos.}

El sueldo mensual es colocado de acuerdo al mercado peruano.

Para el presupuesto de gastos de ventas, se consideró un aumento acorde a las ventas. Además, se designó un presupuesto para las actividades comerciales como ferias y misiones, donde se consideró una misión comercial para el año 2019 y una feria para el año 2020, siendo presupuestado ambos para el año 2021.

Tabla 7.13

Presupuesto de Gastos de Ventas

\begin{tabular}{|c|c|c|c|c|c|c|}
\hline Gastos de Ventas & Mensual & 2018 & 2019 & 2020 & 2021 & 2022 \\
\hline Jefe de marketing y ventas & 3000 & 48780 & 48780 & 48780 & 48780 & 48780 \\
\hline Flete & 432 & 5184 & 5962 & 6856 & 7884 & 9067 \\
\hline $\begin{array}{l}\text { Gastos portuarios, transporte } \\
\text { y agente }\end{array}$ & 1854 & 22253 & 25591 & 29430 & 33844 & 38921 \\
\hline Otros Gastos administrativos & 80 & 960 & 1104 & 1270 & 1460 & 1679 \\
\hline Comisión del Bróker & 10255 & 123058 & 141516 & 162744 & 187155 & 215229 \\
\hline Ferias/Misiones /Pág. & 850 & 850 & 20368 & 33991 & 54025 & 74058 \\
\hline Transporte & 480 & 5760 & 6624 & 7618 & 8760 & 10074 \\
\hline TOTAL & & 206845 & 249946 & 290688 & 341909 & 397808 \\
\hline
\end{tabular}

Elaboración propia

Tabla 7.14

Presupuesto de Gastos Administrativos

\begin{tabular}{|l|r|r|}
\hline \multicolumn{1}{|c|}{ Gastos Administrativos } & Mensual & \multicolumn{1}{c|}{ Anual } \\
\hline Gerente general & 9000 & 146340 \\
\hline Asistente administrativo & 1100 & 17886 \\
\hline Jefe de logística e ingeniería & 3250 & 52845 \\
\hline Almacenero & 1150 & 18699 \\
\hline Limpieza & 1121 & 13446 \\
\hline Vigilancia & 3900 & 46800 \\
\hline Luz & 270 & 721 \\
\hline Internet y telefonía fija & 150 & 1800 \\
\hline Telefonía móvil & 333 & 4000 \\
\hline Agua & 400 & 4800 \\
\hline Depreciaciones no fabril & & 12259 \\
\hline \multicolumn{1}{c}{ TOTAL } & & 319596 \\
\hline
\end{tabular}

Elaboración propia 
Para las depreciaciones no fabriles, se colocó como porcentaje de depreciación el que aconseja Sunat y un tiempo de vida de 5 años.

Tabla 7. 15

Presupuesto de Gastos Financieros

\section{Gastos financieros Anual}

Intereses de deuda 46880

Elaboración propia

La tabla 7.15 muestra el Interés del primer año del proyecto, generado por la deuda a una tasa de interés efectiva anual de $19,5 \%$.

\subsection{Presupuestos financieros}

\subsubsection{Presupuesto de servicio de deuda.}

La deuda generada que representa el $60 \%$ de la inversión será financiada por un banco local que ofrece un interés del 19,5\%, cuyo primer año tendrá una gracia total, siendo pagado en los siguientes años en cuotas constantes por un periodo de 4 años.

Tabla 7. 16

Presupuesto de servicio de deuda

\begin{tabular}{|c|c|c|c|c|c|}
\hline $\mathbf{A n \tilde { n }}$ & $\begin{array}{l}\text { Deuda } \\
\text { inicial }\end{array}$ & Amortización & Interés & Cuota & Deuda final \\
\hline $\mathbf{2 0 1 8}$ & 240409 & - & 46880 & - & 287288 \\
\hline $\mathbf{2 0 1 9}$ & 287288 & 53905 & 56021 & 109926 & 233383 \\
\hline $\mathbf{2 0 2 0}$ & 233383 & 64417 & 45510 & 109926 & 168967 \\
\hline $\mathbf{2 0 2 1}$ & 168967 & 76978 & 32948 & 109926 & 91989 \\
\hline $\mathbf{2 0 2 2}$ & 91989 & 91989 & 17938 & 109926 & - \\
\hline
\end{tabular}

Elaboración propia 


\subsubsection{Presupuesto de estado resultados.}

Tabla 7.17

Estado de Resultados

\begin{tabular}{|c|c|c|c|c|c|}
\hline & 2018 & 2019 & 2020 & 2021 & 2022 \\
\hline Ingresos & 1275849 & 1485275 & 1700927 & 1947589 & 2193751 \\
\hline Costo de Ventas & 788761 & 848186 & 909377 & 979368 & 1049216 \\
\hline Utilidad Bruta & 487088 & 637089 & 791550 & 968221 & 1144535 \\
\hline $\begin{array}{l}\text { Gastos Administrativos, } \\
\text { Operativos y de Ventas }\end{array}$ & 526441 & 569541 & 610284 & 661504 & 717404 \\
\hline Utilidad Operativa & -39352 & 67548 & 181267 & 306717 & 427131 \\
\hline Otros ingresos & 42528 & 59411 & 68037 & 77904 & 87750 \\
\hline Gastos Financieros & 46880 & 56021 & 45510 & 32948 & 17938 \\
\hline Utilidad AIIP & -43704 & 70937 & 203794 & 351672 & 496943 \\
\hline Participación (10\%) & - & 7094 & 20379 & 35167 & 49694 \\
\hline UA Impuestos & -43704 & 63844 & 183415 & 316505 & 447249 \\
\hline Impuesto a la Renta $(29,5 \%)$ & 19138 & 304 & 54107 & 93369 & 131938 \\
\hline $\begin{array}{c}\text { Utilidad Antes de Reserva } \\
\text { Legal }\end{array}$ & -62842 & 63844 & 129307 & 223136 & 315311 \\
\hline Reserva Legal (10\%) & - & 6384 & 12931 & 12739 & - \\
\hline Utilidad Disponible & -62842 & 57186 & 116377 & 210396 & 315311 \\
\hline
\end{tabular}

Nota: Para el cálculo del Impuesto a la Renta del año 2019, se consideró una devolución por parte de la Sunat debido a que las utilidades en el primer año fueron negativas.

Elaboración propia

\subsubsection{Presupuesto de estado de situación financiera.}

Tabla 7. 18

Estado de Situación Financiera

\begin{tabular}{|c|c|c|c|}
\hline $\begin{array}{l}\text { Activo Corriente } \\
\text { Efectivo } \\
\text { Cuentas por cobrar } \\
\text { Inventarios } \\
\text { Mercadería }\end{array}$ & $\begin{array}{c}10399 \\
53160 \\
- \\
-\end{array}$ & $\begin{array}{l}\text { Pasivo Corriente } \\
\text { Intereses por pagar } \\
\text { Cuentas por pagar } \\
\text { Participaciones }\end{array}$ & $\begin{array}{c}46880 \\
10254 \\
-\end{array}$ \\
\hline $\begin{array}{c}\text { TOTAL ACTIVO } \\
\text { CORRIENTE } \\
\end{array}$ & 63559 & $\begin{array}{c}\text { TOTAL PASIVO } \\
\text { CORRIENTE }\end{array}$ & 57134 \\
\hline \multirow{4}{*}{$\begin{array}{l}\text { Activo no corriente } \\
\text { Maquinarias, equipos e } \\
\text { inmuebles } \\
\text { Depreciación } \\
\text { Intangibles } \\
\text { Amortización }\end{array}$} & \multirow[b]{3}{*}{321970} & $\begin{array}{l}\text { Pasivo No corriente } \\
\text { Obligaciones Financieras } \\
\text { Amortización de deuda }\end{array}$ & $\begin{array}{c}240409 \\
-\end{array}$ \\
\hline & & $\begin{array}{l}\text { TOTAL PASIVO NO } \\
\text { CORRIENTE }\end{array}$ & 240409 \\
\hline & & TOTAL PASIVOS & 297543 \\
\hline & $\begin{array}{c}-14433 \\
29848 \\
-5970\end{array}$ & $\begin{array}{l}\text { Patrimonio } \\
\text { Capital Social } \\
\text { Utilidad Disponible } \\
\text { Reserva Legal }\end{array}$ & $\begin{array}{l}160272 \\
-62842 \\
-\end{array}$ \\
\hline $\begin{array}{l}\text { TOTAL ACTIVO NO } \\
\text { CORRIENTE }\end{array}$ & 331415 & TOTAL PATRIMONIO & 97431 \\
\hline ACTIVOS TOTALES & 394974 & $\begin{array}{c}\text { TOTAL PASIVOS Y } \\
\text { PATRIMONIO }\end{array}$ & 394974 \\
\hline
\end{tabular}

Elaboración propia 


\subsubsection{Flujo de caja de corto plazo}

El flujo de caja en soles para el primer año se muestra en el siguiente cuadro

Tabla 7. 19

Flujo de caja

\begin{tabular}{|c|c|c|c|c|c|c|c|c|c|c|c|c|c|}
\hline & Enero & Febrero & Marzo & Abril & Mayo & Junio & Julio & Agosto & Septiembre & Octubre & Noviembre & Diciembre & TOTAL \\
\hline \multicolumn{14}{|l|}{ Ingresos } \\
\hline $\begin{array}{c}\text { Capital de } \\
\text { trabajo }\end{array}$ & 48864 & - & - & - & - & - & - & - & - & - & - & - & 48864 \\
\hline $\begin{array}{l}\text { Devolución del } \\
\text { Drawback }\end{array}$ & & & 4253 & 4253 & 4253 & 4253 & 4253 & 4253 & 4253 & 4253 & 4253 & 4253 & 42528 \\
\hline $\begin{array}{l}\text { Ventas }(50 \% \\
\text { adelantado) }\end{array}$ & 53160 & 53160 & 53160 & 53160 & 53160 & 53160 & 53160 & 53160 & 53160 & 53160 & 53160 & 53160 & 637925 \\
\hline $\begin{array}{c}\text { Ventas }(50 \% \\
\text { en } 50 \text { días) }\end{array}$ & - & 53160 & 53160 & 53160 & 53160 & 53160 & 53160 & 53160 & 53160 & 53160 & 53160 & 53160 & 584764 \\
\hline $\begin{array}{l}\text { Total de } \\
\text { ingresos }\end{array}$ & 102024 & 106321 & 110574 & 110574 & 110574 & 110574 & 110574 & 110574 & 110574 & 110574 & 110574 & 110574 & 1314081 \\
\hline \multicolumn{14}{|l|}{ Egresos } \\
\hline $\begin{array}{c}\text { Compras } \\
\text { material } \\
\text { directo }\end{array}$ & 30169 & 30169 & 30169 & 30169 & 30169 & 30169 & 30169 & 30169 & 30169 & 30169 & 30169 & 30169 & 362023 \\
\hline $\begin{array}{l}\text { Sueldos + } \\
\text { AFP/ONP }\end{array}$ & 42050 & 42050 & 42050 & 42050 & 42050 & 42050 & 45835 & 42050 & 42050 & 42050 & 42050 & 45835 & 512169 \\
\hline $\begin{array}{c}\text { Gratificaciones } \\
\text { y CTS }\end{array}$ & & & & & 14017 & & 42050 & & & & 21025 & 42050 & 119142 \\
\hline $\begin{array}{l}\text { Pagos Essalud, } \\
\text { SCTR y aporte } \\
\text { a Senati }\end{array}$ & 4380 & 4380 & 4380 & 4380 & 4380 & 4380 & 4380 & 4380 & 4380 & 4380 & 4773 & 4773 & 53349 \\
\hline $\begin{array}{l}\text { Materiales } \\
\text { indirectos }\end{array}$ & 205 & 205 & 205 & 205 & 205 & 205 & 205 & 205 & 205 & 205 & 205 & 205 & 2464 \\
\hline $\begin{array}{l}\text { Servicios } \\
\text { básicos }\end{array}$ & 7299 & 7299 & 7299 & 7299 & 7299 & 7299 & 7299 & 7299 & 7299 & 7299 & 7299 & 7299 & 87588 \\
\hline $\begin{array}{l}\text { Servicio de } \\
\text { transporte y } \\
\text { exportación }\end{array}$ & 2846 & 2846 & 2846 & 2846 & 2846 & 2846 & 2846 & 2846 & 2846 & 2846 & 2846 & 2846 & 34157 \\
\hline
\end{tabular}


(continuación)

\begin{tabular}{|c|c|c|c|c|c|c|c|c|c|c|c|c|c|}
\hline $\begin{array}{l}\text { Servicios del } \\
\text { bróker }\end{array}$ & - & 10255 & 10255 & 10255 & 10255 & 10255 & 10255 & 10255 & 10255 & 10255 & 10255 & 10255 & 112803 \\
\hline $\begin{array}{l}\text { Pago de } \\
\text { préstamo }\end{array}$ & - & - & - & - & - & - & - & - & - & - & - & - & - \\
\hline Página Web & 850 & - & - & - & - & - & - & - & - & - & - & - & 850 \\
\hline $\begin{array}{c}\text { Pago de } \\
\text { impuestos (IR) }\end{array}$ & 1595 & 1595 & 1595 & 1595 & 1595 & 1595 & 1595 & 1595 & 1595 & 1595 & 1595 & 1595 & 19138 \\
\hline $\begin{array}{l}\text { Total de } \\
\text { egresos }\end{array}$ & 89394 & 98799 & 98799 & 98799 & 112816 & 98799 & 144634 & 98799 & 98799 & 98799 & 120217 & 145026 & 1627131 \\
\hline & & & & & & & & & & & & & - \\
\hline Flujo de caja & 12629 & 7521 & 11774 & 11774 & -2242 & 11774 & -34060 & 11774 & 11774 & 11774 & -9643 & -34452 & 10399 \\
\hline $\begin{array}{l}\text { Flujo de caja } \\
\text { acumulado }\end{array}$ & 12629 & 20151 & 31925 & 43700 & 41457 & 53232 & 19171 & 30946 & 42720 & 54494 & 44851 & 10399 & \\
\hline
\end{tabular}

Elaboración propia

El incremento de efectivo en el primer año o flujo de caja será de 10399 soles.

Para el presente proyecto, no se consideraron valores sujetos al IGV debido a que las operaciones de la empresa son de exportación, con lo cual se solicitará una devolución del IGV de las compras para el fin del periodo realizando una solicitud del Formulario Virtual $\mathrm{N}^{\circ} 1649$ de devolución del "Saldo a Favor Materia de Beneficio (SFMB) de los exportadores" (Superintendencia Nacional de Aduanas y de Administración Tributaria, 2018). 


\subsection{Flujo de fondos netos}

\subsubsection{Flujo de fondos económicos.}

Tabla 7. 20

Flujo de Fondos Económico

\begin{tabular}{|c|c|c|c|c|c|c|}
\hline & 2017 & 2018 & 2019 & 2020 & 2021 & 2022 \\
\hline Inversión total & -400681 & & & & & \\
\hline Utilidad antes de Reserva Legal & & -62842 & 63540 & 129307 & 223136 & 315311 \\
\hline Depreciación y Amortización (+) & & 20043 & 20043 & 20043 & 20043 & 17146 \\
\hline Gastos Financieros (+) & & 33050 & 39495 & 32084 & 23229 & 12646 \\
\hline Capital de Trabajo (+) & & & & & & \\
\hline Valor Residual (+) & & & & & 254501 \\
\hline Flujo Neto de Fondos Económico & -400681 & -9749 & 123077 & 181434 & 266407 & 648467 \\
\hline
\end{tabular}

Elaboración propia

\subsubsection{Flujo de fondos financieros.}

Tabla 7.21

Flujo de Fondos Financiero

\begin{tabular}{|c|c|c|c|c|c|c|}
\hline & 2017 & 2018 & 2019 & 2020 & 2021 & 2022 \\
\hline Inversión total & -400681 & & & & & \\
\hline Préstamo & 240409 & & & & & \\
\hline Utilidad antes de Reserva Legal & & -62842 & 63540 & 129307 & 223136 & 315311 \\
\hline Depreciación y Amortización (+) & & 20043 & 20043 & 20043 & 20043 & 17146 \\
\hline Amortización del Préstamo (-) & & - & 53905 & 64417 & 76978 & 91989 \\
\hline Capital de Trabajo (+) & & & & & 48864 \\
\hline Valor Residual (+) & & & & & 254501 \\
\hline $\begin{array}{c}\text { Flujo Neto de Fondos Financiero } \\
\text { Elaboración propia }\end{array}$ & -160272 & -42799 & 29677 & 84933 & 166200 & 543832 \\
\hline
\end{tabular}




\section{CAPÍTULO VIII: EVALUACIÓN ECONÓMICA Y FINANCIERA DEL PROYECTO}

Para realizar la evaluación económica y financiera, se definió el costo de oportunidad del accionista según el modelo CAPM (Lira Briceño, 2012).

Se obtuvo la tasa libre de riesgo del mercado de bonos del Tesoro de Estados Unidos de los últimos 5 años de 2,92\% (Fusion Media Ltd, 2018). Según el diario Gestión, este dato proviene del mercado americano debido a que:

El CAPM se basa en la teoría de los mercados de capitales eficientes, la cuales, a su vez, solo puede ser posible en un entorno de competencia perfecta. El mercado de capitales peruano no es profundo, líquido o muy transparente, por lo que no es conveniente tomar data originada allí para calcular los parámetros de la ecuación del CAPM (Lira Briceño, 2012).

Adicionalmente, se consideró un beta de 1,5 debido a que es uno de los valores más altos a pesar de que el promedio del sector a nivel internacional para este año es de 1,02 (Leonard N. Stern School of Business, 2018). La tasa de rentabilidad promedio del mercado se obtuvo del índice "S\&P/BVL Perú General” de 16,5\% (Bloomberg, 2017). Luego, se calculó el costo de oportunidad, obteniendo un valor de 23,3\%.

Para realizar el cálculo del costo promedio ponderado de capital, se utilizó el costo de oportunidad y la tasa de préstamo del BBVA, obteniendo como resultado 17,56\%.

Tabla 8. 1

Costo promedio ponderado de capital

\begin{tabular}{|c|c|c|c|c|}
\cline { 2 - 5 } \multicolumn{1}{c|}{} & Monto & Porcentaje & TEA AI & TEA DI \\
\hline BBVA & 240409 & $60,00 \%$ & $19,5 \%$ & $13,7 \%$ \\
\hline Capital & 160272 & $40,00 \%$ & $23,3 \%$ & $23,3 \%$ \\
\cline { 4 - 5 } & \multicolumn{1}{l}{ CPPC } & $\mathbf{1 7 , 5 6 \%}$ \\
\cline { 4 - 5 } & &
\end{tabular}

Elaboración propia 


\subsection{Evaluación económica: VAN, TIR, B/C, PR}

Se realizó la evaluación económica, obteniendo un valor actual neto positivo, con lo cual se sabe que la empresa obtendrá ganancias al término del periodo del proyecto. Con respecto a la tasa interna de retorno, este valor es mayor al costo de oportunidad del accionista del capital, con lo cual se determina que el proyecto está generando más dinero de lo que cuesta financiarse.

Tabla 8. 2

Evaluación Económica

\begin{tabular}{|c|c|}
\hline VAN económico & S/. 112 136 \\
\hline TIR económico & $31,24 \%$ \\
\hline B/C & 1,28 \\
\hline Período de Recupero & 2,63 años \\
\cline { 2 - 2 } & 31,5 meses \\
\hline
\end{tabular}

Elaboración propia

\subsection{Evaluación financiera: VAN, TIR, B/C, PR}

Se realizó la evaluación financiera, obteniendo un valor actual neto positivo, con lo cual se sabe que la empresa obtendrá ganancias al término del periodo del proyecto. Con respecto a la tasa interna de retorno, este valor es mayor al costo de oportunidad del accionista, con lo cual se determina que el proyecto está generando más dinero de lo esperado por el accionista.

Tabla 8. 3.

Evaluación Financiera

\begin{tabular}{|c|c|}
\hline VAN financiero & S/. 132 699 \\
\hline TIR financiero & $39,93 \%$ \\
\hline B/C & 1,83 \\
\hline Período de Recupero & 2,89 años \\
\cline { 2 - 2 } & 34,7 meses \\
\hline
\end{tabular}

Elaboración propia 


\subsection{Análisis de ratios (liquidez, solvencia, rentabilidad) e indicadores económicos y}

\section{financieros del proyecto}

$\underline{\text { Ratios de liquidez }}$

- Razón corriente:

"Cuanto más elevado es este índice, mayor es la capacidad de la empresa para atender sus deudas a corto plazo" (Arroyo y Vásquez, 2016).

Figura 8. 1

Razón corriente

Razón corriente $=\underline{\text { Activo corriente }}$

Pasivo corriente

Fuente: Arroyo, P. y Vásquez, R., (2016)

La razón corriente es de 1,11 veces. Lo cual implica que la empresa tiene un valor aceptable de efectivo.

- Razón ácida:

"Es un índice más exigente que la liquidez, ya que descarta los inventarios. Cuanto más elevado este índice, mejor será la capacidad de pago" (Arroyo y Vásquez, 2016).

Figura 8. 2

Razón ácida

Razón Ácida = Efectivo y equiv.+ Inversiones en valores + Cuentas por Cobrar Pasivo Corriente

Fuente: Arroyo, P. y Vásquez, R. (2016)

La razón ácida es de 1,11 veces por lo que tiene una buena capacidad de pago.

- Capital de Trabajo:

"Es un índice de estabilidad financiera o de protección marginal que muestra la protección para los acreedores en caso la empresa entre en recesión" (Arroyo y Vásquez, 2016). 
Figura 8. 3

Capital de Trabajo

\section{Capital de Trabajo $=$ Activo Corriente - Pasivo Corriente}

Fuente: Arroyo, P. y Vásquez, R., (2016)

El capital de trabajo de la empresa es de 6425 soles.

$\underline{\text { Ratios de solvencia }}$

- Solvencia Total:

Esta razón "indica la proporción en que el total de recursos existentes en la empresa han sido financiados por personas ajenas a la entidad" (acreedores) (Arroyo y Vásquez, 2016).

Figura 8. 4

Solvencia total

Solvencia total $=\underline{\text { Pasivo total }}$

Activo total

Fuente: Arroyo, P. y Vásquez, R. (2016)

La solvencia del proyecto es de 0,75 veces.

- Deuda - Patrimonio:

Esta razón "indica la deuda total con lo aportado por los propietarios" (Arroyo y Vásquez, 2016).

Figura 8. 5

Deuda - Patrimonio

Deuda Patrimonio $=\frac{\text { Pasivo total }}{\text { Patrimonio Neto }}$

Fuente: Arroyo, P. y Vásquez, R., (2016)

Para el proyecto, el ratio es de 3,05 veces.

- Razón de cobertura de intereses:

Esta razón indica la de la empresa de cubrir sus gastos financieros. 
Figura 8. 6

Cobertura de intereses

Razón de cobertura de intereses $=\frac{\text { UAII }}{\text { Gastos Financieros }}$

Fuente: Arroyo, P. y Vásquez, R., (2016)

La ratio de cobertura es de 0,07 veces.

$\underline{\text { Ratios de rentabilidad }}$

- Rentabilidad Bruta Sobre Ventas:

Determina el margen bruto obtenido de las ventas (Arroyo y Vásquez, 2016).

Figura 8.7

Rentabilidad bruta sobre ventas

$$
\text { Rentabilidad Bruta Sobre Ventas }=\frac{\text { Utilidad Bruta }}{\text { Ventas }}
$$

Fuente: Arroyo, P. y Vásquez, R., (2016)

La Rentabilidad Bruta Sobre Ventas para el proyecto es de 38,2\%.

- Rentabilidad EBITDA:

Es la tasa de rendimiento que refleja lo que realmente la empresa está ganando o perdiendo (Arroyo y Vásquez, 2016). Para este cálculo, se halló el EBITDA del proyecto para el primer año de S/ 23579.

Figura 8. 8

Rentabilidad EBITDA

Rentabilidad EBITDA $=\frac{\text { EBITDA }}{\text { Ventas Netas }}(\%)$

Fuente: Arroyo, P. y Vásquez, R., (2016)

La Rentabilidad EBITDA para el proyecto es de 5,97\% 
- Rentabilidad EBITDA del Patrimonio:

Este indicador mide el retorno del accionista (Arroyo y Vásquez, 2016).

Figura 8. 9

Rentabilidad EBITDA del patrimonio

Rentabilidad EBITDA Patrimonio $=\frac{\text { EBITDA }}{\text { Patrimonio Neto }}(\%)$

Fuente: Arroyo, P. y Vásquez, R., (2016)

La Rentabilidad EBITDA del Patrimonio para el proyecto es de 24,20\%.

\subsection{Análisis de sensibilidad del proyecto.}

Para el análisis de sensibilidad modificaremos las ventas y costos de ventas en un +/2.5\%, que es en promedio la variación del PBI de Reino Unido (Datos macro, 2018). Consideraremos los indicadores financieros para el análisis.

Tabla 8. 4

Análisis de sensibilidad - Ventas

\begin{tabular}{c|c|c|c|c|c|c|c|c|c|}
\hline $\mathbf{\%}$ & Factor & VAN (S/.) & VAR & TIR & VAR & B/C & VAR & PR (años) & VAR \\
\hline $\mathbf{+ 2 , 5 \%}$ & Ventas & S/. 152207 & $15 \%$ & $42,16 \%$ & $6 \%$ & 1,94 & $6 \%$ & 2,76 & $-5 \%$ \\
\hline $\mathbf{0 \%}$ & Ventas & S/. 132699 & $0 \%$ & $39,93 \%$ & $0 \%$ & 1,83 & $0 \%$ & 2,89 & $0 \%$ \\
\hline $\mathbf{- 2 , 5 \%}$ & Ventas & S/. 112404 & $-15 \%$ & $37,39 \%$ & $-6 \%$ & 1,71 & $-6 \%$ & 3,03 & $5 \%$ \\
\hline
\end{tabular}

Nota: El Valor Actual Neto utilizado en el análisis de sensibilidad es el VAN financiero.

Elaboración propia

Tabla 8. 5

Análisis de sensibilidad - Costo de ventas

\begin{tabular}{|c|c|c|c|c|c|c|c|c|c|}
\hline$\%$ & Factor & VAN (S/.) & VAR & TIR & VAR & B/C & VAR & PR (años) & VAR \\
\hline $\mathbf{2 , 5 \%}$ & Costo de venta & S/. 85786 & $-35 \%$ & $33,56 \%$ & $-16 \%$ & 1,53 & $-16 \%$ & 3,17 & $10 \%$ \\
\hline $\mathbf{0 \%}$ & Costo de venta & S/. 132699 & $0 \%$ & $39,93 \%$ & $0 \%$ & 1,83 & $0 \%$ & 2,89 & $0 \%$ \\
\hline $\mathbf{2 , 5 \%}$ & Costo de venta & S/. 178807 & $35 \%$ & $46,18 \%$ & $16 \%$ & 2,11 & $16 \%$ & 2,59 & $-10 \%$ \\
\hline
\end{tabular}

Nota: El Valor Actual Neto utilizado en el análisis de sensibilidad es el VAN financiero.

Elaboración propia

Se puede observar que los indicadores presentan una mayor variación porcentual en el análisis de sensibilidad de costo de ventas que en el de ventas; por lo cual se concluye que el proyecto es más sensible ante cambios en el costo de venta. 


\section{CAPÍTULO IX: EVALUACIÓN SOCIAL DEL PROYECTO}

\subsection{Identificación de las zonas y comunidades de influencia del proyecto}

La ubicación de la planta productora será en Lurín, "situado en el área sur de Lima Metropolitana entre la intersección litoral de la Cuenca Baja del Valle y Río de Lurín" (Municipalidad distrital de Lurín, 2011).

La densidad poblacional de Lurín ha ido en aumento según las últimas encuestas realizadas por el INEI, los cambios en este indicador podrían "estar asociados a la evolución demográfica del componente de fecundidad, al proceso de urbanización (rural/urbano) y a la migración interna" (Instituto Nacional de Estadística e Informática, 2007).

Tabla 9. 1

Densidad poblacional en el distrito de Lurín 2007

\begin{tabular}{c|ccc|} 
& \multicolumn{4}{|c|}{ Densidad poblacional $\left(\mathrm{Hab} / \mathrm{km}^{2}\right)$} \\
\hline Año & $\mathbf{1 9 8 1}$ & $\mathbf{1 9 9 3}$ & $\mathbf{2 0 0 7}$ \\
\hline Lurín & 96,5 & 190,1 & 349,2 \\
\hline
\end{tabular}

Fuente: Instituto Nacional de Estadística e Informática, INEI. (2007)

Con respecto al ámbito, Lurín tiene una predominancia del sector urbano de un $97 \%$, mientras que el $3 \%$ restante es una población rural conformada por centros poblados y áreas agrícolas del distrito.

La distribución de su población según grandes grupos de edad muestra un predominante capital humano productivo de edades entre 15 a 44 años de edad.

Tabla 9.2

Población y porcentaje por grandes grupos de edades del distrito de Lurín

\begin{tabular}{|c|c|c|}
\hline Grandes grupos de edad & Población & $\%$ \\
\hline Menores de 1 año & 1164 & $1,85 \%$ \\
\hline 1 a 14 años & 17624 & $28 \%$ \\
\hline 15 a 29 años & 18842 & $29,94 \%$ \\
\hline 30 a 44 años & 14132 & $22,45 \%$ \\
\hline 4 45 a 64 años & 8324 & $13,23 \%$ \\
\hline 65 a más años & 2854 & $4,53 \%$ \\
\hline
\end{tabular}

Fuente: Instituto Nacional de Estadística e Informática, INEI. (2007) 
Con respecto al nivel socio económico, APEIM nos muestra que la zona 9, conformada por los distritos de Villa El Salvador, Villa María del Triunfo, Lurín y Pachacamac; distritos que pertenecen a la zona sur de Lima, presentan un 78,9\% de habitantes con bajo nivel socioeconómico (C, D y E) (Asociación Peruana de Empresas de Investigación de Mercados, 2016).

Tabla 9. 3

Distrito de zonas APEIM por niveles 2016 - Zona 9

\begin{tabular}{|cc|}
\hline Nivel Socioeconómico & $\%$ \\
\hline A & $0 \%$ \\
\hline B & $6,1 \%$ \\
\hline C & $42,7 \%$ \\
\hline D & $38,7 \%$ \\
\hline E & $12,5 \%$ \\
\hline
\end{tabular}

Fuente: Instituto Nacional de Estadística e Informática, INEI. (2017)

\subsection{Análisis de indicadores sociales (valor agregado, densidad de capital, intensidad} de capital, generación de divisas)

- Valor agregado:

Tabla 9.4

Valor agregado

\begin{tabular}{|c|c|c|c|c|c|}
\hline Ítems & \multicolumn{7}{c}{ Años } \\
\hline Sueldos y salarios & $\mathbf{2 0 1 8}$ & $\mathbf{2 0 1 9}$ & $\mathbf{2 0 2 0}$ & $\mathbf{2 0 2 1}$ & $\mathbf{2 0 2 2}$ \\
\hline Depreciación & 684660 & 684660 & 684660 & 684660 & 684660 \\
\hline Gastos financieros & 20043 & 20043 & 20043 & 20043 & 17146 \\
\hline Utilidad después & 46880 & 56021 & 45510 & 32948 & 17938 \\
\hline $\begin{array}{c}\text { impuestos } \\
\text { Impuestos }\end{array}$ & -62842 & 63540 & 129307 & 223136 & 315311 \\
\hline Servicios & 19138 & 304 & 54107 & 93369 & 131938 \\
\hline Valor Agregado & 42335 & 42335 & 42335 & 42335 & 42335 \\
\hline Elaboración propia & 750214 & 866903 & 975962 & 1096491 & 1209328 \\
\hline
\end{tabular}

Para determinar el valor agregado se considera una tasa social de descuento de 14\% (Comisión Económica para América Latina y el Caribe, 2000).

El valor agregado es de S/. 3261 179,23 
- Densidad capital:

Es el resultado de dividir la inversión total: s/. 400681 entre el número de puestos de trabajos generados: 27.

Es así que la densidad de capital es de S/. 14 840,04/ hab-año. Es decir, por cada empleo generado hay una inversión de 14 840,40 soles.

- Intensidad de capital:

Es el resultado de la inversión total: s/. 400681 entre el valor agregado: S/. 3261 179,23

Es así que la intensidad de capital es de S/. 0,12. Es decir, el aporte que se genera de valor agregado a partir de la inversión es de 0,12 soles.

- Generación de divisas:

Es el resultado existente entre la inversión total y el balance neto de divisas (Exportaciones - Importaciones) que en nuestro caso es igual a las exportaciones (ventas) s/. 1275 849,46, ya que no existen importaciones.

La generación de divisas es de S/. 0,31. Es decir que cada sol de inversión total genera s/. 0,31 en divisas. 


\section{CONCLUSIONES}

- En el estudio de mercado se observa que la población de Reino Unido adquirirá el producto debido al valor agregado de ser un producto orgánico y sostenible.

- La estrategia del uso de bróker para vender nuestro producto en el mercado extranjero es correcta, y nos permitirá no competir directamente con las marcas ya posicionadas en el país destino para generar ganancias desde el primer año.

- El precio obtenido considerando un margen de ganancia del 4\%, nos permitirá ser competitivos con respecto a las empresas exportadoras nacionales.

- Según el estudio de localización de planta, se determinó que la ubicación óptima de la planta es la ciudad de Lima en el distrito de Lurín.

- La capacidad de planta obtenida fue de 41156 conjuntos anuales, que representa una capacidad utilizada de $79 \%$ con respecto a la capacidad disponible, lo cual nos permitirá responder al mercado en los siguientes años de mayor demanda.

- El monto de inversión total estimado es de S/. 400 681,05, con un financiamiento del $60 \%$ con un costo de deuda promedio en el mercado de $19,5 \%$ y el restante $40 \%$ por parte de los accionistas. El capital de trabajo es S/. 48 863,54, necesarios para cubrir las operaciones de 50 días.

- Se afirma que el proyecto es económica y financieramente viable, debido que el VAN económico de S/. 112136 y el VAN financiero de S/. 132699 son mayores a cero; además las tasas de retorno TIR económico es de $31,24 \%$ y el TIR financiero es de 39,93\% mayores al costo de oportunidad de capital (Cok = $23,3 \%)$.

- Con respecto al análisis de sensibilidad, ante los cambios de las variables de precio y tasa de financiamiento, para el escenario pesimista, tanto en el análisis económico como en el financiero se observa un proyecto viable con un VAN positivo. 


\section{RECOMENDACIONES}

- Buscar la entidad financiera que ofrezca una tasa de interés menor, para obtener mayores ganancias.

- La modalidad de bróker para la venta de nuestros productos puede ser usado por un tiempo superior a los cinco años con la finalidad de retener ganancias para invertirlas en almacenes, tiendas, publicidad, etc; cuando se desee vender de forma directa al mercado británico.

- La empresa debe enfocarse en mantener adecuados estándares de calidad tanto en el análisis de la materia prima y la producción, ya que es una de las principales propiedades que ofrece al mercado.

- Al ser nuestro proceso dependiente principalmente de la mano de obra directa, será indispensable realizar capacitaciones, reconocimientos o dar incentivos salariales; de manera que el personal se sienta identificado con la empresa y ofrezca un trabajo eficiente y eficaz, además de evitar la alta rotación o ausentismo.

- Considerar una planta con mayores dimensiones a la propuesta, para poder aumentar la maquinaria y el personal cuando la demanda sea mayor. 


\section{REFERENCIAS}

Actualidad Gubernamental (2014). Nivel de desarrollo humano de departamentos en el Perú. Recuperado de http://www.aempresarial.com/servicios/revista/63 55 TTXKJLYUPMPVFFDI UVDNVDLWEBSVPLZJFWTOHRIWEYSKEVSYQW.pdf

American Association of Textile Chemists and Colorists. (s.f). Materiales de control de calidad. Recuperado de https://www.aatcc.org

Asia Quality Focus. (julio de 2017). Quality Control Blog. Recuperado de http://www.andina.com.pe/agencia/noticia-buscan-establecimiento-clustertextil-la-region-lambayeque-492027.aspx

Asociación Peruana de Empresas de Investigación del Mercado. (2016). Niveles socioeconómicos 2016. Recuperado de http://www.apeim.com.pe/wpcontent/themes/apeim/docs/nse/APEIM-NSE-2016.pdf

Asociación Peruana de Técnicos Textiles. (2016). La industria textil y confecciones. Recuperado de http://apttperu.com/la-industria-textil-y-confecciones/

Autoridad Portuaria Nacional (2017). Proyectos de desarrollo en puertos del Perú. Recuperado de https://www.apn.gob.pe/site/news/category/autoridad-portuaria$\underline{\text { nacional }}$

Banco Central de Reserva. (abril de 2010). Informe Económico y Social región Ica. Recuperado de http://www.bcrp.gob.pe/docs/ProyeccionInstitucional/Encuentros-Regionales/2010/Ica/Informe-Economico-Social/IESIca.pdf

Banco de Crédito del Perú. (2018). Crédito efectivo negocios para capital de trabajo. Recuperado de https://www.viabcp.com/wps/portal/Home/pymes/financiamiento/liquidez-paratu-negocio/credito-efectivo-negocios-capital-de-trabajo

Bergman \& Rivera. (2016). Certificaciones. Recuperado de http://bergmanrivera.com/

Binswanger. (2016). Reporte inmobiliario: parques industriales. Recuperado de http://binswanger.pe/propiedades/Storage/tbl_estudios_de_mercado/fld_935_Ar chivo_file/13-g3Vw5Nm6Uo4Iu4M.pdf

Burbano, R. (2014). Manual de calidad para una fábrica de confección basado en la norma ISO 9001: 2008. Recuperado de http://repository.unimilitar.edu.co/bitstream/10654/11725/1/Manual\%20de\%20 Calidad\%20para\%20una\%20F\%C3\%A1brica\%20de\%20Confecci\%C3\%B3n\% 20basado\%20en\%201a\%20Norma\%20ISO\%2090012008.pdf 
Buscan establecimiento de clúster textil en la región Lambayeque. (28 de enero de 2014). Andina. Recuperado de http://www.andina.com.pe/agencia/noticiabuscan-establecimiento-cluster-textil-la-region-lambayeque-492027.aspx

Cabrejos, D. y Mejía, K. (2013). Mejora de la productividad en el área de confecciones de la empresa Best Group Textil S.A.C. mediante la aplicación de la metodología phva (tesis para optar el título profesional de Ingeniero Industrial). Universidad de San Martín de Porres.

Campaign to push organic cotton as sales rise. (2012). The Guardian Recuperado de www.theguardian.com/environment/2012/oct/04/organic-cotton-productsconsumers

Campos, S. (1995). Proyecto para la instalación de una planta de confecciones de ropa de bebés (tesis para optar por el título profesional de Ingeniero Industrial). Universidad de Lima.

Caro, M., Cuyubamba, H. y Mendoza, A. (2012). Plan de negocios para la comercialización vía Web de ropa orgánica para bebé (tesis de maestría). Universidad Peruana de Ciencias Aplicadas.

Castillo, S. (2014). Estudio de pre-factibilidad para la instalación de un taller textil que elabora prendas para niños con discapacidad motriz (tesis para optar por el título profesional de Ingeniero Industrial). Universidad de Lima.

Centro de Comercio Internacional. (2014). Guía del exportador del algodón. Recuperado de http://www.guiadealgodon.org/guia-de-algodon/futurodesarrollo-del-mercado-de-algodon-organico-xiv/\#sthash.b29tlxSC.dpuf

Centrum Católica Graduate Business School. (27 de setiembre de 2010). Sector Textil del Perú. Recuperado de http://www.latinburkenroad.com/docs/BRLA\%20Peruvian\%20Textile\%20Indus try\%20(201003).pdf

Chavarri, A. (2009). Control Union Certifications: miércoles del exportador. Recuperado de http://export.promperu.gob.pe/Miercoles/Portal/MME/descargar.aspx?archivo=6 1D03D18-92EF-48CF-BFBA-45AB6F02D233.PDF

Círculo de Estudios de Mercados Internacionales. (2013). Especial Textil. Recuperado de http://www.ulima.edu.pe/sites/default/files/page/file/cemi_boletin_mayo.pdf

Coats Industrial. (2018). Todo sobre agujas. Recuperado de:

http://www.coatsindustrial.com/es/information-hub/apparel-expertise/all-about$\underline{\text { needles }}$

Comisión Económica para América Latina y el Caribe. (2000). Anexo SNIP 09:

Parámetros de Evaluación la tasa social de descuento. Recuperado de http://www.cepal.org/ilpes/noticias/paginas/3/27513/Evaluacion.ppt 
Comité Consultivo Internacional del Algodón. (2011). Algodón Comercio Justo.

Situación Mundial del algodón. www.icac.org/wp-

content/uploads/2011/05/srev_junio_web.pdf

¿Cómo quedaría la Unión Europea si Reino Unido se fuese hoy?. (2016). El Comercio.

Recuperado de http://elcomercio.pe/mundo/europa/como-quedaria-union-

europea-si-reino-unido-se-fuese-hoy-noticia-1911867

Conciencia Ecológica. (2011). Los españoles suspendemos en conciencia ecológica según el CIS. Recuperado de http://www.concienciaeco.com/2011/01/27/losespanoles-suspendemos-en-conciencia-ecologica-segun-el-cis/

Conoce los nuevos parques industriales. (25 de septiembre de 2017). Gestión.

Recuperado de https://gestion.pe/suplemento/comercial/lotes-terrenos-

industriales/conoce-nuevos-parque-industriales-lima-1003028

Cottoned On. (2016). Where can i buy organic cotton? ¿¿Dónde puedo comprar algodón orgánico?]. Recuperado de http://www.cottonedon.org/wheretobuy

Creditex. (2016). Proceso fabril. Recuperado de http://www.creditex.com.pe/procesofabril/produccion.html

De textiles. (2016). Maquinaria básica usada en confecciones. Recuperado de http://www.detextiles.com/files/MAQUINARIA\%20BASICA\%20USADA\%20 EN\%20CONFECCIONES.pdf

Desarrollo peruano. (16 de febrero del 2017). Principales Puertos Peruanos 2016. Recuperado de http://desarrolloperuano.blogspot.pe/2017/02/principalespuertos-peruanos-2016.html

Didier, J. (2006). Punto de Equilibrio. Recuperado de http://www.pymesfuturo.com/puntodequilibrio.htm

Dircetur Cusco. (2015). Plan de Desarrollo de Mercado del Reino Unido. Recuperado de http://www.dirceturcusco.gob.pe/wp-content/uploads/2015/08/pomsPOM_Reino_Unido.pdf

Domínguez, C. (2012). Exportador Digital: la comisión del agente comercial - fórmulas de cálculo. Recuperado de http://www.exportadordigital.com/2012/02/la-comisiondel-agente-comercial.html

Ebay (2017). Compra y venta de ropa de bebé de algodón orgánico. Recuperado de https://www.ebay.co.uk/

Ecotintes. (s.f.). Sustentable. Recuperado de http://www.ecotintes.com/category/ecovoces/el-proyecto/sustentable

Emprendedores (24 de enero del 2017). ¿Cuánto cuesta montar un stand de feria? Recuperado de http://www.emprendedores.es/gestion/coste-montar-standeventos-ferias 
Entendiendo la calidad. (2012). Recuperado de http://textiles23.blogspot.pe/2012/03/pruebas-de-laboratorio-para-tejidos.html

Espíritu, M. (2014). Formación de un clúster textil para la exportación de prendas de vestir a base de hilado de algodón orgánico a Brasil (tesis para optar por el título profesional de Licenciada en Negocios Internacionales). Universidad Nacional Mayor de San Marcos.

Euromonitor. (2016). Childrenswear [Ropa de niños]. Recuperado de http://www.euromonitor.com/childrenswear

Euromonitor. (2017). Childrenswear [Ropa de niños]. Recuperado de http://www.euromonitor.com/childrenswear

Expansión (2016). La inseguridad con alto costo en el sector empresarial. Recuperado de https://expansion.mx/nacional/2016/04/12/la-inseguridad-con-alto-costo-enel-sector-empresarial

Explicofacil. (2014). ¿Para qué sirve cada máquina de coser? Y las máquinas que necesitas para iniciar tu negocio. Recuperado de http://www.explicofacil.com/2014/11/para-que-sirve-cada-maquina-de-cosery.html

Export Entreprises S.A. (Abril de 2018). Santander Trade. Recuperado de https://es.portal.santandertrade.com/analizar-mercados/reino-unido/politica-yeconomia

Expower. (2012). Extintores de polvo químico. Recuperado de http://www.expower.es/extintores-polvo-quimico.htm

Fernández, J. (2013). Estudio de pre-factibilidad para la instalación de una planta de confección de ropa deportiva para el mercado local (tesis para optar por el título profesional de Ingeniero Industrial). Universidad de Lima.

Gaille, B. (2014). U.S. prosecutors eye new approach on company misconduct after Toyota [Los fiscales de EEUU observan un nuevo enfoque sobre la conducta indebida de las empresas después de Toyota]. Recuperado de http://www.businessinsurance.com/article/20140325/NEWS06/140329914/USprosecutors-eye-new-approach-on-company-misconduct-after-Toyota

Generalitat de Catalunya (s.f.). Etiqueta textil. Recuperado de http://consum.gencat.cat/temes_de_consum/etiquetatge_textil_calcat_pell/index es.html

Global Organic Textile Standard. (2017). Base de datos público GOTS. Recuperado de http://global-standard.org/es/base-de-datospublicosgots/search/database/search.html

Gomero, L. y Velásquez, H. (2002). Evaluación de la sustentabilidad del sistema de algodón orgánico en la zona de trópico húmedo del Perú. Recuperado de 
http://www.agriculturesnetwork.org/magazines/latin-america/ocho-estudios-de$\underline{\text { caso/evaluacion-de-la-sustentabilidad-del-sistema-de/at_download/article_pdf }}$

Grupo albe consultoría. (2016). Recuperado de http://www.grupoalbe.com/cincoventajas-de-utilizar-la-norma-iso-90012015/

Guía de algodón. (2014). Guía del algodón. Recuperado de www.guiadealgodon.org/

Hernández, K. (2015). Producción y exportación de sábanas de algodón Pima para bebés en el Reino Unido (tesis para optar el título profesional de Licenciado en Negocios Internacionales). Universidad de Lima.

I feel dress. (2016). Moda sostenible en la alfombra roja. Recuperado de http://blog.ifeeldress.es/moda-sostenible-en-la-alfombra-roja/)

Ibérico, M. y Cenzano, R. (1989). Proyecto de una planta de tejido, confección y estampado de camisetas de algodón para la exportación (tesis para optar por el título profesional de Ingeniero Textil). Universidad Nacional de Ingeniería.

Intimedia Express (2018). Precios y costos de diseño de páginas web. Recuperado de http://www.intimedia.net/express/diseno-paginas-web/precios

Instituto Nacional de Estadística e Informática. (2007). Participación en la actividad económica. Recuperado de http://proyectos.inei.gob.pe/web/biblioineipub/bancopub/Est/Lib0838/libro15/ca p03.pdf

Instituto Nacional de Estadística e Informática. (2016). Evolución de la pobreza monetaria en el Perú. Recuperado de https://www.inei.gob.pe/media/cifras_de_pobreza/evolucion-de-la-pobreza2016-10-de-mayo-presentacion.pdf

Instituto Nacional de Estadística e Informática. (2016). Publicaciones digitales. Recuperado de www.inei.gob.pe/

Instituto Nacional de Estadística e Informática. (2017). Base de datos. Recuperado de http://proyectos.inei.gob.pe/web/biblioineipub/bancopub/Est/Lib0838/libro15/ca p03.pdf

Instituto Nacional de Estadística e Informática. (diciembre de 2014). Evolución de indicadores de Empleo e Ingresos. Recuperado de https://www.inei.gob.pe/media/MenuRecursivo/publicaciones_digitales/Est/Lib 1200/libro.pdf

Internacional Standard Worldwide. (2006). Métodos Generales para la Prueba de Textiles. Recuperado de http://www.astm.org/SNEWS/SPANISH/holcombe.html

Konz, S. (1991). Diseño de instalaciones industriales. México D.F.: Limusa Noriega Editores. 
La guía. (2017). Reino Unido: Clima. Recuperado de http://geografia.laguia2000.com/climatologia/reino-unido-clima

Lectra (2016). A new era in fashion and apparel product development [Una nueva era en el desarrollo de productos de moda y ropa]. Recuperado de http://www.lectra.com/en/fashion-apparel/product-development-modaris

Market Access Map (2018). Importaciones a Reino Unido de Bangladesh de ropa de bebé de algodón. Recuperado de https://www.macmap.org/QuickSearch/FindTariff/FindTariffResults.aspx?produ

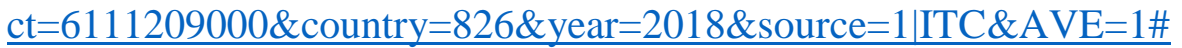

Martínez, E. y Vásquez, A. (2006). Marketing de la moda. Madrid: Ediciones Pirámide.

Martínez, G. (2012). La ingeniería en la industria de la confección. Recuperado de http://sisbib.unmsm.edu.pe/

Meyer, F. (2006). Diseño de instalaciones de manufactura y manejo de materiales (3. ${ }^{\mathrm{a}}$ ed.). México D.F.: Pearson.

Ministerio de Comercio Exterior y Turismo. (2015). Principales datos estadísticos de Ica. Recuperado de www.mincetur.gob.pe/newweb/Portals/0/PUERTOS.pdf

Ministerio de Comercio Exterior y Turismo. (2009). Estudios de Mercado e Identificación de Oportunidades para Prendas de Vestir y Accesorios de Algodón, Alpaca y Mezclas en España, Reino Unido y Alemania. Recuperado de http://www.mincetur.gob.pe/Comercio/ueperu/licitacion/pdfs/Informes/115.pdf

Ministerio de Economía y Finanzas (2018). ¿Qué es el índice de desarrollo humano y qué mide? Recuperado de https://www.mef.gob.pe/es/politica-economica-ysocial-sp-2822/750-preguntas-frecuentes-pol-econ/4858-91-que-es-el-indice-dedesarrollo-humano-idh-y-que-mide

Ministerio de Energía y Minas. (2015). Energía eléctrica. Recuperado de http://www.minem.gob.pe/

Ministerio de la producción. (2014). Parques Industriales. Recuperado de http://www.produce.gob.pe/

Ministerio de Trabajo y Promoción del Empleo. (2011). Diagnóstico socio económico laboral de la región Ica. Recuperado de http://www.trabajo.gob.pe/archivos/file/estadisticas/peel/osel/2012/Ica/Estudios/ Estudio_032012_OSEL_Ica.pdf

Ministry of Foreign Affairs (2016). Clothing, footwear and fashion: International trade regulations. https://www.gov.uk/guidance/clothing-footwear-and-fashion 
Mintel Group Limited (noviembre de 2014). Childrenswear - UK [Ropa de niños Reino Unido]. Recuperado de http://store.mintel.com/childrenswear-uknovember-2014

Morgan, A. (director). (2015). The True Cost [Documental]. Estados Unidos: Life Is My Movie Entertainment

Municipalidad Distrital de Ate. (2011). Distrito de Ate: Perfil demográfico - Edad y género a nivel distrital. Recuperado de http://www.muniate.gob.pe/ate/files/documentoEstadistica/2011/boletin_estadist ico_n_01_2011.pdf

Oficina Nacional de Estadísticas de Reino Unido (2014). National Population Projections: 2014-based Statistical Bulletin [Proyecciones de población total: 2014 - basado en boletín estadístico]. Recuperado de https://www.ons.gov.uk/peoplepopulationandcommunity/populationandmigratio $\underline{\text { n/populationprojections/bulletins/nationalpopulationprojections/2015-10-29 }}$

Organic Trade Association. (2017). Global Organic Textile Standard [Norma global de textiles orgánicos]. Recuperado de https://www.ota.com/advocacy/fiber-andtextiles/global-organic-textile-standard-gots

Organic Trade Association. (enero de 2015). U.S. Organic Cotton Production \& Marketing Trends [Tendencias en la producción y comercialización de algodón orgánico de EEUU]. Recuperado de https://ota.com/sites/default/files/indexed_files/2013\%20and\%202014\%200rga nic\%20Cotton\%20Report.pdf

Organización Internacional para la Estandarización. (2015). Sistemas de gestión de la calidad: Requisitos (ISO 9001:2015). Madrid: Aenor.

Oro blanco. (2017). Algodón Orgánico en el Perú. Recuperado de http://www.oroblanco.com.pe/espanol/organico1.htm

Organismo Supervisor de la Inversión en Energía y Minería. (2017). Electricidad. Recuperado de www.osinergmin.gob.pe/electricidad

Parlamento Europeo y el consejo de la Unión Europea. (2001). Directiva 2001/95/CE del Parlamento Europeo y del Consejo. Recuperado de https://eurlex.europa.eu/legal-content/ES/TXT/PDF/?uri=CELEX:32001L0095\&from=ES

Perú Orgánico. (2011). Congreso peruano prohíbe ingreso de transgénicos al país. Recuperado de http://www.peruorganico.com/blog/archives/1453

Perú podría posicionarse como centro de producción de prendas orgánicas. ( 5 de noviembre del 2013). Gestión. Recuperado de http://gestion.pe/economia/perupodria-posicionarse-como-centro-produccion-prendas-organicas-2080272

Pima Cotton Perú. (2016). ¿Por qué algodón orgánico? .Recuperado de http://polosperuano.com/por_que_el_algodon_organico.html 
Prestamype. (2018). Prestamype. Recuperado de https://www.prestamype.com/prestamos

PromPerú (2009). Directorio de Proveedores Peruanos de Productos Orgánicos. Recuperado de www.siicex.gob.pe/siicex/resources/sectoresproductivos/a9536ce5-ecdd-48d0$\underline{879 \mathrm{~b}-248 \mathrm{e} 9 \mathrm{f} 712480 . \mathrm{pdf}}$

PromPerú. (2014). Reino Unido: Oportunidades para las prendas de vestir y accesorios textiles peruanos. Recuperado de http://www.siicex.gob.pe/siicex/resources/estudio/89003529rad8301D.pdf

PromPerú. (2015). Guía de mercado - Reino Unido. Recuperado de http://www.siicex.gob.pe/siicex/resources/estudio/512178593radB39D0.pdf

PromPerú. (2017). Perfil Logístico para el sector vestimenta a: Reino Unido. Recuperado de https://www.inei.gob.pe/media/cifras_de_pobreza/evolucion-dela-pobreza-2016-10-de-mayo-presentacion.pdf

Puertas, M. y Paredes, J. (2008). Desarrollo de un plan de negocios para la nueva línea de producto confeccionada con algodón orgánico para la empresa Pinto S.A. en el mercado local (tesis para optar por el título profesional de Economista). Escuela Superior Politécnica del Litoral, Ecuador.

Radio Programas del Perú. (20 de octubre del 2016). Historia de la artesanía textil y uso de algodón nativo en Lambayeque. Recuperado de http://rpp.pe/cultura/mascultura/historia-de-la-artesania-textil-y-uso-de-algodon-nativo-en-lambayequenoticia-1003737

Razón Social Perú. (2017). Empresas. Recuperado de https://www.razonsocialperu.com/empresa

Ribes \& Casals. (2015). Características del algodón orgánico. Recuperado de http://www.ribescasals.com/blog/caracteristicas-del-algodon-organico/

Rodríguez, J. (26 de junio de 2011). Los beneficios del algodón ecológico. Conciencia Eco. Recuperado de https://www.concienciaeco.com/2011/06/26/los-beneficiosdel-algodon-ecologico/

Sistema Integrado de Información de Comercio Exterior. (2015). Por qué participar en una misión comercial. Recuperado de http://www.siicex.gob.pe/siicex/resources/calidad/71e0686d-5b95-41b0-b4951952bada5635.pdf

Sistema Integrado de Información de Comercio Exterior. (octubre de 2017). Guía de Mercado Mutisectorial. Recuperado de http://www.siicex.gob.pe/siicex/resources/estudio/1032946766radB4C2E.pdf

Stucchi, M. (2010). Tesis de pre-factibilidad de una fábrica de artículos para la práctica de deportes acuáticos hechos en base de Foam y fibra de vidrio (tesis 
para optar por el título profesional de Ingeniero Industrial). Pontificia Universidad Católica del Perú.

Sule, D. (2001). Instalaciones de manufactura (2. ${ }^{a}$ ed.). México D.F.: Ediciones Paraninfo.

Superintendencia Nacional de Aduanas y de Administración Tributaria. (2018). Consulta por Importador/ Exportador. Recuperado de http://www.aduanet.gob.pe/cl-aditconsultadwh/ieITS01Alias?accion=consultar $\&$ CG_consulta $=1$

Telva. (2015). Pequeñas celebrities que ya marcan tendencias. Recuperado de http://www.telva.com/2015/12/07/ninos/1449489574.html

Textile Exchange. (2016). Quick Guide to Organic Cotton [Guía rápida del algodón orgánico]. Recuperado de http://textileexchange.org/wpcontent/uploads/2017/06/Textile-Exchange_Quick-Guide-To-OrganicCotton_2017.pdf

Trademap. (2012 - 2016). Importaciones y Exportaciones. Recuperado de https://www.trademap.org/Index.aspx

United States Department of Agriculture. (2016). National Organic Program [Programa orgânico nacional].Recuperado de https://www.ams.usda.gov/aboutams/programs-offices/national-organic-program

Universidad Nacional Mayor de San Marcos. (2011). Insumos ecológicos en la serigrafía textil: Caso peruano. Recuperado de http://ateneo.unmsm.edu.pe/ateneo/bitstream/123456789/4360/1/industrial_data 05v14n1_2011.PDF

Urquizo, L. (2014). Análisis y desarrollo de producto para prendas de vestir para exportación (tesis para optar por el título profesional de Ingeniero Industrial). Pontificia Universidad Católica del Perú.

Verde Textil. (2009). Algodón Orgánico. Recuperado de http://verdetextil.com/algodon-organico-porque/

Veritrade. (2018). Cotton export [Exportación de algodón]. Recuperado de http://www.veritrade.info/ConsultaGratis.aspx

Wasser Burlet, N. (2001). Estudio de prefactibilidad para la implementación de una planta de estampado textil sobre tejidos de algodón ecológico (tesis para optar el título profesional de Ingeniero Industrial). Universidad de Lima.

Wolf, M. (16 de noviembre del 2009). Ecológicamente correcto. Descomposición de los Residuos. Recuperado de http://ecologicamentecorrecto.blogspot.pe/2009/11/descomposicion-de-losresiduos.html 


\section{BIBLIOGRAFÍA}

Arroyo, P. y Vásquez, R. (2016). Ingeniería económica: ¿cómo medir la rentabilidad de un proyecto?. Lima: Universidad de Lima.

Baca, G. (2011). Evaluación de Proyectos. México D.F.: Mc Graw - Hill.

Berk, J. (2008). Finanzas Corporativas. Naucalpán de Juárez: Pearson Educación.

Bonilla, E., Díaz, B., Kleeberg, F. y Noriega, M. (2010). Mejora continua de los procesos: herramientas y técnicas. Lima: Universidad de Lima.

Camisón, C. (2007). Gestión de la calidad: conceptos, enfoques, modelos y sistemas. Madrid: Pearson Educación.

Caro, E. (2015). Manual de seguridad y salud en el trabajo. Lima: Gaceta Jurídica.

Cervino, J. (2006). Marketing Internacional. Nuevas perspectivas para un mercado globalizado. España: Pirámide.

Chase, R.,Aquilano, N. y Jacobs, R. (2000). Administración de Producción y Operaciones ( $8 .^{\mathrm{a}}$ ed.). México. D.F.: McGraw - Hill.

Chopra, S. (2013). Supply chain management : strategy, planning, and operation (5. ${ }^{\text {a }}$ ed.). New Jersey: Pearson.

Coyle, J. (2013). Administración de la cadena de suministros: una perspectiva logística (9.a ed.). México D.F.: Cengage

Daniels, J. (2014). Negocios internacionales: ambientales y operaciones (14. $\left.{ }^{\mathrm{a}} \mathrm{ed}.\right)$. México D.F.: Pearson.

David, F. (2013). Conceptos de Administración Estratégica (14. ${ }^{\mathrm{a}}$ ed.). México D.F: Pearson Educación.

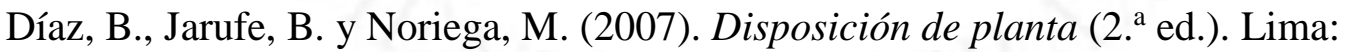
Universidad de Lima.

Díaz, B. y Noriega, M. (2017). Manual para el diseño de instalaciones manufactureras y de servicios. Lima: Universidad de Lima.

Fontaine, E. (2000). Evaluación social de proyectos. Santiago de Chile: Universidad Católica de Chile.

Gómez, L. (2008). Gestión de recursos humanos (5. ${ }^{a}$ ed.). Madrid: Pearson Prentice Hall. 
Instituto Nacional de Defensa de la Competencia y de la Protección de la Propiedad Intelectual. (2009). Textiles - confecciones: compendio de normas técnicas peruanas y guías para su implementación. Lima: Indecopi.

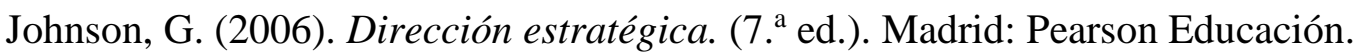

Kotler, P. (2016). Dirección de marketing. (15. ${ }^{a}$ ed.). México D.F.: Pearson.

Martínez, G. (2012). La ingeniería en la industria de la confección. México D.F.: Trillas.

McDaniel, C. (2005). Investigación de mercados (6. ${ }^{\mathrm{a}}$ ed.). México D.F.: Thomson.

Pastor, A. (2013). Sistemas integrados de gestión. Cádiz: Universidad de Cádiz

Platas, J. (2015). Planeación, diseño y layout de instalaciones: un enfoque por competencias. México D.F.: Grupo Editorial Patria

Senge, P. (2009). La revolución necesaria: cómo individuos y organizaciones trabajan por un mundo sostenible. Bogotá: Grupo Editorial Norma.

Tellis, G. (2002). Estrategias de publicidad y promoción. Madrid: Pearson Educación. 
ANEXOS 


\section{ANEXO 1: Términos de referencia}

Impuesto sobre el valor añadido (IVA): Impuesto que se aplica a los bienes y servicios nacionales de Reino Unido como a los importados. En el caso de los bienes importados por Reino Unido, el IVA se impone sobre el valor en aduana más los derechos, otras cargas, y gastos accesorios. (PromPerú, 2015)

Máquina cortadora: Máquina que corta las telas con la ayuda de una cuchilla.

Máquina de costura recta: Máquina que brinda una costura regular en una sola línea. Es la de uso más común en la industria de confecciones.

Máquina remalladora u overlock: Máquina que además de hacer un doble zigzag con los hilos en el borde de la tela hacen una costura recta por encima de estos para asegurar la costura. (Explicofacil, 2014)

Máquina de recubierto: Máquina que brinda una costura regular de dos hilos en dos líneas.

Máquina tapetera: Máquina que se encarga de cortar la tela en cintas para formar los tapetes.

Tapete: Cinta de tela que recubre la costura de los hombros para asegurar la costura y bridar mayor comodidad para el cliente.

USDA Organic: Certificación que verifica que el proceso completo de producción y manejo cumple con los estándares para ser calificado como orgánico. (CCI, 2014) 
ANEXO 2: Ficha técnica

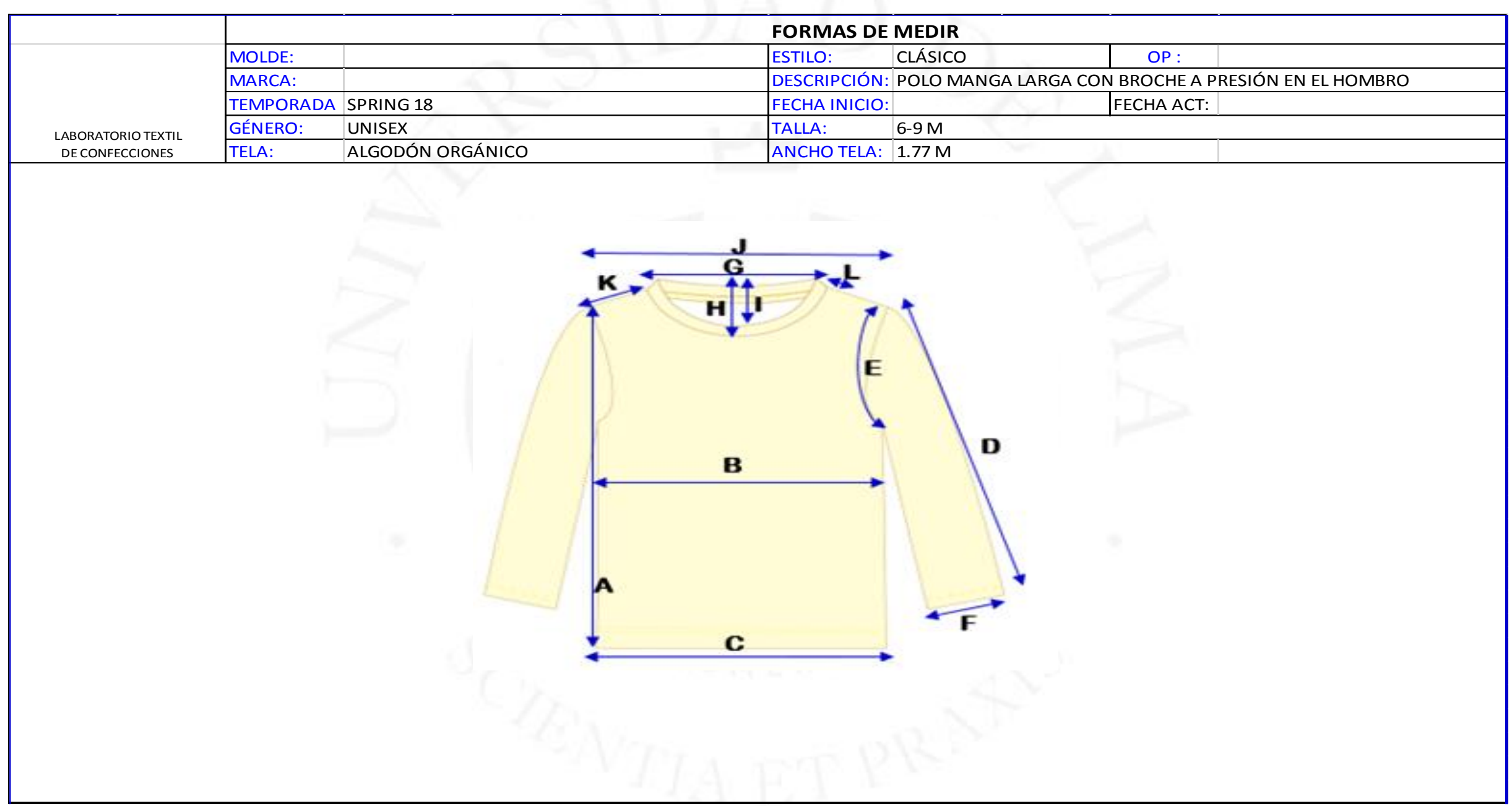

Elaboración propia 


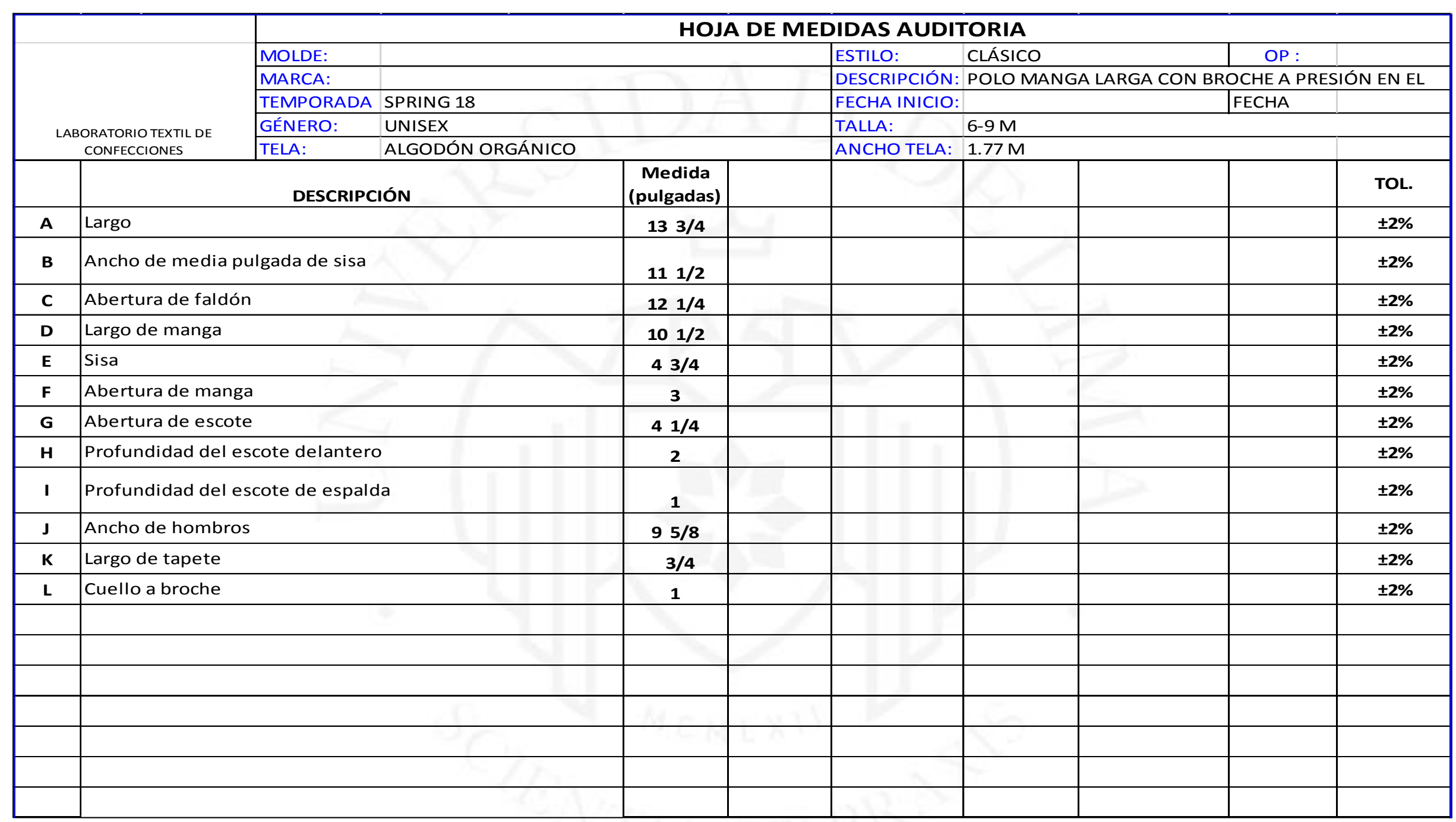

Elaboración propia 


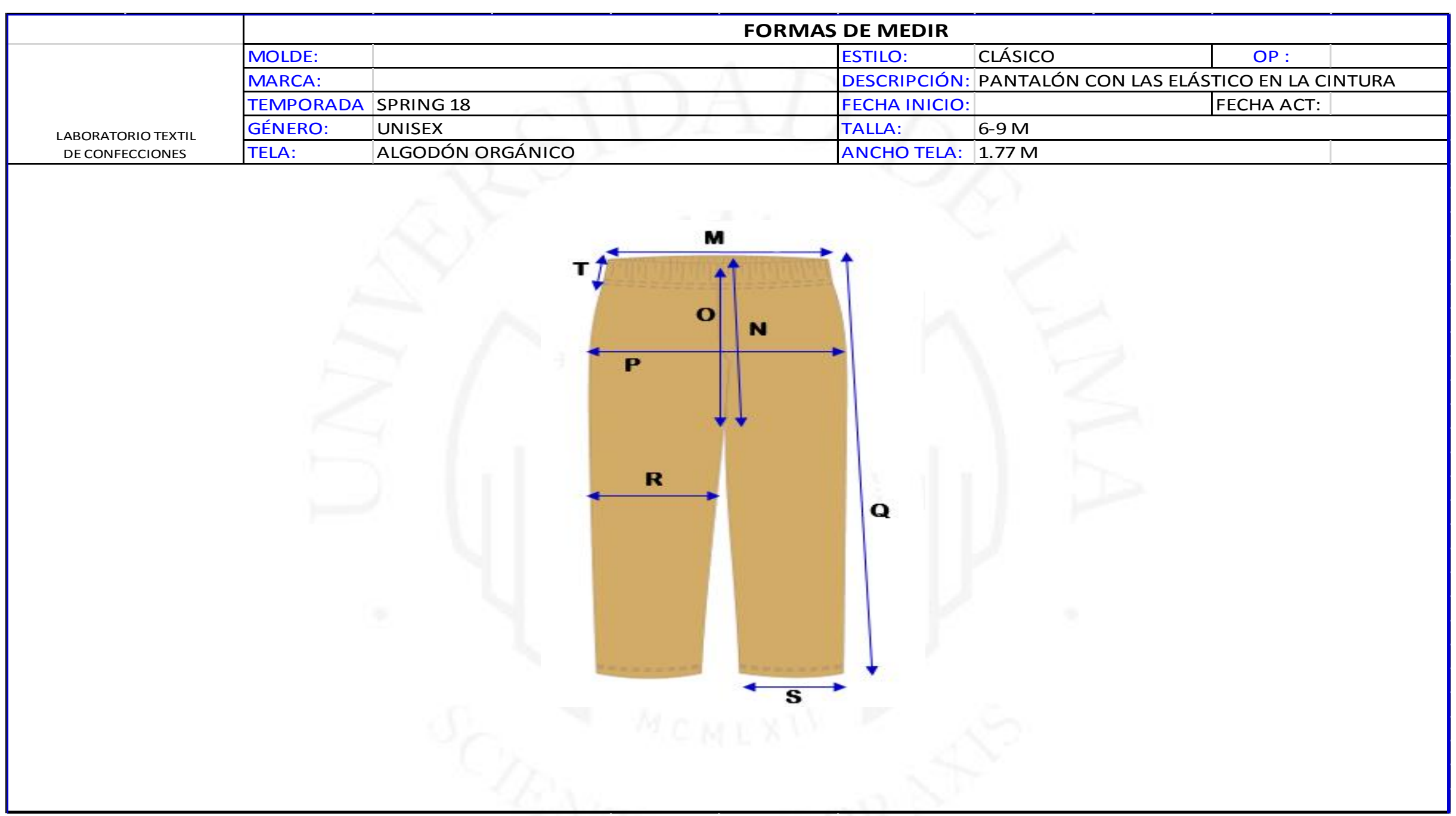

Elaboración propia 


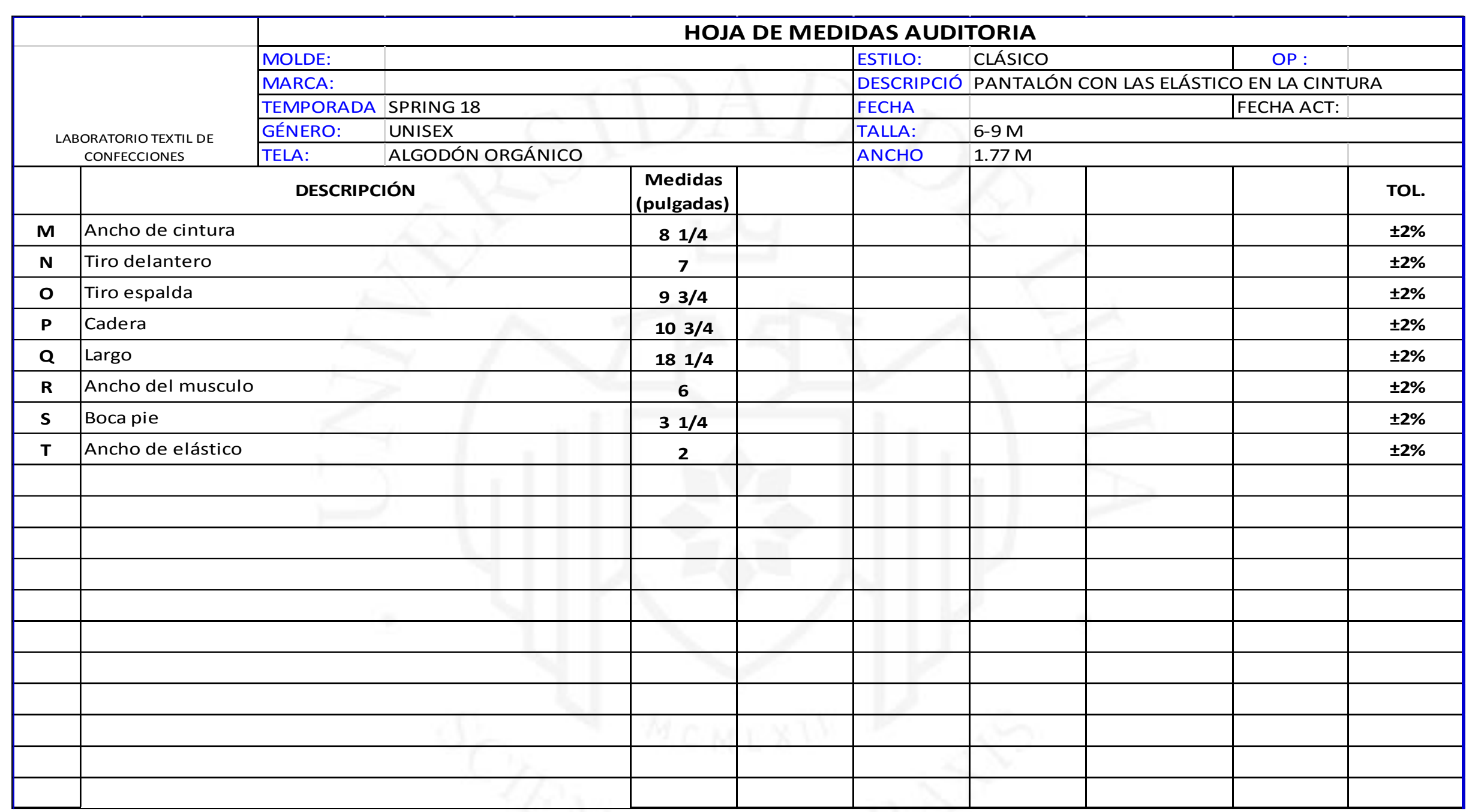

Elaboración propia 


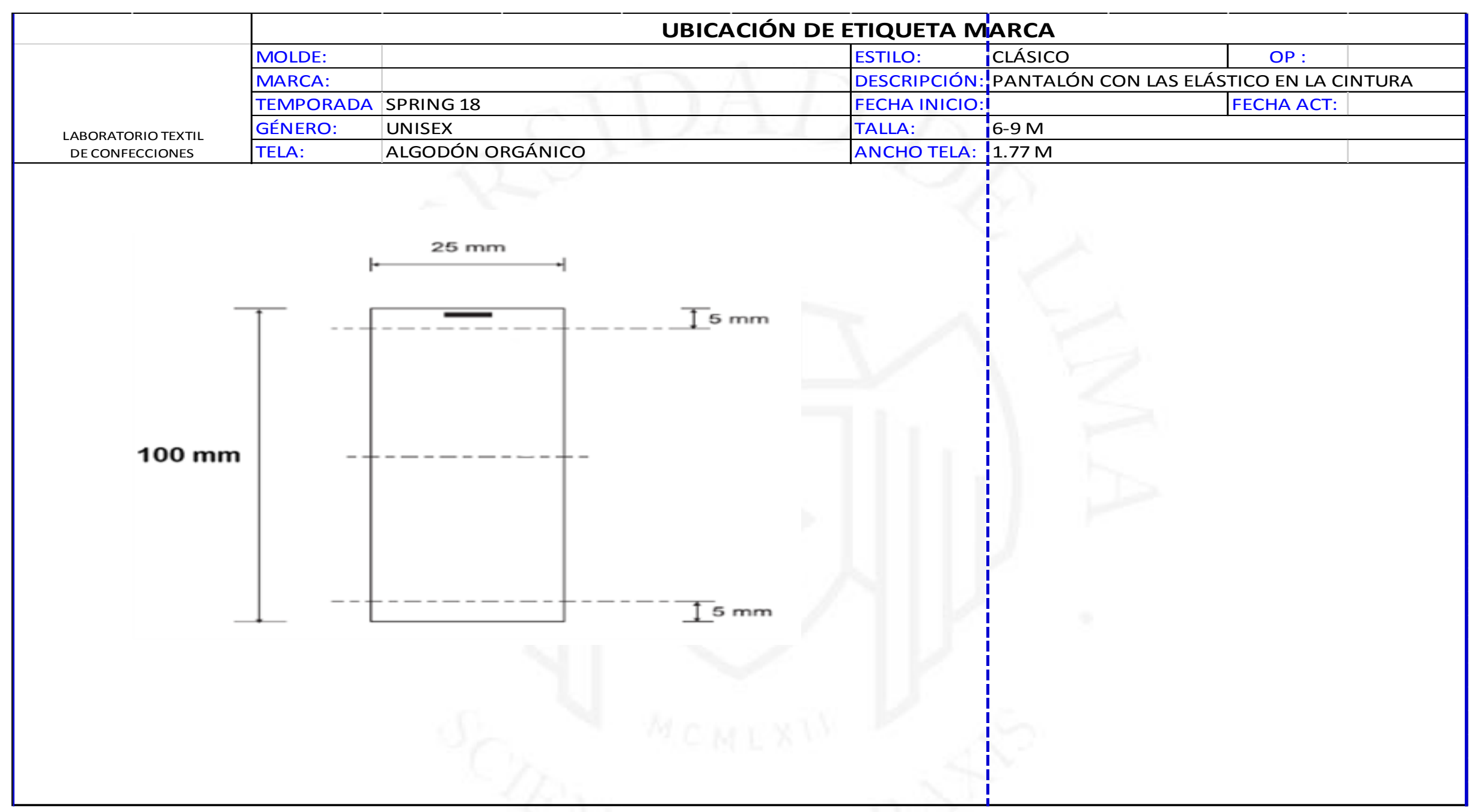

Elaboración propia 


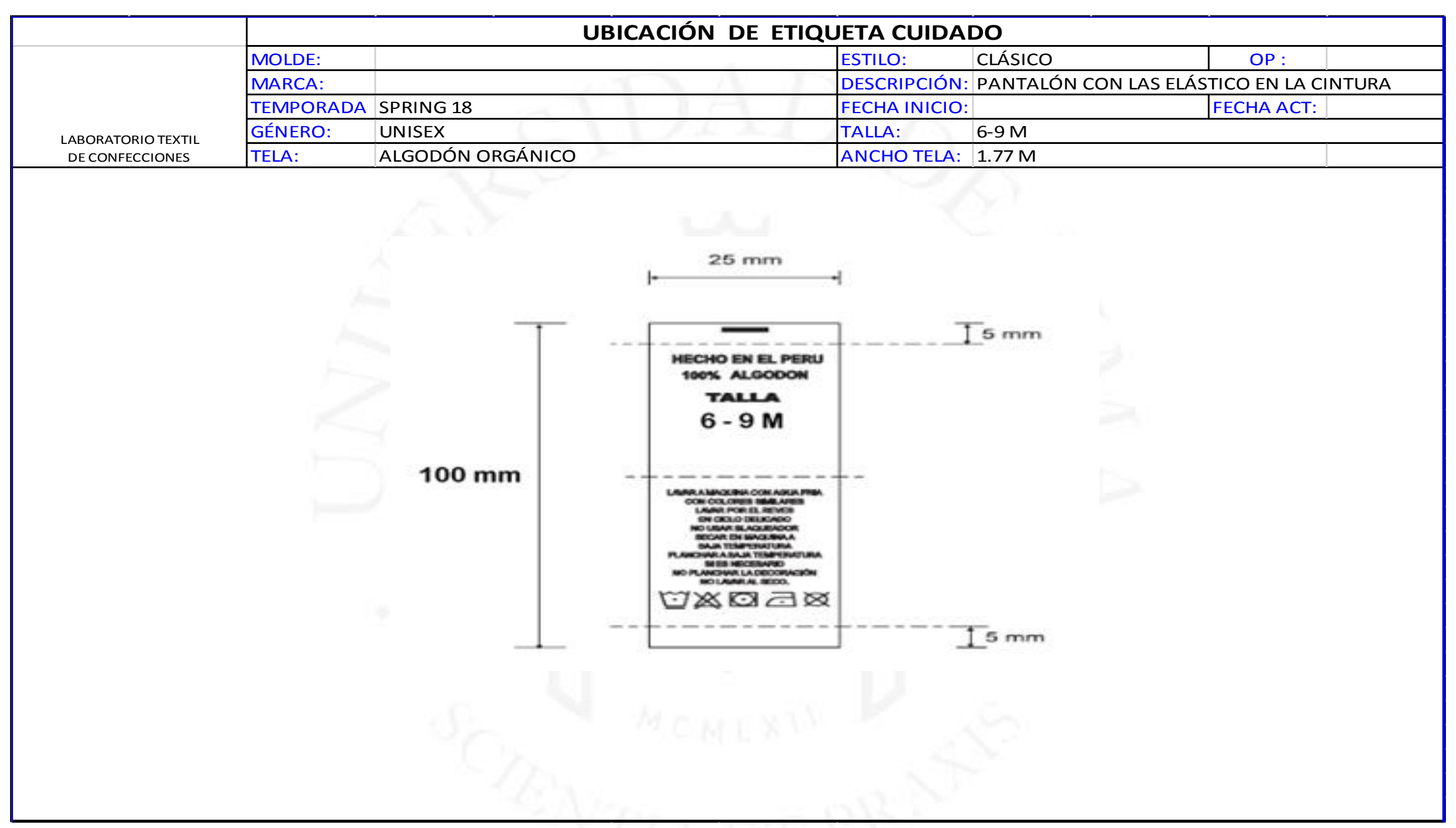

Elaboración propia 


\section{ANEXO 3: Plano de seguridad}

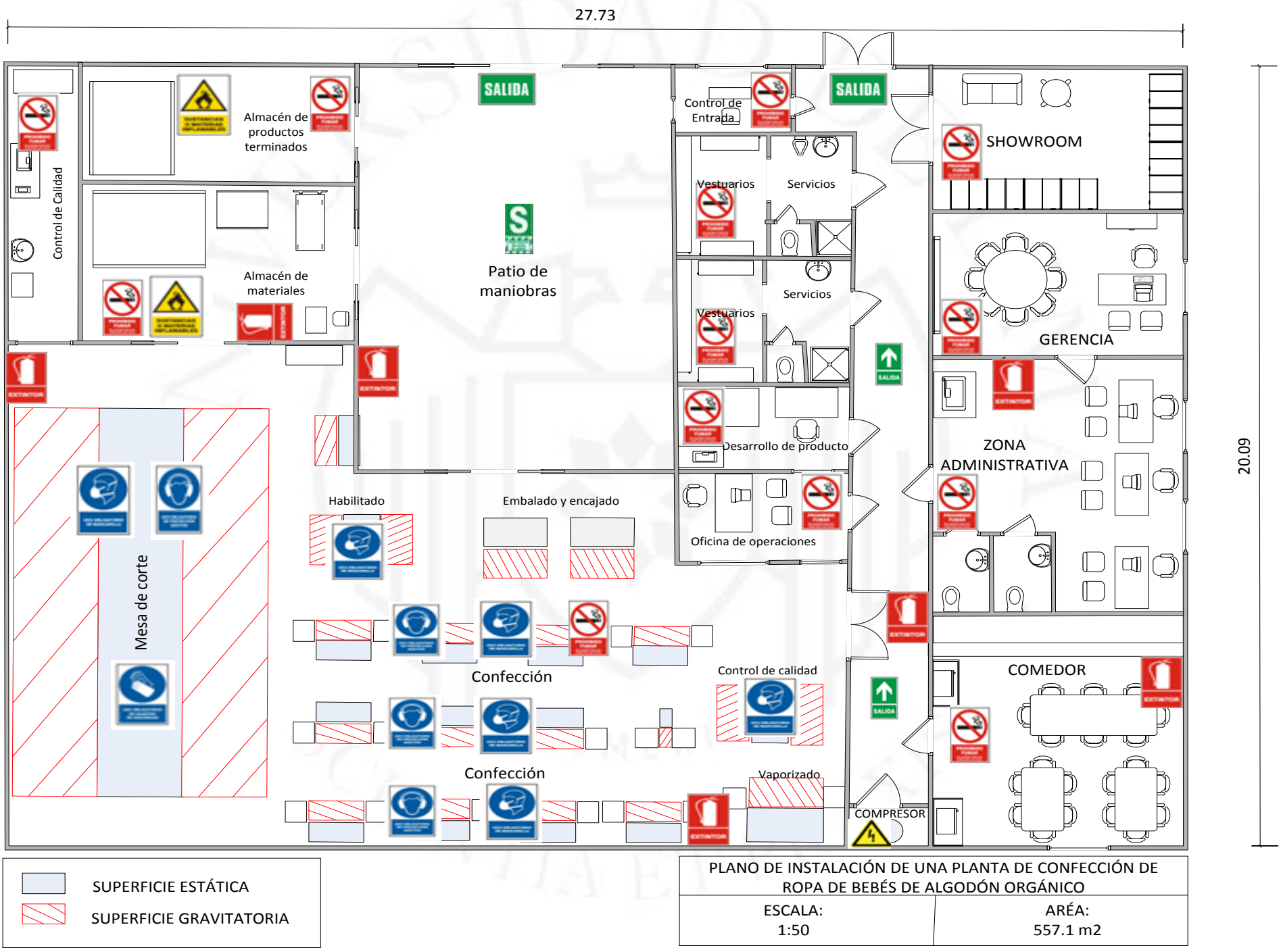




\title{
ANEXO 4: Índice del reporte Childrenswear (UK)
}

\author{
MINTEL

\section{Childrenswear -} \\ UK, November 2014
}

Published by

Mintel Group Ltd 11 Pilgrim Street London EC4V 6RN

tel: 02076064533

fax: 02076065932

Sales hotline: $+44(0) 2076066000$

email: info@mintel.com

(c) Mintel Group Limited. All rights reserved. Statistics in this report are the latest available at the time of research

NOTE: This publication is issued as a series of reports. Each report is a complete work in itself, which is available separately or as part of a subscription

www.mintel.com

\section{CONDITIONS OF USE}

Congratulations on your purchase of a limited license to this Mintel report! Mintel Group Ltd. ("Mintel") is the publisher and licensor of this report; the licensee of this report is the original purchaser (you"). Absent another written agreement between Mintel and you, the following conditions of use govern your access to and use of this report.

1. GRANT AND SCOPE OF LICENSE. Subject to the restrictions under clause 2, Mintel grants to you a personal, revocable, non-exclusive, non-sublicensable,
and non-transferable right and license to access and use this report for your internal business purposes.

2. LICENSE RESTRICTIONS.

A. Absent advance written consent by Mintel, you may not grant access to, sell, pass on, communicate, or distribute this report or its content to any third party, including any of your affiliates. Principles of Fair Use do not apply to your use of this report.

B. The purchase or use by a Non-Participating Retailer (or an agent or professional advisor working on its account) of any Infoscan data sourced by Information Resources, Inc., and contained in this report is prohibited. Accordingly, you will not knowingly disclose any Infoscan data contained in this report to a Non-Participating Retailer. As of 10 October 2013, the Non-Participating Retailers are Aldi, Costco, Dollar Tree, Udl, Trader Joe's, and Whole Foods (current list available at www.mintel.com/legal/non-participating-retallers). 
C. You will neither encourage financial reliance by third parties upon, nor invite investment from others based upon, this report without first obtaining the written consent of Mintel's corporate secretary to do so, which Mintel may withhold in its absolute discretion. Absent such consent, you will defend, indemnify, and hold harmless Mintel against any claims made against Mintel based upon such encouragement or invitation.

3. INTELIECTUAL PROPERTY. As between Mintel and you, this report, including but not limited to the content, design, look, layout, appearance, and graphics, is the copyright property and confidential information of Mintel. You disclaim, and Mintel reserves, all right, title, and interest in this report, and all copies thereof, not expressly granted by these conditions of use, whether by implication, estoppel, or otherwise.

4. DISCLAIMER OF WARRANTY. THIS REPORT IS PROVIDED "AS IS." MINTEL MAKES NO REPRESENTATION OR WARRANTY WITH RESPECT TO CORRECTNESS, COMPLETENESS, OR CURRENTNESS AND SPECIFICALLY DISCLAIMS ANY WARRANTY, WHETHER EXPRESS, IMPLIED, OR STATUTORY, INCLUDING ANY WARRANTY OF MERCHANTABILITY OR FITNESS FOR A PARTICULAR PURPOSE. THIS REPORT NEITHER GIVES INVESTMENT OR PROFESSIONAL ADVICE NOR ADVOCATES ANY COURSE OF ACTION.

5. INDEMNIFICATION. You will defend, indemnify, and hold harmless Mintel from and against all costs, liabilities, losses, and expenses (including reasonable attorneys' fees) (collectively, "Losses") arising from any third party claim, demand, complaint, or action arising from unlicensed access or use of this report. Mintel will defend, indemnify, and hold harmless you from and against any Losses arising from any third party daim, demand, complaint, or action arising from your licensed access or use of this report and alleging that this report infringes any intellectual property right.

6. IMMTATION OF LIBILTYY. TO THE FULLEST EXTENT PERMITTED BY APPLICABLE LAW AND EXCEPT FOR ANY INDEMNTTY UNDER CLAUSE 5 , NEITHER PARTY, NOR ANY OF ITS AFFILIATES, OFFICERS, EMPLOYEES, OR AGENTS, WIL BE LIABLE IN CONNECTION WITH THIS REPORT FOR ANY INDIRECT, SPECIAL, EXEMPLARY, PUNITIVE, OR CONSEQUENTIAL DAMAGES, INCLUDING WITHOUT LIMITATION LOSS OF GOOD WILL AND LOST PROFITS OR REVENUE, WHETHER OR NOT SUCH DAMAGES ARE BASED IN CONTRACT, WARRANTY, TORT, NEGLIGENCE, STRICT UABILTY, OR OTHERWISE (EVEN IF ADVISED OF THE POSSIBILITY OF SUCH DAMAGES), AND NETTHER PARTY'S AGGREGATE LABILTY WILL EXCEED THE FEE PAYABLE TO MINTEL BY YOU FOR THIS REPORT.

7. ENTIRE AGREEMENT. These conditions of use, together with any Mintel documentation of your order, constitute the entire understanding between Mintel and you regarding this report and may be amended only by a written instrument duly executed by Mintel and you. No purchase order issued by you will modify these conditions of use, even if signed by Mintel.

8. CHOICE OF LAW AND JURISDICTION. Use of this report and any dispute arising out of such use is subject to the laws of England, and you irrevocably submit to the exdusive jurisdiction of the English courts situated in London, United Kingdom, provided that if your use or a dispute arising from your use arises within the United States, then such use or dispute is subject to the laws of the State of Illinois, and you irrevocably submit to the exdusive jurisdiction of the state and federal courts situated in Chicago, Illinois.

$\vee 101013$ Single 
INTRODUCTION

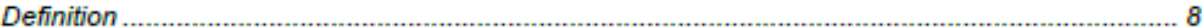

Abbreviations

EXECUTIVE SUMMARY ...................................................................................................... 9

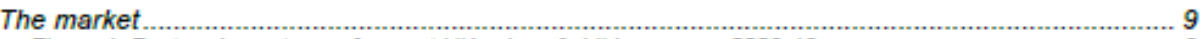

Figure 1: Best and worst case forecast UK sales of childrenswear, 2009-19

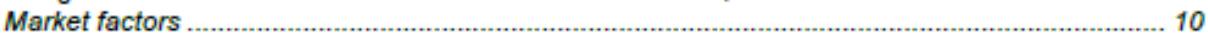

Birth rate slows

Figure 2: Total number of live births in the UK, 2004-13

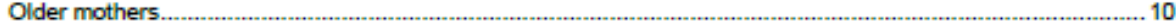

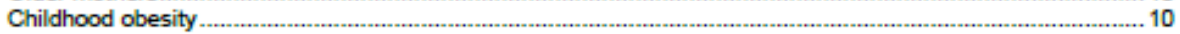

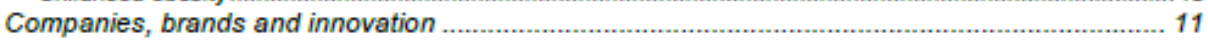

The consumer

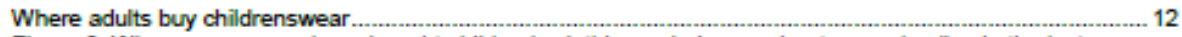

Figure 3: Where consumers have bought children's clothing or babywear in-store and online in the last

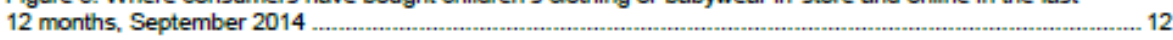

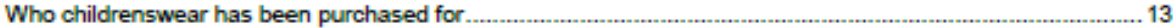

Figure 4: Who clothing was bought for and age of child, September 2014

Most important factors when purchasing ................................................................................ 14

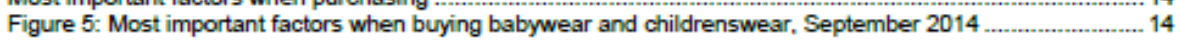

Parents' and grandparents' attitudes towards buying childrenswear

Figure 6: Attitudes towards shopping for babywear and childrenswear, September 2014

Parents' attitudes towards buying schoolwear $\ldots$

Figure 7: Attitudes towards buying schoolwear, September 2014

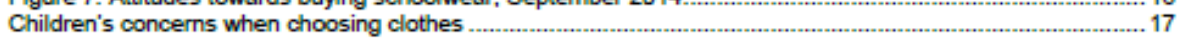

Figure 8: Children's concerns when choosing what clothes to wear, September $2014 \ldots \ldots$

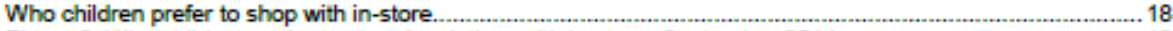

Figure 9: Who children prefer to shop for clothes with in-store, September 2014

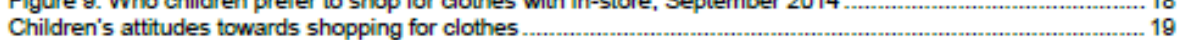

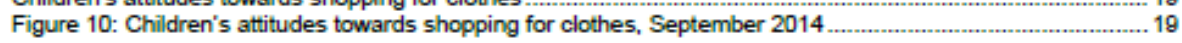

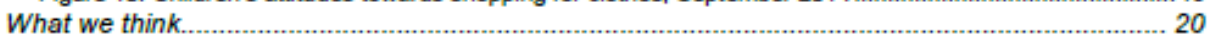

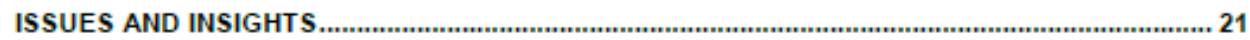

How has the childrenswear market performed over the last year? $\ldots \ldots \ldots \ldots \ldots \ldots \ldots \ldots \ldots \ldots \ldots \ldots \ldots \ldots \ldots . . . .21$

The facts.... 21

The implications.

Which players have performed the best?

The facts.

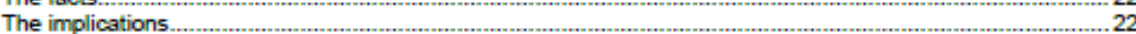

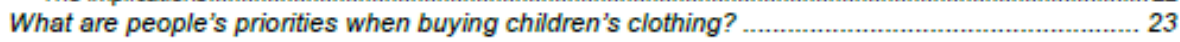

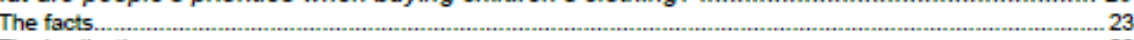

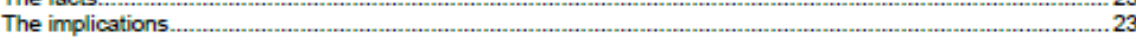

What are the opportunities for growth in the sector? ................................................................. 24

The facts.

The implications

TREND APPLICATIONS …........................................................................................................... 25

Trend: Life an Informal Affair ............................................................................................... 25

Trend: Experience is All ....................................................................................................... 25

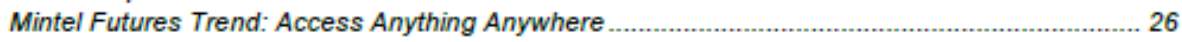

MARKET DRIVERS .................................................................................................................. 27

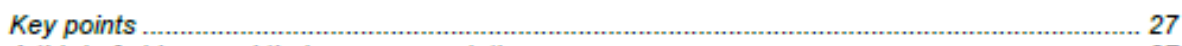

A third of girls spend their money on clothes.................................................................... 27

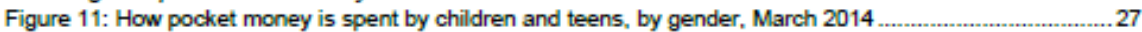

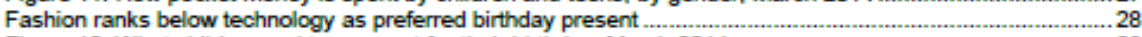

Figure 12: What children and teens want for their birthday. March $2014 \ldots \ldots$

Figure 13: Ideal day of children and teens, by gender, March 2014

Use of technology in the home ................................................................................................ 30

Figure 14: Technology devices used by children and teens, March 2014

MINTEL 


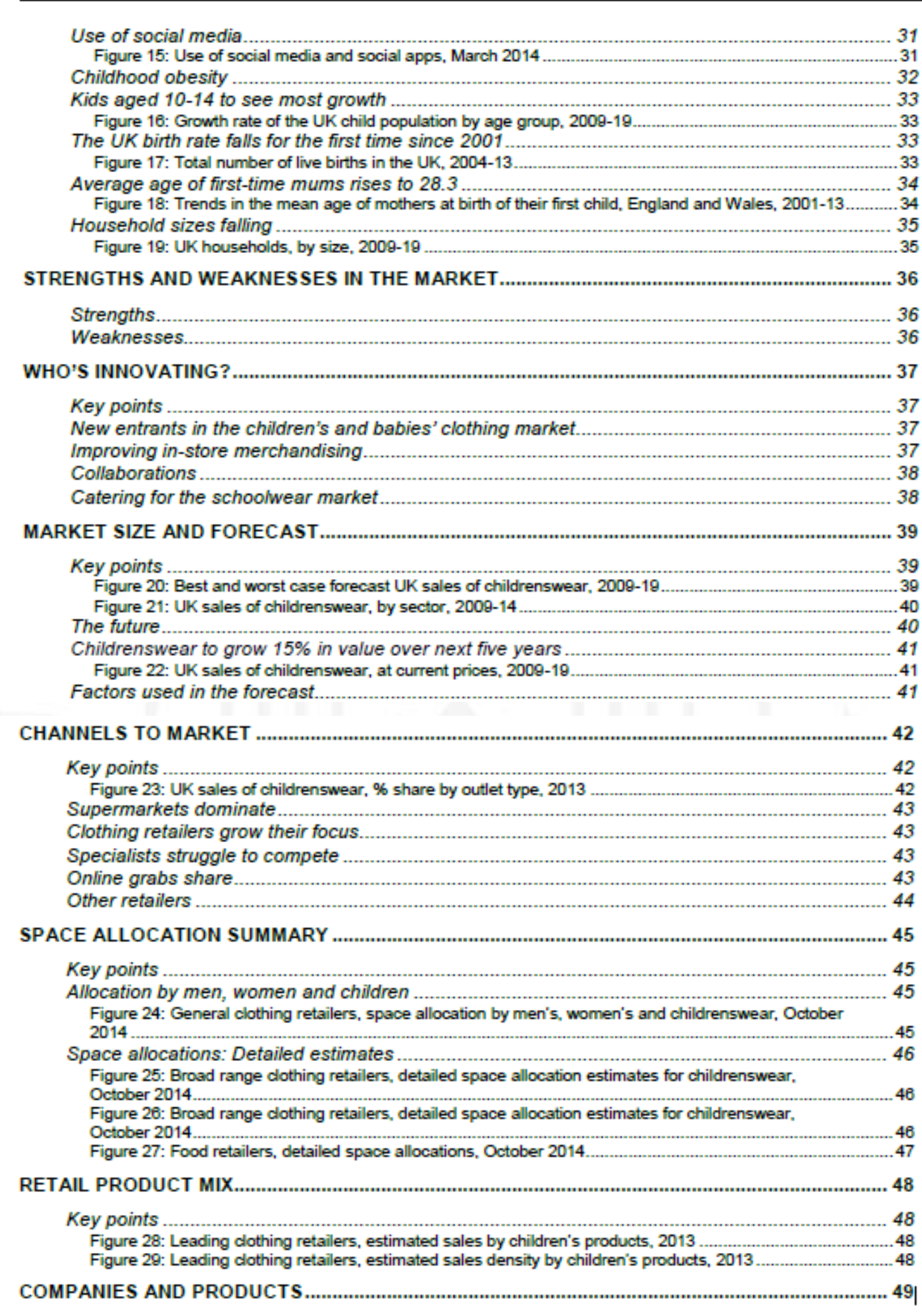




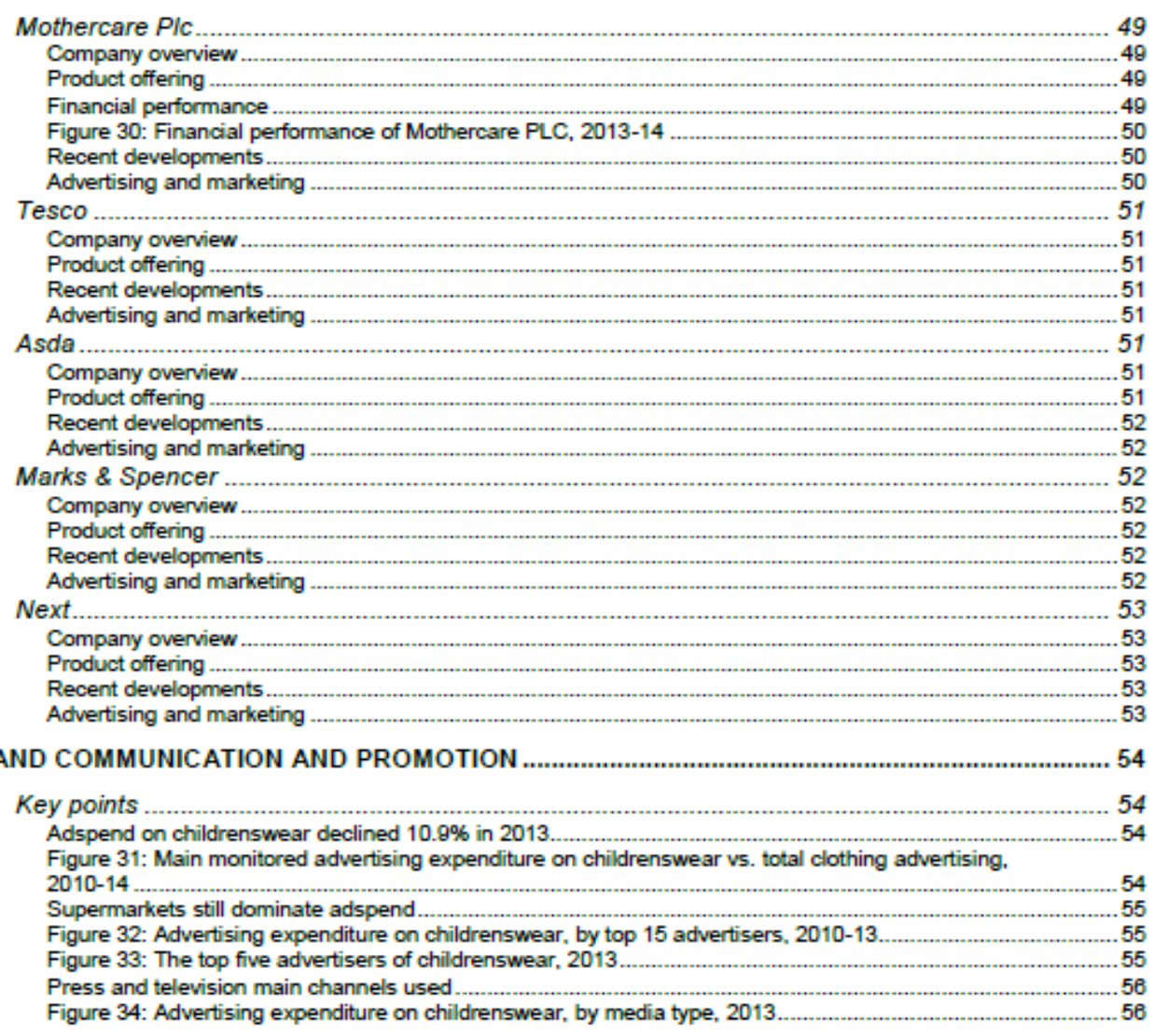

THE CONSUMER - WHERE ADULTS BUY CHILDRENSWEAR ...................................................... 57

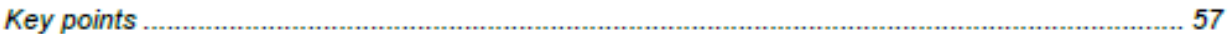

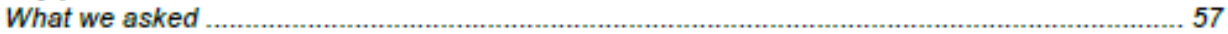

Figure 35: Where consumers have bought children's clothing or babywear in-store and online in the last 12 months, September 2014

Supermarkets lead

Figure 36: Supermarket chains where consumers have bought children's clothing or babywear in-store in the last 12 months, by age of consumer and socio-economic group. September $2014 \ldots . \ldots 59$

Profile of where consumers buy by age and affluence ........................................................ 60

Figure 37: Profile of where consumers buy babywear and childrenswear in-store and online, September

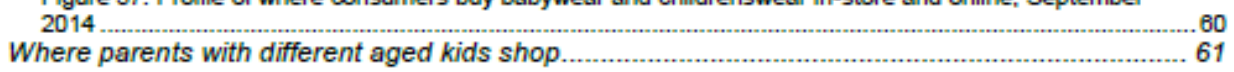

Figure 38: where consumers have bought children's clothing or babywear in-store in the last 12
months, by age of child, September 2014

M\&S and Mothercare

Figure 39: Profile of consumers who have bought children's clothing or babywear in-store from

Mothercare and M\&S in the last 12 months, by age of consumer and socio-economic group. September 2014

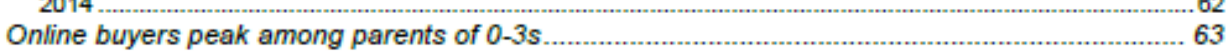

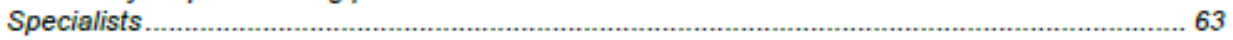

THE CONSUMER - WHO HAS CHILDRENSWEAR BEEN PURCHASED FOR ? ............................. 65

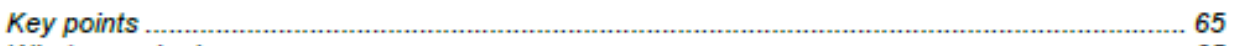

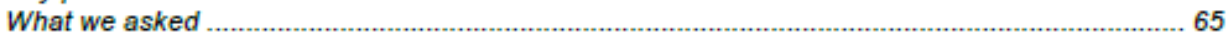


Figure 40: Who clothing was bought for and age of child, September 2014

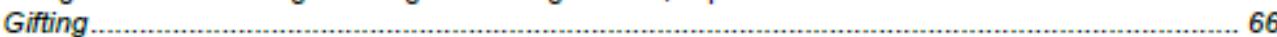

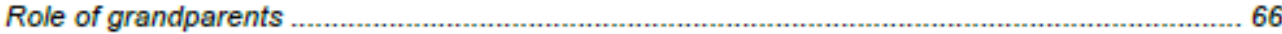

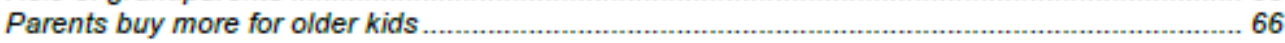

Fathers buy more for older kids than mothers ................................................................. 67

Figure 41: Who clothing was bought for, by retailers where consumers have purchased baby and

\author{
67
}

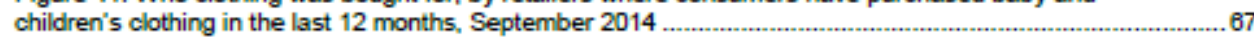

THE CONSUMER - MOST IMPORTANT FACTORS WHEN BUYING BABYWEAR AND

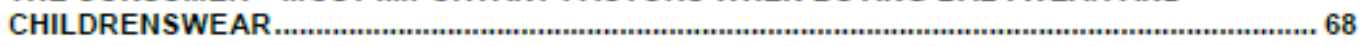

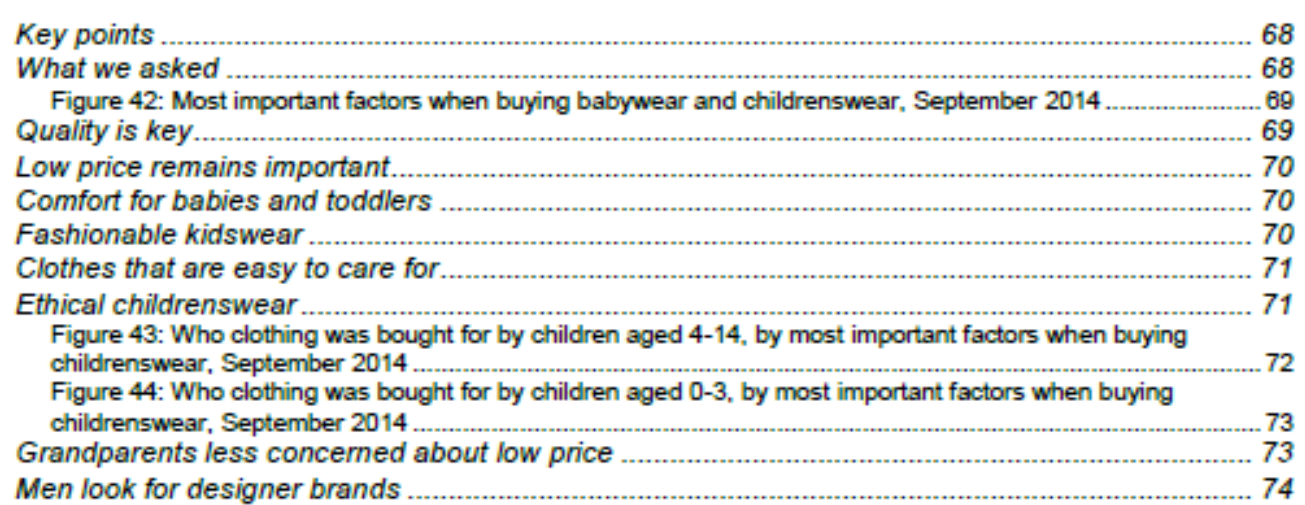

THE CONSUMER - ATTITUDES TOWARDS SHOPPING FOR BABYWEAR AND

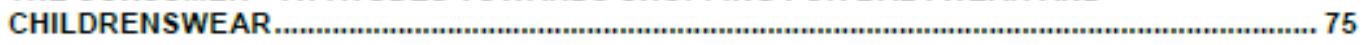

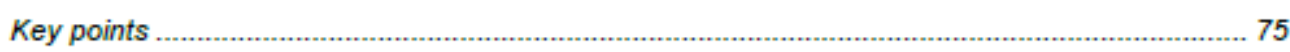

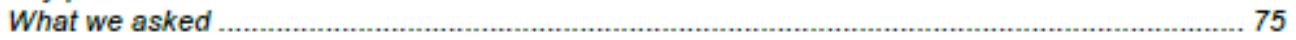

Figure 45: Attitudes towards shopping for babywear and childrenswear, September 2014

Issues with sizing

Three in 10 buy children's and adult clothes together ....................................................... 77

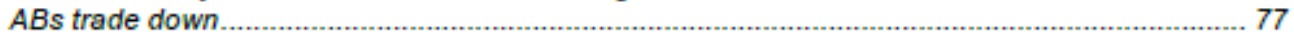

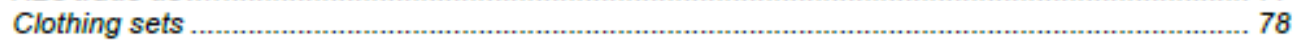

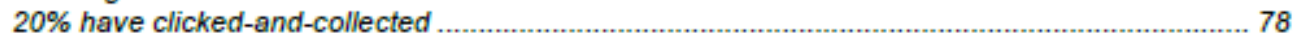

THE CONSUMER - ATTITUDES TOWARDS BUYING SCHOOLWEAR ........................................... 79

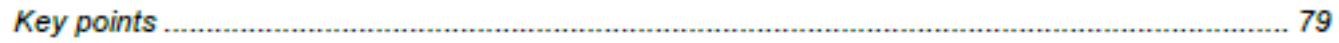

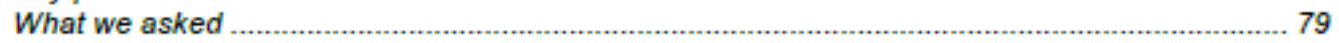

Figure 46: Attitudes towards buying schoolwear, September 2014 $\ldots \ldots \ldots \ldots$

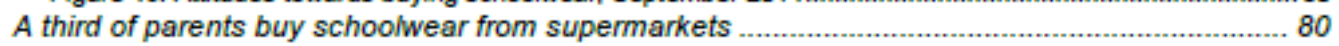

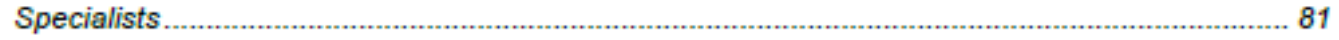

Figure 47: Attitudes towards buying schoolwear, by primary or secondary aged schoolchildren,

Shopping online for schoolwear ...................................................................................... 82

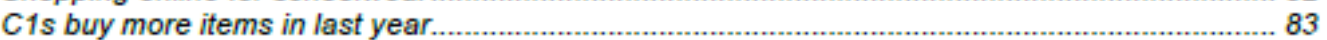

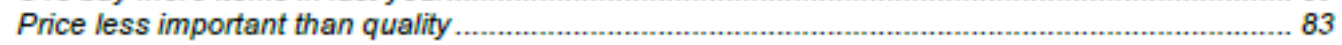

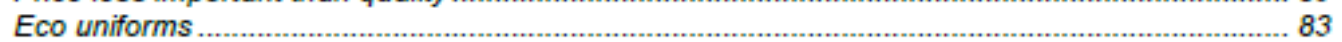

THE CONSUMER - CHILDREN'S CONCERNS WHEN CHOOSING WHAT TO WEAR .................... 85

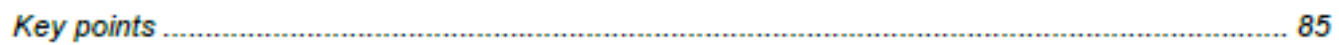

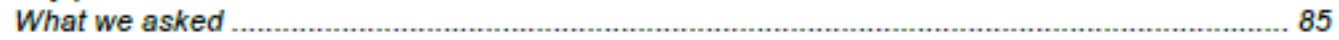

Figure 48: Children's concerns when choosing what clothes to wear, September 2014

Figure 49: Children's concems when choosing what clothes to wear, by gender, September $2014 \ldots \ldots \ldots \ldots \ldots . . .87$

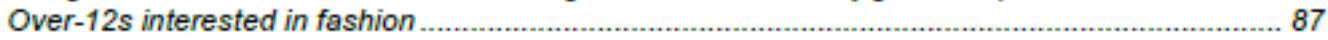

What friends think more important than parent's reactions ............................................................. 88

Figure 50: Children's concerns when choosing what clothes to wear, by age group. September $2014 \ldots \ldots \ldots . . . .88$

Boys care what popular kids think ..................................................................................... 88 
THE CONSUMER - WHO CHILDREN PREFER TO SHOP FOR CLOTHES WITH IN-STORE AND ONLINE

Key points

What we asked $\quad 89$

In-store and online shopping behaviour................................................................................. 89

Figure 51: Who children prefer to shop for clothes with in-store and online, September 2014

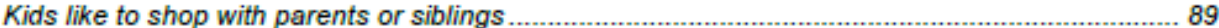

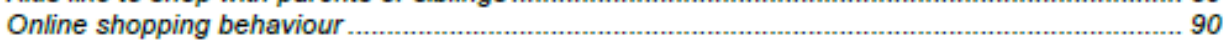

THE CONSUMER - CHILDREN'S ATTITUDES TOWARDS SHOPPING FOR CLOTHES ............... 91

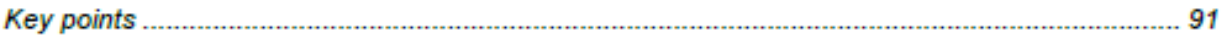

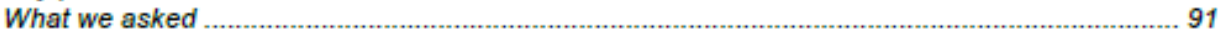

Figure 52: Children's attitudes towards shopping for clothes, September 2014

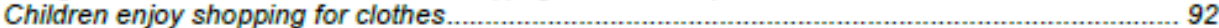

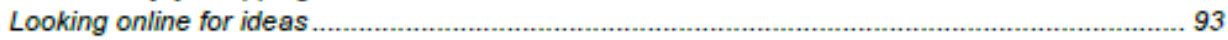

Use of social media .......................................................................................................... 93

Competitions to win clothes .................................................................................................... 94

UK RESEARCH METHODOLOGY...................................................................................................

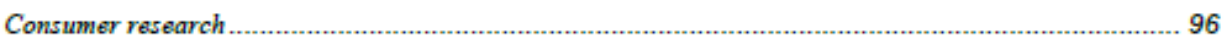

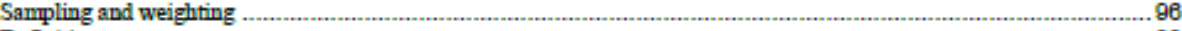

Definitions .

Qualitative Research.

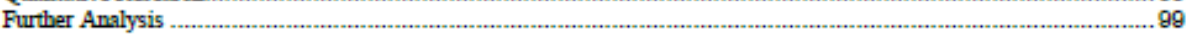

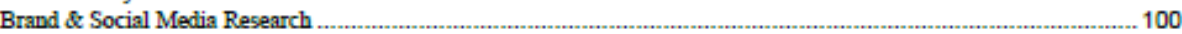

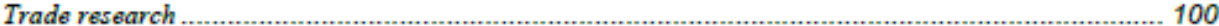

Informal

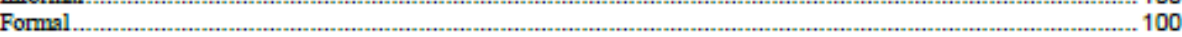

Desk research

Statistical Forecasting ............................................................................................................ 101 